\title{
Advances in CAD/CAM/CAE Technologies
}

Edited by Panagiotis Kyratsis, Konstantinos G. Kakoulis and Angelos P. Markopoulos Printed Edition of the Special Issue Published in Machines 
Advances in CAD/CAM/CAE
Technologies 



\section{Advances in CAD/CAM/CAE Technologies}

Special Issue Editors

Panagiotis Kyratsis

Konstantinos G. Kakoulis

Angelos P. Markopoulos 
Special Issue Editors

Panagiotis Kyratsis

University of Western

Macedonia

Greece
Konstantinos G. Kakoulis

University of Western

Macedonia

Greece
Angelos P. Markopoulos

National Technical University of

Athens

Greece

Editorial Office

MDPI

St. Alban-Anlage 66

4052 Basel, Switzerland

This is a reprint of articles from the Special Issue published online in the open access journal Machines (ISSN 2075-1702) (available at: https:/ / www.mdpi.com/journal/machines/special_issues/ CAD_CAM_CAE).

For citation purposes, cite each article independently as indicated on the article page online and as indicated below:

LastName, A.A.; LastName, B.B.; LastName, C.C. Article Title. Journal Name Year, Article Number, Page Range.

\section{ISBN 978-3-03928-740-6 (Pbk)}

ISBN 978-3-03928-741-3 (PDF)

(C) 2020 by the authors. Articles in this book are Open Access and distributed under the Creative Commons Attribution (CC BY) license, which allows users to download, copy and build upon published articles, as long as the author and publisher are properly credited, which ensures maximum dissemination and a wider impact of our publications.

The book as a whole is distributed by MDPI under the terms and conditions of the Creative Commons license CC BY-NC-ND. 


\section{Contents}

About the Special Issue Editors $\ldots \ldots \ldots \ldots \ldots \ldots$ vii

Panagiotis Kyratsis, Konstantinos Kakoulis and Angelos P. Markopoulos

Advances in CAD/CAM/CAE Technologies

Reprinted from: Machines 2020, 8, 13, doi:10.3390/machines8010013 . . . . . . . . . . . . . 1

Martin Leitner, Roman Aigner and Florian Grün

Numerical Fatigue Analysis of Induction-Hardened and Mechanically Post-Treated Steel Components ${ }^{\dagger}$

Reprinted from: Machines 2019, 7, 1, doi:10.3390/machines7010001 . . . . . . . . . . . .

Stoyan Slavov and Mariya Konsulova-Bakalova

Optimizing Weight of Housing Elements of Two-stage Reducer by Using the Topology Management Optimization Capabilities Integrated in SOLIDWORKS: A Case Study

Reprinted from: Machines 2019, 7, 9, doi:10.3390/machines7010009 _ . . . . . . . . . . . 19

\section{Andrzej Dzierwa and Angelos P. Markopoulos}

Influence of Ball-Burnishing Process on Surface Topography Parameters and Tribological

Properties of Hardened Steel

Reprinted from: Machines 2019, 7, 11, doi:10.3390/machines7010011 . . . . . . . . . . . . 3

Nikolaos E. Karkalos, Nikolaos Efkolidis, Panagiotis Kyratsis and Angelos P. Markopoulos

A Comparative Study between Regression and Neural Networks for Modeling Al6082-T6 Alloy Drilling

Reprinted from: Machines 2019, 7, 13, doi:10.3390/machines7010013 . . . . . . . . . . . .

Oana Dodun, Gheorghe Nagîţ̧, Adelina Hriţuc and Laurenţiu Slătineanu

Optimization of Friction Behavior Characteristics by Coating with Solid Lubricants

Reprinted from: Machines 2019, 7, 16, doi:10.3390/machines7010016 . . . . . . . . . . . . .

Evridiki Papachristou, Panagiotis Kyratsis and Nikolaos Bilalis

A Comparative Study of Open-Source and Licensed CAD Software to Support Garment Development Learning

Reprinted from: Machines 2019, 7, 30, doi:10.3390/machines7020030 . . . . . . . . . . . . 81

Fotios I. Stratogiannis, Nikolaos I. Galanis, Nikolaos E. Karkalos and Angelos P. Markopoulos

Optimization of the Manufacturing Strategy, Machining Conditions, and Finishing of a Radial Impeller

Reprinted from: Machines 2020, 8, 1, doi:10.3390/machines8010001 



\section{About the Special Issue Editors}

Panagiotis Kyratsis is an Associate Professor in the Department of Product and Systems Design Engineering, University of Western Macedonia, Greece. He received his Ph.D. in the area of CAD-based manufacturing process simulations from the Department of Production Engineering and Management, Technical University of Crete, Greece. His main research interests include manufacturing, machining, CAD/CAM/CAE systems, product design, reverse engineering, and prototyping. He has published 20 books and more than 110 papers in scientific journals and at international conferences. He acts as a member of the editorial board and reviewer to numerous scientific journals and holds 12 industrial designs and one patent registered within the Greek Patent Office.

Konstantinos G. Kakoulis is a Professor at the Department of Product and Systems Design Engineering, University of Western Macedonia, Greece. He received a Diploma in Mathematics from the University of Ioannina, Greece (1990), a Master of Science degree in Computer Science from the Saint Joseph's University, Philadelphia, PA., USA (1994), and a Ph.D. in Computer Science from the University of Texas at Dallas, USA (1998). His main research interests include the design and analysis of algorithms, information visualization, Graph drawing, computational geometry, and geometric modeling. He has published an international patent, three book chapters and a number of articles in international journals and proceedings of international conferences.

Angelos P. Markopoulos is an Assistant Professor in the Laboratory of Manufacturing Technology at the School of Mechanical Engineering, National Technical University of Athens, Greece. His research includes topics such as precision and ultraprecision machining processes with a special interest in advanced manufacturing and Industry 4.0. Furthermore, he is an expert in manufacturing technology modeling and simulation, including the finite element method, artificial intelligence, and molecular dynamics. He is the author of more than 110 papers in journals, conferences, and book chapters on the above-mentioned areas and a member of the editorial boards of several international journals. 



\title{
Editorial
}

\section{Advances in CAD/CAM/CAE Technologies}

\author{
Panagiotis Kyratsis ${ }^{1, *}$, Konstantinos Kakoulis ${ }^{1}$ and Angelos P. Markopoulos ${ }^{2}$ \\ 1 Department of Product and Systems Design Engineering, University of Western Macedonia, GR50100 Kila \\ Kozani, Greece; kkakoulis@uowm.gr \\ 2 Laboratory of Manufacturing Technology, School of Mechanical Engineering, National Technical University \\ of Athens, 15780 Zografou, Athens, Greece; amark@mail.ntua.gr \\ * Correspondence: pkyratsis@uowm.gr
}

Received: 6 March 2020; Accepted: 11 March 2020; Published: 13 March 2020

Computer-aided design, computer-aided manufacturing and computer-aided engineering (CAD/CAM/CAE) technologies find more and more applications in today's industry, e.g., in the automotive, aerospace, and naval sectors. These technologies increase, to a great extent, the productivity of engineers and researchers, while at the same time allowing their research activities to achieve higher levels of performance. A number of difficult-to-perform design and manufacturing processes can be simulated using more methodologies available, i.e., experimental work combined with statistical tools (regression analysis, analysis of variance, Taguchi methodology, deep learning), finite element analysis applied early enough at the design cycle, CAD-based tools for design optimizations, and CAM-based tools for machining optimizations. As the tools available have become more sophisticated, engineers/researchers consider this challenge as an opportunity for more accurate design, manufacturing, and simulations. This Special Issue includes papers that cover a variety of relevant issues and provides an opportunity for researchers to present recent advances in $\mathrm{CAD} / \mathrm{CAM} / \mathrm{CAE}$ technologies.

A set of computer aided engineering (CAE) simulations, including induction hardening, superimposed stroke peening (mechanical post-treatment), and a fatigue assessment considering local material properties, is presented in [1]. The electromagnetic-thermal simulation of inductive heating was performed with Comsol ${ }^{\circledR}$, the thermometallurgical-mechanical analysis of the hardening process utilized Sysweld ${ }^{\circledR}$, and the mechanical post-treatment was numerically simulated by Abaqus ${ }^{\circledR}$. A finite element analysis (FEA) based topology management optimization study on a two-stage spur gear reducer housing body and cover is presented in [2]. The study aims at optimizing the overall weight of the reducer by thinning specific areas of the casted gearbox housing elements. The topology optimization algorithm gives an optimal structural shape of the housing elements of the reducer with the largest stiffness, considering the given amount of mass that will be removed from the initial design space. Solidworks ${ }^{\circledR}$ was used as a tool for this research. In [3], the ball-burnishing technique was used to investigate the effect of input parameters of processes on selected surface layer features, i.e., surface roughness and residual stresses on $42 \mathrm{CrMo} 4$ steel and, as a result, to improve its tribological properties. Apart from experimental research, the development of accurate and efficient models is considerably important in the field of manufacturing processes. In [4], a comparison between the performance of various neural network models (multilayer perceptron, radial basis function neural network, adaptive neuro-fuzzy inference system) and the performance of a multiple regression model was done. Data from drilling experiments on an Al6082-T6 workpiece for various process conditions were employed, and the performance of models related to thrust force $\left(\mathrm{F}_{\mathrm{Z}}\right)$ and cutting torque $\left(\mathrm{M}_{\mathrm{Z}}\right)$ was assessed. It was concluded that the multilayer perceptron models were superior to the other neural network models and the regression model. In [5], a method applied with the aim to improve the friction behavior of machine elements is electrostatic coating of the surfaces of interest with polyester layers that include particles of solid lubricant. Grey analysis was employed to identify sets of 
input factors that would lead to the most convenient values of the lifetime and energy friction losses, when using polyester layers that incorporate molybdenum or graphite particles. Most universities have included computer-aided design (CAD) pattern-making system education and training in their clothing technology courses in recent years to respond to the actual needs of the fashion world for high-skilled fashion designers and clothing engineers. The authors of [6] compared two commercial licensed CAD systems for pattern design (Polypattern and Create) to an open source software, Seamly2D, and to Wild Ginger's Caveo V6 program, which runs within an open source software (OSS). The results obtained from the evaluation of a set of open source and licensed CAD systems are presented and critically discussed. In [7], an experimental investigation was conducted during the finishing of impeller blades, using Taguchi L16 orthogonal array. After the analysis of surface roughness was conducted for the 16 experiments, it was found that the most important parameters were the spindle speed and feed. Furthermore, the optimum settings were determined as the maximum spindle speed and the lowest feed per tooth value, and a regression model correlating process parameters with surface roughness was established with a high degree of accuracy.

The guest editors of this Special Issue would like to thank the authors for their valuable high-quality work submitted, the reviewers for their efforts and time spent in order to improve the submissions, and the publisher for their excellent work and cooperation.

Conflicts of Interest: The authors declare no conflict of interest.

\section{References}

1. Leitner, M.; Aigner, R.; Grün, F. Numerical Fatigue Analysis of Induction-Hardened and Mechanically Post-Treated Steel Components. Machines 2019, 7, 1. [CrossRef]

2. Slavov, S.; Konsulova-Bakalova, M. Optimizing Weight of Housing Elements of Two-stage Reducer by Using the Topology Management Optimization Capabilities Integrated in SOLIDWORKS: A Case Study. Machines 2019, 7, 9. [CrossRef]

3. Dzierwa, A.; Markopoulos, A. Influence of Ball-Burnishing Process on Surface Topography Parameters and Tribological Properties of Hardened Steel. Machines 2019, 7, 11. [CrossRef]

4. Karkalos, N.; Efkolidis, N.; Kyratsis, P.; Markopoulos, A. A Comparative Study between Regression and Neural Networks for Modeling Al6082-T6 Alloy Drilling. Machines 2019, 7, 13. [CrossRef]

5. Dodun, O.; Nagîț, G.; Hriţuc, A.; Slătineanu, L. Optimization of Friction Behavior Characteristics by Coating with Solid Lubricants. Machines 2019, 7, 16. [CrossRef]

6. Papachristou, E.; Kyratsis, P.; Bilalis, N. A Comparative Study of Open-Source and Licensed CAD Software to Support Garment Development Learning. Machines 2019, 7, 30. [CrossRef]

7. Stratogiannis, F.; Galanis, N.; Karkalos, N.; Markopoulos, A. Optimization of the Manufacturing Strategy, Machining Conditions, and Finishing of a Radial Impeller. Machines 2020, 8, 1. [CrossRef]

(C) 2020 by the authors. Licensee MDPI, Basel, Switzerland. This article is an open access article distributed under the terms and conditions of the Creative Commons Attribution (CC BY) license (http://creativecommons.org/licenses/by/4.0/). 
Article

\title{
Numerical Fatigue Analysis of Induction-Hardened and Mechanically Post-Treated Steel Components ${ }^{\dagger}$
}

\author{
Martin Leitner *, Roman Aigner and Florian Grün \\ Chair of Mechanical Engineering, Montanuniversität Leoben, 8700 Leoben, Austria; \\ roman.aigner@unileoben.ac.at (R.A.); florian.gruen@unileoben.ac.at (F.G.) \\ * Correspondence: martin.leitner@unileoben.ac.at; Tel.: +43-3842-402-1463 \\ † This paper is an extended version of our conference paper published in Leitner, M., Aigner, R., Dobberke, D. \\ "Local fatigue strength assessment of induction hardened components based on numerical manufacturing \\ process simulation." In Proceedings of the 7th International Conference on Fatigue Design, Fatigue Design \\ 2017, Senlis, France, 29-30 November 2017.
}

Received: 2 November 2018; Accepted: 21 December 2018; Published: 2 January 2019

\begin{abstract}
This paper presents a numerical simulation chain covering induction hardening (IH), superimposed stroke peening (StrP) as mechanical post-treatment, and a final fatigue assessment considering local material properties. Focusing on a notched round specimen as representative for engineering components, firstly, the electro-magnetic-thermal simulation of the inductive heating is performed with the software $\mathrm{Comsol}^{\circledR}$. Secondly, the thermo-metallurgical-mechanical analysis of the hardening process is conducted by means of a user-defined interface, utilizing the software Sysweld ${ }^{\circledR}$. Thirdly, mechanical post-treatment is numerically simulated by Abaqus ${ }^{\circledR}$. Finally, a strain-based approach considering the evaluated local material properties is applied, which reveals sound accordance to the fatigue tests results, exhibiting a minor conservative deviation of only up to two per cent, which validates the applicability of the presented numerical fatigue approach.
\end{abstract}

Keywords: fatigue; induction hardening; mechanical post-treatment; numerical simulation

\section{Introduction}

Induction hardening is a commonly applied post-treatment process in industrial applications, such as for gears [1], crankshafts [2], or railway axles [3]. Generally, the wear resistance [4], as well as the fatigue performance [5], are usually increased due to the surface-hardened layer. Hence, fatigue guidelines [6] provide benefit factors for fatigue strength enhancement, due to induction hardening (IH). However, the fatigue resistance of $\mathrm{IH}$ parts significantly depends on the applied process parameters, as they fundamentally impact the resulting local material properties [7-9]. To evaluate these local characteristics, numerous studies have validated the applicability of numerical analysis techniques to simulate the IH process [10-15]. In order to enhance the fatigue strength further, a previous study [16] proposed that a superimposed mechanical treatment, denoted as stroke peening $(\mathrm{StrP})$, of the $\mathrm{IH}$ surface layer is capable of elevating the local fatigue resistance. In the literature, primarily only mechanical post-treatment, such as deep rolling [17] or shot peening [18], has been investigated. However, a superimposed mechanical treatment of hardened surface layers is rare. Hence, this paper contributes scientifically by presenting a numerical simulation chain covering IH and the superimposed StrP manufacturing process. Finally, the numerically evaluated local material properties, such as hardness and residual stress state, are taken into account when assessing local fatigue behavior. As presented in $[19,20]$ for martensitic surface layers, the local fatigue concept is applicable when properly assessing the fatigue resistance of a hardened surface layer.

Within a previous work [21], the numerical simulation of the IH process and a subsequent application of a local strain-based fatigue approach was demonstrated, whereby the results fit well 
to the experimental data. This paper continues this preliminary study by enhancing the numerical manufacturing process chain with the superimposed StrP process. Hence, the main objective of this work is to consecutively apply available commercial CAE software packages to numerically assess the local fatigue strength of the investigated notched round specimen, incorporating the effects of the manufacturing process, including the IH and subsequent mechanical StrP post-treatment.

\section{Materials and Methods}

In accordance with the previous study [16], the same 50CrMo4 steel was used as base material. The nominal chemical composition was specified as 0.46 to $0.54 \% \mathrm{C}$, maximum content of $0.40 \% \mathrm{Si}$, 0.50 to $0.80 \% \mathrm{Mn}, 0.90$ to $1.20 \% \mathrm{Cr}$, and 0.15 to $0.30 \%$ Mo by mass. The nominal mechanical properties were defined with $780 \mathrm{MPa}$ as yield strength, and a tensile strength of approximately $1000 \mathrm{MPa}$, with an elongation of $10 \%$ at rupture. The round specimen geometry (Figure 1) exhibited a diameter of $\mathrm{d}=30 \mathrm{~mm}$ and a notch, whose radius was designed to representatively cover the local stress distribution in depth, as for the investigated crankshaft in [16]. Details on the manufacturing of the crankshaft, the extraction of the specimens, the measurements of local properties, as well as fatigue test results for the base material, $\mathrm{IH}$, and $\mathrm{IH}+\mathrm{StrP}$ condition are provided in $[16,22,23]$.

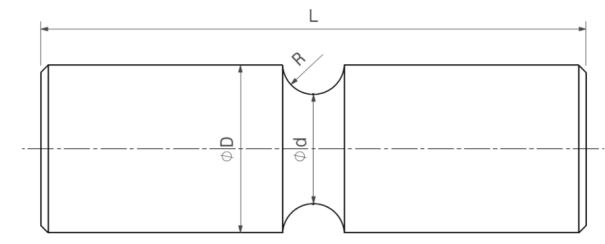

Figure 1. Geometry of the investigated notched round specimen [21].

Induction hardening consists of two parts, inductive heating and subsequent quenching. Thus, the numerical process simulation chain was separated accordingly. Firstly, the inductive heating was performed, utilizing the software $\mathrm{Comsol}^{\circledR}$ [24]. Thereby, a transient simulation model was built up, invoking moving mesh approach, such that the translation of the induction coils was reproduced correctly. The numerically computed position and time dependent temperature field was then transferred to Sysweld ${ }^{\circledR}[25]$, wherewith the simulation of the heat-treatment process was examined. The presented IH process simulation methodology was based on a preliminary work, which is given in $[21,26]$. Beginning with the electro-magnetic-thermal simulation part, selected application studies for the utilized software are presented in $[27,28]$. Further validations of numerical and experimental results are provided in [29]. The main principle of the incorporated electromagnetic analysis was based on Maxwell's equations considering the magnetic vector potential by Equation (1) [30]:

$$
\left(j \omega \kappa-\omega^{2} \varepsilon_{0} \varepsilon_{r}\right) A+\nabla \times\left(\mu_{0}^{-1} \mu_{r}^{-1} B\right)=J_{e} \text { with } B=\nabla \times A .
$$

Thereby, $j$ is the imaginary unit, $\omega$ is the angular frequency, $\kappa$ is the electrical conductivity, $\varepsilon_{0}$ is the permittivity of vacuum, $\varepsilon_{r}$ is the relative permittivity, $A$ is the magnetic vector potential, $\mu_{0}$ is the permeability in vacuum, $\mu_{r}$ is the relative permeability, $B$ is the magnetic flux density, and $J_{e}$ is external current density. The resulting induced heat energy is subsequently coupled with a thermal calculation of the heat transfer according to Equation (2):

$$
\rho C \frac{\partial T}{\partial t}=\nabla \cdot(\lambda \nabla T)+Q_{i n d}
$$

Herein, $\rho$ is the material density, $C$ is the heat capacity, $\lambda$ is the thermal conductivity, and $Q_{i n d}$ is the induced heat energy. In addition, the heat loss due to convection and radiation was considered in the course of the numerical analysis, details see [30,31]. 
In order to properly conduct the numerical analysis, accurate material properties are of utmost importance. Thereby, selected temperature dependent values for the investigated 50CrMo4 steel are provided in [32]. In addition, the study in [32] presents numerous material properties, not only for the electro-magnetic-thermal, but also for the subsequent thermo-metallurgical-mechanical process. Hence, the comprehensive material parameter set used in line with the preliminary works $[21,26]$ was mainly gathered on the basis of [32]. Selected material properties of the steel 50CrMo4 are provided in Appendix A. Further information on the temperature dependent electro-magnetic material properties for the same material are given in [33]. The set-up of the numerical model for the inductive heating process in $\mathrm{Comsol}^{\circledR}$ is depicted in Figure 2. Due to the axial-symmetric specimen geometry, a two dimensional model was set up. Thereby, the surface layer is modeled with a fine mesh as the current density was mainly localized on the surface region based on the skin effect, which skin depth $\delta$ can be evaluated by Equation (3):

$$
\delta=\sqrt{\frac{1}{\pi \cdot \kappa \cdot f \cdot \mu_{0} \cdot \mu_{R}}} \text { with } \kappa(T)=\frac{1}{\rho(T)}
$$

where $f$ is the frequency of the electric current and $\kappa$ is the electrical conductivity depending on the temperature-dependent electric resistance $\rho(T)$ of the base material. In accordance to the real inductive heating process, two separate coil inductors exhibiting different current frequencies were modeled. The first coil featured a medium frequency to ensure global heating and the second coil manifested a high frequency. Thus, the electromagnetic skin depth $\delta$ was significantly reduced in respect to the higher frequency to intensify local heating in the surface layer of the specimen, as seen in Equation (3). As the coils were moving along the axis of the specimen, a moving mesh needed to be designed along this path. The ambient atmosphere was defined as air at room temperature, which was also meshed to incorporate heat loss by convection and radiation during inductive heating.

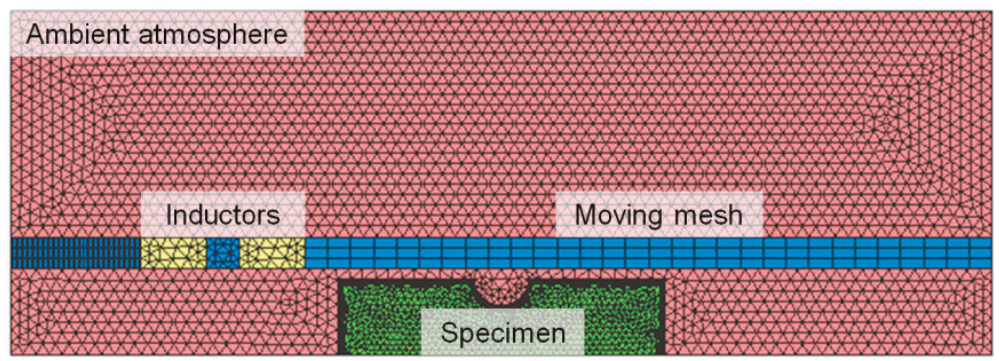

Figure 2. Numerical model of the inductive heating process (based on [26]).

After simulating the inductive heating in $\mathrm{Comsol}^{\circledR}$, the time-dependent temperature data of each node was transferred utilizing a self developed routine [26] to the software package Sysweld ${ }^{\circledR}$, in order to conduct the numerical analysis of the heat-treatment process. This self-written interface converted the temperature-time distribution for each node of the numerical model, which is the result of the simulation in $\mathrm{Comsol}^{\circledR}$, to Sysweld ${ }^{\circledR}$. Herein, this input data acted as the initial heating step for the thermo-metallurgic-mechanical heat-treatment analysis. As the electro-magnetic properties majorly depended on the actual temperature (see Appendix A), and not on the actual metallurgical phase of the investigated steel material, this methodology was applicable. The thermo-metallurgic-mechanical simulation in Sysweld ${ }^{\circledR}$ was performed in accordance to the models provided in the reference manual, see [34]. Further details on the modeling of the quenching process, in order to evaluate the local phase proportions, as well as hardness, distortion, and residual stress conditions are given in [34-38]. Utilizing these models, the residual stress state during, and more importantly, at the end of the IH 
process was numerically computed, which acts, in addition to the hardness condition, as a significant input for the local fatigue analysis at the final stage of the numerical assessment methodology.

The third part of the manufacturing process simulation was the superimposed mechanical StrP process. Therefore, the resulting local material data by IH was transferred from Sysweld ${ }^{\circledR}$ to Abaqus $^{\circledR}$, in order to perform the mechanical simulation. The numerical model was set up in agreement to the experimental investigations [16] incorporating a pin, which iteratively impacted the surface at the notched area of the specimen, as seen in Figure 3. The radius of the pin was comparable to the radius of the notch. The experimental results in [16] highlighted that the superimposed StrP process did not majorly affect the local microstructure and hardness condition. Nevertheless, the subsequent StrP post-treatment did significantly change the residual stress state in depth, which was also the aim of the numerical analysis of the StrP simulation within this work.
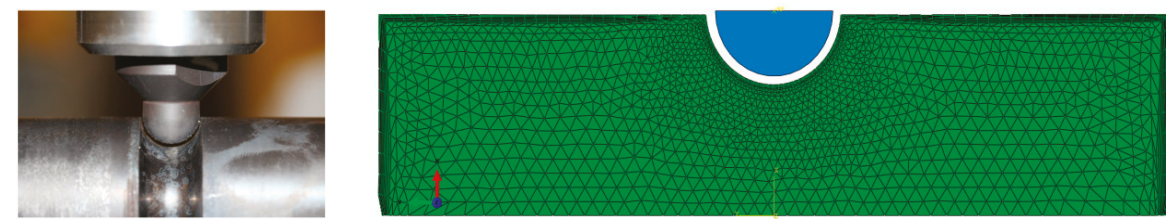

Figure 3. Experimental StrP process of specimen [16] and according to the numerical model.

Based on the preceding heat-treatment simulation in Sysweld ${ }^{\circledR}$, the local node-dependent residual stress state, including the local IH-affected material behavior in terms of stress-strain data, acts as initial condition for the simulation of the mechanical post-treatment in Abaqus ${ }^{\circledR}$. To properly cover hardening effects, a combined isotropic-kinematic hardening model $[39,40]$ was invoked for the analysis, as this model has been shown to be applicable for the simulation of similar mechanical post-treatment processes, such as shot peening, for comparable steel materials (see [41]).

As a final step, the fatigue assessment based on the local strain approach was performed. Thereby, the total strain amplitude $\varepsilon_{a}$ was calculated based on the cyclic stress-strain relationship by Ramberg-Osgood [42], considering the linear-elastic stress amplitude $\sigma_{a}$, the Young's modulus $E$, the cyclic strength coefficient $K^{\prime}$, and the cyclic strain hardening exponent $n^{\prime}$, as seen in Equation (4):

$$
\varepsilon_{a}=\frac{\sigma_{a}}{E}+\left(\frac{\sigma_{a}}{K^{\prime}}\right)^{1 / n^{\prime}} .
$$

As mentioned, the numerically evaluated residual stress state due to the IH and StrP process was considered as a mean stress $\sigma_{m}$ on the basis of the damage parameter $P_{S W T}$ by Smith, Watson, and Topper [43], as seen in Equation (5):

$$
P_{S W T}=\sqrt{\left(\sigma_{a}+\sigma_{m}\right) \varepsilon_{a} E}
$$

The final fatigue assessment evaluating the number of load-cycles $N$ until cyclic failure was performed applying the strain-life model by Manson [44], Coffin [45], and Basquin [46] involving the fatigue strength coefficient $\sigma_{f}^{\prime}$, the fatigue strength exponent $b$, the fatigue ductility coefficient $\varepsilon_{f}^{\prime}$, and the fatigue ductility exponent $c$, as seen in Equation (6):

$$
P_{S W T}=\sqrt{\sigma^{\prime}{ }_{f}^{2}(2 N)^{2 b}+\varepsilon^{\prime}{ }_{f} \sigma^{\prime}{ }_{f} E(2 N)^{b+c}} .
$$

The material parameters $K^{\prime}, n^{\prime}, \sigma_{f}^{\prime}, \varepsilon^{\prime}, b$, and $c$, which were mandatory to perform the fatigue assessment, could be either determined based on low-cycle fatigue tests or by an estimation based on the unified material law (UML), introduced by Bäumel and Seeger [47]. As the original UML was focused on mild steels, an extension for high-strength steels is given in [48]. In both cases, the parameter evaluation mostly depends on the ultimate tensile strength (UTS). As the local Vicker's 
hardness value (HV) was numerically computed by the manufacturing process simulation, the UTS could be estimated based on a suggestion in [49] for steels, as seen in Equation (7):

$$
\text { UTS }=-99.8+3.734 \cdot H V .
$$

Hence, the above presented material parameters were not constant within the fatigue analysis, but depended on the local hardness condition. As observed within the fatigue tests using the $\mathrm{IH}$ and $\mathrm{IH}+\mathrm{StrP}$ specimens, the crack initiation origin was located either right at the very surface, or within the bulk material at the transition from the hardened surface layer to the core region. For simplification, the hardness values were determined for these two points, whereat two material parameter sets were utilized in the course of the fatigue assessment. As low-cycle fatigue test results for the IH hardened material layer were available, wherein the values were in line with the ones based on the estimation from UML, this material data set was used. As no low-cycle fatigue tests were performed for the core region, the estimation based on the local Vicker's hardness was applied.

\section{Results}

\subsection{Fatigue Tests}

To evaluate the fatigue behavior of the researched specimens, fatigue tests under a load stress ratio of $\mathrm{R}=-1$ were conducted. Figure 4 depicts the results for the $\mathrm{IH}$ and the $\mathrm{IH}+\mathrm{StrP}-$ condition. The results were normalized with the statistically evaluated nominal fatigue strength amplitude for the base material (BM), at a number of $5 \mathrm{e} 6$ load-cycles and a survival probability of $\mathrm{P}_{\mathrm{S}}=50 \%$. It was shown that $\mathrm{IH}$ elevated the mean fatigue resistance at $5 \mathrm{e} 6$ load-cycles by a factor of 1.46 , and $\mathrm{IH}+\mathrm{StrP}$ by a factor of 1.75 compared to the BM. These results proved the beneficial effect of the post-treatment processes and the experimental values acted as basis to validate the numerical fatigue analysis. Further details of the fatigue test procedure, statistical evaluation of the fatigue data, as well as extensive fracture surface analysis, is provided in [16].

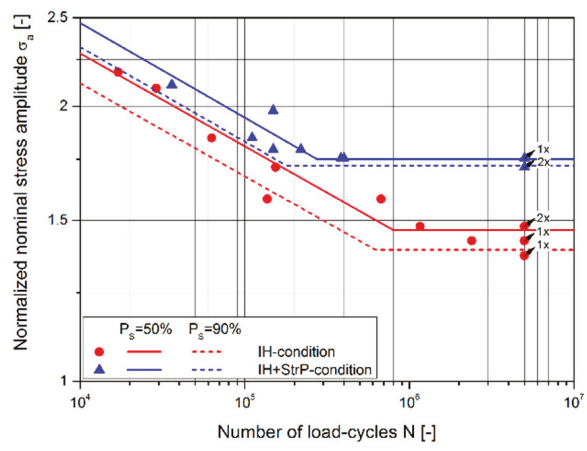

Figure 4. Fatigue test results for induction hardening $(\mathrm{IH})$ and $\mathrm{IH}+$ superimposed stroke peening (StrP) - condition (according to [16]).

\subsection{Numerical Simulation}

\subsubsection{Electro-Magnetic-Thermal Simulation}

The results of the inductive heating simulation in $\mathrm{Comsol}^{\circledR}$ are illustrated in Figure 5. At first, Figure 5a depicts the increment at which induction coil \#1 started at the top end of the specimen. It is shown that a peak temperature of about $330{ }^{\circ} \mathrm{C}$ occurred at this time step. Further on, Figure $5 \mathrm{~b}$ presents the time increment at which induction coil \#2 additionally began at the top end of the specimen. Thereby, a maximum temperature of around $900{ }^{\circ} \mathrm{C}$ was computed within the model. 
The final condition directly after finishing the inductive heating utilizing the two coils, is depicted in Figure $5 \mathrm{c}$. In this case, the peak temperature was about $840{ }^{\circ} \mathrm{C}$ and the localization of the heat input in the surface layer due to skin-effect was clearly observable. Subsequently, these time-dependent nodal temperature data were transferred to Sysweld ${ }^{\circledR}$, utilizing a self-written script.
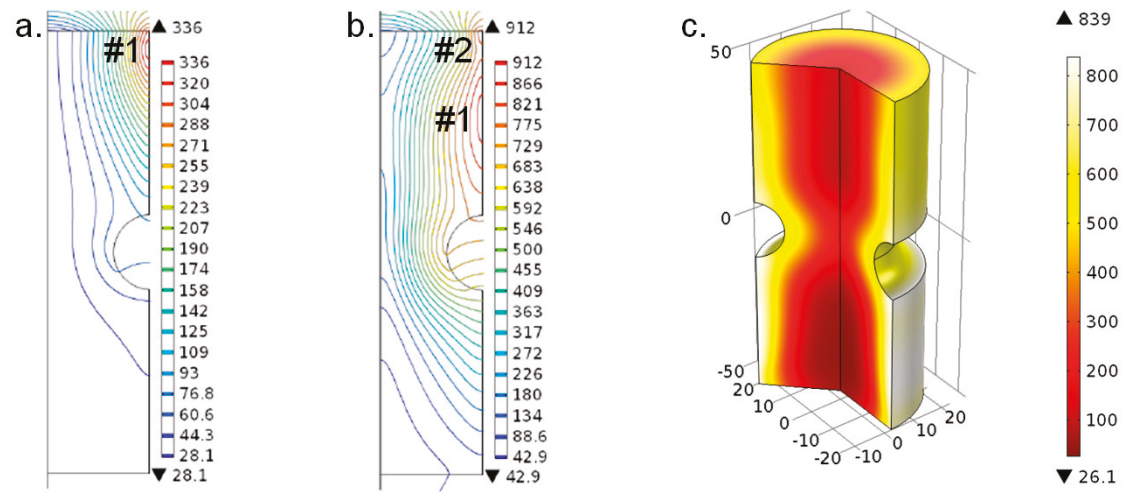

Figure 5. Numerical results of inductive heating simulation in $\mathrm{Comsol}^{\circledR}$ (based on $[21,26]$ ).

\subsubsection{Thermo-Metallurgical-Mechanical Simulation}

After transferring the time-dependent temperature data for each node of the model from Comsol ${ }^{\circledR}$ to Sysweld ${ }^{\circledR}$, as an initial step, the heating process was computed in Sysweld ${ }^{\circledR}$. The results are shown Figure 6. At first, Figure 6a displays the increment at which induction coil \#1 started at the top end of the specimen. It was observed that a similar peak temperature of about $330{ }^{\circ} \mathrm{C}$ occurred at this time step. Further on, Figure $6 \mathrm{~b}$ presents the time increment at which coil \#2 began, where again a similar maximum temperature of around $900{ }^{\circ} \mathrm{C}$ was computed. The final condition after finishing the heating process is depicted in Figure $6 \mathrm{c}$ revealing a peak temperature of about $850{ }^{\circ} \mathrm{C}$, which was in sound accordance to the previous simulation in $\mathrm{Comsol}^{\circledR}$. To sum up, the numerically computed temperature distribution in Sysweld ${ }^{\circledR}$ was similar to the simulation results given by $\mathrm{Comsol}^{\circledR}$, which validated the applicability of the self-written interface.
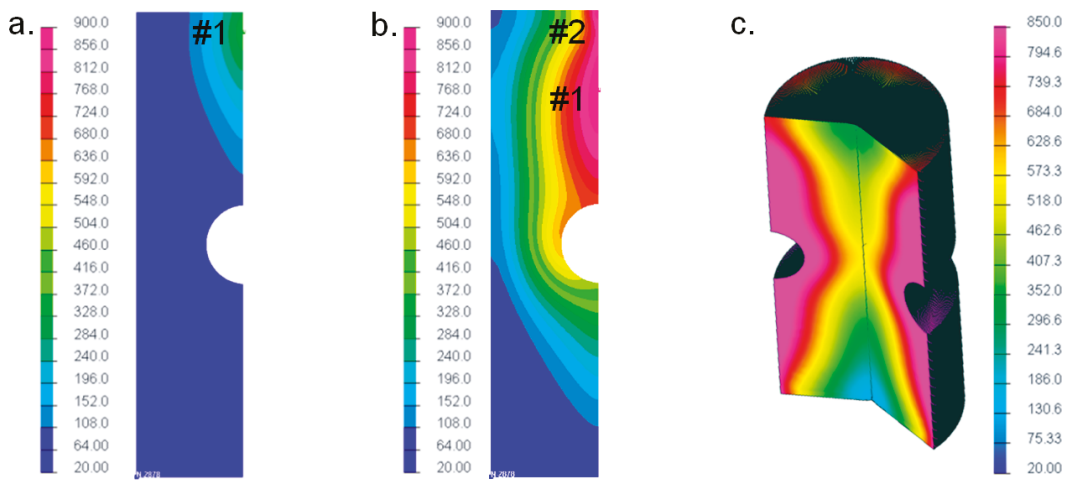

Figure 6. Numerical results of corresponding heating processes in Sysweld ${ }^{\circledR}$ (based on $[21,26]$ ).

Subsequently to the heating process, the quenching of the specimen was numerically simulated in Sysweld ${ }^{\circledR}$. Firstly, water spray cooling, and then air cooling was modeled. These cooling steps were defined in accordance to the experimental induction hardening process of the round specimen. 
Figure 7a demonstrates the temperature distribution during water spray cooling at the top end and Figure $7 \mathrm{~b}$ at the notch area of the specimen. Figure $7 \mathrm{c}$ depicts the time increment after finishing the water spray cooling, which shows that the IH heat-treatment was effective especially at the surface-layer of the specimen. After cooling down to room temperature, the numerically computed metallurgical and mechanical results were analyzed. Figure 8a illustrates the total amount of the martensitic and Figure $8 b$ of the ferritic/pearlitic phase. The simulated induction hardening depth fit well to a micrographical analysis of the one real specimen, see Figure 8c.

a.

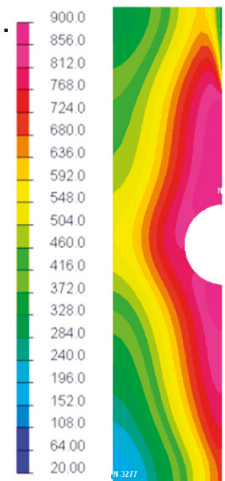

b.

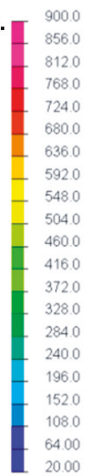

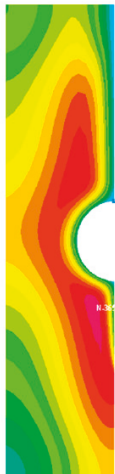

c.

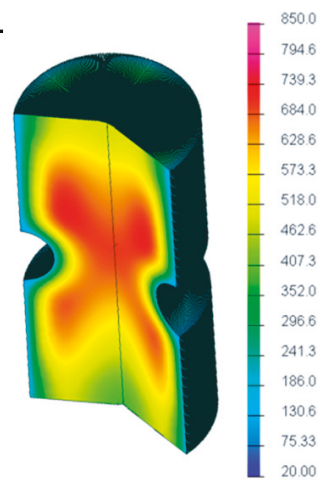

Figure 7. Numerical results of quenching processes in Sysweld ${ }^{\circledR}$ (based on $[21,26]$ ).
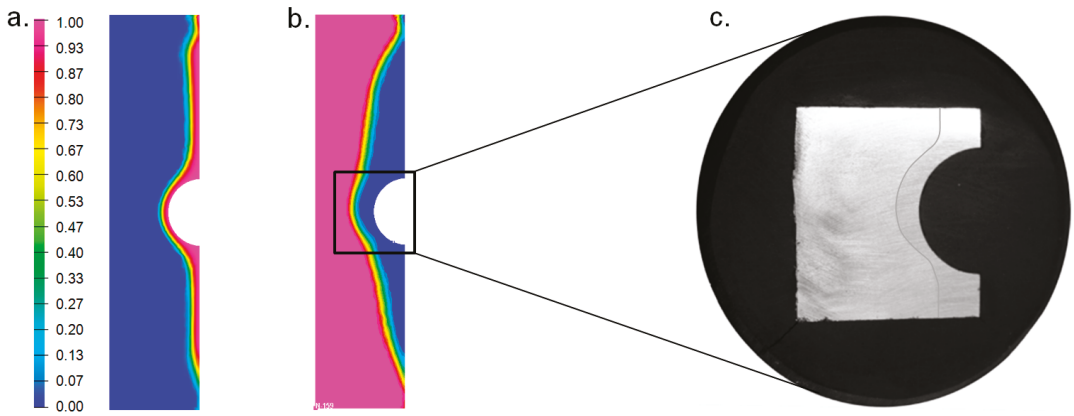

Figure 8. Numerically computed amount of the martensitic (a) as well as ferritic/pearlitic phase (b) and comparison of induction hardening depth of a real specimen (c) (based on [21,26]).

A comparison of the numerically evaluated and measured Vicker's hardness is presented in Figure 9. Therein, the values were normalized by the measured hardness of the BM. It is shown that both measurement and numerical simulation agreed well, whereby an increase of a factor of two in hardness was gained within the surface layer, due to the IH process. The effect of IH was observed up to a depth of roughly $3 \mathrm{~mm}$ beneath the surface at the notch root, which fit well to the numerical and experimental evaluation in Figure 8.

The finally computed axial residual stress state is shown in Figure 10. Therein, the stress values were normalized with the yield strength of the BM, which was evaluated based on quasi-static tensile tests [23]. The numerical results highlighted surface compressive residual stresses of about -0.55 times the yield strength of the BM. In depth, at the transition from the IH surface layer to the core material, a shift from compressive to tensile residual stresses with a normalized value of around +0.20 was maintained. Furthermore, the residual stress values were considered within the fatigue analysis. In order to simulate the third step of the manufacturing process, the mechanical StrP and the local material data was then transferred from Sysweld ${ }^{\circledR}$ to Abaqus ${ }^{\circledR}$. 

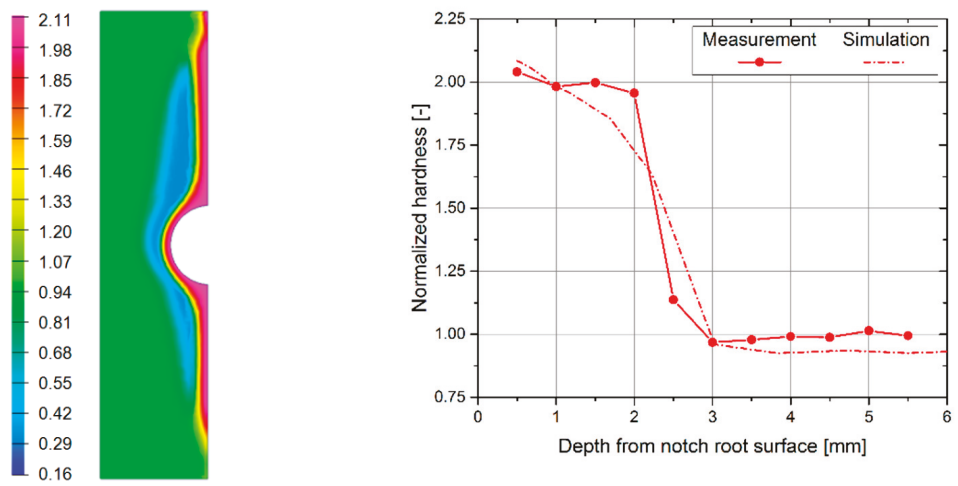

Figure 9. Numerically computed Vicker's hardness state and comparison of distribution in depth with measurement (based on [21,26]).
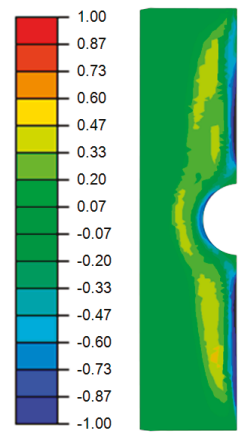

Figure 10. Numerically computed axial residual stress distribution for IH condition.

\subsubsection{Simulation of Mechanical Stroke-Peening Process}

After transferring the IH process-dependent local material, as well as residual stress data from Sysweld ${ }^{\circledR}$ to Abaqus ${ }^{\circledR}$, the superimposed StrP process as mechanical post-treatment was simulated. The axial stress results before, see Figure 11a, and during the peak compressive load, see Figure 11b, are shown as follows.

During the mechanical post-treatment, it was observed that there occured comparably high compressive stress peaks below a normalized value of -1.00 within the contact area at the notch root, as seen in the black region in Figure 11b. Due to this stress state, the IH surface layer, as well as the subjacent core material, was additionally post-treated, which influenced the local residual stress state in depth. As shown by X-ray residual stress measurements in [16], not only the axial but also the residual stresses in tangential direction were significantly affected by the superimposed StrP process. To cover this multiaxial residual stress state, the von Mises equivalent stress was evaluated. The final von Mises residual stress condition after the superimposed StrP is depicted in Figure 12. 

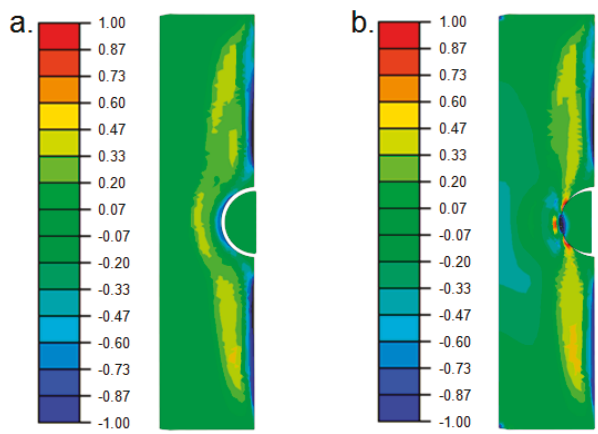

Figure 11. Axial residual stress state before (a) and during the peak compressive load (b) of the mechanical StrP process.

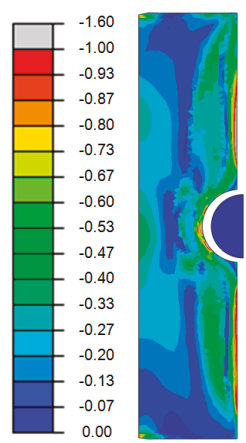

Figure 12. Numerically computed von Mises residual stress distribution for $\mathrm{IH}+\mathrm{StrP}$ condition.

The numerical simulation results maintained that, especially at the surface of the notch root the compressive residual stress state by IH was elevated due to the StrP process. Therein, a comparably high value of -1.60 times the yield strength of the BM occurred. Focusing on the core region in depth, again at the transition from the hardened surface layer to the core material, the tensile residual stress state due to IH was then shifted to compressive stress, with a value of about -0.24 . This again proved the beneficial effect of the superimposed mechanical post-treatment in this case. Same as for the IH condition, these residual stress values are further on considered within the fatigue analysis.

\subsection{Local Fatigue Strength Assessment}

As described above, the local hardness as well as residual stress states, were utilized as input parameters for the final fatigue assessment based on the local strain-approach. Figure 13 shows a comparison of the fatigue test data and the evaluated fatigue behavior based on the local fatigue approach. It is observable that the results by the model met the average of the experimental data within the finite life region well. Focusing on the long life fatigue strength at $5 \mathrm{e} 6$ load-cycles, a minor conservative assessment was highlighted. However, in this case, the fatigue model fit well to the statistically evaluated $\mathrm{S} / \mathrm{N}$-curve for a survival probability of $\mathrm{P}_{\mathrm{S}}=90 \%$, as presented within the subsequent discussion. As a conservative fatigue assessment with values of $P_{S} \geq 90 \%$ is preferentially applied, the presented fatigue model was capable of estimating the fatigue strength in this region. 


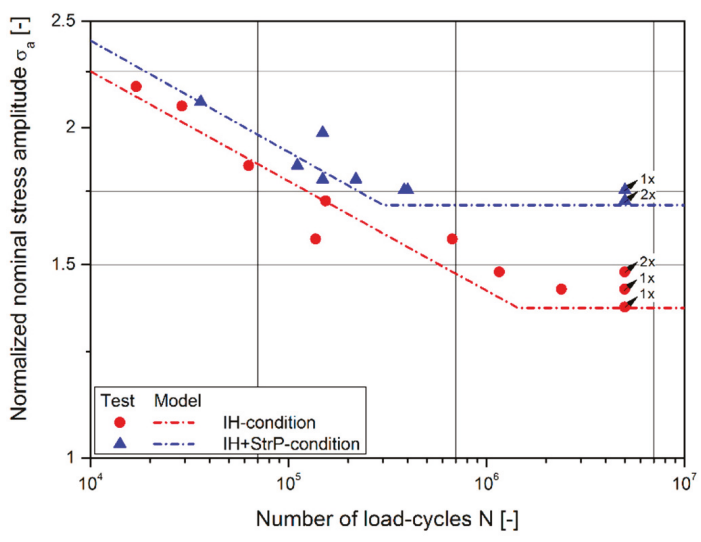

Figure 13. Comparison of fatigue test data points to S/N-curve by fatigue model.

\section{Discussion}

Within this section, details of the experimental, numerical, and fatigue assessment results are given. First, Table 1 presents the statistically evaluated parameters of the $\mathrm{S} / \mathrm{N}$-curves based on the fatigue test results. As mentioned, the results were normalized with the statistically evaluated nominal fatigue strength amplitude for the base material (BM), at a number of $5 \mathrm{e} 6$ load-cycles and a survival probability of $\mathrm{P}_{\mathrm{S}}=50 \%$. It is shown that the normalized fatigue strength amplitude at $5 \mathrm{e} 6$ load-cycles was majorly elevated, by $46 \%$, due to the $\mathrm{IH}$, and by as much as $75 \%$ due to $\mathrm{IH}+\mathrm{StrP}$ compared to the $\mathrm{BM}$ state. In addition, the number of load-cycles at the transition knee point $N_{T}$ were reduced, which contributed to the beneficial effect of the post-treatment processes. No significant change of the slope within the finite life region was evaluated for $\mathrm{IH}+\mathrm{StrP}$ compared to $\mathrm{IH}$, concluding that the StrP was most effective within the long life fatigue region at 5e6 load-cycles.

Table 1. Comparison of the fatigue test results (evaluated at $P_{S}=50 \%$ ) for base material (BM), IH, and $\mathrm{IH}+\mathrm{StrP}-$ condition [16].

\begin{tabular}{cccc}
\hline Condition & $\sigma_{a}$ at 5e6 & Slope $k$ & Knee Point $\boldsymbol{N}_{\boldsymbol{T}}$ \\
\hline $\mathrm{BM}$ & 1.00 & 15.8 & $1.4 \mathrm{e} 6$ \\
$\mathrm{IH}$ & 1.46 & 9.8 & $7.9 \mathrm{e} 5$ \\
$\mathrm{IH}+\mathrm{StrP}$ & 1.75 & 9.7 & $2.7 \mathrm{e} 5$ \\
\hline
\end{tabular}

As shown in [16], extensive residual stress investigations for the IH and IH+StrP condition were performed applying the $\mathrm{X}$-ray diffraction technique. The results were taken as a basis for validating the numerical results of the manufacturing process simulation within this paper. Table 2 provides a comparison of the measured and numerically computed axial residual stresses due to $\mathrm{IH}$, at the surface and in depth, at the transition from the hardened surface layer to the core material. As previously mentioned, the stress values were normalized with the yield strength of the BM, which was evaluated based on quasi-static tensile tests [23]. It is shown that the simulation led to a normalized residual stress at the surface of -0.55 , which was only about two percent different to the measurement result and hence, validates the applicability of the numerical simulation. In depth, a tensile stress value of +0.20 was computed, which could not be compared to the measurements, as electro-chemical polishing is not applicable exceeding a depth of about two to three millimeters. 
Table 2. Comparison of axial residual stresses for IH-condition by X-ray measurements and numerical simulation.

\begin{tabular}{ccc}
\hline Evaluation & At Surface & In Depth \\
\hline X-ray measurement & -0.54 & Not evaluable ${ }^{1}$ \\
Numerical simulation & -0.55 & +0.20 \\
\hline 1 Electro-chemical polishing
\end{tabular}

Table 3 demonstrates a comparison of the measured and numerically computed von Mises residual stresses due to $\mathrm{IH}+\mathrm{StrP}$, at the surface and in depth, at the transition from the hardened surface layer to the core material. As described, in [16], it has been revealed that the superimposed StrP process affects not only the axial, but also the residual stress state in a tangential direction. Hence, to compare this distinctive multiaxial stress state, the von Mises equivalent stress was invoked. It was shown that again the numerical manufacturing process simulation agreed well with the $\mathrm{X}$-ray measurements, revealing a similar difference of only about one percent. On the contrary to the IH condition, compressive residual stresses of -0.24 were computed in depth, which proved the beneficial effect of the superimposed StrP post-treatment. However, due to the aforementioned limitations by the electro-chemical polishing process, X-ray measurements could not be performed in this depth. In addition to the previously shown local hardness condition, whereby also sound agreement between the measurements and simulation was achieved, it can be summarized that the presented simulation approach is a practical way to numerically assess the local residual stress state of induction hardened and mechanically post-treated steel components.

Table 3. Comparison of von Mises residual stresses for IH+StrP-condition by X-ray measurements and numerical simulation.

\begin{tabular}{ccc}
\hline Evaluation & At-Surface & In Depth \\
\hline X-ray measurement & -1.58 & Not evaluable ${ }^{1}$ \\
Numerical simulation & -1.59 & -0.24 \\
\hline
\end{tabular}

${ }^{1}$ Electro-chemical polishing not applicable up to this depth

The results of the final fatigue assessment based on the local strain approach utilizing the local hardness as well as residual stress state based on the simulation as input parameter is presented in Table 4 . Therein, the long life fatigue strength amplitude at $5 \mathrm{e} 6$ load-cycles evaluated by the model and the fatigue tests is compared. The results of the experiments are given for a survival probability of $\mathrm{P}_{\mathrm{S}}=90 \%$, considering a conservative fatigue assessment. It is shown that in both cases $\mathrm{IH}$, as well as $\mathrm{IH}+\mathrm{StrP}$ condition, the fatigue model is capable of estimating the experimental results. For both conditions, the deviation of the model to the experiments was only between one and two percent, which validates the applicability of the presented numerical fatigue assessment.

Table 4. Comparison of fatigue strength amplitude $\sigma_{a}$ at 5e6 load-cycles evaluated by model and experiments $\left(\mathrm{P}_{\mathrm{S}}=90 \%\right)$, for $\mathrm{IH}$ and $\mathrm{IH}+\mathrm{StrP}$-condition.

\begin{tabular}{cccc}
\hline Condition & Model & Experiment & Difference \\
\hline $\mathrm{IH}$ & 1.37 & 1.39 & $-1.4 \%$ \\
$\mathrm{IH}+\mathrm{StrP}$ & 1.70 & 1.72 & $-1.2 \%$ \\
\hline
\end{tabular}

\section{Conclusions}

Based on the experimental, numerical, and fatigue assessment results within this work, the following scientific conclusions can be drawn:

- The fatigue test results reveal that induction hardening (IH) leads to an increase of $46 \%$ of the long life fatigue strength amplitude at $5 \mathrm{e} 6$ load-cycles compared to the base material (BM). 
The superimposed stroke peening (StrP) process even elevates this value again by about $20 \%$, leading to a benefit of $75 \%$ compared to the BM.

- The numerically computed hardness state, as well as residual stress condition utilizing an electro-magnetic-thermal and thermo-metallurgical-mechanical simulation for the IH process, shows a sound agreement to the measurements. Residual stress values at the surface in an axial direction reveal a difference of only about two percent when comparing simulation and X-ray residual stress measurements.

- The simulation of the superimposed StrP process leads to similar results, whereby a minor difference of the von Mises equivalent residual stress state at the surface of only one percent between the numerical analysis and measurements is also observed.

- The final fatigue assessment highlights a sound agreement of the fatigue model, which incorporates the local hardness and residual stress state, to the experiments. Focusing on the long life fatigue strength, a minor conservative estimation with a difference of only one to two percent is shown for both $\mathrm{IH}$ as well as $\mathrm{IH}+\mathrm{StrP}$ condition.

These conclusions basically prove the applicability of the presented numerical fatigue analysis approach for $\mathrm{IH}$ and $\mathrm{IH}+\mathrm{StrP}$ steel components. Further work will focus on the incorporation of statistical size effects for post-treated steel layers, as shown in [22] for the BM condition.

Author Contributions: Conceptualization, M.L. and R.A.; methodology, M.L. and F.G.; software, M.L. and R.A.; validation, M.L.; formal analysis, M.L. and R.A.; investigation, M.L.; writing-original draft preparation, M.L.; writing-review and editing, R.A. and F.G.; supervision, M.L. and F.G.; project administration, M.L.

Funding: This research received no external funding. Scientific support was provided in the course of the "Christian Doppler Laboratory for Manufacturing Process based Component Design".

Conflicts of Interest: The authors declare no conflict of interest.

\section{Appendix A}

In Appendix A, selected material parameters for the investigated steel 50CrMo4 are provided, which are mainly taken from [32]. Table A1 shows the temperature dependence for the electrical conductivity $\kappa$, the thermal conductivity $\lambda$, and the product of the material density $\rho$ and the heat capacity $C$.

Table A1. Temperature dependence of selected material parameters for 50CrMo4 steel [32]

\begin{tabular}{|c|c|c|c|}
\hline$T\left[{ }^{\circ} \mathrm{C}\right]$ & $\kappa\left[\mathrm{MS} \mathrm{m}^{-1}\right]$ & $\lambda\left[\mathrm{W} \mathbf{m}^{-1} \mathbf{K}^{-1}\right]$ & $\rho C\left[\mathrm{~J} \mathrm{~kg}^{-1} \mathrm{~K}^{-1}\right]$ \\
\hline 0 & 4.91 & 43.1 & 451 \\
\hline 100 & 3.90 & 42.7 & 488 \\
\hline 200 & 3.02 & 41.7 & 528 \\
\hline 300 & 2.40 & 40.6 & 552 \\
\hline 400 & 1.95 & 38.9 & 619 \\
\hline 500 & 1.60 & 37.3 & 731 \\
\hline 600 & 1.25 & 33.7 & 762 \\
\hline 700 & 1.05 & 31.0 & 828 \\
\hline 800 & 1.00 & 29.5 & 836 \\
\hline 900 & 0.97 & 28.4 & 830 \\
\hline 1000 & 0.94 & 28.1 & 790 \\
\hline 1100 & 0.92 & 28.8 & 732 \\
\hline 1200 & 0.90 & 30.1 & 672 \\
\hline
\end{tabular}

Table A2 provides the magnetization characteristic as B-H-curve at room temperature, which values are estimated based on [32] for the same steel 50CrMo4. 
Table A2. Magnetization characteristic at room temperature for 50CrMo4 steel [32].

\begin{tabular}{cc}
\hline B [T] & H [A/m] \\
\hline 0.08 & 500 \\
0.32 & 1000 \\
0.88 & 1500 \\
1.28 & 2000 \\
1.40 & 2500 \\
1.48 & 3000 \\
1.52 & 3500 \\
1.56 & 4000 \\
1.60 & 4500 \\
1.64 & 5000 \\
1.66 & 5500 \\
1.68 & 6000 \\
1.70 & 6500 \\
1.72 & 7000 \\
\hline
\end{tabular}

Further electro-magnetic properties as well as the temperature-dependence of the $\mathrm{B}-\mathrm{H}$-curve are presented in [33] for the same steel. In addition, thermo-metallurgic-mechanical material data, such as a continuous cooling transformation (CCT) diagram, for the same base material is given in [32]. This material data is used for the numerical simulation of the heat-treatment in this work.

\section{Appendix B}

In Appendix B, the unified material law (UML) extended for high-strength steels as provided in [48] is presented. Table A3 shows the fatigue model parameters and their estimation based on the extended UML. The parameter $\psi$ can be evaluated as follows: $\psi=0.5\{\cos [\pi(\mathrm{UTS}-400) / 2200]+1\}$

Table A3. Extended unified material law (UML) [48].

\begin{tabular}{cc}
\hline Parameter & Estimation \\
\hline$K^{\prime}$ & $\sigma_{\mathrm{f}}^{\prime} /\left(\varepsilon_{\mathrm{f}}^{\prime}\right)^{\mathrm{n}^{\prime}}$ \\
$n^{\prime}$ & $\mathrm{b} / \mathrm{c}$ \\
$\sigma_{f}^{\prime}$ & $\mathrm{UTS}(1+\psi)$ \\
$\varepsilon_{f}^{\prime}$ & $0.58 \psi+0.01$ \\
$b$ & $-\log \left(\sigma_{\mathrm{f}}^{\prime} / \sigma_{\mathrm{E}}\right) / 6$ \\
$\sigma_{E}$ & $\mathrm{UTS}(0.32+\psi / 6)$ \\
$c$ & -0.58 \\
\hline
\end{tabular}

\section{References}

1. Rudnev, V.; Loveless, D.; Cook, R.; Black, M. Induction Hardening of Gears: A Review. Heat Treat. Met. 2003, 30, 97-103.

2. Garcia, F. Crankshaft Fillet Hardening: Challenges and Prospects. Ind. Heat. 2014, 12, 47-48.

3. Fajkoš, R.; Zima, R.; Strnadel, B. Fatigue limit of induction hardened railway axles. Fatigue Fract. Eng. Mater. Struct. 2015, 38, 1255-1264. [CrossRef]

4. Šofer, M.; Fajkoš, R.; Halama, R. Influence of Induction Hardening on Wear Resistance in Case of Rolling Contact. J. Mech. Eng. 2016, 66, 17-26. [CrossRef]

5. Bertini, L.; Fontanari, V. Fatigue behaviour of induction hardened notched components. Int. J. Fatigue 1999, 21, 611-617. [CrossRef]

6. McKelvey, S.A.; Lee, Y.-L.; Barkey, M.E. Stress-based uniaxial fatigue analysis using methods described in FKM-guideline. J. Fail. Anal. Prev. 2012, 12, 445-484. [CrossRef]

7. Savaria, V.; Bridier, F.; Bocher, P. Predicting the effects of material properties gradient and residual stresses on the bending fatigue strength of induction hardened aeronautical gears. Int. J. Fatigue 2016, 85, 70-84. [CrossRef] 
8. Palin-Luc, T.; Coupard, D.; Dumas, C.; Bristiel, P. Simulation of multiaxial fatigue strength of steel component treated by surface induction hardening and comparison with experimental results. Int. J. Fatigue 2011, 33, 1040-1047. [CrossRef]

9. Jiang, Y. Stress and fatigue analyses of an induction hardened component. Met. Mater. 1998, 4, 520-523.

10. Cajner, F.; Smoljan, B.; Landek, D. Computer simulation of induction hardening. J. Mater. Process. Technol. 2004, 157, 55-60. [CrossRef]

11. Ivanov, D.; Markegård, L.; Asperheim, J.I.; Kristoffersen, H. Simulation of Stress and Strain for Induction-Hardening Applications. J. Mater. Eng. Perform. 2013, 22, 3258-3268. [CrossRef]

12. Fuhrmann, J.; Hömberg, D.; Uhle, M. Numerical simulation of induction hardening of steel. COMPEL 1999, 18, 482-493. [CrossRef]

13. Hömberg, D.; Liu, Q.; Montalvo-Urquizo, J.; Nadolski, D.; Petzold, T.; Schmidt, A.; Schulz, A. Simulation of multi-frequency-induction-hardening including phase transitions and mechanical effects. Finite Elem. Anal. Des. 2016, 121, 86-100. [CrossRef]

14. Montalvo-Urquizo, J.; Liu, Q.; Schmidt, A. Simulation of quenching involved in induction hardening including mechanical effects. Comput. Mater. Sci. 2013, 79, 639-649. [CrossRef]

15. Li, H.; He, L.; Gai, K.; Jiang, R.; Zhang, C.; Li, M. Numerical simulation and experimental investigation on the induction hardening of a ball screw. Mater. Des. 2015, 87, 863-876. [CrossRef]

16. Leitner, M.; Grün, F.; Tuncali, Z.; Chen, W. Fatigue and Fracture Behavior of Induction-Hardened and Superimposed Mechanically Post-treated Steel Surface Layers. J. Mater. Eng. Perform. 2018, 27, 4881-4892. [CrossRef]

17. Ho, S.; Lee, Y.-L.; Kang, H.-T.; Wang, C.J. Optimization of a crankshaft rolling process for durability. Int. J. Fatigue 2009, 31, 799-808. [CrossRef]

18. Bhuvaraghan, B.; Srinivasan, S.M.; Maffeo, B.; McCLain, R.D.; Potdar, Y.; Prakash, O. Shot peening simulation using discrete and finite element methods. Adv. Eng. Softw. 2010, 41, 1266-1276. [CrossRef]

19. Winderlich, B. Das Konzept der lokalen Dauerfestigkeit und seine Anwendung auf martensitische Randschichten, insbesondere Laserhärtungsschichten. Materialwissenschaft und Werkstofftechnik 1990, 21, 378-389. (In German) [CrossRef]

20. Kloos, K.H.; Velten, E. Berechnung der Dauerschwingfestigkeit von plasmanitrierten bauteilähnlichen Proben unter Berücksichtigung des Härte-und Eigenspannungsverlaufs. Konstruktion 1984, 36, 181-188. (In German)

21. Leitner, M.; Aigner, R.; Dobberke, D. Local fatigue strength assessment of induction hardened components based on numerical manufacturing process simulation. Procedia Eng. 2018, 213, 644-650. [CrossRef]

22. Leitner, M.; Vormwald, M.; Remes, H. Statistical size effect on multiaxial fatigue strength of notched steel components. Int. J. Fatigue 2017, 104, 322-333. [CrossRef]

23. Leitner, M.; Tuncali, Z.; Steiner, R.; Grün, F. Multiaxial fatigue strength assessment of electroslag remelted 50CrMo4 steel crankshafts. Int. J. Fatigue 2017, 100, 159-175. [CrossRef]

24. Pryor, R.W. Multiphysics Modeling Using COMSOL. A First Principles Approach; Jones and Bartlett Publication: Boston, MA, USA, 2011.

25. Pont, D.; Guichard, T. Sysweld ${ }^{\circledR}$ : Welding and Heat Treatment Modelling Tools. In Computational Mechanics'95; Springer: Berlin, Germany, 1995; pp. 248-253.

26. Aigner, R. Aufbau Einer Numerischen Simulationskette für Induktionsgehärtete Randschichten. Master's Thesis, Montanuniversität Leoben, Leoben, Austria, 2016. (In German)

27. Istardi, D.; Triwinarko, A. Induction heating process design using comsol multiphysics software. Telecommun. Comput. Electron. Control 2013, 9, 327-334. [CrossRef]

28. Ocilka, M.; Kovác, D. Simulation model of induction heating in Comsol Multiphysics. AEI 2015, 15, 29-33. [CrossRef]

29. Kennedy, M.; Shahid, A.; Jon Arne, B.; Ragnhild, E.A. Analytical and Experimental Validation of Electromagnetic Simulations Using COMSOL ${ }^{\circledR}$, re Inductance, Induction Heating and Magnetic Fields. In Proceedings of the COMSOL Users Conference, Stuttgart, Germany, 26-28 October 2011.

30. Rudnev, V.; Loveless, D.; Cook, R.L. Handbook of Induction Heating; CRC Press: Boca Raton, FL, USA, 2017.

31. Comsol, A.B. COMSOL Reference Manual, version 5.2a; COMSOL Inc.: Burlington, MA, USA, 2016.

32. Barglik, J.; Smalcerz, A.; Przylucki, R.; Doležel, I. 3D modeling of induction hardening of gear wheels. J. Comput. Appl. Math. 2014, 270, 231-240. [CrossRef] 
33. Fisk, M.; Lindgren, L.-E.; Datchary, W.; Deshmukh, V. Modelling of induction hardening in low alloy steels. Finite Elem. Anal. Des. 2018, 144, 61-75. [CrossRef]

34. ESI Group. SYSWELD Reference Manual; ESI Group: Paris, France, 2009.

35. Liščić, B. Quenching Theory and Technology, 2nd ed.; CRC Press: Boca Raton, FL, USA, 2010.

36. Wolff, M.; Acht, C.; Böhm, M.; Meier, S. Modelling of carbon diffusion and ferritic phase transformations in an unalloyed hypoeutectoid steel. Arch. Mech. 2007, 59, 435-466.

37. Magnabosco, I.; Ferro, P.; Tiziani, A.; Bonollo, F. Induction heat treatment of a ISO C45 steel bar: Experimental and numerical analysis. Comput. Mater. Sci. 2006, 35, 98-106. [CrossRef]

38. Jung, M.; Kang, M.; Lee, Y.-K. Finite-element simulation of quenching incorporating improved transformation kinetics in a plain medium-carbon steel. Acta Mater. 2012, 60, 525-536. [CrossRef]

39. Hibbit, D.; Karlsson, B.; Sorenson, P. ABAQUS Reference Manual 6.7; ABAQUS Inc.: Pawtucket, RI, USA, 2005.

40. Chaboche, J.-L. Constitutive equations for cyclic plasticity and cyclic viscoplasticity. Int. J. Plast. 1989, 5, 247-302. [CrossRef]

41. Klemenz, M.; Schulze, V.; Rohr, I.; Löhe, D. Application of the FEM for the prediction of the surface layer characteristics after shot peening. J. Mater. Process. Technol. 2009, 209, 4093-4102. [CrossRef]

42. Ramberg, W.; Osgood, W.R. Description of Stress-Strain Curves by Three Parameters; National Advisory Committee for Aeronautics: Washington, DC, USA, 1943.

43. Smith, K.N.; Watson, P.; Topper, T. Stress-Strain function for fatigue of metals. J. Mater. 1970, 5, 767-778.

44. Manson, S.S. Fatigue: A complex subject-Some simple approximations. Exp. Mech. 1965, 5, 193-226. [CrossRef]

45. Coffin, L.F. A study of the effect of cyclic thermal stresses on a ductile material. Trans. ASME 1954, 76, 931-950.

46. Basquin, O.H. The exponential law of endurance tests. Am. Soc. Test. Mater. Proc. 1910, 10, 625-630.

47. Baumel, A., Jr.; Seeger, T. Materials Data for Cyclic Loading. Supplement 1; Elsevier Science Publishers: Amsterdam, The Netherlands, 1990.

48. Korkmaz, S. Extension of the Uniform Material Law for High Strength Steels. Master's Thesis, Bauhaus University, Weimar, Germany, 2008.

49. Pavlina, E.J.; van Tyne, C.J. Correlation of Yield Strength and Tensile Strength with Hardness for Steels. J. Mater. Eng. Perform. 2008, 17, 888-893. [CrossRef]

(c) 2019 by the authors. Licensee MDPI, Basel, Switzerland. This article is an open access article distributed under the terms and conditions of the Creative Commons Attribution (CC BY) license (http:/ / creativecommons.org/licenses/by/4.0/). 



\title{
Article
}

\section{Optimizing Weight of Housing Elements of Two-stage Reducer by Using the Topology Management Optimization Capabilities Integrated in SOLIDWORKS: A Case Study}

\author{
Stoyan Slavov * and Mariya Konsulova-Bakalova \\ Department of Mechanical Engineering and Machine Tools, Technical University of Varna, 9010 Varna, Bulgaria; \\ mbakalova@tu-varna.bg \\ * Correspondence: sdslavov@tu-varna.bg; Tel.: +359-52-383-690
}

Received: 15 December 2018; Accepted: 11 January 2019; Published: 15 January 2019

\begin{abstract}
This paper presents the results of a conducted topology management optimization study based on the finite element analysis on a two-stage spur gear reducer housing body and cover using the SOLIDWORKS Simulation module. The main goal of the study is to optimize the overall weight of the reducer by thinning specific areas of the casted gearbox housing elements according to the calculated minimal strain energy. The topology optimization algorithm that is used in current research gives an optimal structural shape of the housing elements of the reducer with the largest stiffness, considering the given amount of mass that will be removed from the initial design space. The complete sequence of steps for conducting the topology management optimization study is shown, taking into account the constraints arising from the construction features and the method of manufacturing the housing elements of the gear reducer. Conclusions on the use of the topology optimization results are given and potential directions for further development of the approach are also identified.
\end{abstract}

Keywords: topology management optimization; gear reducer housings; power transmission; finite element analysis; SOLIDWORKS

\section{Introduction}

Toothed gear reducers are the most commonly used mechanisms for changing the motion parameters and torque in the operation of many different machine actuators, lifting and transporting devices in many manufacturing industries, and in automotive, shipbuilding, aerospace, etc. For obtaining the needed direction of movement and (usually high) transmission ratios, gear reducers may have one or more stages, being equipped with cylindrical gears (with parallel axes), conical gears (with concurrent axes), worm gears (with cross axles), or with a combination thereof. They usually are made with fixed axles but they can also be movable, for example, in planetary or differential gear reducers, which results in a higher transmission ratio with smaller overall dimensions of the reducer. In addition, the toothed wheel gear reducers have a relatively simple construction, high efficiency, and they are easy to install and maintain [1-4].

Regardless of the type of gear reducer, however, in order to be able to operate reliably and to meet its functional requirements, the relative position of the shafts (respectively the position of the gear wheels and bearings) of the reducer must be precisely fixed in space. An important role in achieving this requirement has two main elements of the gear reducer housing - the lower part (or the body) and the upper part (or the cover). In addition, suitable roller bearings are mounted and fixed by these two gear reducer housing parts in order to balance and transmit the reaction forces from the gears 
to the foundation to which the gear reducer is mounted. The housing cover usually is fastened to the housing body by bolts and nuts, and the body is mounted on the foundation using anchor bolts. An important role in ensuring the rigidity of the gear reducer has a degree of tightening (i.e., axial loads) of the screw connections.

Despite the diversity of the existing designs of the gear housing, they are mainly produced in two ways: as welded structures made of steel sheets in the case of small-scale production, or by a sand casting process using gray cast iron, in large-scale production. In the case of sand casting of the gear housing elements, a number of requirements arising from good practice in the casting process and subsequent machining operations are recommended to be followed. This includes the requirements as follows [1-7]:

- The thickness of the wall must be as uniform as possible, in order to avoid any hot tears, shrinkage cavities, or incomplete cavity filling of the sand casting form; additional ribs in the construction are recommended to be used in order to increase the filling ability, strength, and stiffness of the castings;

- Ensuring a certain minimal thickness of the walls of housing casting, depending on the properties of the material used and the casting technology;

- To reduce residual stresses in the castings, smooth transitions from thick to thin sections of the walls should be provided;

- To facilitate removal of the castings from the sand molds, large enough inclines and rounding of the corner of the walls of the gear reducer housing must be provided;

- Machined surfaces must be reduced to the smallest needed number. They are usually limited to machining of the bearing holes, the contact surfaces of the body flanges and the cover, the holes for the fastening bolts, the bearing covers, the threaded plugs, etc.

When the housings of gear reducers are manufactured by the casting process, designers usually follow some general guidance in determining the sidewall thickness, the thickness and width of the bearing flanges, the thickness of the supporting ribs, the diameters of the bolts for attaching the cover to the body or the reducer to the foundation, etc. In the manuals [1-3] for constructing transmissions can be found available empirical formulas for calculating the values of these parameters as they are based on pre-calculated diameters of shafts and rolling bearings, the largest distance between axes of the reducer shafts, or the nominal torque at the output shaft. The authors of the gear design guidelines note that the values calculated in that manner are approximate and it is recommended to be followed in the production process. In order to simplify the design process, the dimensions calculated by the empirical formulas are kept the same for all sidewalls, ribs, flanges, and fastening bolts.

Although the requirements for the gear reducer housing are largely satisfied, the described approach does not allow for optimal design solutions, in line with today's increased production requirements, such as lower weight products, reduced material consumption, less energy consumption per unit of production, environmental protection, etc. In this respect, the present work has the primary objective to demonstrate a different approach for optimal designing of gear reducer housings that optimize the distribution of the material in the body and the cover parts while preserving their stiffness.

\section{Topology Management Optimization Approach Description}

From about 40 years ago, the topology management optimization approach has achieved rapid development and has been successfully applied to the design of parts in many industrial fields, including the aerospace, automobile, and even biomedical industries. Many different topology optimization methods have been proposed during the years. These include some methods $[8,9]$ gaining wider popularity like the level set methods [10,11], the density approach [12], evolutionary approaches (evolutionary structural optimization/bi-directional evolutionary structural optimization, ESO/BESO) [13], and several others. There are also a number of variations and modifications of these basic methods aimed at solving specific optimization problems [8]. In general, topology optimization 
is a mathematical method that optimizes material layout within a given design space $\Omega$, as shown in Figure 1a. Usually it uses given design space $\Omega$, loads condition $\mathrm{L}$, boundary conditions $\Gamma$ consisting of $\Gamma_{\mathrm{o}}, \Gamma_{\mathrm{s}}, \Gamma_{\mathrm{t}}$, and $\Gamma_{\mathrm{u}}$ parts, where $\Gamma=\Gamma_{\mathrm{u}} \cup \Gamma_{\mathrm{o}} \cup \Gamma_{\mathrm{t}} \cup \Gamma_{\mathrm{s}}$ and one or more manufacturing constraints. The surface tractions " $\mathrm{t}$ " are applied at region $\Gamma_{\mathrm{t}}$; regions $\Gamma_{\mathrm{u}}$ represent the support conditions; regions $\Gamma$ s denote the non-optimizable areas; and $\Gamma$ o are the geometric boundaries of the design space $\Omega$.

For finding the optimum layout of a structural system composed by linearly elastic isotropic material, the material distribution methods can be used [14]. The main question here is how to distribute material volume into domain $\Omega$ in order to minimize a specific criterion. The usually most used criterion is the compliance $C$. Density values $x$ (distributed over the domain $\Omega$ ) are used to control the distribution of the material volume in the domain. It is controlled by design parameters that are represented by the densities $x$ assigned to the finite element (FE) discretization of domain $\Omega$. The densities $x$ take values in the range $(0-1)$, where zero means no material in the specific point (s).

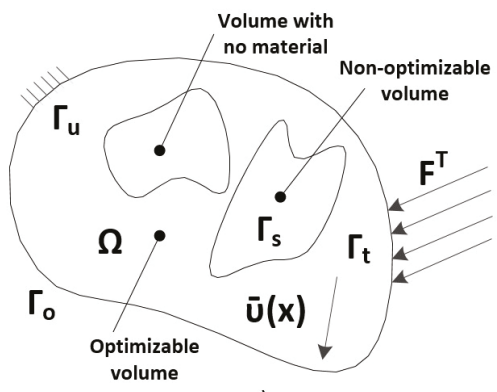

a)

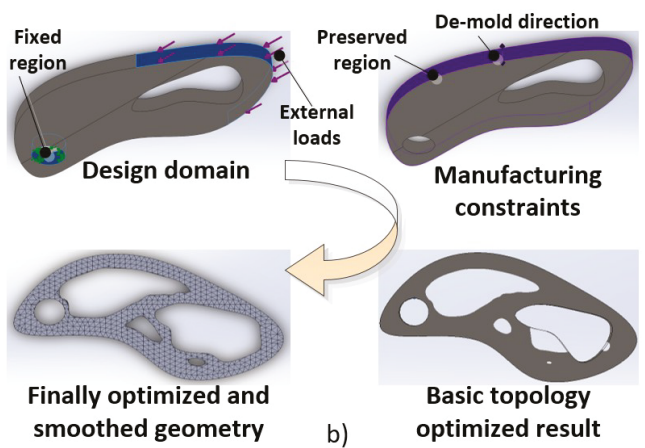

Figure 1. (a) Generalized shape design problem of finding the optimal material distribution in the 3D domain, and (b) topology optimization process steps.

A topology management optimization problem can be written in the general form as [14]

$$
\begin{array}{ll}
\operatorname{minimize} \mathrm{x} & C(x)=F^{T} \cdot \bar{u}(x) \\
\text { subject to }: & \frac{V(x)}{V_{0}}=f \\
& F=K(x) \cdot \bar{u}(x) \\
& 0<x_{\min } \leq x \leq 1 .
\end{array}
$$

where:

- $\quad C(x)$ represents the compliance of the structure;

- $F^{T}$ is an applied vector of forces;

- $\bar{u}(\mathrm{x})$ denotes the corresponding global displacement vector.

The second expression of Equation (1) refers to a volume constraint, where $f$ is the volume fractions of domain $\Omega$ that the optimized layout should occupy. The global stiffness matrix $K(x)$ of the structural system takes place in the third expression of Equation (1) and corresponds to the equilibrium equation, and the last inequality represents the definition set of the density values.

The topology optimization approach usually involves four major stages, as shown in Figure $1 \mathrm{~b}$. The first phase includes the definition of the original (i.e., not optimized) 2D or 3D geometry of the object. The following model parameters are set here: the design material characteristics, the fixed surfaces of the model, the surfaces to which the external loads are applied, the type and magnitude of the external loads, etc. The second phase involves setting manufacturing constraints, such as preserved regions that will not be modified during a topology optimization, de-mold direction, load symmetry 
about a specified plane, minimum wall thickness that prohibits the creation of very thin or very thick regions that may be difficult to manufacture, etc. The third stage involves obtaining the basic topology optimized result after the FE analysis is performed. At this step, it is possible to adjust the volume ratio of the remaining and removed material precisely, as well as to use surface smoothing algorithms in order to remove or modify elements that create jagged edges and/or sharp angles. At the last stage of the topology optimization process, Computer Aided Design (CAD) software tools are used to transform the "organic looking" areas from the optimized model into simpler ones in order to facilitate the manufacturing process.

Topology optimization modules have been developed and integrated into many contemporary CAD-CAE (Computer Aided Engineering) software products for 2D and 3D designing, such as SIMULIA Abaqus and Tosca Structure (Dassault Systèmes, Vélizy-Villacoublay, France), SOLIDWORKS (SolidWorks Corporation, Waltham, MA, USA), ANSYS (ANSYS, Inc., Canonsburg, PA, USA), Fusion 360, Inventor and Nastran (Autodesk, Inc., San Rafael, CA, USA), COMSOL Multiphysics ${ }^{\circledR}$ (COMSOL, Inc., Stockholm, Sweden), etc. Topology optimization capabilities are also integrated into some freeware open source 3D software products such as Blender, Top3d, etc. A more detailed list of software products that support topology optimization capabilities can be found in Reference [15].

\section{Case Study of Weight Optimizing of Spur Gear Reducer Housing}

According to the primary objective of the present work, in this section the main steps of the process for topology management optimization will be described using a specific case study of a two-stage gear reducer housing and cover, whose constructive features are presented in Figure 2a-e.

\subsection{Initial Constructive Features of the Housing and Cover of the Reducer}

In the Figure 2 are presented two views, as shown in Figure $2 b, c$, and three section views, as shown in Figure 2d-f, on which the dimensions of the constructive elements of a spur gear reducer housing and cover (assembled to each other) are shown.

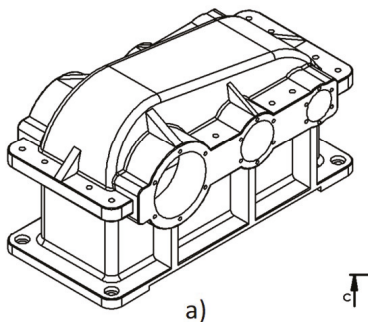

a)
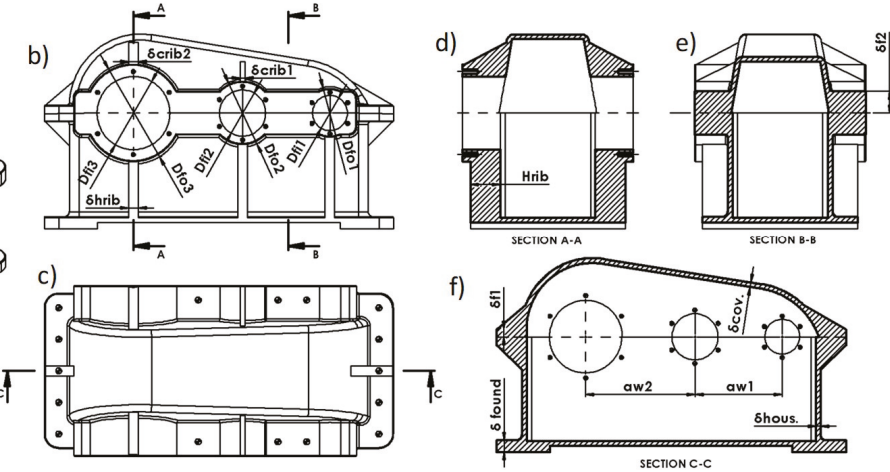

Figure 2. (a) Isometric view of the housing body and cover of the gear reducer; front (b) and top (c) view of the reducer; (d-f) section views, respectively, A-A, B-B, and C-C.

The dimension labels and their calculated values are shown in Table 1 . The values were calculated using the empirical equations or table data with recommended values, purposed in the References [2,3]. 
Table 1. Calculated dimensions' values of the characteristic elements of the housing body and cover.

\begin{tabular}{|c|c|c|}
\hline Dimension Labels & Empirically Calculated Values (mm) & Description \\
\hline$\delta$ cov. & 9.0 & Thickness of the side walls of reducer cover \\
\hline Shous. & 10.0 & Thickness of the side walls of reducer housing \\
\hline$\delta \mathrm{f} 1$ & 17.0 & $\begin{array}{l}\text { Thickness of the side part of reducer cover flange (side } \\
\text { part of reducer housing flange has the same value) }\end{array}$ \\
\hline$\delta \mathrm{f} 2$ & 45.0 & $\begin{array}{l}\text { Thickness of the front part of reducer cover flange (front } \\
\text { part of reducer housing flange has the same value) }\end{array}$ \\
\hline sfound. & 24.0 & Thickness of the foundation of the reducer \\
\hline Shrib & 15.0 & Thickness of the housing ribs located below bearing seats \\
\hline$\delta \mathrm{crib} 1$ & 10.0 & Thickness of the cover rib located above bearing seat \\
\hline$\delta$ crib2 & 10.0 & Thickness of the cover rib located above bearing seat \\
\hline Hrib & 164.0 & Height of the housing ribs located below bearing seats \\
\hline aw1 & 180.0 & Distance between axes of the shafts on first stage \\
\hline aw2 & 225.0 & Distance between axes of the shafts on second stage \\
\hline$\delta \mathrm{b} 1=\mathrm{Dfo} 1-\mathrm{Dfi} 1$ & 14.0 & Thickness of the bearing seats around the input shaft \\
\hline$\delta \mathrm{b} 2=\mathrm{Dfo} 2-\mathrm{Dfi} 2$ & 17.5 & Thickness of the bearing seats around the middle shaft \\
\hline$\delta \mathrm{b} 3=\mathrm{Dfo} 3-\mathrm{Dfi} 3$ & 25.0 & Thickness of the bearing seats around the output shaft \\
\hline
\end{tabular}

\subsection{Preparatory Steps for Topology Optimization Process}

In order to perform needed finite element analysis and carry out topology management optimization of the objects using the simulation module of SOLIDWORKS [16], the following particular steps must be completed.

\subsubsection{Digitization of the Model}

The digitization process of the model was carried out using the 3D modeling capabilities and powerful design automation tools integrated in SOLIDWORKS. Although, in reality the housing and the cover of the gear reducer are separate parts, here they were modelled as a single (monolithic) body, as shown in Figure 3. This is an important condition, because the topology optimization module of SOLIDWORKS does not allow simultaneous optimizing of several parts or assemblies. In order to speed up the process of topology optimization, the construction of the 3D model was simplified by removing some auxiliary elements such as oil inlets, vents, oil level indicators, service hatch, etc.

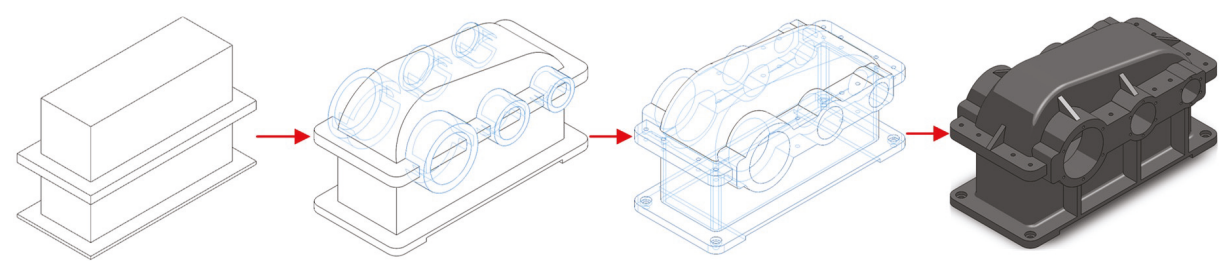

Figure 3. Steps from the digitizing process of the housing and cover in SOLIDWORKS as a single body.

In the case that the housing elements are pre-modelled as separate parts, in order to be able to perform the topology optimization in SOLIDWORKS, they must be combined into a single body.

\subsubsection{Material Selection}

Gray cast iron G150 (according ISO 185 [17]) was selected as a material of the 3D model, because the housing body and cover parts will be produced by the sand casting method. It is a widely used material in heavier gearboxes, which have sufficient rigidity and good vibration damping properties. The grade G150 cast iron material used in model had the following mechanical characteristics: elastic modulus $=66,178.1\left(\mathrm{~N} / \mathrm{mm}^{2}\right)$; Poisson's ratio $=0.27$; shear modulus $=50,000\left(\mathrm{~N} / \mathrm{mm}^{2}\right)$; mass density $=7200\left(\mathrm{~kg} / \mathrm{m}^{3}\right)$; tensile strength $=151.66\left(\mathrm{~N} / \mathrm{mm}^{2}\right)$; Compressive Strength $=572.17\left(\mathrm{~N} / \mathrm{mm}^{2}\right)$.

The Material Dialog Box of the SOLIDWORKS was used to assign the material to the 3D model. 


\subsubsection{Defining the External Loads and Fixtures}

The loads of the housing elements depend on the constructive configuration of the gear reducer and its specific input parameters. They usually involve: transmission ratio $i$; inclination angle of the teeth $\beta,\left(^{\circ}\right)$ in case of helical gears; the transmitted power $\mathrm{P},(\mathrm{kW})$; the input speed $\mathrm{n}_{1},(\mathrm{rev} / \mathrm{min})$, and the largest required distance between axes $\mathrm{a}_{\mathrm{w}}{ }^{\max },(\mathrm{mm})$, and they can be separated into two main groups:

1. The radial loads $F R_{i, X}$ and $F R i_{i, Y}, i=1,2,3$. They were transmitted by the rolling bearings to the bearing seats and cause contact stresses. They arose from the radial and tangential forces acting on the toothing of the spur gear wheels. When the reducer has helical gears, axial load occurs. The direction of this load was parallel to the axes of the shafts and must also be taken into account in the calculations;

2. The axial loads in "bolt-nuts" connections for fastening the gear reducer to the foundation and for the bolts fastening the cover flange to the flange of the housing body.

The values of these loads can be calculated for each particular gearbox configuration using well-known techniques and formulas from Statics and Strength of Materials [1,2,18]. The spur gear reducer considered in this work has the input parameters that are shown in Table 2. The spur gears from the stages were designed according to them using specialized software MITCalc [19], and the values of the radial load $F R_{i, X}$ and $F R_{i, Y}, i=1,2,3$ were calculated for the six roller bearings of the reducer, as shown in Table 3.

Table 2. Main input parameters of the reducer.

\begin{tabular}{cc}
\hline Parameter & Value \\
\hline Transmission ratio, $\mathrm{i}$ & 22.78 \\
Inclination angle of the teeth, $\beta$ & $0\left({ }^{\circ}\right)$, spur gears \\
Transmitted power, $\mathrm{P}$ & $6.3(\mathrm{~kW})$ \\
Input speed, $\mathrm{n}_{1} \quad$ (rev $\left./ \mathrm{min}\right)$ \\
Max distance between axes, $\mathrm{a}_{\mathrm{w}}$ max & see Table 1 \\
\hline
\end{tabular}

Table 3. Calculated values of the radial loads in bearings.

\begin{tabular}{|c|c|c|c|c|c|c|c|c|}
\hline \multirow[t]{2}{*}{ Shaft № } & \multicolumn{3}{|c|}{$\begin{array}{l}\text { Loads in the Bearings on the } \\
\text { Left Side }\end{array}$} & \multirow{2}{*}{$\begin{array}{c}\begin{array}{c}\text { Direct. } \\
\text { of } F R^{\mathrm{L}}\end{array} \\
\alpha^{\mathrm{L}},\left(^{\circ}\right)\end{array}$} & \multicolumn{3}{|c|}{$\begin{array}{l}\text { Loads in the Bearings on the } \\
\text { Right Side }\end{array}$} & \multirow{2}{*}{$\begin{array}{c}\begin{array}{c}\text { Direct. } \\
\text { of } F R^{\mathrm{R}}\end{array} \\
\alpha^{\mathrm{R}},\left(^{\circ}\right)\end{array}$} \\
\hline & $F R_{X},(\mathrm{~N})$ & $F R_{Y},(\mathrm{~N})$ & $F R^{\mathrm{L}},(\mathrm{N})$ & & $F R_{X},(\mathrm{~N})$ & $F R_{Y},(\mathrm{~N})$ & $F R^{\mathrm{R}},(\mathrm{N})$ & \\
\hline 1 & 2364.38 & 1930.76 & 3052.56 & $50^{\circ}, 46^{\prime}$ & -21.07 & 1684.88 & 1685.02 & $359^{\circ}, 11^{\prime}$ \\
\hline 2 & -28.92 & -100.71 & 104.77 & $106^{\circ}, 01^{\prime}$ & 1257.11 & 3460.85 & 3682.09 & $19^{\circ}, 57^{\prime}$ \\
\hline 3 & 1551.90 & 4263.81 & 4537.45 & $20^{\circ}, 00^{\prime}$ & 789.81 & 2169.97 & 2309.24 & $20^{\circ}, 00^{\prime}$ \\
\hline
\end{tabular}

The resultant magnitudes of bearing loads $F R_{i}(i=1,2,3)$, as shown in Table 3, applied in the bearing seats from left $(\mathrm{L})$ and the right $(\mathrm{R})$ side of the reducer were calculated as a vector sum using the equation

$$
F R_{i}^{(\mathrm{L}, \mathrm{R})}=\sqrt{F R_{i, X}^{(\mathrm{L}, \mathrm{R})_{2}}+F R_{i, Y}^{(\mathrm{L}, \mathrm{R})_{2}}}(i=1,2,3),(\mathrm{N}) .
$$

The angles $\alpha_{i}{ }^{(L, R)}$ of direction of resultant loads vector $F R_{i}(i=1,2,3)$ are calulated by use $F R_{X}$ and $F R_{Y}$ values of the reactions components in horizontal and vertical direction and sine, cosines, or tangent trigonometric functions. The calculated values for $\alpha_{\mathrm{i}}{ }^{(\mathrm{L}, \mathrm{R})}$ are shown in Table 3 also.

The calculated values of resultant loads $F R_{i}{ }^{(\mathrm{L}, \mathrm{R})}$ by Equation (2) in Table 3 were set as a bearing load component [20] with sinusoidal distribution for every bearing seat in the 3D model in the section "External loads" of the SOLIDWORKS Simulation, as shown in Figure 4. The Bearing Load was used because this component distributes the applied bearing loads radially and non-uniformly along the cross-section of a cylindrical faces of the bearing seats. Thus, the bearing load are applied to the half of 
the selected faces only. In order to correctly set the loads, the cylindrical faces on which it is applied have a lesser width $\mathrm{Wb}$, as shown in Figure 4, than the total width $\mathrm{W}$ of the bearing seats. Usually the dimension $\mathrm{Wb}$ is equal to the width of the chosen roller bearing. The directions of the applied bearing loads were defined using different Coordinate Systems in SOLIDWORKS. The Z-axis was always coincident with the rotating axis of the bearing, and the $\mathrm{X}$-axis must be rotated at previously calculated angles $\alpha_{i}^{(\mathrm{L}, \mathrm{R})}$.

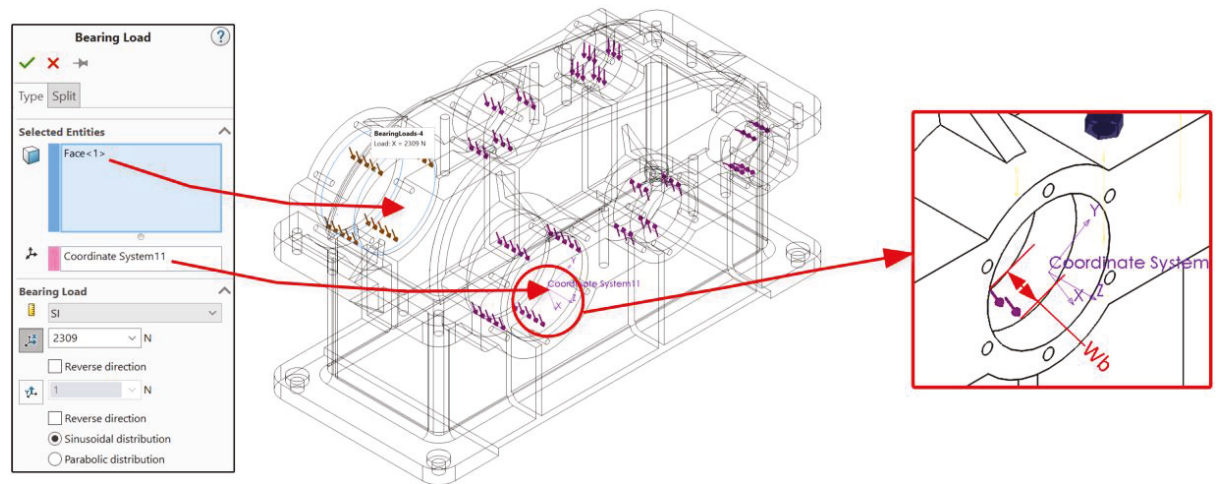

Figure 4. Defining the calculated resultant loads in the bearing seats in SOLIDWORKS simulation.

The axial loads in preloaded anchor bolt-nut connections and those in the flanges of the cover and base body were also calculated using MITCalc software. The obtained values were respectively 1500, (N) for anchor bolts, and 1200, (N) for flange connections. These two values were set in the SOLIDWORKS 3D model as bolt-connectors, as it is shown in Figure 5a,b.
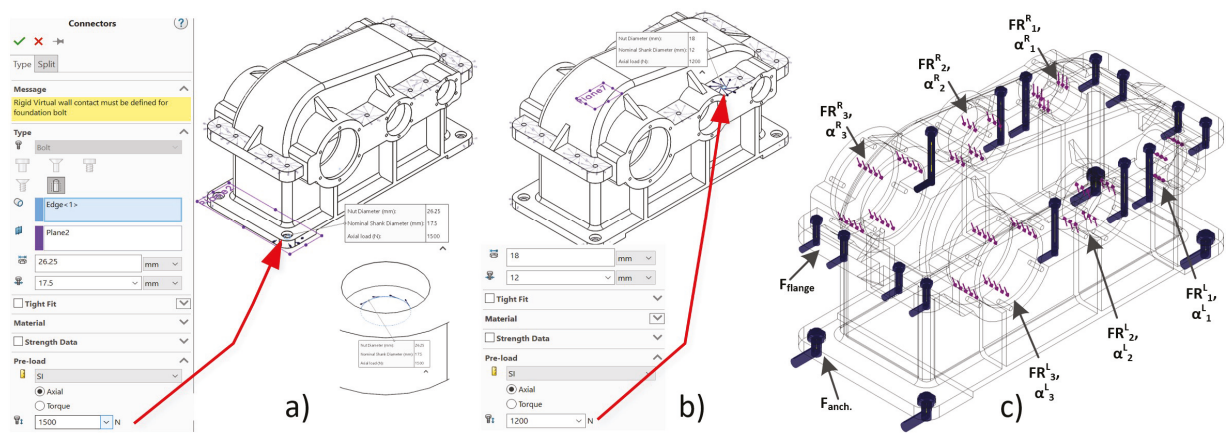

Figure 5. Defining the axial loads for anchor (a) and flange (b) bolt-nut connections in SOLIDWORKS Simulation; (c) Diagram of the reducer body and cover housing 3D model with all load applied.

The 3D model of the reducer housing with all bearing loads and fastening axial forces applied, produced by the fixtures, is shown in Figure $5 \mathrm{c}$.

\subsubsection{Defining Goals and Constraints of the Model}

In this section of the topology optimization study, the optimization goals and constraints must be chosen. The topology study will try to find the stiffest structure possible given a certain amount of material removal. Defining the goal and constraints will impact the material removal. The optimization algorithm gives the shape of the most rigid components of the 3D model, defined by the amount of mass that will be removed from the original maximum design space $\Omega$. When the "Best Stiffness 
to Weight ratio" option is selected, the algorithm will try to minimize the global compliance of the 3D model which is a measure of the overall flexibility (contrary to stiffness). Compliance is defined by the sum of strain energies of all elements. Constraints limit the $\Omega$-space solutions by imposing the percentage of the mass that can be removed to be under a certain value, or by setting limits for the maximum displacement observed in the 3D model. In SOLIDWORKS Simulation (version 2018), up to two constraints for one optimization goal can be defined at the same time. For the current study, the option "Best Stiffness to Weight ratio" and 30\% reduction of the mass, were chosen (i.e., applied settings by default). In this way, from the initial mass of $106.93(\mathrm{~kg})$ of the considered gear reducer housing, after the topology optimization, theoretically its mass will be reduced to 74.86 (kg) (or by $30 \%$ ).

\subsubsection{Defining the Manufacturing Controls}

The topology optimization process creates a layout of the material that corresponds to the optimization goal at the specified geometric constraints. However, the 3D model may be impossible to manufacture using usual manufacturing processes, such as casting or forging. The formation of undercuts and hollow parts can be prevented by applying proper manufacturing controls in the optimization model. Manufacturing restrictions ensure that the optimized 3D model can be extracted from a mold for example, or can be stamped properly. SOLIDWORKS Simulation allows four types of manufacturing controls. They are as follows:

- Thickness Control. Sets a limitation to the topology optimization of the model that prevents the production of too thin walls or very thick regions that would be difficult to manufacture.

- $\quad$ Preserved Region(s). This property adds preserved region(s) to the 3D model that will not be modified during topology optimization, and thus leaving unchanged the geometry of those surfaces that are important to its proper operation.

- Symmetry Control. Symmetry control forces the optimized 3D model to be symmetric to a specified plane or planes. A half, quarter, or one-eighth planar symmetry can be chosen depending on the design configuration.

- De-mold Control. This property can be used to ensure that the optimized 3D model can be extracted from a mold.

Half-symmetry and de-mold manufacturing controls were used in the current study in addition to several preserved regions, as shown in Figure 6a. Preserved regions in the model include the fundament area of the reducer and flanges both of the body and the cover. As can be seen from Figure $6 \mathrm{a}$, some of the fillets located at the corners and along the edges of the body and the cover are included in the list of the preserved regions. The preservation of these elements of the design aims to facilitate the closure process of the housing elements after topology optimization. The depth of all the preserved regions that will remain unchanged during optimization was set to $8 \mathrm{~mm}$, according to the recommended minimal thickness of the side walls for gray cast iron. 

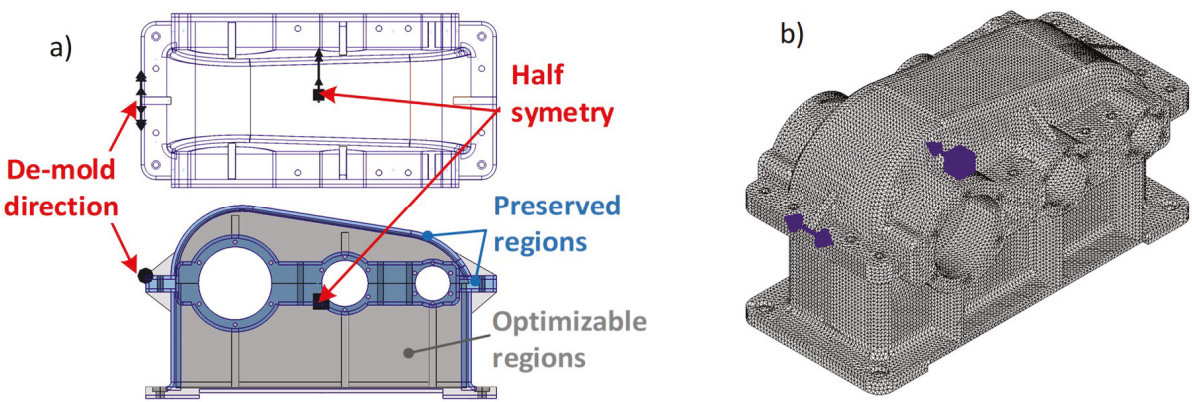

Figure 6. (a) Defined manufacturing controls and preserved regions in the 3D model; (b) meshed 3D model of the reducer housing.

The 3D model is divided into 308,263 finite elements, as shown in Figure 6b, with standard solid mesh which has 498,985 nodes. The minimal element size is $7.25(\mathrm{~mm})$ with a tolerance of $0.363(\mathrm{~mm})$ and its size is smaller than the thickness of preserved regions $(8 \mathrm{~mm})$.

\subsection{Results Obtained after Implementation of the Topology Management Optimization}

The topology optimization study was carried out using the SOLIDWORKS Simulation module with the particular load scenario, boundary conditions, and manufacturing controls as described in Section 3.2. The resultant stress (von Mises) plots that show the distribution of the stresses in the material of the reducer housing elements are shown in Figure 7a.

Three views of the resultant topology optimized 3D model are shown in Figure 7b. The topology optimization algorithm couple material's Young's modulus of each mesh element with a relative mass density factor ranging from 0.0001 for a void element without any load-carrying capacity to 1.0 for a solid element with load-carrying capacity. Here, the "soft" elements selected as "Ok to Remove" (with relative mass density less than 0.3 ) are deep purple. They do not contribute significantly to the stiffness of the reducer housing elements and were removed from the design. The elements selected by the algorithm as "Must Keep" (with high relative mass densities larger than 0.7) are yellow. After deleting the "soft" elements of the design, the mass was reduced to $73 \%$ in comparison to the initial one.

Because the optimized 3D model, shown in Figure 7b, has a very "organic" shape with many jagged edges and sharp angles after the topology optimization, it was not very suitable for further processing and closing the side walls of the reducer housing. For this reason, additional smoothing of the optimized model was carried out with maximum possible iteration cycles to obtain a smoother surface mesh of the optimized model.

The final mass plot of the reducer housing elements after applying additional smoothing of the surfaces is shown in the Figure 7c. After the topology optimization was carried out, the initial mass $106.93(\mathrm{~kg})$ was reduced to $76.30(\mathrm{~kg})$ or $71 \%$ of the original mass. 

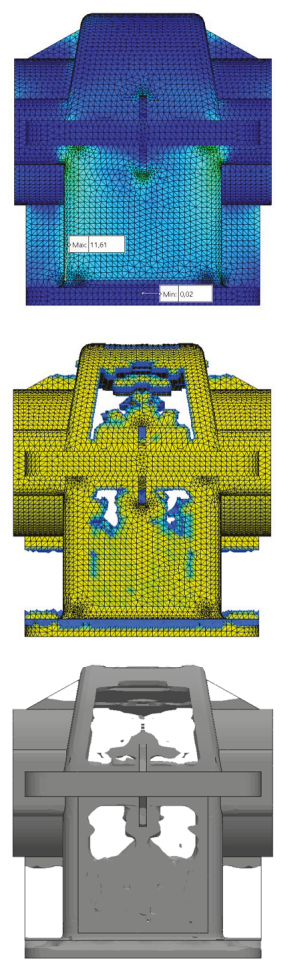

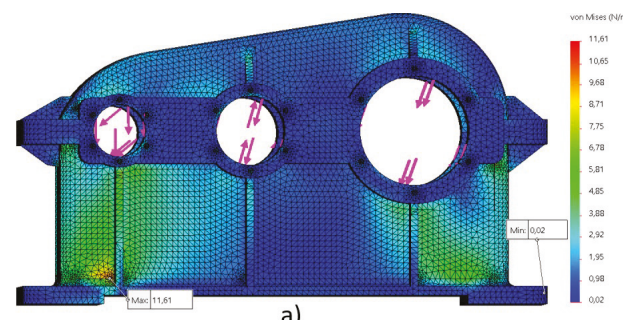

a)

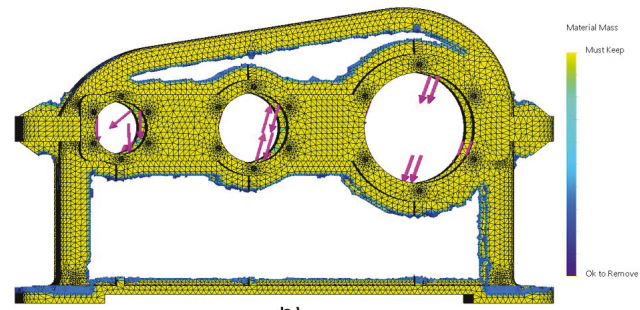

b)

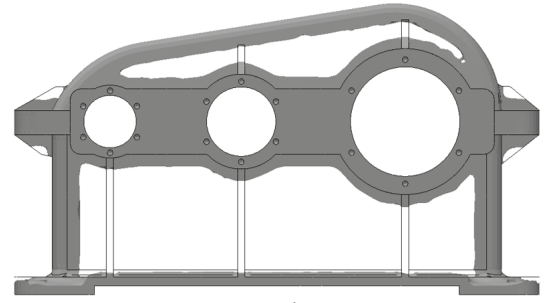

c)
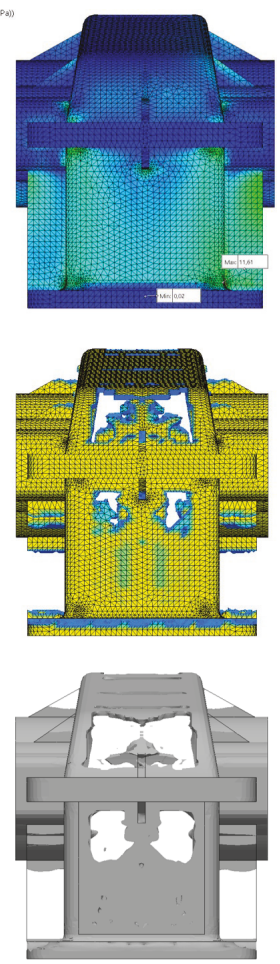

Figure 7. (a) Views of resultant stress plot obtained from a preliminarily carried out static study of the 3D model; (b) views of the material mass plot after topology optimization; (c) views of the smoothed surface mesh of the topology optimized model.

\section{Post-Processing of the Topology Optimized Gear Reducer Housing and Cover}

As it can be seen from Figure 7c, all elements considered as "soft" were removed from the design and the reducer housing elements acquires a near to "building carcass" structure. They cannot be left in this way (as a carcass structure) because in this shape they will not be able to fully meet their functional purpose; besides balancing power loads, also being able to keep the lubricant in the operating area of the gears, and to isolate them from the impact of the environment (such as moisture, dustiness, etc.). Therefore, all voids and openings obtained in the gearbox housing after optimization should be suitably closed. Closure of the gaps in the 3D model can be done by adding material with a minimum wall thickness defined only by the casting manufacturing requirements, and in particular from the fluidity index of the used cast iron grade.

The optimized 3D model can be exported as graphic body, solid body, or surface body. The options "Surface body" and "Solid body" are useful when the model will be printed on a 3D printer without further editing of the design. The option "Graphic body" exports optimized design in the boundary geometry representation format, which is more suitable for further editing and modifying. SOLIDWORKS allows exported graphic body to be inserted in the initial 3D model of the gear reducer housing, as can be seen in Figure 8. The first step after superimposing two 3D models is to estimate the differences between them. The easiest way to do this is to change the transparency of the initial model to semitransparent and keep the optimized model as opaque. 


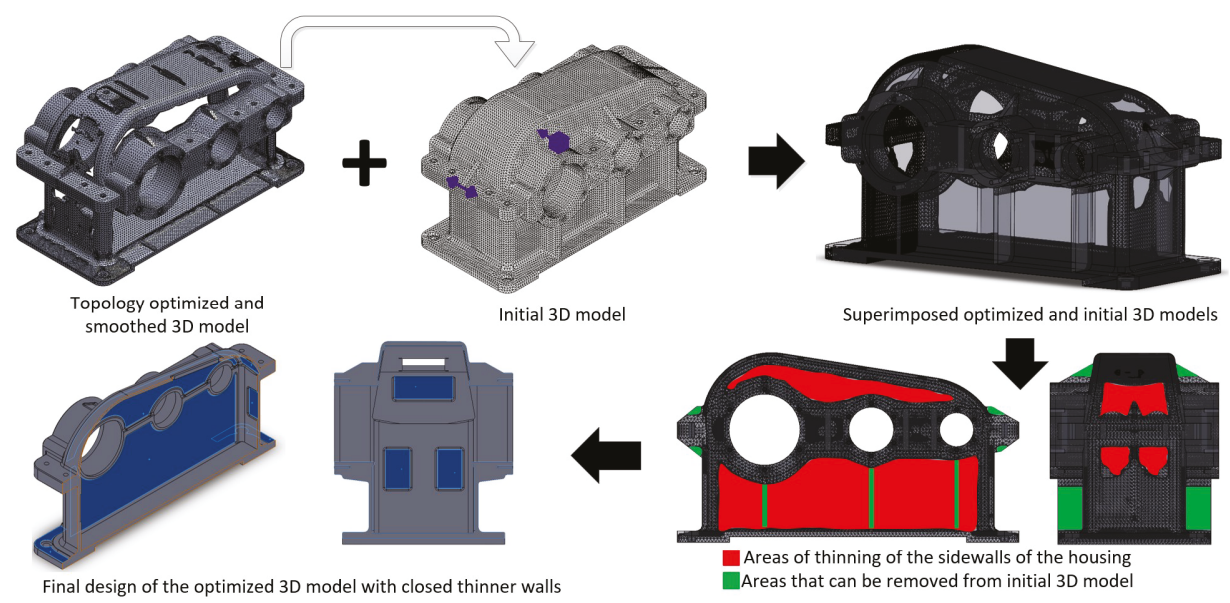

Figure 8. Postprocessing steps to obtain the final optimized $3 \mathrm{D}$ design of the gear reducer housing elements.

As can be seen from Figure 8, some areas from the sidewalls of the reducer housing elements (coloured in red) are suitable for thinning (because the gear housing can not remain as open structure), while other areas like the material around the lifting holes and the ribs above and below the bearing's seats (coloured in green) can be partially removed. When modifying the 3D model it is necessary to comply with the requirements for designing parts which are manufactured by sand casting, i.e., minimum sidewall thickness, drafts, and to have rounded transitions between the thin and thick sections of the construction [21-23].

Using integrated SOLIDWORKS CAD-tools, all optimized areas were adjusted or removed according to the above mentioned conditions and the final result is shown in Figure 8. The final 3D model can be sliced into two different parts- the housing body and cover, and some additional features, such as holes for oil inlets, vents, oil level indicators, service hatch, etc. can be added to the design. The position of the hole of the upper service hatch is selected in accordance with the topology optimized results of the top side of the housing cover. The mass properties of the initial, the topology optimized, and the final optimized 3D models are shown in Table 4.

Table 4. Mass properties of the initial, the topology optimized, and the final optimized 3D models.

\begin{tabular}{cccc}
\hline Mass Properties & Initial 3D Model & $\begin{array}{c}\text { Topology Optimized } \\
\text { 3D Model }\end{array}$ & $\begin{array}{c}\text { Finally Optimized } \\
\text { Model }\end{array}$ \\
\hline Mass, $(\mathrm{kg})$ & 106.94 & 76.30 & 99.10 \\
Volume, $\left(\mathrm{mm}^{3}\right)$ & $14,852,768.38$ & $10,238,437.15$ & $13,902,279.95$ \\
\hline
\end{tabular}

As can be seen from Table 4, the mass of the topology optimized 3D model was decreased by $28.65 \%$, which is close to the set target value $(30 \%)$ in the goal parameter of the topology optimization study. The mass of the finally optimized model after adjusting geometry was decreased by $7.33 \%$ from those of the initial 3D model.

\section{Verification by Static Load and Natural Resonant Frequencies Studies of the Initial and Optimized 3D Models}

For verification of the behavior of the optimized 3D design, static load FE-analysis to check the stress levels and displacement, and simulations of the resonant frequencies before and after the 
optimization of the reducer housing elements, were carried out. In these simulations was used the same load pattern as in the topology optimization study.

The resultant stresses (von Mises) from the static load simulation is shown in Figure 9a and the displacement diagrams are shown in Figure $9 \mathrm{~b}$. As can be seen, the obtained maximum equivalent stress values $13.26(\mathrm{MPa})$ were much lower than the modulus of elasticity $6.62 \times 10^{4}(\mathrm{MPa})$ of gray cast iron. Corresponding to the obtained stress values, the maximum displacement value was $0.035(\mathrm{~mm})$. The minimal obtained factor of safety (FOS) value was 11.44 . These static study results show that the final optimized housing 3D model of the reducer will withstand the loads from the gears without the risk of plastic deformation or rupture.
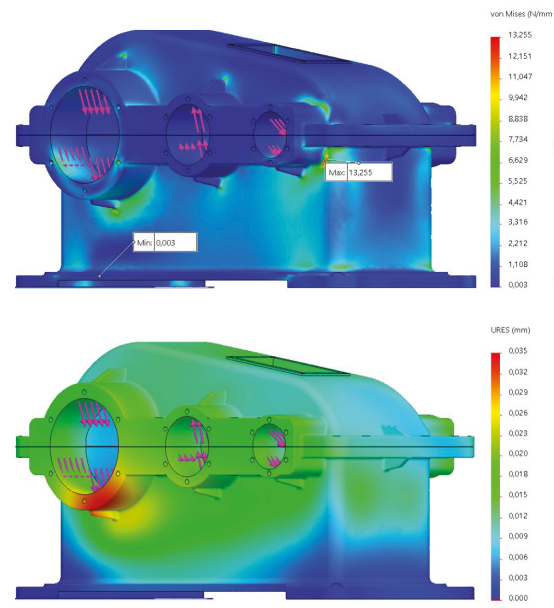

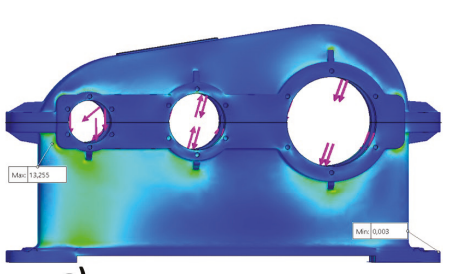

a)

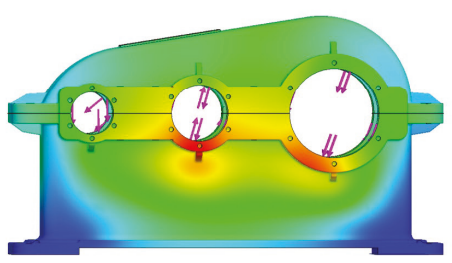

b)
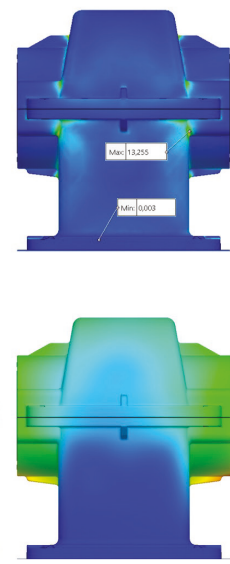

Figure 9. Diagrams of the stress plots (a) and maximum displacements (b) of the final optimized 3D model.

Thinning of the specific areas of the reducer housing and the removal of material from its initial construction will affect the natural resonant frequencies of the finally optimized design. As the gear housing is subjected to forced oscillations, resulting from the transmission of the load on the gears, it is necessary to check for the possibility of falling into resonance after the optimization. For this purpose, two similar natural frequencies studies were carried out, firstly for the initial design of the reducer housing model, and secondly for the finally optimized model. Here, the same load and fixture patterns as in the topology optimization and in the static studies were used again. The obtained results from the studies for the first four modes are shown in Table 5.

Table 5. Obtained results for the first four modes and natural frequencies.

\begin{tabular}{ccccccc}
\hline \multirow{2}{*}{ Mode No } & \multicolumn{2}{c}{ Initial 3D Model } & \multicolumn{2}{c}{ Final Optimized 3D Model } & \multicolumn{2}{c}{ Forced Oscilation } \\
\cline { 2 - 6 } & $\begin{array}{c}\text { Frequency } \\
\mathbf{( H z )}\end{array}$ & $\begin{array}{c}\text { Frequency } \\
\text { (rev/min) }\end{array}$ & $\begin{array}{c}\text { Frequency } \\
\mathbf{( H z )}\end{array}$ & $\begin{array}{c}\text { Frequency } \\
\text { (rev/min) }\end{array}$ & $\begin{array}{c}\text { Frequency } \\
\text { (Hz) }\end{array}$ & $\begin{array}{c}\text { Frequency } \\
\text { (rev/min) }\end{array}$ \\
\hline 1 & 235.48 & $14,128.8$ & 263.2 & $15,792.0$ & & \\
2 & 316.86 & $19,011.6$ & 480.28 & $28,816.8$ & 24.17 & 1450 \\
3 & 410.66 & $24,639.6$ & 539.97 & $32,398.2$ & & \\
4 & 480.56 & $28,833.6$ & 552.79 & $33,167.4$ & & \\
5 & 509.60 & $30,576.0$ & 652.62 & $39,157.2$ & & \\
\hline
\end{tabular}

Comparison of the obtained results in Table 5 show that the natural frequencies for the first five modes of the final optimized 3D model are greater than those for the initial 3D model. The increase in 
natural frequency values is explained by the decrease in mass of the final optimized model while the stiffness of the gearbox housing elements remains almost unchanged due to the nature of the used topology management optimization approach. As can be seen from Table 5, the natural frequencies of the final optimized 3D model was far away in comparison to the frequencies of the forced oscillations. The resonant frequency $263.20(\mathrm{~Hz})$ or 15.792 (rev/min) for first mode was 10.89 times greater than the highest rotational speed $1450(\mathrm{rev} / \mathrm{min})$ of the input shaft (or $24.17(\mathrm{~Hz})$ ) of the gear reducer. Therefore, it can be concluded that thinning the sidewalls of the gear reducer housing based on carried out topology management optimization will not lead to falling into resonance condition during its regular operation.

\section{Conclusions}

Because the topology optimization module of SOLIDWORKS does not allow assemblies to be subjected to the topology optimization algorithm, but only the single part (i.e., the single 3D body), the 3D models of the parts of the housing body and cover were combined into a single 3D body, and the result was saved as a part file. Thus, the limitations of the simulation module were overcome in the presented case study. Additionally, as demonstrated by the exemplary topology optimization of the gear reducer housing, the embedded algorithm in SOLIDWORKS Simulation can be successfully applied even for relatively complex 3D models of device and machine housings.

Another point that must be considered were the results obtained from the static stress analysis and nodal displacements of the topology optimized and smoothed 3D model, as shown in Figure 7c. In the simulation results section of SOLIDWORKS, there is a notification which alerts that the obtained values are based on the entire optimized model which may contain porous elements that are less rigid than fully dense elements. For this reason, these values should be thought of as a rough estimate on how the topology optimized model might behave [16]. For example, in the present topology optimization study, the obtained values for the static stress reach $4943.94(\mathrm{MPa})$ and the obtained maximal nodal displacement is $15.45(\mathrm{~mm})$, which obviously can not be achieved by real physical construction. Therefore, it is not advisable to take these results as valid, and static analysis should be conducted on the final closed 3D design, as shown in Figure 9, as it was described in Section 5. To avoid obtaining resonance, the natural frequencies must be determined before and after the topology based optimization of the model, and they should be compared to the frequency of forced oscillations arising from the drive of the gearbox. For stable and reliable operation of the device, there must be no approximation between them.

By applying the finite element method to analyse an exemplary gear reducer housing element and carried out topology optimization, a reduction in the total weight of these parts within about $7.33 \%$ has been achieved. At first glance, this may not sound like a very large reduction in the weight of the gear reducer, relative to a single piece of a product, but with a larger production series, the effect of saving the material will be felt. The proposed approach can also be applied to the optimization of the housing elements of heavy gear reducers and gearboxes, which are usually designed with increased factors of safety; for example, for use in large ships and marine equipment, as well as in lifting, construction, and/or metalworking machinery.

In conclusion, it should be noted that the results obtained in the present work are strictly related to the used model and construction of gearbox and its input parameters, as shown in Table 2. In other gear designs and operational parameters, topology management optimization results may differ materially from those shown in this work. Therefore, each construction should be considered individually, in accordance with the constructional features and requirements of the final product.

It should also be noted that the presented topology management optimization was based only on the load of the housing elements of the gear reducer. It did not include some additional factors, such as gearbox heating, noise emissions, etc., which may also affect its design parameters. Opportunities for further development of the present work can be the creation of approaches and algorithms for implementing the topology management optimization approach of similar three-dimensional housing 
bodies of other types of devices and machines, taking into account the influence of additional factors in their operation, besides only the work load from the transmitted forces, torques, and/or reactions in the bearings.

Author Contributions: S.S. proposed the basic concept of current work, the sequence of steps to perform topology optimization, static and frequency analysis of the original and optimized models, he made all verifications of the obtained before and after optimization results. He also participates in the writing of Section 1, Section 2, Section 3, and Section 6, as well as in the overall editing of the work; M.K.-B. specified the model of the used two-stage gear reducer, preparation of all 3D CAD models, performed all finite element analyses in SOLIDWORKS Simulation, and made their visual presentation. She wrote Sections 4 and 5 of the present paper.

Funding: This research received no external funding.

Conflicts of Interest: The authors declare no conflict of interest.

\section{References}

1. Bhandari, V.B. Design of Machine Elements; Tata McGraw-Hill Education: New York, NY, USA, 2010.

2. Baltadjiev, A.; Atanasov, T. Machine elements, part I and II. In Guidance for Course Project Development; Technical University of Varna: Varna, Bulgaria, 2009; ISBN 978-954-20-0439-4.

3. Maciejczyk, A.; Zdziennicki, Z. Design Basic of Industrial Gear Boxes. Calculation and Design Case Example. Technical U. Lodz (April 2011). Available online: http://cybra.lodz.pl/Content/3714 (accessed on 2 November 2018).

4. Davis, M.; Mohammed, Y.S.; Elmustafa, A.A.; Martin, P.F.; Ritinski, C. Designing for Static and Dynamic Loading of a Gear Reducer Housing with FEA; Technical Ressources; American Gear Manufacturers Association: Alexandria, VA, USA, 2009.

5. Miklos, I.Z.; Miklos, C.C.; Alic, C.I.; Raţiu, S. Analysis of gear reducer housing using the finite element method. In Materials Science and Engineering; IOP Conference Series; IOP Publishing: Bristol, UK, 2018; Volume 294, p. 012034.

6. Gramblička, S.; Kohár, R.; Madaj, R.; Vrabec, M. Analysis of the effect deformations of individual components of gearbox on hers total lifetime. In Materials Science and Engineering; IOP Conference Series; IOP Publishing: Bristol, UK, 2018; Volume 393, p. 012061.

7. Rackov, M.; Knežević, I.; Kuzmanović, S.; Čavić, M.; Penčić, M. Analysis of housing models of modern single-stage universal gear reducers. In Materials Science and Engineering; IOP Conference Series; IOP Publishing: Bristol, UK, 2018; Volume 393, p. 012048.

8. Sigmund, O.; Maute, K. Topology optimization approaches. Struct. Multidiscip. Optim. 2013, 48, 1031-1055. [CrossRef]

9. Bendsoe, M.P. Sigmund, Topology Optimization-Theory, Methods and Applications; Springer-Verlag: Berlin/Heidelberg, Germany, 2003.

10. Osher, S.; Fedkiw, R.P. Level set methods: An overview and some recent results. J. Comput. Phys. 2001, 169, 463-502. [CrossRef]

11. Stefanescu, D.M. Science and Engineering of Casting Solidification, 2nd ed.; Springer: Berlin/Heidelberg, Germany, 2008; ISBN 978-0-387-74609-8.

12. St-Amant, A.; Salahub, D.R. New algorithm for the optimization of geometries in local density functional theory. Chem. Phys. Lett. 1990, 169, 387-392. [CrossRef]

13. Radman, A. Bi-Directional Evolutionary Structural Optimization (BESO) for Topology Optimization of Material's Microstructure. Ph.D. Thesis, RMIT University, Melbourne, Australia, 2013.

14. Kazakis, G.; Kanellopoulos, I.; Sotiropoulos, S.; Lagaros, N.D. Topology optimization aided structural design: Interpretation, computational aspects and 3D printing. Heliyon 2017, 3, e00431. [CrossRef] [PubMed]

15. Topology Optimization Guide. Available online: http://www.topology-opt.com/software-list/ (accessed on 28 October 2018).

16. SOLIDWORKS Simulation Help. Available online: http://help.solidworks.com/2018/english/solidworks/ cworks/idc_help_helptopics.htm (accessed on 29 October 2018).

17. ISO 185:2005 Grey Cast Irons_Classification. Available online: https://www.iso.org/standard/35128.html (accessed on 12 December 2018). 
18. Patel, P.D.; Shah, D.S. Steady State Thermal Stress Analysis of Gearbox Casing by Finite Element Method. Int. J. Mech. Ind. Eng. 2012, 2, 26-30.

19. MITCalc-Mechanical, Industrial and Technical Calculations. Available online: http://www.mitcalc.com/ (accessed on 12 December 2018).

20. SOLIDWORKS Help. Bearing Loads. Available online: http://help.solidworks.com/2018/english/SolidWorks/ cworks/c_Bearing_Loads.htm?id=c301f32f0de54bffba1656c0c47f1907\#Pg0 (accessed on 5 January 2019).

21. Degarmo, E.P.; Black, J.T.; Kohser, R.A. Materials and Processes in Manufacturing, 9th ed.; Wiley: Hoboken, NJ, USA, 2003; ISBN 0-471-65653-4.

22. Schleg, F.P.; Kohloff, F.H.; Sylvia, J.G.; American Foundry Society. Technology of Metal Casting; American Foundry Society: Schaumburg, IL, USA, 2003; ISBN 978-0-87433-257-5.

23. Wang, Y.; Kang, Z. Structural shape and topology optimization of cast parts using level set method. Int. J. Numer. Methods Eng. 2017, 111, 1252-1273. [CrossRef]

(C) 2019 by the authors. Licensee MDPI, Basel, Switzerland. This article is an open access article distributed under the terms and conditions of the Creative Commons Attribution (CC BY) license (http://creativecommons.org/licenses/by/4.0/). 



\title{
Influence of Ball-Burnishing Process on Surface Topography Parameters and Tribological Properties of Hardened Steel
}

\author{
Andrzej Dzierwa ${ }^{1, *}$ and Angelos P. Markopoulos ${ }^{2}$ \\ 1 Faculty of Mechanical Engineering and Aeronautics, Rzeszow University of Technology, \\ Powstancow Warszawy 8 str., 35-959 Rzeszow, Poland \\ 2 Laboratory of Manufacturing Technology, School of Mechanical Engineering, National Technical University \\ of Athens, Iroon Polytechniou Avenue 9, 15780 Athens, Greece; amark@mail.ntua.gr \\ * Correspondence: adktmiop@prz.edu.pl; Tel.: +48-17-865-1904
}

Received: 20 December 2018; Accepted: 15 January 2019; Published: 19 January 2019

\begin{abstract}
The ball-burnishing process is a particular finishing treatment that can improve selected properties of different materials. In the present study, the ball-burnishing technique was used to investigate the effect of input parameters of processes on selected surface layer features like surface roughness and residual stresses of the $42 \mathrm{CrMo} 4$ steel surfaces. The burnishing process was conducted on Haas CNC Vertical Mill Center VF-3 using a tool with tungsten carbide tip. A further objective of our research was to improve tribological properties of the aforementioned steel by the ball-burnishing process. The results of the investigations showed that it was possible to reduce the root mean square height of the surface Sq from $0.522 \mu \mathrm{m}$ to $0.051 \mu \mathrm{m}$ and to increase wear resistance compared to ground samples.
\end{abstract}

Keywords: ball burnishing; surface topography; friction; wear

\section{Introduction}

At present, the manufacturing industry is focusing much attention on dimensional accuracy and surface finish. Surface quality depends largely on the applied finishing treatments, and on the values of input parameters used in them [1]. One of the major possible predictors of machining performance is through the deep analysis of surface textures [2]. There are many finishing treatments used in the mechanical industry, such as polishing, grinding, lapping, or honing. However, one of the most competent surface finishing processes is the burnishing process [3], which includes roller burnishing [4], ball burnishing [5] diamond burnishing, [6] and even similar techniques like pneumatic ball peening or shot peening [7]. The ball-burnishing process, as well as shot peening and laser-assisted burnishing technique [8], can be applied to materials of high hardness. The fundamental role of the ball-burnishing process is to create surface layers of high quality [9]. In this example, high quality is understood as being highlighted by the low values of amplitude parameters of surface topography.

It is possible to categorize burnishing mechanisms into three major groups [10]:

- Surface smoothing (geometrical) mechanism,

- Surface enhancement (mechanical) mechanism,

- The microstructural (metallurgical [11]) mechanism.

During the burnishing of a hard and smooth burnishing element, usually a spherical tip is pressed against the machined surface with the required force, thus causing a sliding friction in the burnishing zone. As a result of this process, surface smoothing occurs. Furthermore, this process improves several other mechanical properties [12]. The choice of a material for burnishing elements is a very important 
issue. Diamond can be such a material, but for economic and technical reasons, diamond tools are often replaced by ceramic tools. The burnishing process creates materials with better surface quality [13-15] and a higher value of surface hardness [16] and creates compressive residual stresses in a surface layer of elements [17]. After the burnishing process, one can also obtain a surface layer without abrasive contaminants. These features have a positive effect on a number of functional properties, including tribological wear, fatigue strength, and corrosion resistance. Moreover, it is possible to obtain most of the aforementioned improvements without special and sophisticated tools and in a relatively short time [18]. Analysis of the ball-burnishing process in terms of the surface roughness reduction has been conducted by, among others, Shiou and Cheng [19]. They reported that after the burnishing process, the improvement of NAK 80 steel reached almost $90 \%$. Furthermore, it was possible to obtain a value of the arithmetical mean height Ra parameter lower than $0.1 \mu \mathrm{m}$. Similar results were obtained by the authors of [20], taking into consideration materials like aluminum A92017 and steel G10380. The main purpose of the research by Tekkaya et al. [21] was the improvement of the friction behavior of thermally sprayed coatings. The possibility of such improvement was tested using ball-burnishing and grinding processes. It was found that by applying the ball-burnishing process, the friction coefficient was reduced significantly in comparison to only coated elements. Investigations of tribological properties of different materials using the ball-burnishing technique have been conducted in References [22-24]. El-Tayeb et al. [22] applied ball burnishing to the aluminum 6061 material. As a result of that process, the authors pointed out a significant reduction of the friction coefficient. The value of the friction coefficient was lower by up to $48 \%$ in comparison to non-burnished surfaces. Wear resistance of Rb40 steel was the subject of research carried out by the authors of [24]. They reported that the surface layers after the burnishing process were similar to ground surfaces, but they were characterized by high level of wear resistance. Revankar et al. [25] also indicated the positive effect of the ball-burnishing process on wear resistance of titanium alloys. Nevertheless, they pointed out to the importance of process parameter selection.

In this work, the effect of the ball-burnishing process on surface topography of the $42 \mathrm{CrMo} 4$ steel samples was investigated. Haas CNC Vertical Mill Center was used as a work stand. Usually, the pre-treatment of the ball-burnishing process is through turning or milling, but in this work, a grinding process was used. However, the grinding parameters were applied in such a way that the values of statistical surface topography parameters (like Sq or Sa) were similar to those found after the milling process. In addition, the investigation of the influence of surface topography after the burnishing process on tribological properties was also studied.

\section{Materials and Methods}

Ball-burnishing tests were conducted at room temperature using Haas CNC Vertical Mill Center VF-3 (Figure 1). The material used in this study was $42 \mathrm{CrMo} 4$ chromium-molybdenum alloy constructional steel of hardness $46 \pm 2 \mathrm{HRC}$. The samples to be burnished had a diameter of $25.4 \mathrm{~mm}$ and a height of $8.9 \mathrm{~mm}$ so that they could be used for tribological tests. Before burnishing, samples were ground in order to obtain parameters as presented in Figure 2. The grinding process was performed using a flat-surface grinder FS $420 \mathrm{SD}$ and the grinding parameters were as follows: Peripheral velocity of the wheel $-40 \mathrm{~m} / \mathrm{s}$, table feed speed $-0.25 \mathrm{~m} / \mathrm{s}$, stroke $-4 \mathrm{~mm}$, grinding depth $-0.015 \mathrm{~mm}$, grinding wheel dimensions $-225 \times 25 \times 51 \mathrm{~mm}$. The material of the ball $(\varphi 6 \mathrm{~mm})$ used in the burnishing process was tungsten carbide (WC), with a grit size of $2.5 \mu \mathrm{m}$. Measurement of surface topography parameters was conducted after ball-burnishing tests. For that purpose, an Altisurf 520 optical profilometer with a CL1 confocal probe was used. The measurement area was $4 \times 4 \mathrm{~mm}^{2}$. Measured textures were only levelled without digital filtration. Then, surface topography parameters were calculated using the TalyMap software. Investigations were conducted based on Hartley's static, determined plan. Such a plan can be built on a hypercube or hypersphere. In this work, a hypercube 
was used. In the case of a three-level plan, Hartley's plan makes it possible to determine the regression function in the form of a polynomial of the second degree. Its general form is presented in Formula (1):

$$
y=b_{0}+\sum b_{k} x_{k}+\sum b_{k k} x_{k}^{2}+\sum b_{k j} x_{k} x_{j}
$$

where: $b$ - coefficients of regression equation; $x$-input parameters.

a)

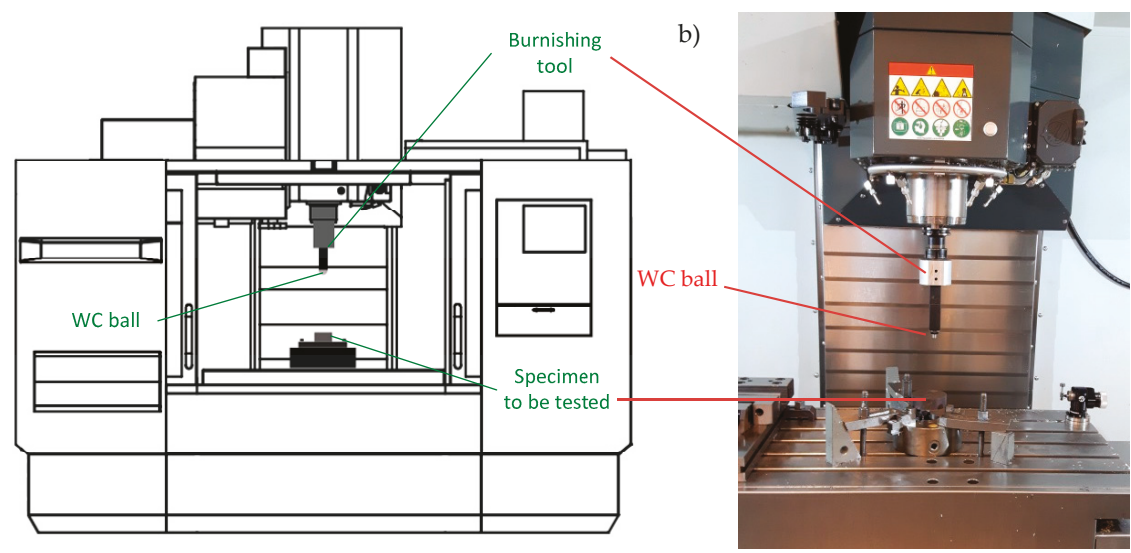

Figure 1. Scheme of the Computer Numerical Control (CNC) test stand (a) and photo of working chamber (b).

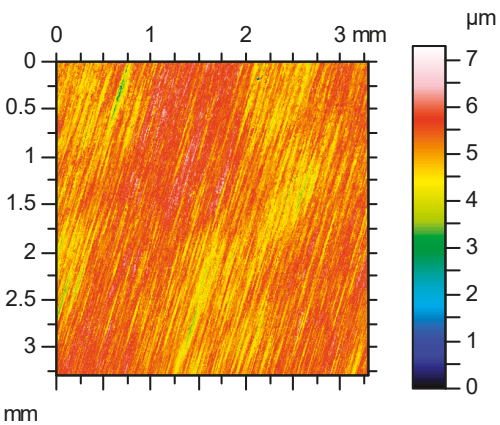

$\begin{array}{ll}\text { Sq }=0.522 \mu \mathrm{m} & \text { Str }=0.383 \\ \text { Ssk }=-0.431 & \text { Std }=73.3^{\circ} \\ \text { Sku }=3.78 & \text { Sdq }=0.101 \\ \text { Sp }=2.37 \mu \mathrm{m} & \text { Sdr }=0.499 \% \\ \text { Sv }=5.92 \mu \mathrm{m} & \text { Spd }=5021 / \mathrm{mm}^{2} \\ \text { Sz }=8.29 \mu \mathrm{m} & \text { Spc }=81.81 / \mathrm{mm} \\ \text { Sa }=0.412 \mu \mathrm{m} & \text { Sk }=1.04 \mu \mathrm{m} \\ \text { Smr }=0.162 \% & \text { Spk }=0.358 \mu \mathrm{m} \\ \text { Smc }=0.639 \mu \mathrm{m} & \text { Svk }=0.557 \mu \mathrm{m} \\ \text { Sxp }=1.15 \mu \mathrm{m} & \text { Smr1 }=8.68 \% \\ \text { Sal }=0.188 \mathrm{~mm} & \text { Smr2 }=87.8 \%\end{array}$

Figure 2. Contour plot of ground surface and its surface topography parameters.

In the three-level plans, input factors assume values on three levels of variation. The " + " sign means the maximum value, the "- " sign means the minimum value, and " 0 " the middle value. The central values of the three entry factors (burnishing pressure force, burnishing speed, stepover), the units of variation as well as encoded input factors are shown in Table 1. The following levels of entry factors were assumed (the number of tool passes was 1):

$\mathrm{x}_{1}$-burnishing pressure force: 10,20 , and $30 \mathrm{MPa}$,

$\mathrm{x}_{2}$-burnishing speed: 400, 700, and $1000 \mathrm{~mm} / \mathrm{min}$,

$\mathrm{x}_{3}$-stepover: 30,50 , and $70 \mu \mathrm{m}$ : 
Table 1. Central values, variation units, and coding entry factors for experiment.

\begin{tabular}{ccc}
\hline Central Values of the Entry Factors & Units of Variation & Encoded Input Factors \\
\hline$\hat{\mathrm{x}}_{10}=\frac{\mathrm{P}_{\max }+\mathrm{P}_{\min }}{2}=20$ & $\Delta \hat{\mathrm{x}}_{1}=\frac{\mathrm{P}_{\max }-\mathrm{P}_{\min }}{2}=10$ & $\mathrm{x}_{1}=\frac{\mathrm{P}-\hat{\mathrm{x}}_{10}}{\Delta \hat{\mathrm{x}}_{1}}=\frac{\mathrm{P}-20}{10}$ \\
$\hat{\mathrm{x}}_{20}=\frac{\mathrm{v}_{\max }+\mathrm{v}_{\min }}{2}=700$ & $\Delta \hat{\mathrm{x}}_{2}=\frac{\mathrm{v}_{\max }-\mathrm{v}_{\min }}{2}=300$ & $\mathrm{x}_{2}=\frac{\mathrm{v}-\mathrm{x}_{20}}{\Delta \hat{\mathrm{x}}_{2}}=\frac{\mathrm{v}-700}{300}$ \\
$\hat{\mathrm{x}}_{30}=\frac{\mathrm{a}_{\max }-\mathrm{a}_{\min }}{2}=50$ & $\Delta \hat{\mathrm{x}}_{3}=\frac{\mathrm{a}_{\max }-\mathrm{a}_{\min }}{2}=20$ & $\mathrm{x}_{3}=\frac{\mathrm{a}-\mathrm{X}_{30}}{\Delta \hat{\mathrm{x}}_{3}}=\frac{\mathrm{a}-50}{20}$ \\
\hline
\end{tabular}

Where: $P_{\max }, P_{\min }-$ maximum and minimum value of burnishing pressure force; $v_{\max }, v_{\min }-\operatorname{maximum}$ and minimum value of burnishing speed; $a_{\max }, a_{\min }-$ maximum and minimum value of stepover.

Table 2 presents the matrix of the plan. The ball-burnishing process was conducted in random order according to the 11 machining variants presented in Table 2. The methodology of the research as well as the analysis were precisely described by the authors of $[26,27]$. The result parameters (mean value of the three measurements) were denoted by $\bar{y}_{i}$. The root mean square height of the surface Sq $\left(\bar{y}_{i 1}\right)$, maximum height of the surface Sz $\left(\bar{y}_{i 2}\right)$, as well as maximum value of stresses in the surface layer $\sigma_{\max }\left(\bar{y}_{i 3}\right)$ were taken as the result factors. Other surface topography parameters were also measured and compared to the values achieved after the grinding process (see Table 3 ).

Measurements of the residual stresses in surface layer of disc samples were carried out using a portable Xstress 3000 G3R X-ray diffractometer. The sin $2 \psi$ method described in Reference [28] was used with an angle of incidence $\psi$ ranging from $-45^{\circ}$ to $+45^{\circ}$ divided in 7 tilt positions. The $X$-ray penetration depth was set to $10 \mu \mathrm{m}$. The XTronic software was used to process the diffraction peaks and compute the residual stresses. The size of the collimator was $1.0 \mathrm{~mm}$ in diameter and exposure time was set to $40 \mathrm{~s}$. For each disc surface, the residual stresses were determined in 2 points in orthogonal directions and the average value is presented in Table 2 .

Table 2. Matrix of research plan.

\begin{tabular}{ccccccccccccc}
\hline No & $x_{1}$ & $x_{2}$ & $x_{3}$ & $x_{1}^{2}$ & $x_{2}^{2}$ & $x_{3}^{2}$ & $x_{1} x_{2}$ & $x_{1} x_{3}$ & $x_{2} x_{3}$ & $\bar{y}_{i 1}(S q), \mu \mathrm{m}$ & $\bar{y}_{i 2}(S z), \mu \mathrm{m}$ & $\bar{y}_{i 3}\left(\sigma_{\max }\right), M P a$ \\
\hline 1 & + & + & + & + & + & + & + & - & - & 0.0835 & 1.19 & -401 \\
2 & + & - & - & + & + & + & - & - & + & 0.0685 & 0.85 & -493 \\
3 & - & + & - & + & + & + & - & + & - & 0.141 & 1.47 & -282 \\
4 & - & - & + & + & + & + & + & + & + & 0.169 & 1.65 & -361 \\
5 & + & 0 & 0 & + & 0 & 0 & 0 & 0 & 0 & 0.051 & 0.558 & -466 \\
6 & - & 0 & 0 & + & 0 & 0 & 0 & 0 & 0 & 0.153 & 1.79 & -308 \\
7 & 0 & + & 0 & 0 & + & 0 & 0 & 0 & 0 & 0.149 & 1.07 & -338 \\
8 & 0 & - & 0 & 0 & + & 0 & 0 & 0 & 0 & 0.162 & 1.11 & -457 \\
9 & 0 & 0 & + & 0 & 0 & + & 0 & 0 & 0 & 0.194 & 1.46 & -397 \\
10 & 0 & 0 & - & 0 & 0 & + & 0 & 0 & 0 & 0.175 & 1.17 & -382 \\
11 & 0 & 0 & 0 & 0 & 0 & 0 & 0 & 0 & 0 & 0.133 & 1.19 & -359 \\
\hline
\end{tabular}

After the burnishing process, all samples were subjected to the wear tests. Wear tests were carried out using a pin/ball-on-disc tribological tester. In this study, ball-on-disc configuration was used. Ball-burnished steel discs were placed in contact with a WC ball of hardness about 70 HRC. The ball diameter used in tests was $6.35 \mathrm{~mm}$. Dry sliding tests were carried out at room temperature $\left(20-22{ }^{\circ} \mathrm{C}\right)$. Investigations were carried out at three different sliding speeds $(0.16,0.32$, and $0.48 \mathrm{~m} / \mathrm{s})$. The sliding distance was $282.6 \mathrm{~m}$ (the time was set to $30 \mathrm{~min}$ ) and the applied load was $9.81 \mathrm{~N}$. The maximum Hertzian contact pressure was $1.78 \mathrm{GPa}$, and the diameter of the elastic contact equaled $0.103 \mathrm{~mm}$. During the tribological research, the test chamber went through blow-by with compressed air to remove the wear products. All dry sliding tests were repeated at least 3 times. The friction force was measured continuously during the tribological tests. The wear of the disc samples was calculated after the dry sliding tests using a surface topography analysis. Worn surfaces were measured by means of white light interferometer Talysurf CCI Lite using objective $5 \times$. The measuring area of $3.3 \mathrm{~mm} \times 3.3 \mathrm{~mm}$ contained $1024 \times 1024$ points. After measurements, at least 7 profiles were taken in four positions $\left(90^{0}\right.$ apart) perpendicular to the wear track in order to obtain the cross-sectional area of the wear tracks. Then, the values of the cross-sectional area of the wear track (in TalyMap software 
defined as the area of the hole) were averaged and the value of volumetric wear was calculated using Formula (2):

$$
\mathrm{VD}=\pi \mathrm{d} S
$$

where:

$\mathrm{d}$-diameter of the wear track (in our tests $\mathrm{d}=10 \mathrm{~mm}$ ),

$\mathrm{S}$-area of the hole (the cross-sectional area of the wear track).

Table 3. Comparison of surface texture parameters of ground and ball-burnished surfaces.

\begin{tabular}{|c|c|c|c|c|c|}
\hline \multicolumn{3}{|c|}{ Surface Topography Parameters [29] } & \multicolumn{3}{|c|}{ Workpiece } \\
\hline & & & \multirow[t]{2}{*}{ Ground } & \multicolumn{2}{|l|}{ Burnished } \\
\hline & & & & Min. & Max. \\
\hline \multirow[t]{7}{*}{ Height } & Root mean square height & $\mathrm{Sq}[\mu \mathrm{m}]$ & 0.522 & 0.051 & 0.194 \\
\hline & Skewness & Ssk & -0.431 & -0.345 & 0.244 \\
\hline & Kurtosis & Sku & 3.78 & 1.99 & 3.26 \\
\hline & Maximum peak height & $\mathrm{Sp}[\mu \mathrm{m}]$ & 2.37 & 0.294 & 0.805 \\
\hline & Maximum pit height & $\operatorname{Sv}[\mu \mathrm{m}]$ & 5.92 & 0.264 & 1.03 \\
\hline & Maximum height & $\mathrm{Sz}[\mu \mathrm{m}]$ & 8.29 & 0.558 & 1.79 \\
\hline & Arithmetic mean height & $\mathrm{Sa}[\mu \mathrm{m}]$ & 0.412 & 0.041 & 0.339 \\
\hline \multirow[t]{3}{*}{ Functional } & Areal material ratio & Smr [\%] & 0.162 & 93.5 & 100 \\
\hline & Inverse areal material ratio & $\mathrm{Smc}[\mu \mathrm{m}]$ & 0.639 & 0.0647 & 0.266 \\
\hline & Extreme peak height & $\operatorname{Sxp}[\mu \mathrm{m}]$ & 1.15 & 0.0969 & 0.339 \\
\hline \multirow[t]{3}{*}{ Spatial } & Auto-correlation length & Sal $[\mathrm{mm}]$ & 0.188 & 0.0358 & 0.217 \\
\hline & Texture-aspect ratio & Str & 0.383 & 0.0237 & 0.245 \\
\hline & Texture direction & Std $\left[{ }^{\circ}\right]$ & 73.3 & 0.623 & 7.1 \\
\hline \multirow[t]{2}{*}{ Hybrid } & Root mean square gradient & Sdq & 0.101 & 0.00613 & 0.0234 \\
\hline & Developed interfacial area ratio & $\operatorname{Sdr}[\%]$ & 0.499 & 0.00188 & 0.0273 \\
\hline \multirow{6}{*}{$\begin{array}{l}\text { Functional } \\
\text { (volume) }\end{array}$} & Material volume & $\mathrm{Vm}\left[\mathrm{mm}^{3} / \mathrm{mm}^{2}\right]$ & $2.01 \times 10^{-5}$ & $2.53 \times 10^{-6}$ & $6.90 \times 10^{-6}$ \\
\hline & Void volume & $\mathrm{Vv}\left[\mathrm{mm}^{3} / \mathrm{mm}^{2}\right]$ & 0.000659 & $6.72 \times 10^{-5}$ & $2.73 \times 10^{-4}$ \\
\hline & Peak material volume & $\mathrm{Vmp}\left[\mathrm{mm}^{3} / \mathrm{mm}^{2}\right]$ & $2.01 \times 10^{-5}$ & $2.53 \times 10^{-6}$ & $6.90 \times 10^{-6}$ \\
\hline & Core material volume & $\mathrm{Vmc}\left[\mathrm{mm}^{3} / \mathrm{mm}^{2}\right]$ & 0.000466 & $4.47 \times 10^{-5}$ & $1.88 \times 10^{-4}$ \\
\hline & Core void volume & $\mathrm{Vvc}\left[\mathrm{mm}^{3} / \mathrm{mm}^{2}\right]$ & 0.00059 & $6.16 \times 10^{-5}$ & $2.55 \times 10^{-4}$ \\
\hline & Pit void volume & $\mathrm{Vvv}\left[\mathrm{mm}^{3} / \mathrm{mm}^{2}\right]$ & $6.93 \times 10^{-5}$ & $5.61 \times 10^{-6}$ & $2.08 \times 10^{-5}$ \\
\hline \multirow[t]{9}{*}{ Feature } & Density of peaks & Spd $\left[1 / \mathrm{mm}^{2}\right]$ & 502 & 243 & 448 \\
\hline & Arithmetic mean peak curvature & $\mathrm{Spc}[1 / \mathrm{mm}]$ & 81.8 & 6.05 & 15.5 \\
\hline & Ten-point height & $\mathrm{S} 10 \mathrm{z}[\mu \mathrm{m}]$ & 3.77 & 0.325 & 1.08 \\
\hline & Five-point peak height & S5p $[\mu \mathrm{m}]$ & 1.42 & 0.188 & 0.489 \\
\hline & Five-point pit height & $\mathrm{S} 5 \mathrm{v}[\mu \mathrm{m}]$ & 2.35 & 0.136 & 0.591 \\
\hline & Mean dale area & Sda $\left[\mathrm{mm}^{2}\right]$ & 0.0019 & 0.00151 & 0.00447 \\
\hline & Mean hill area & Sha $\left[\mathrm{mm}^{2}\right]$ & 0.00195 & 0.00181 & 0.00372 \\
\hline & Mean dale volume & $\mathrm{Sdv}\left[\mathrm{mm}^{3}\right]$ & $7.06 \times 10^{-8}$ & $1.16 \times 10^{-8}$ & $2.62 \times 10^{-8}$ \\
\hline & Mean hill volume & Shv $\left[\mathrm{mm}^{3}\right]$ & $7.85 \times 10^{-8}$ & $1.19 \times 10^{-8}$ & $2.14 \times 10^{-8}$ \\
\hline \multirow{5}{*}{$\begin{array}{l}\text { Functional } \\
\text { (stratified } \\
\text { surfaces) }\end{array}$} & Core roughness depth & $\mathrm{Sk}[\mu \mathrm{m}]$ & 1.04 & 0.106 & 0.421 \\
\hline & Reduced summit height & Spk $[\mu \mathrm{m}]$ & 0.358 & 0.0433 & 0.0853 \\
\hline & Reduced valley depth & Svk $[\mu \mathrm{m}]$ & 0.557 & 0.0407 & 0.162 \\
\hline & Upper bearing area & Smr1 [\%] & 8.68 & 3.66 & 11.4 \\
\hline & Lower bearing area & Smr2 [\%] & 87.8 & 90.2 & 95.2 \\
\hline
\end{tabular}

\section{Results and Discussion}

\subsection{Effect of the Ball-Burnishing Parameters on the Surface Topography and Residual Stresses}

The results of experiments for the parameters Sq, Sz, and $\sigma_{\max }$ are presented in Table 2. Table 3 shows the ranges of all measured surface topography parameters obtained through the ball-burnishing process. A comparison to the parameters obtained after the grinding process was also presented in Table 3. Figure 3 presents isometric views of the selected samples after ball burnishing with the highest and the lowest value of the Sq parameter as well as the Abbott-Firestone curve and distribution of surface ordinates. 
As a result of the ball-burnishing process, the root mean square height of the surface Sq decreased in all variants. The values of the Sq parameter were between $0.051 \mu \mathrm{m}$ (for $\mathrm{P}=30 \mathrm{MPa}$, $\mathrm{v}=700 \mathrm{~mm} / \mathrm{min}, \mathrm{a}=50 \mu \mathrm{m}$ ) and $0.194 \mu \mathrm{m}$ (for $\mathrm{P}=20 \mathrm{MPa}, \mathrm{v}=700 \mathrm{~mm} / \mathrm{min}, \mathrm{a}=70 \mu \mathrm{m}$ ).

Other amplitude parameters like Sv, Sp, and Sz also clearly decreased in comparison to ground sample. For example, the reduction of maximum height $\mathrm{Sz}$ was from $8.29 \mu \mathrm{m}$ after the grinding process to the values between $0.56 \mu \mathrm{m}$ (variant 5) and $1.79 \mu \mathrm{m}$ (variant 6). Skewness Ssk is the third and kurtosis Sku is the fourth moment of the height distribution histogram. The negative value of the Ssk parameter indicates the valley structures and a positive value of Ssk-the predominance of peaks. For a Gaussian surface of a symmetric shape, the skewness is zero. The Sku parameter is a measure of the peaks or sharpness of the surface height distribution [30]. When height distribution is normal, Sku equals 3 . The ground surface was characterized by a more negative value of Ssk $(-0.431)$ than all burnished samples $(-0.345 \div 0.244)$. On the other hand, the value of the Sku parameter of the ground sample (3.78) was the largest compared to all burnished surfaces $(1.99 \div 3.23)$.

a)

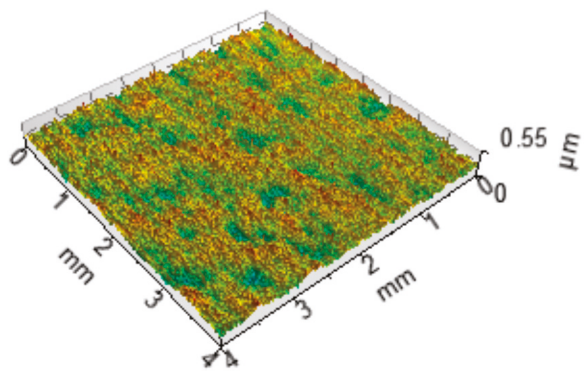

C)

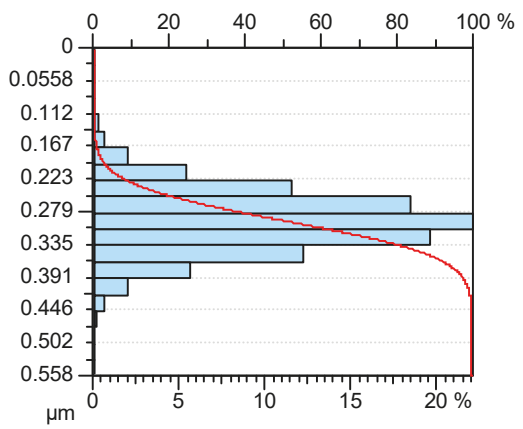

b)

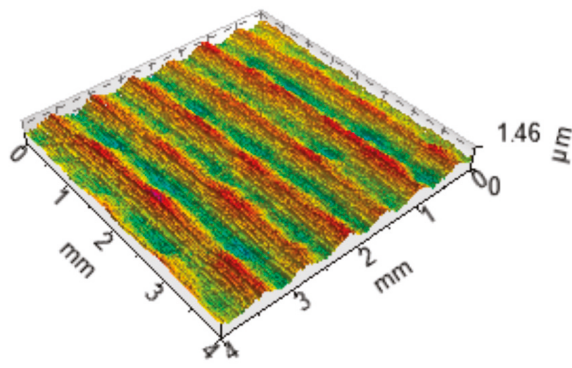

d)

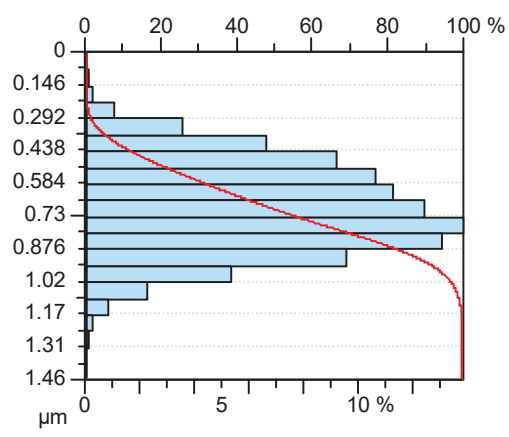

Figure 3. Isometric views $(\mathbf{a}, \mathbf{b})$ and Abbott-Firestone curves with distribution of surface ordinates $(\mathbf{c}, \mathbf{d})$ for the samples with the lowest $(\mathbf{a}, \mathbf{c})$ and the highest $(\mathbf{b}, \mathbf{d})$ value of the Sq parameter.

The texture aspect ratio of ball-burnished disc samples Str was lower than 0.245 . The Str parameter is a measure of surface texture and ranges between 0 and 1 (values close to 1 indicate a high level of isotropy). Values lower than 0.245 indicate the anisotropic character of the burnished surfaces. The value of the length of the fastest decay of the autocorrelation function in any direction Sal in most of all practical applications is set to 0.2. Large values of the Sal parameter denote surfaces dominated by low-frequency components, while small values of that parameter indicate the opposite. Most burnished samples were characterized by a lower value of Sal than ground surface and, thus, were dominated by higher-frequency components. The only exception was the sample in variant 1 , where the Sal parameter reached the value of 0.217 . 
Both hybrid parameters (Sdq and Sdr) also decreased after the ball-burnishing process in all tested variants. The developed interfacial area ratio of the scale-limited surface Sdr represents the ratio of the increment of the interfacial area of the scale-limited surface over the flat sampling area. Values of the Sdr parameter lower than $1 \%$ are usually associated to superfinished surfaces. In all analyzed variants, that value was distinctly lower than $1 \%$ (between $0.00188 \%$ and $0.0273 \%$ ). The Sdq parameter is defined as the root mean square of the surface slope within the sampling area. This parameter characterizes slopes on a surface and its higher values denote rougher surfaces. Values obtained after the ball-burnishing process were smaller than after grinding and, thus, indicate the smoothing nature of that treatment.

As a result of the ball-burnishing process, all functional (volume) parameters decreased in comparison to the ground surface. A similar tendency was observed in the case of the density of peaks Spd, arithmetic mean peak curvature Spc, ten point height S10z, as well as most parameters from the Sk family (such as Sk, Spk, and Svk).

The improvement of surface quality (mainly of amplitude parameters) can be explained in terms of the elimination of surface irregularities that occurred by the pressing of the ball, which slides on the flat surfaces with pressing burnishing force. Additionally, applying only one tool pass caused the ball to penetrate only a small distance into a work surface and, as a consequence, a limited deformation of asperities occurred. This resulted in smoothing the surface.

It was found that compressive stresses occurred in the surface layer of all the ball-burnished workpieces. The measured value of $\sigma_{\max }$ for the ground surface was $96 \mathrm{MPa}$ (tensile stress). After ball burnishing, $\sigma_{\max }$ achieved values in the range of $-283 \div-493 \mathrm{MPa}$ (compressive stresses). The largest value of the compressive stresses was calculated for the sample from variant 2 , where the burnishing pressure force equaled $30 \mathrm{MPa}$, the burnishing speed $400 \mathrm{~mm} / \mathrm{min}$, and stepover was set to $30 \mu \mathrm{m}$.

Three mathematical models to illustrate the effect of the starting parameters of the ball-burnishing process on the result parameters were achieved (Formulas (3)-(5)):

$$
\begin{gathered}
S q=-160.216+0.0045 a+0.000325 v-0.0000065 a v+16.0185 P-0.40057 P^{2} \\
S z=0.355132+0.0315 a+0.00225 v-0.000045 a v-0.038533 P \\
\sigma_{\max }=629.585-7.75833 a-0.554167 v+0.0110833 a v+7.06667 P .
\end{gathered}
$$

Mathematical models pointed out the existence of nonlinear relationships between ball burnishing and the resulting parameters. Analyzing the obtained mathematical models, one can see that surface topography parameters (Sq and Sz) depend on all entry parameters of ball burnishing, but in the case of the Sz parameter and mainly in the case of the Sq parameter, the influence of the burnishing pressure force was the largest.

The significant impact of the burnishing pressure force observed in mathematical models (Formulas (3) and (4)) was confirmed in the graphical analysis. Figures 4-6 present the dependences between the ball-burnishing process parameters and surface topography parameters Sq and Sz. Fragments in green color represent areas with lower values of Sq and Sz. On the other hand, the red color indicates higher values of the mentioned parameters. One can see that the green areas are only visible in the case of the highest burnishing pressure force values. This is particularly evident in the case of the Sq parameter (Figures $4 \mathrm{a}$ and 5a). A similar dependency does not occur if we take into account other input parameters of the ball-burnishing process. Figure 6 presents the influence of burnishing speed and stepover on the Sq and Sz parameters. One can see that it is difficult to find clear relationships between input $(\mathrm{v}, \mathrm{a})$ and result parameters $(\mathrm{Sq}, \mathrm{Sz})$. 
a)

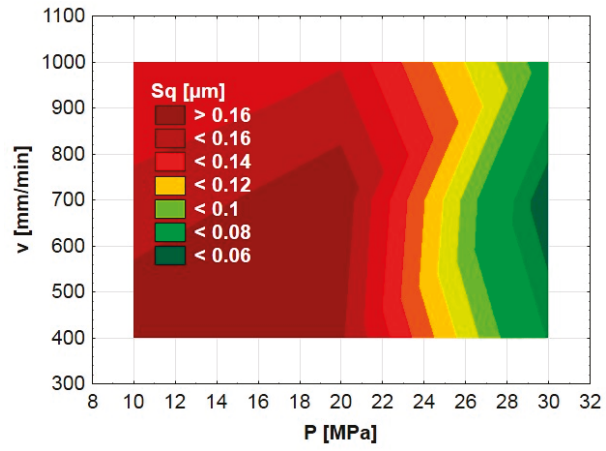

b)

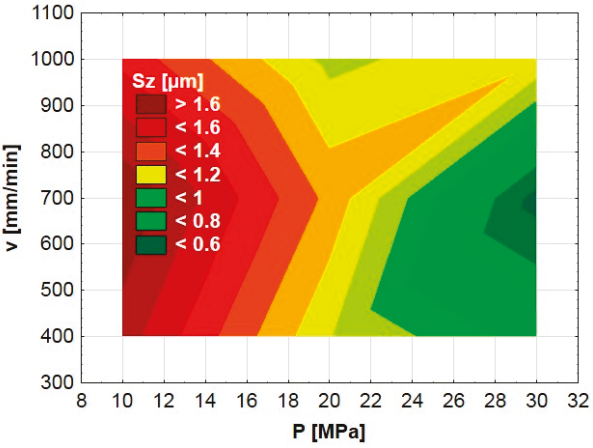

Figure 4. Dependence between ball-burnishing parameters $(P, v)$ and surface topography parameters $\mathrm{Sq}(\mathbf{a}), \mathrm{Sz}(\mathbf{b})$.

a)

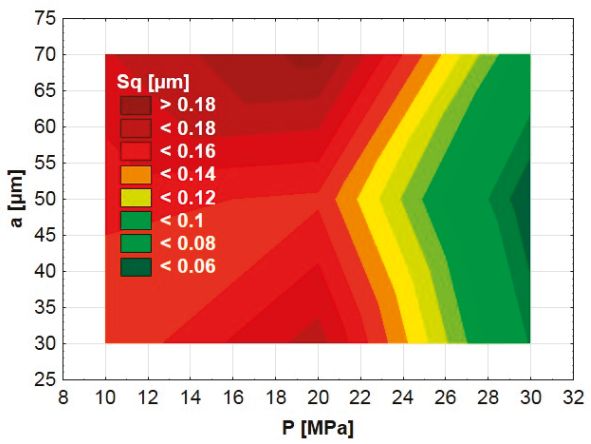

b)

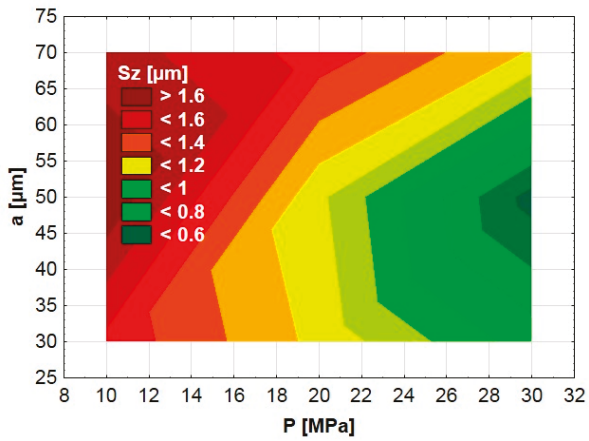

Figure 5. Dependence between ball-burnishing parameters $(P, a)$ and surface topography parameters $\mathrm{Sq}(\mathbf{a}), \mathrm{Sz}(\mathbf{b})$.

a)

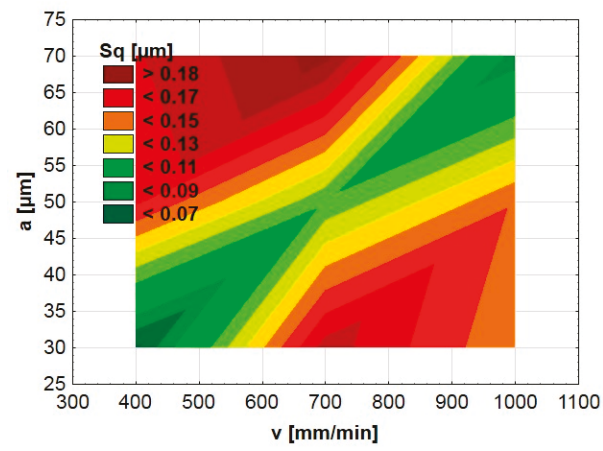

b)

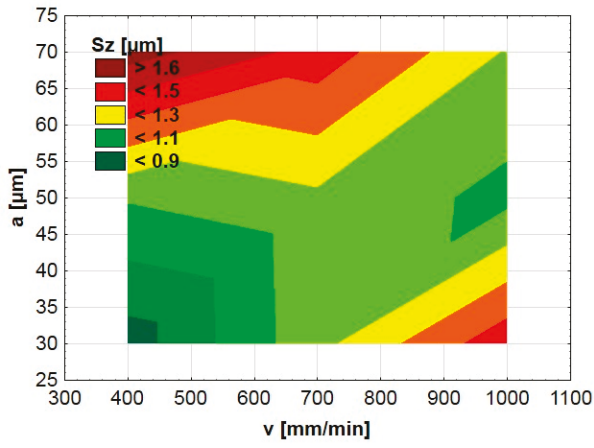

Figure 6. Dependence between ball-burnishing parameters $(v, a)$ and surface topography parameters Sq (a), Sz (b). 


\subsection{Effect of the Ball-Burnishing Parameters on the Tribological Properties}

Table 4 presents the results of the tribological tests. For each disc sample, several indicators were calculated:

- The mean value of the volumetric wear of the disc samples (VD),

- The sliding distance after which the friction force obtains steady-state conditions (DSS),

- $\quad$ The average value of the friction force after obtaining the steady-state condition (Fav).

Figure 7 presents the profiles of the wear tracks with the areas of hole marked in red on the selected disc surfaces (with the highest and the lowest value of VD parameter) at the smallest sliding speed $\mathrm{v}_{\mathrm{S}}=0.16 \mathrm{~m} / \mathrm{s}$.

Table 4. Results of the tribological tests. VD: Mean value of the volumetric wear of the disc samples. DSS: Sliding distance after which the friction force obtains steady-state conditions. Fav: Average value of the friction force after obtaining the steady-state condition.

\begin{tabular}{|c|c|c|c|c|c|c|c|c|c|}
\hline \multirow[t]{2}{*}{ No } & \multicolumn{3}{|c|}{$\mathrm{v}_{\mathrm{s}}=0.16, \mathrm{~m} / \mathrm{s}$} & \multicolumn{3}{|c|}{$\mathrm{v}_{\mathrm{s}}=0.32, \mathrm{~m} / \mathrm{s}$} & \multicolumn{3}{|c|}{$\mathrm{v}_{\mathrm{s}}=0.48, \mathrm{~m} / \mathrm{s}$} \\
\hline & $\mathrm{VD}, \mathrm{mm}^{3}$ & DSS, $\mathrm{m}$ & Fav, N & $\mathrm{VD}, \mathrm{mm}^{3}$ & DSS, $\mathrm{m}$ & Fav, N & $\mathrm{VD}, \mathrm{mm}^{3}$ & DSS, $\mathrm{m}$ & Fav, N \\
\hline 1 & 0.166 & 68 & 5.44 & 0.171 & 62 & 4.87 & 0.191 & 54 & 5.42 \\
\hline 2 & 0.147 & 81 & 4.69 & 0.162 & 70 & 4.78 & 0.171 & 62 & 4.92 \\
\hline 3 & 0.219 & 22 & 5.54 & 0.231 & 18 & 5.36 & 0.245 & 19 & 5.48 \\
\hline 4 & 0.205 & 64 & 5.26 & 0.193 & 40 & 4.92 & 0.233 & 28 & 5.37 \\
\hline 5 & 0.159 & 71 & 5.19 & 0.174 & 44 & 4.81 & 0.186 & 37 & 4.98 \\
\hline 6 & 0.208 & 65 & 4.89 & 0.222 & 25 & 5.09 & 0.249 & 15 & 5.49 \\
\hline 7 & 0.188 & 33 & 4.95 & 0.197 & 34 & 5.18 & 0.213 & 46 & 5.14 \\
\hline 8 & 0.178 & 59 & 5.11 & 0.183 & 64 & 5.33 & 0.177 & 37 & 4.98 \\
\hline 9 & 0.191 & 38 & 5.37 & 0.188 & 51 & 4.97 & 0.206 & 55 & 5.23 \\
\hline 10 & 0.198 & 52 & 4.91 & 0.214 & 30 & 5.22 & 0.221 & 49 & 5.31 \\
\hline 11 & 0.189 & 55 & 5.04 & 0.204 & 38 & 5.02 & 0.198 & 61 & 4.92 \\
\hline Ground & 0.278 & 79 & 5.71 & 0.285 & 72 & 5.45 & 0.309 & 68 & 5.77 \\
\hline
\end{tabular}

a)

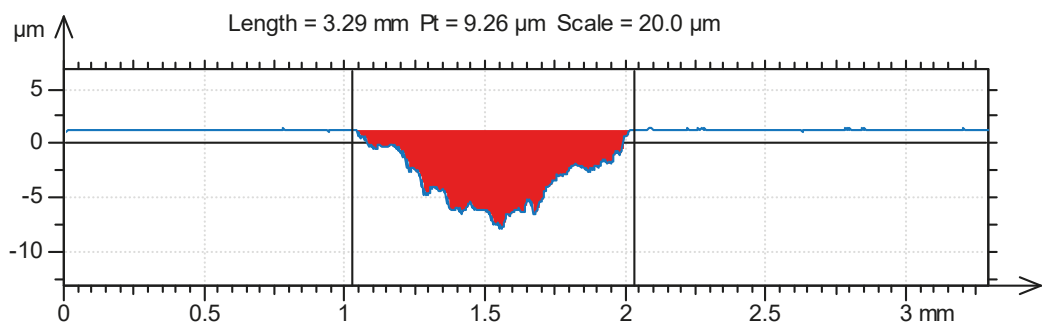

Maximum depth

$9.18 \mu \mathrm{m} \quad$ Area of the hole

$4647 \mu \mathrm{m}^{2}$

b)

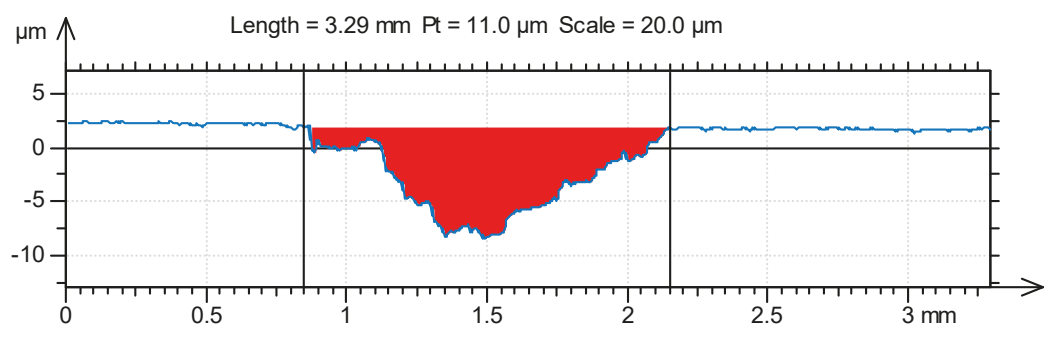

Maximum depth

$10.5 \mu \mathrm{m}$ Area of the hole

$6834 \mu m^{2}$

Figure 7. Worn disc profiles (a) sample 2, (b) sample 3, obtained at $\mathrm{v}_{\mathrm{s}}=0.16 \mathrm{~m} / \mathrm{s}$. 
In the initial phases of the tribological tests, the friction force distinctly increased and reached a stable value, usually in the range of 4.5-5.5 N, independently of sliding speed. Differences between values of friction forces in the early phase of each test were smaller than $20 \%$, but the distance to obtain steady-state conditions of the friction force DSS was different. At the sliding speed of $0.16 \mathrm{~m} / \mathrm{s}$, the value of DSS parameter was in the range $22-81 \mathrm{~m}$. The highest value of DSS corresponded with the smallest value of wear volume $\left(0.147 \mathrm{~mm}^{3}\right)$. On the other hand, the largest wear volume $\left(0.219 \mathrm{~mm}^{3}\right)$ was observed when the DSS parameter was the smallest $(22 \mathrm{~m})$.

An increase of sliding speed caused a slight increase of volumetric wear and slight decrease of the distance to obtain steady-state conditions of the friction force DSS. A similar tendency was found at the highest sliding speed $\mathrm{v}_{\mathrm{s}}=0.48 \mathrm{~m} / \mathrm{s}$. At the sliding speed of $0.32 \mathrm{~m} / \mathrm{s}$, the largest value of wear volume was calculated for sample $2\left(0.162 \mathrm{~mm}^{3}\right)$. For this sample, DSS parameter was the largest $(70 \mathrm{~m})$ and Fav was the smallest $(4.78 \mathrm{~N})$. The maximum wear volume was observed in the case of sample 3. The value of VD reached $0.231 \mathrm{~mm}^{3}$.

At the highest sliding speed $\mathrm{v}_{\mathrm{s}}=0.48 \mathrm{~m} / \mathrm{s}$, the smallest value of wear volume was also observed for sample 2. In this case, the value of the VD parameter reached $0.171 \mathrm{~mm}^{3}$ and, like at lower sliding speeds, corresponded to largest value of the DSS parameter $(62 \mathrm{~m})$. The average value of the friction force after obtaining the steady-state condition Fav was also the smallest but identical to the sample $11(4.62 \mathrm{~N})$. The highest value of wear volume was characterized by sample 3 and it was $0.245 \mathrm{~mm}^{3}$. In this case, the distance to obtain steady-state conditions of the friction force DSS reached the value of $19 \mathrm{~m}$, but shorter distance was observed for sample $6(15 \mathrm{~m})$.

At a sliding speed of $\mathrm{v}_{\mathrm{s}}=0.16 \mathrm{~m} / \mathrm{s}$, the average value of the coefficient of friction ranged between 0.478 (sample 2) and 0.565 (sample 3) during dry sliding tests; at $\mathrm{v}_{\mathrm{s}}=0.32 \mathrm{~m} / \mathrm{s}$, it was between 0.478 (sample 2) and 0.546 (sample 3); and at a highest sliding speed, the value of the friction coefficient reached 0.501 (for sample 2) and 0.559 (for sample 6).

The improvement of wear resistance of ball-burnished surfaces in comparison to ground samples can be explained by the effect of plastic cold strain. This effect causes changes in the crystalline structure and has a vital influence on the properties of the machined materials.

In order to find potential relationships between surface topography parameters and tribological properties, the linear coefficient of correlation $\mathrm{R}$ was used. The estimated value is always in the range of -1 to 1 . If the coefficient is zero $(R=0)$, there is no linear correlation between the two features. If the absolute value of a correlation coefficient becomes higher (close to 1), a stronger linear relationship between variables occurs. One can notice a strong linear correlation existence between volumetric wear VD and the skewness Ssk (Figure 8). In this case, the linear coefficient of correlation was in the range of -0.71 (at the sliding speed $\mathrm{v}_{\mathrm{s}}=0.32 \mathrm{~m} / \mathrm{s}$ ) to $-0.83\left(\mathrm{v}_{\mathrm{s}}=0.48 \mathrm{~m} / \mathrm{s}\right)$. Linear relationships were also observed in the case of wear volume and several surface topography parameters, like Sz, Sdq, Spc, Sk, and Svk. The correlation coefficient oscillated between 0.69 and 0.86 .

a)

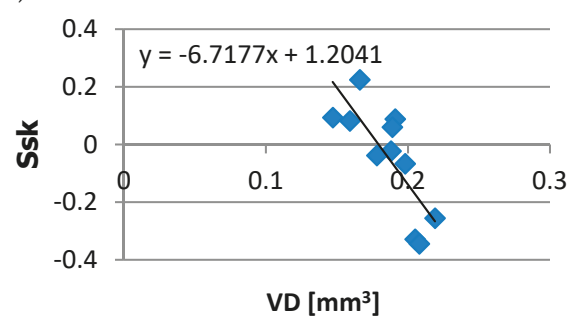

b)

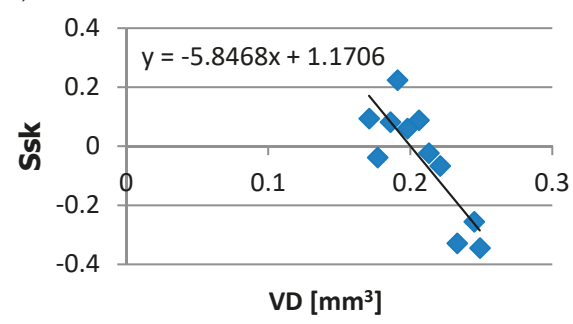

Figure 8. Dependency between disc volumetric wear VD and skewness Ssk at the sliding speed of: (a) $0.16 \mathrm{~m} / \mathrm{s}$; (b) $0.48 \mathrm{~m} / \mathrm{s}$. 
Strong linear correlations were also found between wear volume and maximum value of stresses in the surface layer $\sigma_{\max }$ (Figure 9). It was an inversely proportional relationship and the correlation coefficient reached the values up to -0.9 . A similar value was observed between wear volume and the sliding distance DSS.

a)

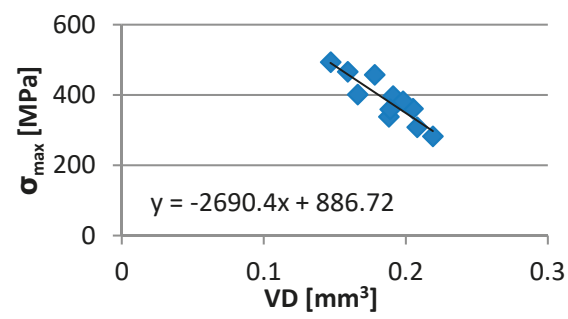

b)

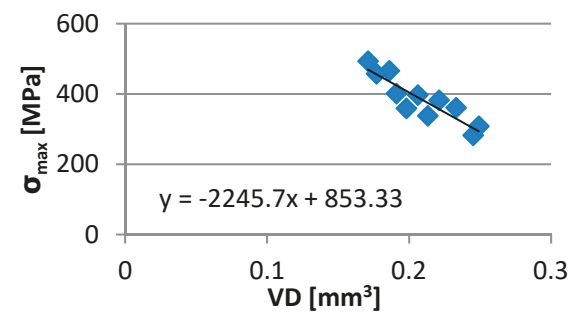

Figure 9. Dependency between disc volumetric wear VD and maximum value of stresses in the surface layer $\sigma_{\max }$ at the sliding speed of: (a) $0.16 \mathrm{~m} / \mathrm{s}$; (b) $0.48 \mathrm{~m} / \mathrm{s}$.

Analysis of the surface topography revealed the formation of anisotropic texture after tribological tests. The obtained values of the Str parameter were in the range of 7.23 to $12.86 \%$. Such values are typical for anisotropic surfaces after abrasive wear. Microscopic observations also confirmed that the wear of the tested disc samples in dry sliding contact conditions was mainly dominated by plastic deformation and abrasive wear. In some cases, adhesive tracks were also visible on the disc surfaces.

\section{Conclusions}

The effect of the ball-burnishing process with various mechanical input parameters on surface topography and tribological properties of hardened steel was investigated. Based on the experimental results achieved, the following conclusions are derived:

It was found that the ball-burnishing process can be a very effective finishing treatment of the surface. Using this process, one can achieve a root mean square height Sq lower than $0.1 \mu \mathrm{m}$. In order to obtain such a value of Sq input parameter, like $\mathrm{P}=30 \mathrm{MPa}, \mathrm{v}=400 \mathrm{~mm} / \mathrm{min}, \mathrm{a}=30 \mu \mathrm{m}$ are recommended.

During the ball-burnishing process, the values of the height parameters (Sq, Sz, Sp, Sv) got reduced. A similar tendency was observed with hybrid, functional (volume), and most feature parameters. Other parameters, e.g., those important from a tribological point of view (Sk family), were also improved.

It was found that the burnishing pressure force was the most important input factor in the process. The smallest values of root mean square height Sq and maximum height Sz were achieved when the pressure force was the highest. The other input parameters had a minor impact.

The ball-burnishing process caused the presence of compressive stresses in the surface layer of the tested discs. The maximum value of residual stresses was observed when the burnishing pressure force achieved maximum value and other input parameters reached minimum. The maximum value of residual stresses $\sigma_{\max }$ was correlated with wear volume.

Surface topography parameters like Sz, Sdq, Spc, and Sk can be used to predict the level of volumetric wear of burnished surfaces. This is also possible with the Ssk parameter, the increase of which, in most cases, resulted in reduced wear volume. However, skewness Ssk is a very sensitive surface parameter and in that case, it should be used with great care.

Author Contributions: Conceptualization: A.D and A.M.; methodology: A.D and A.M.; investigation: A.D.; writing - original draft preparation: A.D and A.M.; writing—review and editing: A.D and A.M.

Funding: This research received no external funding. 
Conflicts of Interest: The authors declare no conflict of interest.

\section{References}

1. John, M.R.S.; Wilson, A.W.; Bhardwaj, A.P.; Abraham, A.; Vinayagam, B.K. An investigation of ball burnishing process on CNC lathe using finite element analysis. Simul. Model. Pract. Theory 2016, 62, 88-101. [CrossRef]

2. Sagbas, A. Analysis and optimization of surface roughness in the ball burnishing process using response surface methodology and desirabilty function. Adv. Eng. Softw. 2011, 42, 992-998. [CrossRef]

3. Revankar, G.D.; Shetty, R.; Rao, S.S.; Gaitonde, V.N. Analysis of surface roughness and hardness in ball burnishing of titanium alloy. Measurement 2014, 58, 256-268. [CrossRef]

4. Hassan, A.M. The effects of ball and roller burnishing on the surface roughness and hardness of some non-ferrous metals. J. Mater. Process Technol. 1997, 72, 385-391. [CrossRef]

5. Kovács, Z.F.; Viharos, Z.J.; Kodácsy, J. Determination of the working gap and optimal machining parameters for magnetic assisted ball burnishing. Measurement 2018, 118, 172-180. [CrossRef]

6. Okada, M.; Shinya, M.; Matsubara, H.; Kozuka, H.; Tachiya, H.; Asakawa, N.; Otsu, M. Development and characterization of diamond tip burnishing with a rotary tool. J. Mater. Process. Technol. 2017, 244, 106-115. [CrossRef]

7. Korzynski, M.; Dzierwa, A.; Pacana, A.; Cwanek, J. Fatigue strength of chromium coated elements and possibility of its improvement with ball peening. Surf. Coat. Tech. 2009, 204, 615-620. [CrossRef]

8. Tian, Y.; Shin, Y.C. Laser-assisted burnishing of metals. Int. J. Mach. Tools Manuf. 2007, 47, 14-22. [CrossRef]

9. Loh, N.H.; Tam, S.C. Effects of ball burnishing parameters on surface finish-A literature survey and discussion. Prec. Eng. 1988, 10, 215-220. [CrossRef]

10. Li, F.L.; Xia, W.; Zhou, Z.Y.; Zhao, J.; Tang, Z.Q. Analytical prediction and experimental verification of surface roughness during the burnishing process. Int. J. Mach. Tools Manuf. 2012, 62, 67-75. [CrossRef]

11. Zaborski, A.; Tubielewicz, K.; Major, B. Contribution of burnishing to the microstructure and texture in surface layers of carbon steel. Arch. Metall. 2000, 45, 333-341.

12. Konefal, K.; Korzynski, M.; Byczkowska, Z.; Korzynska, K. Improved corrosion resistance of stainless steel X6CrNiMoTi17-12-2 by slide diamond burnishing. J. Mater. Process. Technol. 2013, 213, 1997-2004. [CrossRef]

13. Luca, L.; Neagu-Ventzel, S.; Marinescu, I. Effects of working parameters on surface finish in ball-burnishing of hardened steels. Precis. Eng. 2005, 29, 253-256. [CrossRef]

14. Shiou, F.J.; Chen, C.H. Freeform surface finish of plastic injection mold by using ball-burnishing proces. J. Mater. Process. Technol. 2003, 140, 248-254. [CrossRef]

15. El-Axir, M.H. An investigation into roller burnishing. Int. J. Mach. Tools Manuf. 2000, 40, 1603-1617. [CrossRef]

16. Shiou, F.J.; Hsu, C.C. Surface finishing of hardened and tempered stainless tool steel using sequential ball grinding, ball burnishing and ball polishing processes on a machining centre. J. Mater. Process. Technol. 2008, 205, 249-258. [CrossRef]

17. Teimouri, R.; Amini, S.; Bami, A.B. Evaluation of optimized surface properties and residual stress in ultrasonic assisted ball burnishing of AA6061-T6. Measurement 2018, 116, 129-139. [CrossRef]

18. Rodríguez, A.; López de Lacalle, L.N.; Celaya, A.; Lamikiz, A.; Albizuri, J. Surface improvement of shafts by the deep ball-burnishing technique. Surf. Coat. Technol. 2012, 206, 2817-2824. [CrossRef]

19. Shiou, F.J.; Cheng, C.H. Ultra-precision surface finish of NAK80 mould tool steel using sequential ball burnishing and ball polishing processes. J. Mater. Process. Technol. 2008, 201, 554-559. [CrossRef]

20. Travieso-Rodríguez, J.A.; Dessein, G.; González-Rojas, H.A. Improving the surface finish of concave and convex surfaces using a ball burnishing process. Mater. Manuf. Process. 2011, 26, 1494-1502. [CrossRef]

21. Tekkaya, A.E.; Kleiner, M.; Biermann, D.; Hiegemann, L.; Rausch, S.; Franzen, V.; Kwiatkowski, L.; Kersting, P. Friction analysis of thermally sprayed coatings finished by ball burnishing and grinding. Prod. Eng. 2013, 7, 601-610. [CrossRef]

22. El-Tayeb, N.S.M.; Low, K.O.; Brevern, P.V. Enhancement of surface quality and tribological properties using ball burnishing process. Mach. Sci. Technol. 2008, 12, 234-248. [CrossRef]

23. Hassan, A.M.; Al-Dhifi, S.Z.S. Improvement in the wear resistance of brass components by the ball burnishing process. J. Mater. Process. Technol. 1999, 96, 73-80. [CrossRef] 
24. Hamadache, H.; Laouar, L.; Zeghib, N.E.; Chaoui, K. Characteristics of Rb40 steel superficial layer under ball and roller burnishing. J. Mater. Process. Technol. 2006, 180, 130-136. [CrossRef]

25. Revankar, G.D.; Shetty, R.; Rao, S.S.; Gaitonde, V.N. Wear resistance enhancement of titanium alloy (Ti-6Al-4V) by ball burnishing process. J. Mater. Res. Technol. 2017, 6, 13-32. [CrossRef]

26. Montgomery, D.G. Design and Analysis of Experiments, 8th ed.; John Wiley \& Sons: Hoboken, NJ, USA, 2005; ISBN 978-1-118-14692-7.

27. Korzynski, M. Methodology of Experiment; Science Publishing Home: Warszawa, Poland, 2006; ISBN 83-204-3203-0. (In Polish)

28. Fitzpatric, M.E.; Fry, A.T.; Holdway, P.; Kandil, F.A.; Shackleton, J.; Suominen, L.L. Determination of Residual Stresses by X-ray Diffraction-Issue 2. A National Measurement Good Practice Guide No. 52; National Physical Laboratory: Teddington, UK, 2005.

29. ISO 25178-2:2012. Geometrical Product Specifications (GPS)—Surface Texture: Areal_Part 2: Terms, Definitions and Surface Texture Parameters; ISO: Geneva, Switzerland, 2012.

30. Dzierwa, A. Influence of surface preparation on surface topography and tribological behaviours. Arch. Civ. Mech. Eng. 2017, 17, 502-510. [CrossRef]

(c) 2019 by the authors. Licensee MDPI, Basel, Switzerland. This article is an open access article distributed under the terms and conditions of the Creative Commons Attribution (CC BY) license (http:/ / creativecommons.org/licenses/by/4.0/). 



\title{
Article \\ A Comparative Study between Regression and Neural Networks for Modeling Al6082-T6 Alloy Drilling
}

\author{
Nikolaos E. Karkalos ${ }^{1}$, Nikolaos Efkolidis ${ }^{2}$, Panagiotis Kyratsis ${ }^{2, *}$ and \\ Angelos P. Markopoulos ${ }^{1}$ \\ 1 School of Mechanical Engineering, Section of Manufacturing Technology, National Technical University of \\ Athens, Heroon Polytechniou 9, 15780 Athens, Greece; nkark@mail.ntua.gr (N.E.K.); \\ amark@mail.ntua.gr (A.P.M.) \\ 2 Department of Mechanical Engineering \& Industrial Design, Western Macedonia University of Applied \\ Sciences, GR 50100 Kila Kozani, Greece; efknikos@gmail.com \\ * Correspondence: pkyratsis@teiwm.gr; Tel.: +30-24610-68086
}

Received: 31 December 2018; Accepted: 29 January 2019; Published: 2 February 2019

\begin{abstract}
Apart from experimental research, the development of accurate and efficient models is considerably important in the field of manufacturing processes. Initially, regression models were significantly popular for this purpose, but later, the soft computing models were proven as a viable alternative to the established models. However, the effectiveness of soft computing models can be often dependent on the size of the experimental dataset, and it can be lower compared to that of the regression models for a small-sized dataset. In the present study, it is intended to conduct a comparison of the performance of various neural network models, such as the Multi-layer Perceptron (MLP), the Radial Basis Function Neural Network (RBF-NN), and the Adaptive Neuro-Fuzzy Inference System (ANFIS) models with the performance of a multiple regression model. For the development of the models, data from drilling experiments on an Al6082-T6 workpiece for various process conditions are employed, and the performance of models related to thrust force $\left(\mathrm{F}_{\mathrm{Z}}\right)$ and cutting torque $\left(\mathrm{M}_{\mathrm{z}}\right)$ is assessed based on several criteria. From the analysis, it was found that the MLP models were superior to the other neural networks model and the regression model, as they were able to achieve a relatively lower prediction error for both models of $\mathrm{F}_{\mathrm{z}}$ and $\mathrm{M}_{\mathrm{z}}$.
\end{abstract}

Keywords: drilling; Al6082-T6; multiple regression; multi-layer perceptron; radial basis function neural network; adaptive neuro-fuzzy inference system; thrust force; cutting torque

\section{Introduction}

Aluminum is among the most widely-used metallic elements. Due to its beneficial properties such as being lightweight and having high corrosion resistance for a considerable range of factors, it is preferred for the fabrication of various parts in the automotive and aerospace industry. Aluminum is often found in the form of an alloy with various elements such as copper, magnesium, manganese, and silicon, among others, and can be subjected to special treatment such as quenching or precipitation hardening in order to alter its properties, such as strength. Various aluminum alloys exhibit considerably high strength-to-weight ratios, and most of the alloys have excellent machinability.

As aluminum is used for a wide variety of applications, a large amount of experimental work has already been conducted regarding various machining processes. Especially in the case of the drilling process, several parameters regarding the influence of process parameters on the forces, surface quality, or tool wear have been conducted, providing useful details for the appropriate processing of this material. Nouari et al. [1] investigated the effect of drilling process parameters and tool coating on tool wear during dry drilling of AA2024 aluminum alloy. They noted that at a certain cutting speed, a transition in tool wear mechanisms occurs, leading in higher tool wear, and thus, they investigated the 
shift in wear mechanism for various tool coating materials. Their results indicated that, at high cutting speeds, larger deviations from the nominal hole diameters are obtained mainly due to the higher temperature generated on the rake face of the tool, leading to increased tool damage. While abrasion or adhesion wear is observed for lower speeds in the form of built-up edge or built-up layer, the increase of temperature for high cutting speeds resulted in diffusion wear and the increase of the material adhered to the tool. Furthermore, although the uncoated tool produced more accurate hole dimensions at low cutting speeds, this trend was reversed in the case of higher cutting speeds, and the use of the uncoated HSS tool was found to produce the least accurate holes. Girot et al. [2] also conducted experiments regarding tool wear during dry drilling of aluminum alloys. In their work, they aimed at the reduction of the built-up layer in the cutting tool by altering the process parameters and tool coating and geometry. They employed an uncoated carbide drill, a nano-crystalline diamond-coated drill, a nano-crystalline Balinit-coated drill, and a Mo diamond-coated drill and conducted experiments with variable cutting speed. After they established the relationship between the cutting parameters, thrust force, and burr height, they found that diamond coatings were superior due to their low friction coefficient and adequate adhesion of the coating on the tool, and the nano-structured diamond coated tools were the best performing in particular.

Farid et al. [3] conducted a study on chip morphology during high speed drilling of Al-Si alloy. More specifically, they investigated the effect of cutting speed and feed rate on chip morphology by conducting observations at various surfaces of the chip using microscopy techniques. For the drilling experiments, uncoated WC drills were employed to produce $15 \mathrm{~mm}$-diameter holes under various cutting speeds and feed values, in the range of $240-320 \mathrm{~m} / \mathrm{min}$ and $0.16-0.24 \mathrm{~mm} / \mathrm{rev}$, respectively. It was found that, on the free surface of the chip, lamella structures were created and that an increase of speed and feed rate led to a decrease of the frequency of the appearance of these lamella structures. Regarding chip morphology, the increase of cutting speed and feed led to the increase of chip pitch and height and a decrease of the chip compression ratio. Finally, thrust force was found to increase with a decrease of cutting speed and an increase of the feed rate, so it was suggested that high cutting speeds are essential in order to minimize thrust force in the case of Al-Si alloys' drilling.

Qiu et al. [4] investigated the use of high-performance drills during drilling of aluminum and titanium alloys with a view toward minimizing cutting force and torque. For their experiments, they employed two conventional and two modified types of drills, which had larger point, primary relief, and helix angles and a lower second clearance angle. For the aluminum alloy, the cutting speed was varied from $100-200 \mathrm{~m} / \mathrm{min}$ and the feed rate from $0.1-0.2 \mathrm{~mm} / \mathrm{rev}$. The experiments indicated that the tools with the modified geometry were able to reduce thrust force and torque in the majority of cases, with the average reduction of force being $9.78 \%$ and torque $21.08 \%$. Dasch et al. [5] conducted a thorough comparison regarding various categories of coated cutting tools for the drilling process of aluminum. For their study, they used five different types of coating materials, namely carbon, graphitic, hydrogenated and hydrogen-free diamond-like carbon, and diamond on two types of drills, namely HSS and carbide drills. In the tests, they measured tool wear, temperature, and spindle power. After conducting tests on various cases of cutting speed and feed combinations, they concluded that the most important is to coat the flutes of the tool rather than the cutting edge, that coated tools were able to drill up to 100-times more holes than the uncoated, and that hydrogenated carbon coatings are superior to the other types of coating.

Regarding modeling of the drilling process, various studies have been conducted due to its popularity. Kurt, Bagci, and Kaynak [6] determined the optimum cutting parameters for high surface quality and hole accuracy using the Taguchi method. In their work, they conducted experiments at various cutting speeds, feed rates, and depths of drilling and tested the performance of both uncoated and coated HSS drills. After the experiments were conducted by the Taguchi method, regression models for $\mathrm{Ra}$, and hole diameter accuracy were derived, and the optimum parameters were identified by analyzing the S/N ratio results. Kilickap [7] used the Taguchi method and Response Surface Methodology (RSM) to predict burr height during drilling of aluminum alloys and to determine the 
optimum drilling parameters. He conducted experiments using various cutting speeds, feed rates, and point angles and observed the burr height and surface roughness. Analysis using the Taguchi method and Analysis Of Variance (ANOVA) revealed the optimum parameters for reducing the burr height and surface roughness, and regression models created using RSM were proven to be adequate to describe the correlation between process parameters and process outcome. Sreenivasulu and Rao [8], Efkolidis et al [9], and Kyratsis et al [10] also employed the Taguchi method to determine the optimum levels of the process parameters for the minimization of thrust force and torque during drilling of aluminum alloys. After they performed experiments at various cutting speeds, feed rates, and various drill diameters and geometries, they determined the most significant parameters of the process and their optimum values.

Apart from regression models, several studies based on neural network models have been reported in the relevant literature. Singh et al. [11] employed an Artificial Neural Network (ANN) model to predict tool wear during drilling of copper workpieces. As inputs for the neural network, feed rate, spindle speed, and drill diameter were selected, and thrust force, torque, and maximum wear were the outputs. After the optimum number of hidden layers and neurons, as well as the optimum learning rate and momentum coefficient were determined, it was shown that the best neural network predicted tool wear with a maximum error of 7.5\%. Umesh Gowda et al. [12] presented an ANN model for the prediction of circularity, cylindricity, and surface roughness when drilling aluminum-based composites. After the experiments, tool wear, surface roughness, circularity, and cylindricity were obtained as a function of machining time, and $\mathrm{NN}$ models were used to correlate process parameters with these quantities.

Besides the usual MLP models, other similar approaches such as RBF-NN or hybrid approaches combining MLP with fuzzy logic or genetic algorithms have also been presented. Neto et al. [13] also presented MLP and ANFIS models for the prediction of hole diameter during drilling of various alloys. For the neural network models, inputs from various sensors such as acoustic emission, electric power, force, and vibration were employed. Thorough analysis of the predicted results' errors revealed that MLP models had superior performance to ANFIS models. Ferreiro et al. [14] conducted a comprehensive study in developing an AI-based burr detection system for the drilling process of Al7075-T6. For that reason, they employed data-mining techniques and tested various approaches with a view toward reducing the classification errors. All developed models performed better than the existing mathematical model for burr prediction, and in particular, it was shown that a model based on the naive Bayes method exhibited the maximum accuracy.

Lo [15] employed an ANFIS model for the prediction of surface roughness in end milling. In their models, they employed both a triangular and trapezoidal membership function with 48 sets of data for training and 24 for testing. The error was found to be minimum using the triangular membership function. Zuperl et al. [16] used an ANFIS model for the estimation of flank wear during milling. The model was trained with 140 sets of data (75 for training and 65 for testing) and included 32 fuzzy rules. It was shown that a model with a triangular membership function was again capable of exhibiting the lowest error. Song and Baseri [17] applied the ANFIS model for the selection of drilling parameters in order to reduce burr size and improve surface quality. In this work, a different model was built for each of the four outputs, namely burr height, thickness, type, and hole overcut. One hundred and fifty datasets were used, 92 for the training, 25 for checking, and 25 for testing of the model. For the first output, the best model had four membership functions of a triangular type; for the second one, the best model had a three-membership function of a Gaussian type; and the last two three- and four-membership functions of a generalized bell type, respectively. Fang et al. [18] used an RBF model for surface roughness during machining of aluminum alloys. Their model included eight inputs, related to process parameters, cutting forces, and vibration components, and five outputs, related to surface roughness. The RBF model was proven to be faster than an MLP model, but it was inferior in terms of accuracy. Elmounayri et al. [19] employed an RBF model for the prediction of cutting forces during ball-end milling. The model had four inputs, related to the process parameters 
and four outputs, namely the maximum, minimum, mean, and standard deviation of instantaneous cutting force. In this case, it was noted that the RBF network was more efficient and accurate and faster than the classical MLP.

Although comparisons between regression models and neural network model for cases of machining processes have already been conducted, comparison between several soft computing methods has rarely been conducted, and only a few relevant studies exist. Tsai and Wang [20] conducted a thorough comparison between various neural network models such as different variants of MLP, RBF-NN, and ANFIS for the cases of electrical discharge machining. They concluded that the best performing method was ANFIS, as it exhibited the best accuracy among the tested methods. Nalbant et al. [21] conducted a comparison between regression and artificial neural network models for $\mathrm{CNC}$ turning cases and concluded that although the neural network model was performing slightly better, both models were appropriate for modeling the experimental results. Jurkovic et al. [22] compared support vector regression, polynomial regression, and artificial neural networks in the case of high-speed turning. Their models included feed, cutting speed, and depth of cut as inputs, and separate models were created for three output quantities, namely cutting forces, surface roughness, and cutting tool life. In the cases of cutting force and surface roughness, they found that the polynomial regression model was the best, whereas in the case of cutting tool life, ANN performed better than the other methods.

In the present study, a comparison of various neural network models, as well as multiple regression models is conducted with a view toward determining the best performing model for the case of drilling Al6082-T6. As in this case, a relatively small dataset is used, it is expected that the results of regression models and neural network models will be comparable, and so, it is interesting to find out whether there can be a clear difference in the performance of these methods in the present case. The various neural network models are trained with different parameters, and the comparison between them is conducted by criteria relevant to the prediction error, both for training and testing datasets.

\section{Artificial Neural Networks}

Artificial neural networks are among the most important soft computing methods, widely used for a great range of applications spanning across various scientific fields. This method is able to successfully predict the outcome of a process by using pairs of input and output data in a learning procedure. In fact, this method imitates the function of biological neurons, which receive inputs, process them, and generate a suitable output. The most common ANN model, namely MLP, has a structure containing various interconnected layers of neurons, starting from an input layer and ending at an output layer. The middle layers are called hidden layers, and their number is variable, depending on the size and the characteristics of each problem. Each neuron is connected by artificial synapses to the neurons of the following layer, and a weighting coefficient, or weight, is assigned to each synapse. The inputs for each neuron are multiplied by the weighting coefficient of the respective synapse, and then, they are summed; after that, the output from each neuron is generated by using an activation function, which usually is a sigmoid function, such as the hyperbolic tangent.

The ANN model is created by a learning process, containing three different stages, i.e., training, validation, and testing. For each stage, a part of the total input/output data is reserved, most commonly $70 \%, 15 \%$, and $15 \%$, respectively. The learning process consists of the determination of suitable weight values according to real input/output data pairs and is an iterative process. This process is called error backpropagation, as the difference of the predicted and actual output is first computed in the output layer, and then, the error is propagated through the network in the opposite way, from the output to the input layer; after various iterations, or epochs, the network weights are properly adjusted so that the error is minimized. The training and validation stage both involve adjustment of the weights, and it is possible to stop the learning process if the error is not decreasing after some epochs, a technique that is named the early stopping technique. Finally, during the testing stage, the trained model is checked 
for its generalization capabilities by providing it with unknown data from the testing data sample. Usually, the Mean Squared Error (MSE) is used for the determination of model performance:

$$
M S E=\frac{1}{n} \sum_{i=1}^{n}\left(Y_{i}-A_{i}\right)^{2}
$$

where $n$ is the number of data samples, $Y_{i}$ are the predicted values and $A_{i}$ the actual values.

Furthermore, the Mean Absolute Percentage Error (MAPE) can be also employed to evaluate the results of neural network models:

$$
M A P E=\frac{100 \%}{n} \sum_{i=1}^{n}\left|\frac{Y_{i}-A_{i}}{A_{i}}\right|
$$

Finally, RBF-NN is constructed by using an appropriate radial function as the activation function for a neural network model with a single layer. Most commonly, a Gaussian-type function is used as the activation function:

$$
\varphi(r)=e^{-\varepsilon r^{2}}
$$

where $\varepsilon$ is a small number and $\mathrm{r}=\left\|x-x_{i}\right\|$, with $\mathrm{x}$ being an input and $\mathrm{x}_{\mathrm{i}}$ the center of the radial basis function. Apart from the widely-used MLP model and RBF-NN models, various other types of neural networks exist, as well as hybrid models, combining ANN with other soft computing methods such as fuzzy logic. In addition to the learning and optimization ability of the neural networks, fuzzy logic systems are able to provide a means for reasoning to the system with the use of IF-THEN rules. ANFIS is a soft computing method with characteristics related both to neural networks and fuzzy logic. Generally, the creation of an ANFIS model has several similarities to the creation of a MLP model, but there exist also some basic differences. This model has a structure similar to the MLP structure, but there are some additional layers, related to membership functions of the Fuzzy Inference System (FIS). One of the most common fuzzy models used in ANFIS models is the Sugeno fuzzy model. By the training process, fuzzy rules are formed, and an FIS is created. At first, the input data are converted into fuzzy sets through a fuzzification layer, and then, membership functions are generated. Membership functions can have various shapes such as triangular, trapezoid, or Gaussian, among others. In the second layer, the number of nodes is equal to the number of fuzzy rules of the system; the determination of the number of fuzzy rules is conducted using a suitable method such as the subtractive clustering method. The output of the second layer nodes is the product of the input signals, which they receive from the previous nodes. Then, in the third layer, the ratio of each rule's firing strength to the sum of the firing strengths of all rules is calculated, and it is used in the defuzzification layer to determine the output values from each node. Finally, the total output is calculated by summation of the outputs of the fourth layer. The FIS parameters are updated by means of a learning algorithm in order to reduce the prediction error, such as in the case of MLP model.

\section{Methods and Materials}

\subsection{Technics of Experiments}

In the present work, it is intended to conduct a comparison of various methods, which can be employed for modeling of the drilling process of Al6082-T6. The datasets for the models were obtained by conducting experiments on an Al6082-T6 workpiece. This work material used for the present investigation was a $140 \mathrm{~mm} \times 100 \mathrm{~mm} \times 30 \mathrm{~mm}$ plate with the chemical composition and main mechanical properties as summarized in Table 1. 
Table 1. Chemical composition and mechanical properties of Al6082.

\begin{tabular}{|c|c|c|c|c|c|c|}
\hline \multicolumn{7}{|c|}{ Chemical Composition } \\
\hline Elements & $\mathrm{Mg}$ & $\mathrm{Cu}$ & $\mathrm{Fe}$ & $\mathrm{Mn}$ & Others & $\mathrm{Al}$ \\
\hline Percentage & 0.8 & 0.25 & 0.5 & 0.9 & 0.3 & Balance \\
\hline \multicolumn{7}{|c|}{ Mechanical Properties } \\
\hline Alloy & Temper & $\begin{array}{c}\text { Thermal } \\
\text { Conductivity }\end{array}$ & $\begin{array}{l}\text { Coefficient of Thermal } \\
\text { Expansion }\end{array}$ & $\begin{array}{l}\text { Melting } \\
\text { Point }\end{array}$ & $\begin{array}{l}\text { Elastic } \\
\text { Modulus }\end{array}$ & $\begin{array}{c}\text { Electrical } \\
\text { Resistivity }\end{array}$ \\
\hline & & $\mathrm{W} / \mathrm{m} \cdot \mathrm{K}$ & $\mathrm{K}^{-1}$ & $\begin{array}{l}\text { Min } \\
\operatorname{Max}\end{array}$ & GPa & $\Omega \cdot m$ \\
\hline Al6082 & $\mathrm{T} 6$ & 180 & $24 \times 10^{-6}$ & $\begin{array}{l}555 \\
650\end{array}$ & 70 & $0.038 \times 10^{-6}$ \\
\hline
\end{tabular}

Drilling experiments were carried out on a HAAS VF1 CNC machining center using solid carbide drill tools. Two components of drilling loads (thrust force $F_{z}$ and torque $M_{z}$ values) were recorded with a Kistler dynamometer Type 9123 connected to a three-channel charge amplifier with a data acquisition system. Dynoware software (Type 2825D-02) was used in order to monitor and record the experimental values of the cutting forces, as shown in Figure 1.

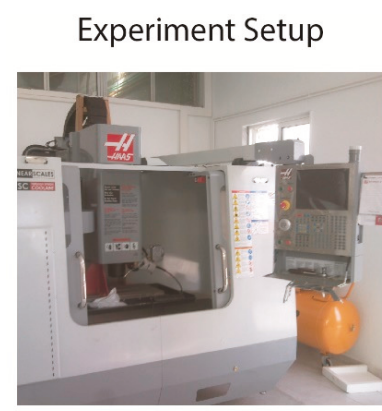

HAAS VF1 CNC

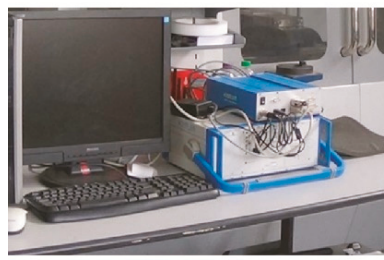

Amplifier

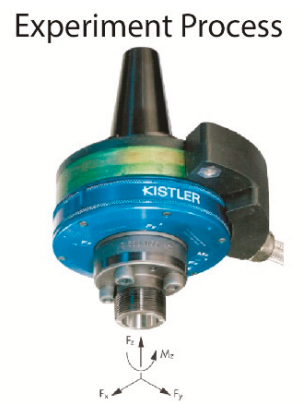

Kistler 9123 Dynamometer

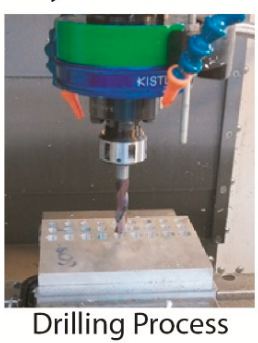

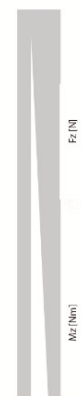
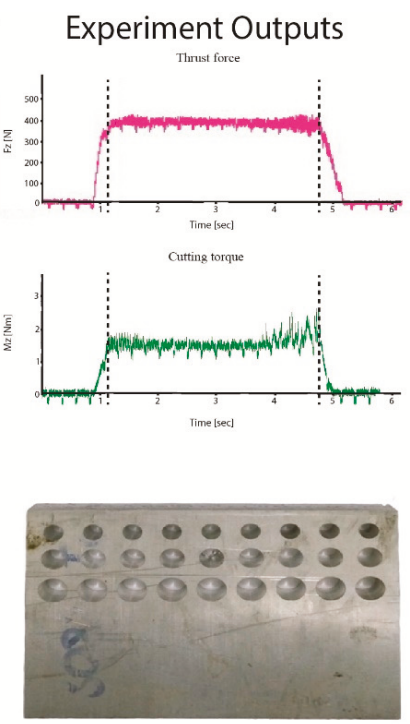

Al 6082

Figure 1. The workflow used for the research.

\subsection{Methodology of Results Analysis}

The experiments were conducted according to a full factorial strategy. The three cutting parameters selected for the present investigation were the cutting speed (V), the feed rate (f), and the cutting tool diameter (D). Cutting velocity values of $50 \mathrm{~m} / \mathrm{min}, 100 \mathrm{~m} / \mathrm{min}$, and $150 \mathrm{~m} / \mathrm{min}$ together with feed rates of $0.15 \mathrm{~mm} / \mathrm{rev}, 0.2 \mathrm{~mm} / \mathrm{rev}$, and $0.25 \mathrm{~mm} / \mathrm{rev}$ were used in combination with three cutting tool diameters (D) of $8 \mathrm{~mm}, 10 \mathrm{~mm}$, and $12 \mathrm{~mm}$. The constant depth of the holes drilled was $30 \mathrm{~mm}$. The machining parameters used and their levels are shown in Table 2. 
Table 2. Machining factors and their levels.

\begin{tabular}{ccccc}
\hline Factors & Notation & \multicolumn{3}{c}{ Levels } \\
\hline & & I & II & III \\
Cutting speed $(\mathrm{m} / \mathrm{min})$ & $\mathrm{V}$ & 50 & 100 & 150 \\
Feed rate $(\mathrm{mm} / \mathrm{rev})$ & $\mathrm{f}$ & 0.15 & 0.2 & 0.25 \\
Tool diameters $(\mathrm{mm})$ & $\mathrm{D}$ & 8 & 10 & 12 \\
\hline
\end{tabular}

During the experimental process, 27 different solid carbide drilling tools (one tool for each hole) were clamped to a Weldon clamping device with a high rigidity, while a mechanical vise was used for clamping the workpiece. As the type of cutting tools (KENNAMETAL B041A/KC7325) is non-through coolant solid carbide, the cutting fluid used (KOOLRite 2270) was provided by the delivery system near them. Figure 2 demonstrates all the dimensional details of the main shape of the cutting tools. All the possible combinations of the manufacturing parameters were used (cutting speed, feed rate, tool diameter).

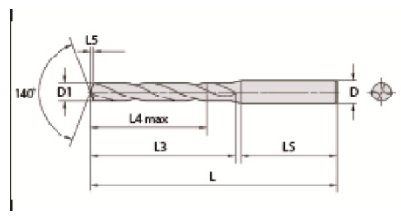

\begin{tabular}{|cccccc|}
$\begin{array}{c}\text { Catalogue } \\
\text { number }\end{array}$ & Grade & $\begin{array}{c}\text { (L4) max drill } \\
\text { depth [mm] }\end{array}$ & $\begin{array}{c}\text { (L3) flute } \\
\text { length [mm] }\end{array}$ & $\begin{array}{c}\text { (LS) flute } \\
\text { length [mm] }\end{array}$ & $\begin{array}{c}\text { (D) shank } \\
\text { diameter [mm] }\end{array}$ \\
\hline B041A08000CPG & KC7325 & 29 & 41 & 36 & 8 \\
B041A10000CPG & KC7325 & 35 & 47 & 40 & 10 \\
B041A10000CPG & KC7325 & 40 & 55 & 45 & 12
\end{tabular}

Figure 2. Cutting tool geometry details.

As shown in Figure 3, apart from multiple regression method, three soft computing methods, related to artificial neural networks, namely MLP, RBF-NN, and ANFIS methods, were used.

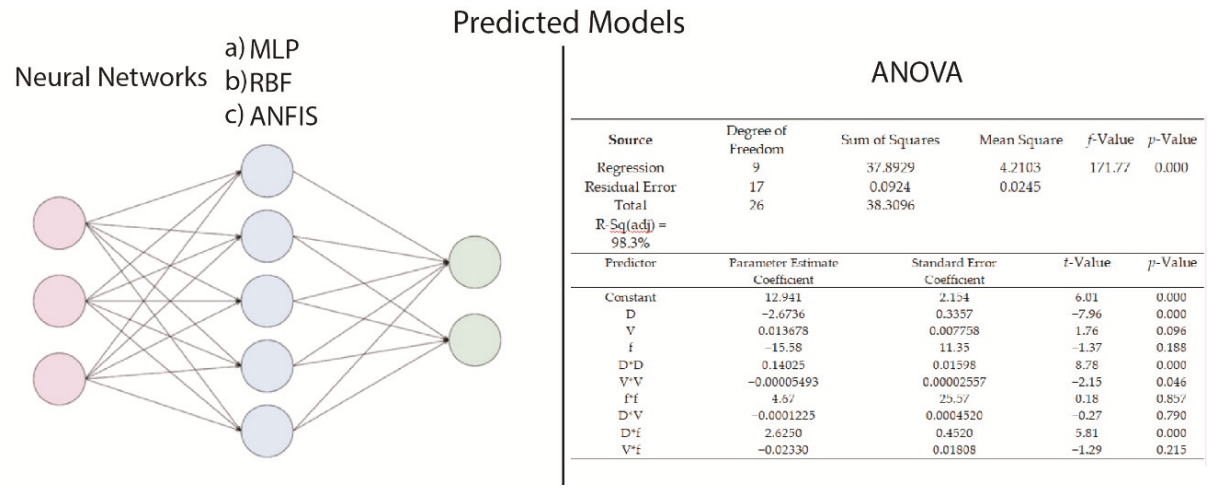

Figure 3. Development of the predicted models.

For the development of the model, MATLAB ${ }^{\mathrm{TM}}$ software was employed. For each method, only one characteristic, mainly related to the architecture of the network, was varied, and the other settings were assumed to be equal to the default settings of the software. For the MLP and RBF-NN, the number of hidden neurons was varied, and for the ANFIS, where the number of inner nodes cannot be altered in the same way as in the other two types of networks, the number of clusters used for the data, using the fuzzy c-means clustering method, which directly affects the number of parameters of the system, was varied. In all cases, the lower and upper boundaries for the variable parameters were chosen in a way that it did not lead to extreme overfitting; the analysis conducted was able to determine exactly the limit values of the variable parameters, which can lead to a properly-functioning model. 
The choice of the number of hidden neurons is crucial in the case of MLP and RBF-NN, as it can increase the accuracy of the network up to a point, and then, it causes problems of overfitting. In the relevant literature, no certain methodology for the determination of the exact number of hidden neurons exists; there are several empirical rules, which usually relate the appropriate number of hidden neurons with the number of input and output variables. However, the number of available pairs of input/output data also affects the choice of the number of hidden neurons, as it is not appropriate to use more network parameters, e.g., weights and biases, than the number of available input/output data pairs. This is especially important for the present study, as the size of dataset was relatively small, namely 27 input/output data pairs. For the determination of the lower and upper value of the number of hidden neurons, in order not to conduct an exhaustive search, the recommendations from some empirical relationships were taken into consideration. In [23], it was proposed that the number of hidden neurons could be approximated as follows:

$$
n=\sqrt{N_{\text {inp }}+N_{\text {out }}}+a
$$

where $\mathrm{N}_{\text {inp }}$ is the number of input neurons, $\mathrm{N}_{\text {out }}$ the number of output neurons, and $\alpha$ is a number between zero and 10. In the present case, $\mathrm{N}_{\text {inp }}$ equals to three, i.e., drill diameter, cutting speed, and feed, and $\mathrm{N}_{\text {out }}$ is one, i.e., thrust force or cutting torque. Thus, according to this formula, the lower and upper boundaries for the number of hidden neurons in the present study was between two and 12. However, in the present study, an investigation of the optimum value of hidden neurons was conducted by taking into consideration the performance of the models regarding not only MSE, but also MAPE, both for the training and testing dataset, as it is required to achieve a low value of error for the training data, but also to prevent the network from overfitting, something that is indicated by the error in the testing dataset. For the MLP and RBF-NN, the number of hidden neurons is varied between one and eight, a choice that is comparable to the suggestions offered by Equation (4). Each network was trained 50 times with the same settings in order to overcome the effect of the random initialization of weights. For the ANFIS models, the parameter that was varied was the number of clusters, in the range of 2-4. As with the other two types of networks, the training was repeated 50 times, and the results regarding MSE and MAPE for training and testing data are presented.

For all models, the data pairs reserved for the testing stage of the network assessment were selected randomly, but were the same in order to conduct a more appropriate comparison between these models. Models were developed separately for thrust force $\mathrm{F}_{\mathrm{z}}$ and torque $\mathrm{M}_{\mathrm{z}}$. In Figure 4, a flowchart presenting graphically the procedure followed in the present study is depicted.

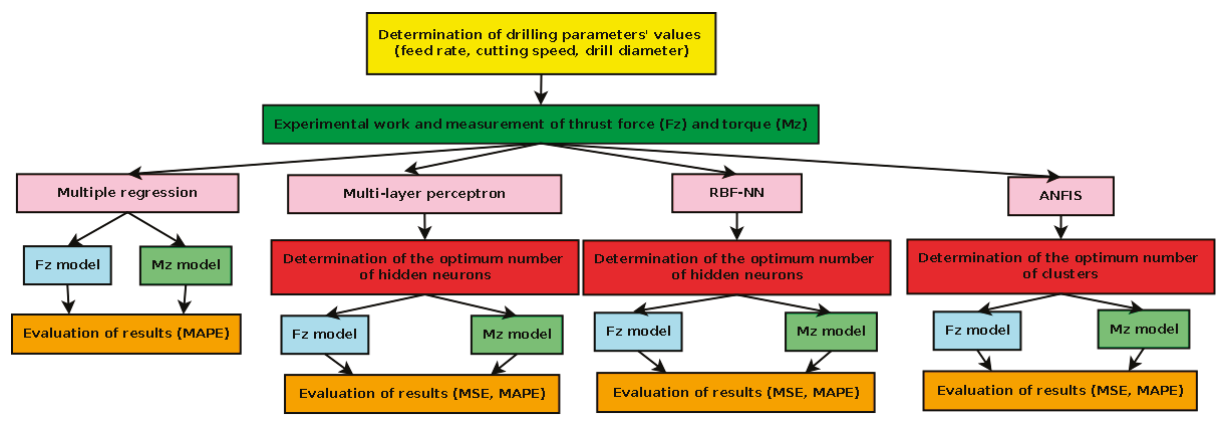

Figure 4. Flowchart of the procedure followed in the present research. 


\section{Results and Discussion}

\subsection{Result of Experiment}

Figure 5 shows the experimental values derived from the whole process. It is clear that there was a relationship between cutting parameters and cutting forces. When the tool diameter increased, both cutting forces increased. As the feed rate values increased, the cutting forces increased respectively. The cutting speed did not noticeably affect either cutting force. A full factorial strategy was applied, and twenty seven (27) drilling experiments were performed, while both $\mathrm{F}_{\mathrm{Z}}$ and $\mathrm{M}_{\mathrm{Z}}$ were modelled separately using polynomial mathematical models.
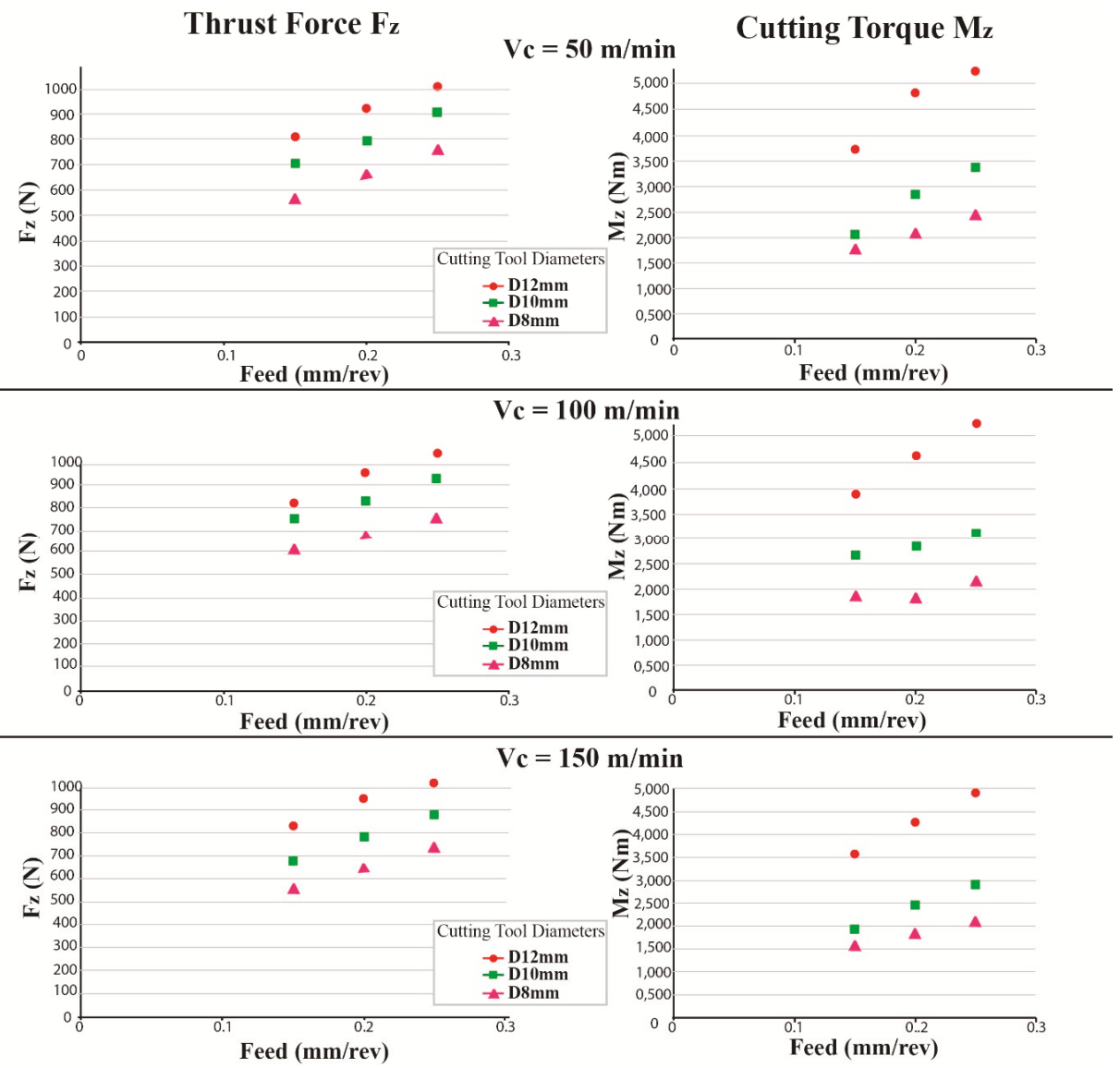

Figure 5. Experimental values derived from Kistler 9123.

\subsection{Multiple Regression Models}

The RSM is a tool based on the collection of statistical and mathematical techniques used for process optimization. Optimization can be managed by creating an empirical relationship between independent variables and the response of the system using the quantitative data collected from experiment $[5,6]$. The experiments were designed and executed by employing second-order nonlinear mathematical models in order to predict the thrust force and the cutting torque, which are of the following form: 


$$
Y=b_{0}+b_{1} X_{1}+b_{2} X_{2}+b_{3} X_{3}+b_{4} X_{1}^{2}+b_{5} X_{2}^{2}+b_{6} X_{3}^{2}+b_{7} X_{1} X_{2}+b_{8} X_{1} X_{3}+b_{9} X_{2} X_{3}
$$

where $Y$ is the response, $X_{i}$ stands for the coded values, and bi stand for the models' regression coefficients.

When the level of significance is very small, less than 0.05 , this indicates that the results were high and probably not randomly scattered. The significant terms were found by Analysis Of Variance (ANOVA) for each response (Tables 3 and 4).

Table 3. ANOVA table for $\mathrm{F}_{\mathrm{Z}}$ (thrust force).

\begin{tabular}{|c|c|c|c|c|c|}
\hline Source & Degree of Freedom & Sum of Squares & Mean Square & $f$-Value & $p$-Value \\
\hline Regression & 9 & 514.673 & 57.186 & 471.95 & 0.000 \\
\hline Residual Error & 17 & 2060 & 121 & & \\
\hline Total & 26 & 516.733 & & & \\
\hline \multicolumn{6}{|l|}{ R-Sq(adj) = 99.4\% } \\
\hline Predictor & $\begin{array}{c}\text { Parameter Estimate } \\
\text { Coefficient }\end{array}$ & \multicolumn{2}{|c|}{ Standard Error Coefficient } & $t$-Value & $p$-Value \\
\hline Constant & -221.9 & \multicolumn{2}{|c|}{151.4} & -1.47 & 0.161 \\
\hline $\mathrm{D}$ & 57.59 & \multicolumn{2}{|c|}{23.60} & 2.44 & 0.026 \\
\hline $\mathrm{V}$ & 1.9550 & \multicolumn{2}{|c|}{0.5455} & 3.58 & 0.002 \\
\hline $\mathrm{f}$ & 1291.8 & \multicolumn{2}{|c|}{798.0} & 1.62 & 0.124 \\
\hline$D^{*} \mathrm{D}$ & -0.762 & \multicolumn{2}{|c|}{1.123} & -0.68 & 0.506 \\
\hline $\mathrm{V}^{*} \mathrm{~V}$ & -0.011660 & \multicolumn{2}{|c|}{0.001798} & -6.49 & 0.000 \\
\hline$f^{*} f$ & -667 & \multicolumn{2}{|c|}{1798} & -0.37 & 0.715 \\
\hline $\mathrm{D}^{*} \mathrm{~V}$ & 0.05600 & \multicolumn{2}{|c|}{0.03178} & 1.76 & 0.096 \\
\hline$D^{*} f$ & 103.25 & \multicolumn{2}{|c|}{31.78} & 3.25 & 0.005 \\
\hline$V^{*} f$ & -1.203 & \multicolumn{2}{|c|}{1.271} & -0.95 & 0.357 \\
\hline
\end{tabular}

Table 4. ANOVA table for $\mathrm{M}_{\mathrm{z}}$ (torque).

\begin{tabular}{|c|c|c|c|c|c|}
\hline Source & Degree of Freedom & Sum of Squares & Mean Square & $f$-Value & $p$-Value \\
\hline Regression & 9 & 37.8929 & 4.2103 & 171.77 & 0.000 \\
\hline Residual Error & 17 & 0.0924 & 0.0245 & & \\
\hline Total & 26 & 38.3096 & & & \\
\hline \multicolumn{6}{|l|}{$\mathrm{R}-\mathrm{Sq}(\operatorname{adj})=98.3 \%$} \\
\hline Predictor & $\begin{array}{c}\text { Parameter Estimate } \\
\text { Coefficient }\end{array}$ & \multicolumn{2}{|c|}{ Standard Error Coefficient } & $t$-Value & $p$-Value \\
\hline Constant & 12.941 & \multicolumn{2}{|c|}{2.154} & 6.01 & 0.000 \\
\hline $\mathrm{D}$ & -2.6736 & \multicolumn{2}{|c|}{0.3357} & -7.96 & 0.000 \\
\hline $\mathrm{V}$ & 0.013678 & \multicolumn{2}{|c|}{0.007758} & 1.76 & 0.096 \\
\hline $\mathrm{f}$ & -15.58 & \multicolumn{2}{|c|}{11.35} & -1.37 & 0.188 \\
\hline$D^{*} \mathrm{D}$ & 0.14025 & \multicolumn{2}{|c|}{0.01598} & 8.78 & 0.000 \\
\hline $\mathrm{V}^{*} \mathrm{~V}$ & -0.00005493 & \multicolumn{2}{|c|}{0.00002557} & -2.15 & 0.046 \\
\hline$f^{*} f$ & 4.67 & \multicolumn{2}{|c|}{25.57} & 0.18 & 0.857 \\
\hline$D^{*} \mathrm{~V}$ & -0.0001225 & \multicolumn{2}{|c|}{0.0004520} & -0.27 & 0.790 \\
\hline$D^{*} f$ & 2.6250 & \multicolumn{2}{|c|}{0.4520} & 5.81 & 0.000 \\
\hline$V^{*} f$ & -0.02330 & \multicolumn{2}{|c|}{0.01808} & -1.29 & 0.215 \\
\hline
\end{tabular}

The following regression equations for the thrust force and the cutting torque as a function of three input process variables were developed:

$$
\begin{aligned}
& F_{z}=-222+57.6 D+1.96 V+1292 f-0.76 D * D-0.0117 V * V-667 f * f \\
& +0.0560 D * V+103 D * f-1.20 V * f
\end{aligned}
$$


and:

$$
\begin{aligned}
& M_{z}=12.9-2.67 D+0.0137 V-15.6 f+0.140 D * D-0.000055 V * V+4.7 f * f \\
& \quad-0.000122 D * V+2.63 D * f-0.0233 V * f
\end{aligned}
$$

where $\mathrm{D}$ is the tool diameter $(\mathrm{mm}), \mathrm{f}$ is the feed rate $(\mathrm{mm} / \mathrm{rev})$, and $\mathrm{V}$ is the cutting speed $(\mathrm{m} / \mathrm{min})$.

The $p$-values are used as a basic tool to check the importance of each of the coefficients. The smaller the amount of $\mathrm{P}$, the more significant is the corresponding coefficient. In our case, for $\mathrm{F}_{\mathrm{Z}}$, these factors are: $\mathrm{D}(p$-value $=0.026), \mathrm{V}(p$-value $=0.002), \mathrm{V}^{*} \mathrm{~V}(p$-value $=0.000)$, and $\mathrm{D}^{*} \mathrm{f}(p$-value $=0.005)$, while for $\mathrm{M}_{\mathrm{z}}$, the significant terms are: $\mathrm{D}(p$-value $=0.000), \mathrm{D}^{*} \mathrm{D}(p$-value $=0.000), \mathrm{V}^{*} \mathrm{~V}(p$-value $=0.046)$, and $\mathrm{D}^{*} \mathrm{f}$ $(p$-value $=0.000)$. Moreover, from Tables 3 and 4 , it is evaluated that the coefficient of multiple determination was very close to unity for both cases $\left(R^{2}=99.6 \%\right.$ for $F_{z}$ and $R^{2}=98.9 \%$ for $\left.M_{z}\right)$, and the adjusted coefficient ( $\mathrm{R}^{2}$ adj) was $99.4 \%$ for $\mathrm{F}_{\mathrm{z}}$ and $98.3 \%$ for $\mathrm{M}_{\mathrm{z}}$. All these statistical estimators indicate an appropriate RSM model with the degree of freedom and optimal architecture that can be used for predictive simulations of the reactive extraction. Of course, for both cases, only the significant terms can be included in order to present a set of simplified equations. The agreement between experimental and RSM predicted data is shown in Figure 6. Residual analysis was performed to test the models' accuracy; in both cases, all points were positioned near to a straight line, indicating that RSM predicts the experimental data for the considered valid region well.

\section{Residuals Plots for $\mathrm{Fz}$}

\section{Residuals Plots for $\mathrm{Mz}$}

Normal Probability Plot of the Residuals
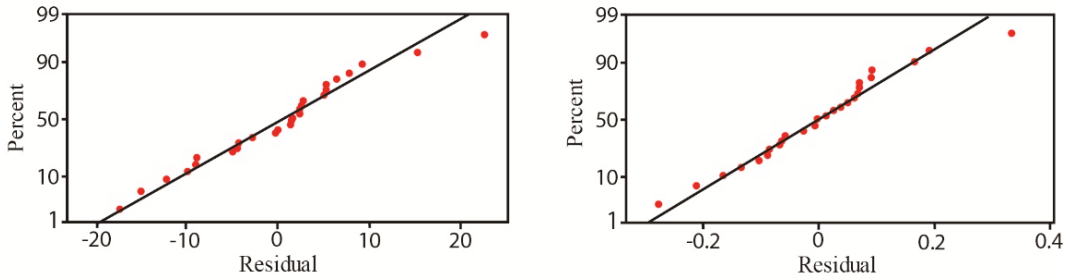

Figure 6. Residuals analyses for $F_{z}$ and $M_{z}$.

\subsection{Multi-Layer Perceptron Models}

As was described in the Methods and Materials section, in the case of MLP models, an investigation of the optimum number of hidden neurons was conducted based on various criteria. After the MLP models were developed, the results obtained were as presented in Table 5.

Table 5. Results regarding the MLP models for thrust force $\left(\mathrm{F}_{\mathrm{Z}}\right)$.

\begin{tabular}{ccccc}
\hline No. of Hidden Neurons & MSEtrain & MSEtest & MAPEtrain (\%) & MAPEtest (\%) \\
\hline 1 & $2.35 \times 10^{-4}$ & $6.36 \times 10^{-4}$ & $1.46 \times 10^{0}$ & $2.93 \times 10^{0}$ \\
2 & $8.42 \times 10^{-5}$ & $1.05 \times 10^{-4}$ & $9.84 \times 10^{-1}$ & $1.14 \times 10^{0}$ \\
3 & $2.72 \times 10^{-7}$ & $1.53 \times 10^{-4}$ & $5.32 \times 10^{-2}$ & $1.36 \times 10^{0}$ \\
4 & $2.20 \times 10^{-6}$ & $6.10 \times 10^{-5}$ & $1.36 \times 10^{-1}$ & $8.23 \times 10^{-1}$ \\
5 & $1.78 \times 10^{-15}$ & $1.31 \times 10^{-4}$ & $2.50 \times 10^{-6}$ & $9.45 \times 10^{-1}$ \\
6 & $3.40 \times 10^{-22}$ & $4.42 \times 10^{-4}$ & $2.04 \times 10^{-9}$ & $2.22 \times 10^{0}$ \\
7 & $4.98 \times 10^{-24}$ & $2.59 \times 10^{-4}$ & $2.12 \times 10^{-10}$ & $2.02 \times 10^{0}$ \\
8 & $5.03 \times 10^{-23}$ & $2.60 \times 10^{-4}$ & $6.41 \times 10^{-10}$ & $2.06 \times 10^{0}$ \\
\hline
\end{tabular}

As can be seen from Table 5 and Figure 7, in the case of the thrust force model, the MSE for the training dataset was generally decreasing with an increase of the number of hidden neurons. Especially, for models with over five neurons, the MSE became extremely small, indicating that the 
training dataset can be reproduced with a high level of accuracy by this model. However, the MSE for the testing dataset, which is an indication of overfitting, became the minimum for the model with four hidden neurons and then increased again. A similar situation was observed in the case of MAPE, where MAPE for the training dataset became extremely small for networks with more than four hidden neurons, but the minimum MAPE for the testing dataset was obtained for the model with five hidden neurons. Thus, the optimum number of hidden neurons was four or five, and the final choice was conducted in terms of total error, as the error values for these cases were very close. Finally, the case with four neurons was chosen as the total error was very close to the total error of the case with five neurons, and this network was less complex than the other.

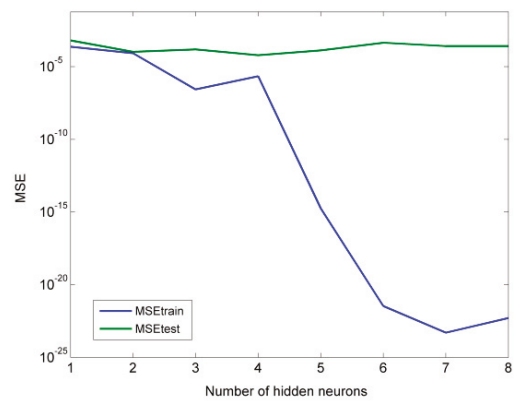

(a)

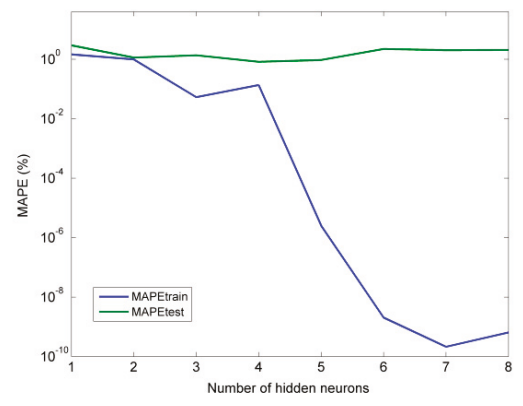

(b)

Figure 7. Results regarding the MLP model for $\mathrm{F}_{\mathrm{z}}$ : (a) MSE for training and testing datasets, (b) MAPE for training and testing datasets.

As can be seen from Table 6 and Figure 8, in the case of the torque model, the MSE for training was decreasing with an increasing number of hidden neurons, mainly for models with more than six hidden neurons. However, the minimum value of MSE for the testing dataset was obtained for the model with four hidden neurons. Regarding MAPE, the minimum value for the training dataset was obtained for the model with seven hidden neurons, whereas the minimum value for the testing dataset was obtained for the model with six hidden neurons. Thus, the best model was determined again by checking the total error, and it was determined that the network with six hidden neurons was the best performing one. Generally, it was observed that the error values for the $\mathrm{M}_{\mathrm{z}}$ model were considerably larger than those of the $\mathrm{F}_{\mathrm{Z}}$ model. Nevertheless, the results confirmed that the optimum number of neurons was dependent on the size of the dataset; as for the relatively small dataset of 27 samples, a model with six hidden neurons was sufficient.

Table 6. Results regarding the MLP models for torque $\left(\mathrm{M}_{\mathrm{Z}}\right)$.

\begin{tabular}{ccccc}
\hline No. of Hidden Neurons & MSEtrain & MSEtest & MAPEtrain (\%) & MAPEtest (\%) \\
\hline 1 & $7.39 \times 10^{-4}$ & $1.57 \times 10^{-3}$ & $4.75 \times 10^{0}$ & $6.86 \times 10^{0}$ \\
2 & $4.11 \times 10^{-4}$ & $1.08 \times 10^{-3}$ & $3.53 \times 10^{0}$ & $3.48 \times 10^{0}$ \\
3 & $1.14 \times 10^{-4}$ & $9.34 \times 10^{-4}$ & $1.65 \times 10^{0}$ & $4.15 \times 10^{0}$ \\
4 & $6.65 \times 10^{-6}$ & $6.66 \times 10^{-4}$ & $3.32 \times 10^{-1}$ & $3.20 \times 10^{0}$ \\
5 & $5.36 \times 10^{-6}$ & $1.14 \times 10^{-3}$ & $3.59 \times 10^{-1}$ & $4.10 \times 10^{0}$ \\
6 & $5.53 \times 10^{-7}$ & $1.86 \times 10^{-4}$ & $1.30 \times 10^{-1}$ & $2.19 \times 10^{0}$ \\
7 & $6.60 \times 10^{-23}$ & $7.81 \times 10^{-4}$ & $6.79 \times 10^{-10}$ & $4.36 \times 10^{0}$ \\
8 & $8.68 \times 10^{-23}$ & $1.45 \times 10^{-3}$ & $1.36 \times 10^{-9}$ & $6.01 \times 10^{0}$ \\
\hline
\end{tabular}




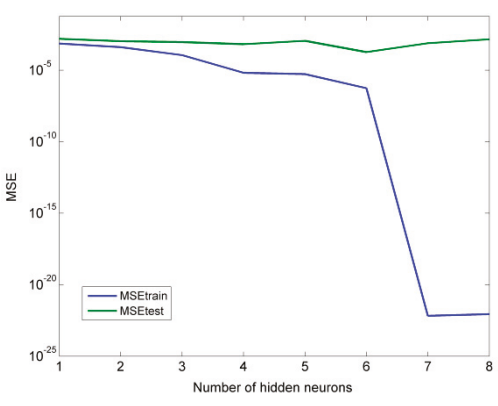

(a)

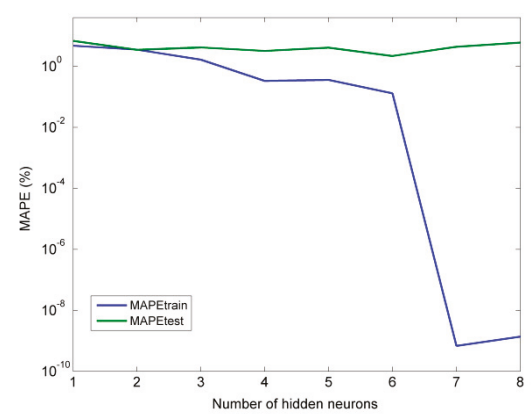

(b)

Figure 8. Results regarding the MLP model for $\mathrm{M}_{\mathrm{z}}$ : (a) MSE for the training and testing datasets and (b) MAPE for the training and testing datasets.

\subsection{Radial Basis Function Neural Network Models}

As was previously mentioned, in the case of RBF-NN models, it is intended to determine the optimum number of hidden neurons. In Table 3, the results from the RBF-NN models are presented.

For the RBF-NN models in the case of thrust force, it can be observed from Table 7 and Figure 9 that MSE for the training set was decreasing with an increasing number of hidden neurons, but there was not such a large decrease as in the case of MLP models. For the testing dataset, MSE was the minimum for the model with seven hidden neurons, and the same was noted for MAPE for the training dataset. Thus, the model with seven hidden neurons was the optimum in this case. It is to be noted that the value of MAPE for both the training and testing dataset was considerably reduced for models with over three neurons, something that was not observed to a similar extent in the case of MLP models, at least for the testing dataset.

Table 7. Results regarding the RBF-NN models for thrust force $\left(\mathrm{F}_{\mathrm{Z}}\right)$.

\begin{tabular}{ccccc}
\hline No. of Hidden Neurons & MSEtrain & MSEtest & MAPEtrain (\%) & MAPEtest (\%) \\
\hline 1 & $9.92 \times 10^{-3}$ & $2.01 \times 10^{-2}$ & $1.08 \times 10^{-1}$ & $1.94 \times 10^{1}$ \\
2 & $1.20 \times 10^{-3}$ & $6.62 \times 10^{-4}$ & $4.09 \times 10^{0}$ & $2.70 \times 10^{0}$ \\
3 & $1.59 \times 10^{-4}$ & $2.78 \times 10^{-4}$ & $1.34 \times 10^{0}$ & $1.98 \times 10^{0}$ \\
4 & $1.30 \times 10^{-4}$ & $1.39 \times 10^{-4}$ & $1.21 \times 10^{0}$ & $1.51 \times 10^{0}$ \\
5 & $9.99 \times 10^{-5}$ & $1.60 \times 10^{-4}$ & $1.12 \times 10^{0}$ & $1.52 \times 10^{0}$ \\
6 & $9.07 \times 10^{-5}$ & $1.65 \times 10^{-4}$ & $1.02 \times 10^{0}$ & $1.45 \times 10^{0}$ \\
7 & $8.19 \times 10^{-5}$ & $1.14 \times 10^{-4}$ & $9.42 \times 10^{-1}$ & $1.13 \times 10^{0}$ \\
8 & $7.67 \times 10^{-5}$ & $1.32 \times 10^{-4}$ & $9.29 \times 10^{-1}$ & $1.35 \times 10^{0}$ \\
\hline
\end{tabular}

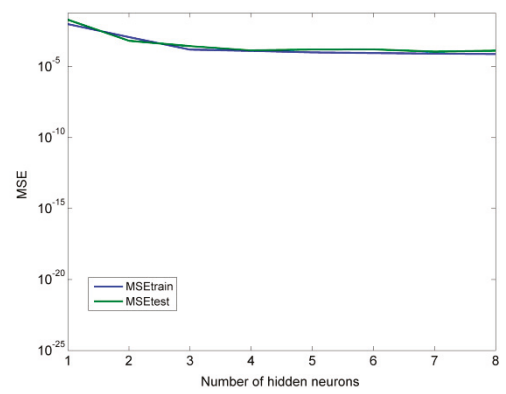

(a)

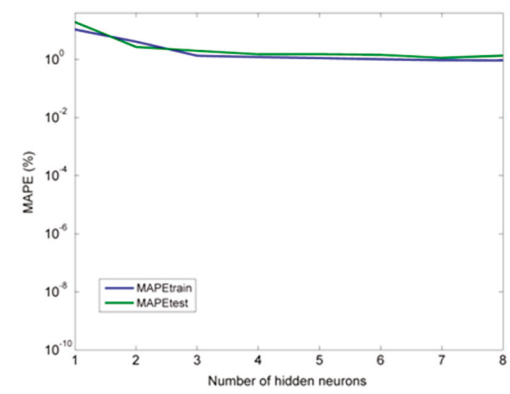

(b)

Figure 9. Results regarding the RBF-NN model for $\mathrm{F}_{\mathrm{Z}}$ : (a) MSE for training and testing datasets and (b) MAPE for training and testing datasets. 
As for the torque $\left(\mathrm{M}_{\mathrm{z}}\right)$ cases, it was observed from Table 8 and Figure 10 that the optimum model was the one with eight hidden neurons, as it exhibited both a lower MSE and MAPE for the testing dataset. Thus, it can be stated that for RBF-NN models, a slightly larger number of hidden neurons was required compared to MLP models.

Table 8. Results regarding the RBF-NN models for torque $\left(\mathrm{M}_{\mathrm{z}}\right)$.

\begin{tabular}{ccccc}
\hline No of Hidden Neurons & MSEtrain & MSEtest & MAPEtrain (\%) & MAPEtest (\%) \\
\hline 1 & $3.31 \times 10^{-2}$ & $5.94 \times 10^{-2}$ & $3.03 \times 10^{1}$ & $3.60 \times 10^{1}$ \\
2 & $5.60 \times 10^{-3}$ & $1.26 \times 10^{-2}$ & $1.37 \times 10^{1}$ & $2.13 \times 10^{1}$ \\
3 & $4.20 \times 10^{-3}$ & $1.05 \times 10^{-2}$ & $1.14 \times 10^{1}$ & $1.98 \times 10^{1}$ \\
4 & $2.74 \times 10^{-3}$ & $1.05 \times 10^{-2}$ & $9.51 \times 10^{0}$ & $2.04 \times 10^{1}$ \\
5 & $2.65 \times 10^{-3}$ & $1.23 \times 10^{-2}$ & $9.52 \times 10^{0}$ & $2.38 \times 10^{1}$ \\
6 & $2.37 \times 10^{-3}$ & $7.83 \times 10^{-3}$ & $9.20 \times 10^{0}$ & $1.83 \times 10^{1}$ \\
7 & $6.49 \times 10^{-4}$ & $1.24 \times 10^{-3}$ & $4.63 \times 10^{0}$ & $6.27 \times 10^{0}$ \\
8 & $4.82 \times 10^{-4}$ & $8.73 \times 10^{-4}$ & $3.75 \times 10^{0}$ & $5.81 \times 10^{0}$ \\
\hline
\end{tabular}

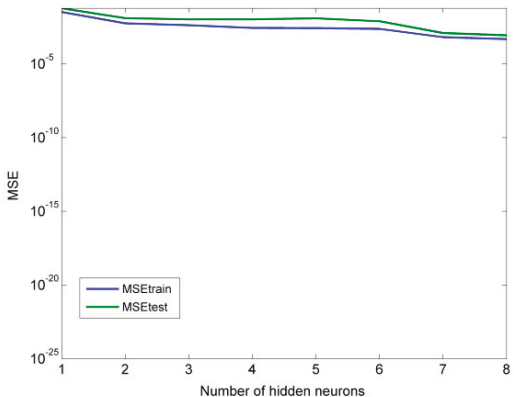

(a)

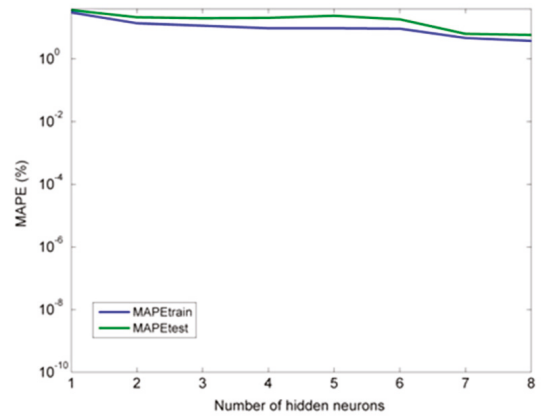

(b)

Figure 10. Results regarding the RBF model for $\mathrm{M}_{\mathrm{z}}$ : (a) MSE for training and testing datasets and (b) MAPE for training and testing datasets.

\subsection{Adaptive Neuro-Fuzzy Inference System Models}

In the case of ANFIS models, results from cases with a different number of clusters are presented in Table 9.

Table 9. Results regarding the ANFIS models for thrust force $\left(\mathrm{F}_{\mathrm{Z}}\right)$.

\begin{tabular}{ccccc}
\hline No of Clusters & MSEtrain & MSEtest & MAPEtrain (\%) & MAPEtest (\%) \\
\hline 2 & $4.94 \times 10^{-5}$ & $3.68 \times 10^{-4}$ & $8.03 \times 10^{-1}$ & $2.49 \times 10^{0}$ \\
3 & $1.37 \times 10^{-5}$ & $4.47 \times 10^{-4}$ & $3.60 \times 10^{-1}$ & $2.74 \times 10^{0}$ \\
4 & $2.80 \times 10^{-6}$ & $1.20 \times 10^{-4}$ & $1.40 \times 10^{-1}$ & $1.07 \times 10^{0}$ \\
\hline
\end{tabular}

In the case of the ANFIS models for thrust force, it can be seen from Table 9 and Figure 11 that the MSE for both training and testing datasets was reduced with an increasing number of clusters. Furthermore, the same can be observed for the MAPE for both datasets; thus, the ANFIS model with four clusters was selected as the best performing network. In the case of torque models, whose results are presented in Table 10 and Figure 12, the optimum value of MSE for the testing dataset was obtained for the model with two clusters, whereas the optimum value of MAPE for the testing dataset was obtained for the model with four clusters. Therefore, the best model was selected according to the total error values, which were lower for the model with four clusters. 
Table 10. Results regarding the ANFIS models for torque $\left(\mathrm{M}_{\mathrm{z}}\right)$.

\begin{tabular}{ccccc}
\hline No of Clusters & MSEtrain & MSEtest & MAPEtrain (\%) & MAPEtest (\%) \\
\hline 2 & $5.39 \times 10^{-4}$ & $1.49 \times 10^{-3}$ & $3.66 \times 10^{0}$ & $8.38 \times 10^{0}$ \\
3 & $2.75 \times 10^{-5}$ & $2.52 \times 10^{-3}$ & $8.22 \times 10^{-1}$ & $1.03 \times 10^{1}$ \\
4 & $5.90 \times 10^{-6}$ & $2.63 \times 10^{-3}$ & $3.16 \times 10^{-1}$ & $7.78 \times 10^{0}$ \\
\hline
\end{tabular}

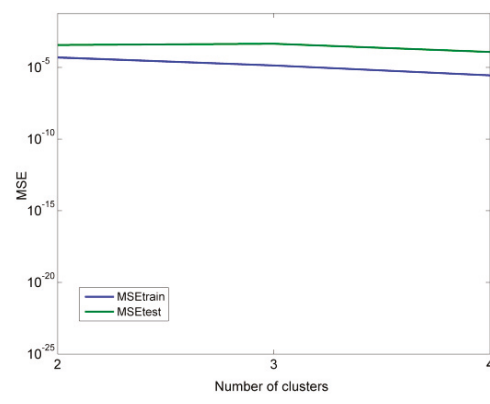

(a)

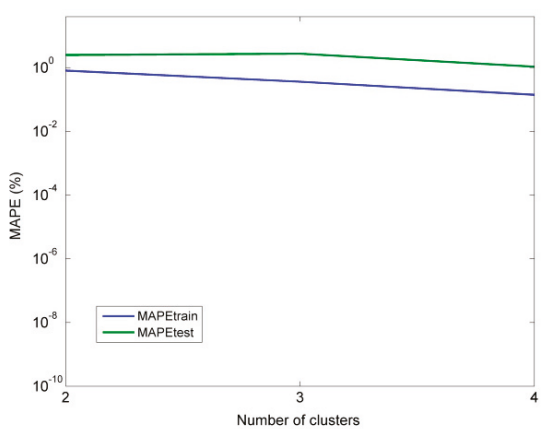

(b)

Figure 11. Results regarding the ANFIS model for $\mathrm{F}_{\mathrm{Z}}$ : (a) MSE for training and testing datasets and (b) MAPE for training and testing datasets.

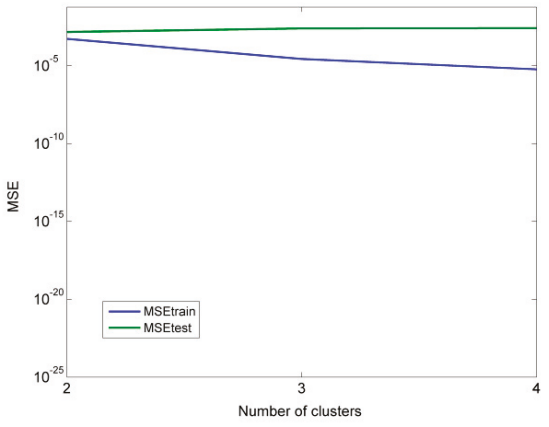

(a)

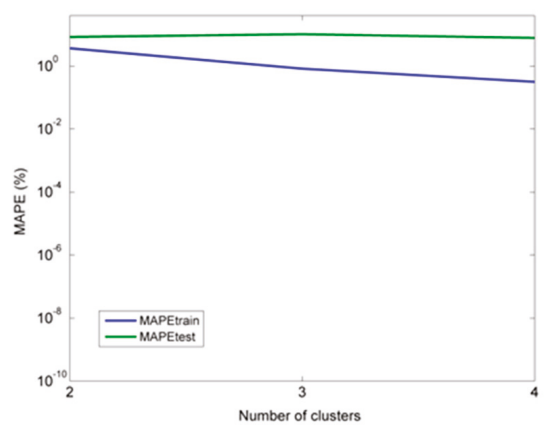

(b)

Figure 12. Results regarding the ANFIS model for $\mathrm{M}_{\mathrm{z}}$ : (a) MSE for training and testing datasets and (b) MAPE for training and testing datasets.

\subsection{Comparison of Regression and Neural Network Models}

The thrust force and cutting torque predictive models were developed by RSM and ANN by implementing a full factorial experimentation design depending on the effects of the selected cutting parameters such as cutting speed, feed rate, and tool diameter. Figures 13 and 14 illustrate the comparison between the experimental values of $F_{z}$ and $M_{z}$ and their values of the ANN and RSM models, respectively.

After the results regarding all developed models were presented, a comparison between these models was conducted. For the comparison, the best model from each method was selected, and its performance was evaluated using the same criteria, as can be seen in Table 11. As for the regression model, the MSE was not calculated, and also, no separate dataset for training and testing exists, so the total MAPE for each case was chosen as the criterion for the comparison between all models. 
Thrust Force

Experimental values $\square$ RA values NN MLP values $\square$ NN RBF values $\square$ NNANFIS values

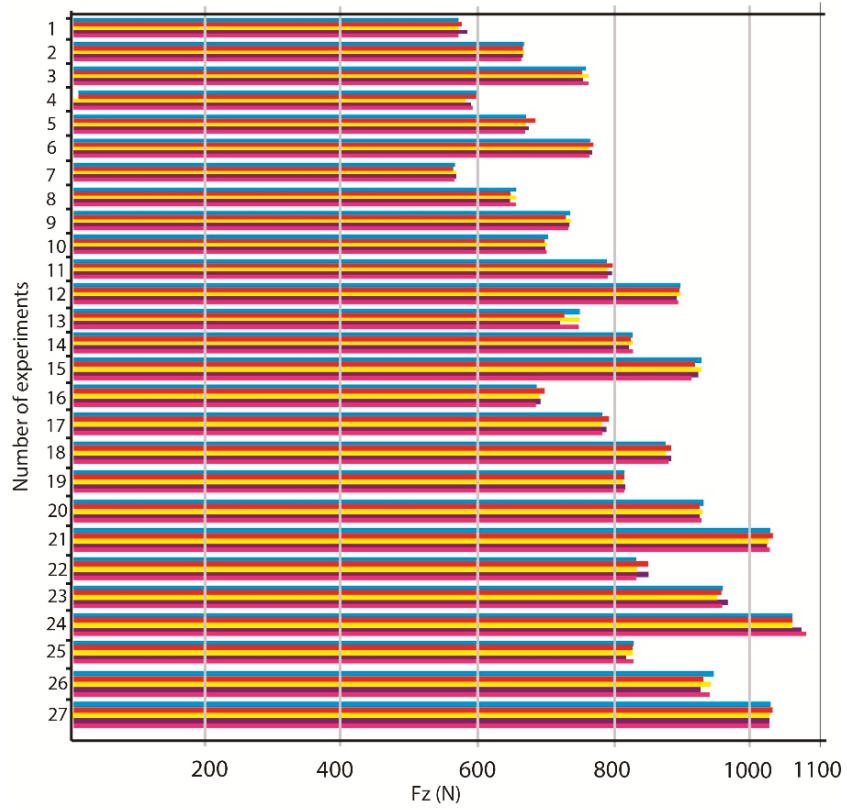

Figure 13. Comparison of the experimental values with the predicted values for $F_{z}$.

Cutting Torque

Experimental values $\square$ RA values NN MLP valucs $\square$ NN RBF valucs $\square$ NN ANFIS valucs

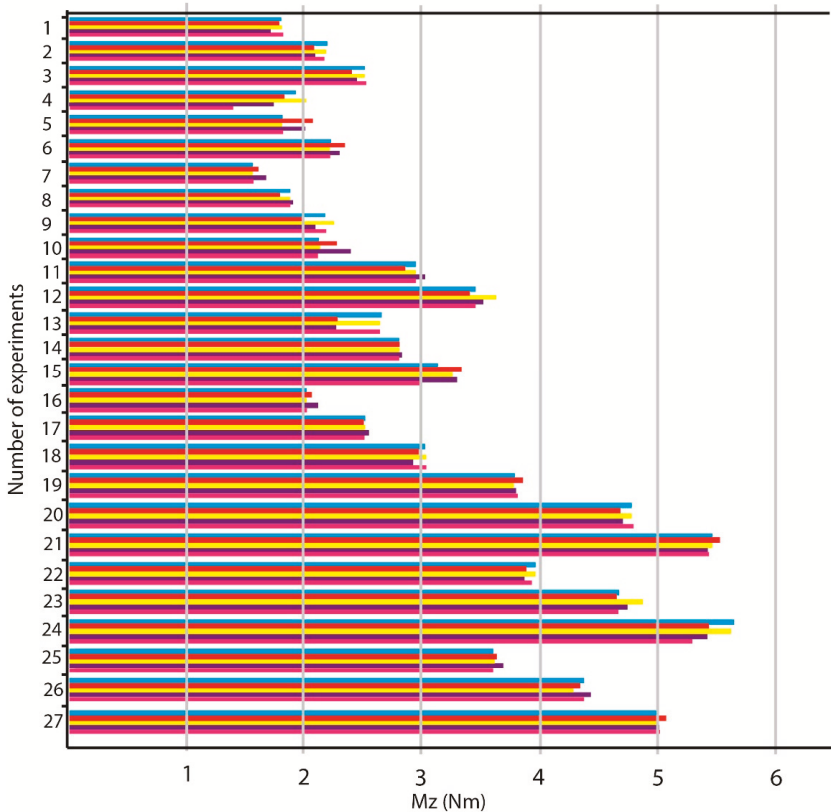

Figure 14. Comparison of the experimental values with the predicted values for $\mathrm{M}_{\mathrm{z}}$. 
Table 11. Comparison of error values for all models.

\begin{tabular}{ccc}
\hline Type of model & MAPEtotal $\left(\mathbf{F}_{\mathbf{z}}\right)$ & MAPEtotal $\left(\mathbf{M}_{\mathbf{z}}\right)$ \\
\hline Multiple Regression & $0.86305 \%$ & $3.0495 \%$ \\
MLP & $0.2979 \%$ & $0.9667 \%$ \\
RBF-NN & $0.978 \%$ & $4.129 \%$ \\
ANFIS & $0.312 \%$ & $1.698 \%$ \\
\hline
\end{tabular}

Among the three neural network models, it can be seen that the MLP model had the lowest MAPE values in all cases, followed by the ANFIS model and the RBF model. The MLP and ANFIS models were clearly superior to the RBF model and also better than the regression model. Thus, it can be concluded that the MLP model was more appropriate for the modeling of thrust force and torque in the presented case. Finally, given the relatively small size of the neural networks model, there was no significant difference in terms of computational time between these approaches and the regression model, and so, it was shown that these models can perform efficiently for the presented case.

\section{Conclusions}

In the present paper, various methods for the modeling of the drilling process, such as regression and neural network models, were compared in order to determine which is the most accurate and efficient one. These models were applied to cases of drilling Al 6082-T6 alloy under various process conditions. From this study, several conclusions can be drawn.

From the statistical analysis and derivation of the multiple regression models, it can be deduced that the developed models are sufficiently accurate, as they exhibited high correlation coefficient values, namely $99.6 \%$ and $98.9 \%$ for the $\mathrm{F}_{\mathrm{z}}$ and $\mathrm{M}_{\mathrm{z}}$ models, respectively, and also low MAPE values, namely $0.86305 \%$ and $3.0495 \%$ for the $\mathrm{F}_{\mathrm{z}}$ and $\mathrm{M}_{\mathrm{z}}$ models, respectively.

As for the neural network models, it was determined that an MLP model with 4 hidden neurons was more suitable for the prediction of thrust force, and an MLP model with six hidden neurons was more appropriate for the prediction of cutting torque. Furthermore, for the RBF-NN model, a higher number of hidden neurons was shown to lead to better accuracy, namely seven and eight in the cases of thrust force and torque, respectively. Finally, for the ANFIS models with fuzzy c-means clustering, the use of four clusters was the best choice in both the $\mathrm{F}_{\mathrm{z}}$ and $\mathrm{M}_{\mathrm{Z}}$ cases.

From the comparison of all models, it was concluded that the MLP model performed better in all cases, followed by ANFIS, multiple regression, and RBF-NN. Thus, it was shown that MLP can be competitive with multiple regression models even for relatively small datasets and that ANFIS and RBF-NN are less suitable for cases with small datasets.

Author Contributions: Conceptualization, N.E.K., N.E., P.K., and A.P.M.; methodology, N.E.K., N.E., P.K., and A.P.M.; software, N.E.K. and N.E.; validation, N.E. and P.K.; formal analysis, N.E.K. and N.E.; investigation, N.E.K., N.E., P.K., and A.P.M.; resources, P.K. and A.P.M.; writing, original draft preparation, N.E.K. and N.E.; writing, review and editing, P.K. and A.P.M.; supervision, P.K. and A.P.M.

Funding: This research received no external funding.

Conflicts of Interest: The authors declare no conflict of interest.

\section{References}

1. Nouari, M.; List, G.; Girot, F.; Gehin, D. Effect of machining parameters and coating on wear mechanisms in dry drilling of aluminum alloys. Int. J. Mach. Tools Manuf. 2005, 45, 1436-1442. [CrossRef]

2. Girot, F.; Gutierre-Orrantia, M.E.; Calamaz, M.; Coupard, D. Modeling and adhesion tool wear in dry drilling of aluminum alloys. AIP Conf. Proc. 2011, 1315, 1639-1644.

3. Farid, A.A.; Sharif, S.; Idris, M.H. Chip morphology study in high speed drilling of Al-Si alloy. Int. J. Adv. Manuf. Technol. 2011, 57, 555-564. [CrossRef] 
4. Qiu, K.; Qin, S.; Ge, C.; Chen, M. A study of high-performance drills in the drilling of aluminum alloy and titanium alloy. Key Eng. Mater. 2014, 589-590, 163-167. [CrossRef]

5. Dasch, J.M.; Ang, C.C.; Wong, C.A.; Cheng, Y.T.; Weiner, A.M.; Lev, L.C.; Konca, E. A comparison of five categories of carbon-based tool coatings for dry drilling of aluminum. Surf. Coat. Technol. 2006, 200, 2970-2977. [CrossRef]

6. Kurt, M.; Kaynak, Y.; Bagci, E. Evaluation of drilled hole quality in Al2024 alloy. Int. J. Adv. Manuf. Technol. 2008, 37, 1051-1060. [CrossRef]

7. Kilickap, E. Modeling and optimization of burr height in drilling of Al-7075 using Taguchi method and response surface methodology. Int. J. Adv. Manuf. Technol. 2010, 49, 911-923. [CrossRef]

8. Sreenivasulu, R.; Rao, C.S. Effect of drilling parameters on thrust force and torque during drilling of aluminum 6061 alloy-based on Taguchi design of experiments. J. Mech. Eng. 2016, 46, 41-48. [CrossRef]

9. Efkolidis, N.; Garcia-Hernandez, C.; Huertas-Talon, J.L.; Kyratsis, P. Modelling and prediction of thrust force and torque in drilling operations of Al7075 using ANN and RSM Methodologies. Strojinski Vestn. J. Mech. Eng. 2018, 64, 351-361.

10. Kyratsis, P.; Markopoulos, A.; Efkolidis, N.; Maliagkas, V.; Kakoulis, K. Prediction of thrust force and cutting torque in drilling based on the response surface methodology. Machines 2018, 6, 24. [CrossRef]

11. Singh, A.K.; Panda, S.S.; Pal, S.K.; Chakraborty, D. Predicting drill wear using an artificial neural network. Int. J. Adv. Manuf. Technol. 2006, 28, 456-462. [CrossRef]

12. Umesh Gowda, B.M.; Ravindra, H.V.; Ullas, M.; Naveen Prakash, G.V.; Ugrasen, G. Estimation of circularity, cylindricity and surface roughness in drilling Al-Si3N4 metal matrix composites using artificial neural network. Procedia Mater. Sci. 2014, 6, 1780-1787. [CrossRef]

13. Neto, F.C.; Geronimo, T.M.; Cruz, C.E.D.; Aguiar, P.R.; Bianchi, E.E.C. Neural models for predicting hole diameters in drilling processes. Procedia CIRP 2013, 12, 49-54. [CrossRef]

14. Ferreiro, S.; Sierra, B.; Irigoien, I.; Gorritxategi, E. Data mining for quality control: Burr detection in the drilling process. Comput. Ind. Eng. 2011, 60, 801-810. [CrossRef]

15. Lo, S.P. An adaptive-network based fuzzy inference system for prediction of workpiece surface roughness in end milling. J. Mater. Process. Technol. 2003, 142, 665-675. [CrossRef]

16. Zuperl, U.; Cus, F.; Kiker, E. Adaptive network based inference system for estimation of flank wear in end-milling. J. Mater. Process. Technol. 2009, 209, 1504-1511.

17. Azarrang, S.; Baseri, H. Selection of dry drilling parameters for minimal burr size and desired drilling quality. Proc. Inst. Mech. Eng. E 2017, 231, 480-489. [CrossRef]

18. Fang, N.; Srinivasa Pai, P.; Edwards, N. Neural network modeling and prediction of surface roughness in machining aluminum alloys. J. Comput. Commun. 2016, 4, 66460. [CrossRef]

19. El-Mounayri, H.; Briceno, J.F.; Gadallah, M. A new artificial neural network approach to modeling ball-end milling. Int. J. Adv. Manuf. Technol. 2010, 47, 527-534. [CrossRef]

20. Tsai, K.M.; Wang, P.J. Comparisons of neural network models on material removal rate in electrical discharge machining. J. Mater. Process. Technol. 2001, 117, 111-124. [CrossRef]

21. Nalbant, M.; Gokkaya, H.; Toktas, I. Comparison of regression and artificial neural network models for surface roughness prediction with the cutting parameters in CNC turning. Model. Simul. Eng. 2007, 2007, 92717. [CrossRef]

22. Jurkovic, Z.; Cukor, G.; Brezocnik, M.; Brajkovic, T. A comparison of machine learning methods for cutting parameters prediction in high speed turning process. J. Intell. Manuf. 2018, 29, 1683-1693. [CrossRef]

23. Zhang, Z.H.; Yan, D.N.; Ju, J.T.; Han, Y. Prediction of the flow stress of a high alloyed austenitic stainless steel using artificial neural network. Mater. Sci. Forum 2012, 724, 351-354. [CrossRef]

(C) 2019 by the authors. Licensee MDPI, Basel, Switzerland. This article is an open access article distributed under the terms and conditions of the Creative Commons Attribution (CC BY) license (http:/ / creativecommons.org/licenses/by/4.0/). 


\title{
Article \\ Optimization of Friction Behavior Characteristics by Coating with Solid Lubricants
}

\author{
Oana Dodun, Gheorghe Nagîț, Adelina Hriţuc * and Laurenţiu Slătineanu \\ Department of Machine Manufacturing Technology, "Gheorghe Asachi” Technical University of Iași, \\ Blvd. D. Mangeron, 59 A, 700050 Iași, Romania; oanad@tcm.tuiasi.ro (O.D.); nagit@tcm.tuiasi.ro (G.N.); \\ slati@tcm.tuiasi.ro (L.S.) \\ * Correspondence: hrituc.adelina3295@yahoo.com; Tel: +40-751-640-117
}

Received: 30 December 2018; Accepted: 7 February 2019; Published: 9 March 2019

\begin{abstract}
Increasing the lifetime of machine elements whose operation involves the development of friction processes and diminishing energy losses by friction can be achieved by using solid lubricants. In this regard, a method applied to improve the friction behavior of machine elements is electrostatic coating of the surfaces of interest with polyester layers that include particles of solid lubricants, such as molybdenum disulfide or graphite. Experimental research was conducted to highlight the influence of normal force, the concentration of solid lubricant particles in polyester, and specific sliding between surfaces involved in the friction process on the deposited layer's lifetime and on the friction coefficient. Grey analysis was employed to identify sets of input factors that would lead to the most convenient values of the lifetime and energy friction losses when using polyester layers that incorporate molybdenum or graphite particles. Specialized software was elaborated in a MATLAB environment to use the grey relational analysis in identifying the optimal values of the process input factors for distinct weights of the output parameters.
\end{abstract}

Keywords: friction behavior; polyester coating; solid lubricants particles; molybdenum disulfide; graphite; disk to disk test; Grey analysis

\section{Introduction}

Friction is a physical phenomenon that appears when there is relative motion between solid surfaces, fluid layers, and material elements sliding against each other. Essentially friction can be observed and studied using the friction force.

Information concerning friction is important due to the influence exerted by the friction on energy consumption and on the wear of the bodies found in contact.

There are distinct criteria to classify the friction and many factors are able to affect the size specific to the friction phenomenon. Thus, kinetic friction appears when there is a linear relative motion between two solid bodies. Among the factors able to affect the friction processes, we should consider the materials of the bodies found in contact, the surface roughness of the contact surfaces, the normal force exerted between the bodies found in contact, the presence and the nature of the fluid found in the zone between bodies, the temperature of the bodies and of the fluid, etc.

Sliding friction is specific to the operation of distinct machine elements. For example, sliding friction appears in sliding bearings, in gear teeth, in sliding couples. etc. There are certain situations when the friction phenomenon is useful, but more frequently, friction intensifies the machine elements' wear and consumes additional energy to achieve the relative motion between the machine elements.

As above mentioned, machine manufacturers are interested in diminishing the friction processes' intensity, to decrease the energy consumption and the wear of the machine elements between which relative motions develop [1-3]. Various solutions can be applied to decrease the friction process intensity. We can diminish the height of the asperities corresponding to the bodies' surfaces found in 
contact, introduce substances able to facilitate the sliding between the bodies' surfaces, or use bodies made of or covered with substances able to diminish the friction forces. A good way to diminish the consequences of the friction processes can be offered by the use of the contactless mechanical components [3], but for now, this solution may be difficult to apply in various situations.

Covering the bodies surfaces involved in intense friction processes with substances that reduce friction forces can be sometimes preferred. For example, the use of the molybdenum disulfide to diminish the friction forces between the punching tools and the workpiece in the process of manufacturing parts by material forming is known. In such a case, the oils containing particles of molybdenum disulfide can be used to cover the surfaces of the punching tools on which intense friction develops. In other situations, the oils including graphite particles can also be used to diminish the intensity of friction.

Currently applied distinct coating alternatives are characterized by various properties, advantages, and disadvantages.

Thus, the magnetron sputtering technology is based on physical vapor deposition, when the material to be deposited is ejected from a target onto a substrate, as a consequence of ion or atom bombardment $[4,5]$. The magnetron sputtering technology is able to ensure antireflection properties in glass, to facilitate the deposition of very thin layers on transistors or to achieve multilayer deposition with good adhesion to the substrate, to deposit materials with very high melting points, etc. As limitations of the magnetron sputtering technology, we can consider the more difficult control of the deposit layer growth, the risk of contaminating zones where the deposition is not wanted, the high price of the sputtering equipment, etc. Martins et al. used a direct current magnetron sputtering to obtain a low friction composite coating that included molybdenum disulfide and titanium [5]. A complex technology was designed and applied to ensure the deposition of a $\mathrm{MoS}_{2} / \mathrm{Ti}$ layer on the gears' teeth surfaces. Experimental research was developed to test the gear efficiency and gear anti-scuffing performance when the work surfaces of teeth were covered with $\mathrm{MoS}_{2} / \mathrm{Ti}$. The paper's authors observed a decrease in the operating temperature, the friction coefficient value, and of the gears' teeth wear intensity.

The introduction of solid lubricant particles to industrial oil diminishes the friction process by up to 25 to $50 \%$. The nanoparticles can penetrate into very narrow spaces between parts found in relative motion, and sometimes they can be used inclusively in dry friction conditions [6-10]. An essential advantage of using solid lubricant particles is the fact that they do not need specialized equipment to be applied. As for disadvantages, there are situations when the use of the industrial oils is not allowed, when a certain polluting effect is signalized, or when the solid lubricant particles are expensive, etc. Lee et al. investigated the tribological characteristics of the graphite nano lubricants obtained by including graphite nanoparticles in industrial gear oil. They noticed that the nano lubricants ensured a lower friction coefficient and diminished wear of the specimens when using a disk-on-disk tribotester [9]. In 2011, Hwang et al. published the results of research concerning the influence exerted by the size and morphology of particles included in mineral oil on the friction coefficient value when also using a disk-on-disk tribotest [10]. They concluded that when spherical nanoparticles additives are found in the mineral oil, diminished value of the friction coefficient could be observed, compared with the situation when carbon black, graphite nanofibers, and nanotubes are dispersed in the mineral oil. Huang et al. appreciated that the explanation could be based on the possible role of ball bearings filled with the spherical nanoparticles.

Arc-sprayed coating uses direct current power to energize two conductive wires that feed into a gun where the electric arc melts the material, and the compressed air sends the molten material to the surface to coat an object $[11,12]$. Such a technology facilitates the deposition of layers with controllable thicknesses and can ensure a protective anodic layer on the steel parts for very long periods. Some essential disadvantages of this coating technology are a certain porosity of the deposited material, the use of only the electroconductive materials, and the fact that these materials must be able to melt without affecting the properties of interest in terms of the use of the coated parts. Pokhmurska et al. used a method of arc-spraying of $\mathrm{FeCrB}+\mathrm{Al}$ and $\mathrm{FeCr}+\mathrm{Al}+\mathrm{C}$ powder wires to 
increase wear resistance [12]. The experimental tests made in a block-on-ring configuration with boundary lubrication and using an abrasive-oil mixture showed a high wear resistance of the coatings.

Laser cladding coating technology facilitates coatings based on the use of nonconductive materials, for example, ceramics. Generally, the laser cladding coating can ensure a high hardness of the deposited layers and, as a consequence, a very high wear resistance. In other situations, the deposited layers obtained by laser cladding can ensure a high bonding strength, better corrosion resistance, good behavior to the adhesive and abrasive wear, the possibility to mix dissimilar materials, achieving of punctual deposit, generation of nonsignificant workpiece distortions, etc. As less convenient aspects of the laser cladding coating, the reduced plasticity of the deposited layer, the necessity of relatively expensive coating equipment, etc., need to be considered [13-16]. Wu et al. investigated the wear behavior of laser cladding ceramic coating [16]. They deposited in situ $\mathrm{VC}-\mathrm{Cr}_{7} \mathrm{C} 3$ ceramic coating on a steel substrate. A hardness of up to $1050 \mathrm{HV}$ was obtained, far exceeding the hardness of $150 \mathrm{HV}$ of the steel substrate. The wear resistance of the clad coating was higher by about four times than that of the steel substrate.

In the case of plasma spray coating, the granules, powders, and wires are melted and join the workpiece surface under plasma beam action $[13,17,18]$. The deposited layers can be characterized by high wear resistance, corrosion and oxidation resistance, low content of impurities, with the possibility of depositing pure or mixture materials, etc. The main disadvantages of this coating technology can be determined by the relatively high cost of the operation and the possible non-homogenization of the layers' structures. The wear resistance of in-situ TiC reinforced Ni-based composite coating obtained by plasma spray welding was studied by Huang et al. [18]. The composite coating had a complex microstructure, including $\gamma-\mathrm{Ni}, \mathrm{Cr}_{23} \mathrm{C}_{6}, \mathrm{Cr}_{7} \mathrm{C}_{3}, \mathrm{Ni}_{3} \mathrm{Si}, \mathrm{Cr}_{5} \mathrm{~B}_{3}, \mathrm{CrB}, \mathrm{FeNi}_{3}$, and $\mathrm{TiC}$ phases. The hardness of the composite coating was of $1142 \mathrm{HV}$ and, thus, a higher wear resistance was proved by experimental tests.

The current processes of electrochemical deposition may ensure hard layers, corrosion resistance layers, decorative surfaces or high reflectance surfaces, etc. $[13,19,20]$. As some less convenient aspects, the general limitation to the electroconductive materials to be deposited, a certain polluting character of the substances used in the process, and relatively high electrical energy consumption need to be considered. However, we should mention that, at present, a co-deposition of ceramic materials with metals and polymers is possible and hybrid layers can, thus, be generated. The electrochemical deposition of $\mathrm{Ni}$ and Ni-Co matrix composites with $\mathrm{SiC}$ nano-particles was applied by Srivastava et al. to improve the wear resistance of the parts involved in friction processes [20]. They appreciated that wear resistance of the composite material is higher than that obtained in the case of pure Ni coatings. Experiments developed a pin-on-disc wear tester which showed an evolution of the composite material's wear behavior in accordance with Archard's law.

A comparison of some distinct coating methods by considering the wear behavior of the steel part surface layer was elaborated by Habig [21]. As coating methods, he used electrochemical deposition, thermomechanical treatment, chemical vapor deposition, and physical vapor deposition. In this way, he succeeded in offering an overview concerning the advantages and disadvantages of the different coating methods.

When selecting a coating technology, one of the criteria used could be the total cost of the operation and of the materials. Generally, parts manufacturing costs are strongly influenced by the production character. For example, in mass production, the cost of a certain operation can be significantly diminished when equipment with a high level of automatization is used. In similar manufacturing costs, a coating operation can be expensive when using complex equipment and high-cost materials, and when there is high energy consumption. In comparison with other coating technologies, including solid lubricant particles in industrial oil is less expensive, essentially due to the simplicity of the operation process, even if the added material (particles of solid lubricant) cost is a little higher.

When it is not possible to use oil between the contact surfaces in relative motion, a decrease in the friction intensity can be obtained by covering the surfaces with layers that incorporate solid lubricants. 
As above mentioned, metallic layers including molybdenum disulfide can be used. To diminish the coating cost and when the friction processes are not very intense, coating technologies based on the use of plastic layers that include solid lubricants particles can be taken into consideration. One such plastic is polyester, for which electrostatic deposition technologies are largely used in industrial practice. Among the processes of plastic deposition on parts' friction surfaces, electrostatic deposition can be characterized by low costs, especially when adequate equipment for deposition and for the postdeposition processes is available.

Empirical mathematical models that correspond to the influence exerted by some process input factors on the size of the friction coefficient and lifetime of the layers deposited by electrostatic painting and that included particles of molybdenum disulfide or graphite are presented in [22]. The problem of finding the set of values of the friction process input factors (normal force, the concentration of solid lubricant particles in the polyester, and the specific sliding) for distinct weightings of the lifetime and friction coefficients as friction process output parameters are addressed in this paper. It was considered that the use of the grey relational analysis to identify the sets of process input factors values able to ensure certain weightings for the process output parameters could be an optimization solution in this case.

\section{Stresses Specific to the Friction Processes}

A way to evaluate the behavior of distinct materials in conditions of friction processes can be based on the use of two disks found in contact by their peripheral surfaces. Such a testing scheme was applied in the case of the Amsler type testing machine. The two disks could have diameters of 30 to $60 \mathrm{~mm}$ and a width of $10 \mathrm{~mm}$.

A mechanism based on the use of a pendulum mechanism facilitates the determination of the friction moment $M_{t}$ developed on the testing machine. The two disks have rotation movements with distinct peripheral rotation speeds, $v_{1}$ and $v_{2}$, ensured by separate kinematic chains. Due to the distinct peripheral rotation speeds $n_{1}$ and $n_{2}$ of the two disks with diameters $D_{1}$ and $D_{2}$, a relative sliding will develop in the contact zone of the two disks. The higher is the difference between the peripheral rotation speeds $n_{1}$ and $n_{2}$, the higher the specific sliding $\varepsilon$ is.

If the normal radial force $Q$ is known, the friction coefficient $\mu$ could be calculated by means of the relation [2].

$$
\mu=\frac{2 M_{t}}{Q D_{1}}
$$

The specific sliding $\varepsilon$ is given by the relation:

$$
\varepsilon=\frac{2\left(v_{1}-v_{2}\right)}{v_{1}+v_{2}}=2\left(1-k \frac{D_{2}}{D_{1}}\right) /\left(1+k \frac{D_{2}}{D_{1}}\right)
$$

where $k=n_{2} / n_{1} \approx 0.906$ in the case of the Amsler type testing machine.

When the disks have the same diameter, a specific sliding $\varepsilon$ of about $10 \%$ is generated. By changing the diameters of the disks, values of the specific sliding $\varepsilon$ between 0 and $100 \%$ can be ensured.

When the specific sliding $\varepsilon$ is of $0 \%$, there is a pure rolling, while for a specific sliding $\varepsilon$ of $100 \%$ there is a pure sliding.

A change in the kinematic chain that ensures the rotation of the disks can lead to the change of the rotation direction of one of the disks, and, thus, a higher sliding can be obtained.

\section{Electrostatic Deposition of Polyester Layers that Include Solid Lubricants Particles}

Many methods can be used to deposit polyester layers that include solid lubricants particles on the surfaces affected by friction processes. For example, such methods can be based on pulverizing, immersion, painting etc. If the deposition technologies are analyzed, we notice that physical phenomena (in the cases of deposition in liquids solutions or deposition in gases), chemical phenomena (in the cases of autocatalytic deposition, chemical vapor deposition, low pressure chemical vapor deposition) or 
physical-chemical phenomena (in the cases of thermochemical deposition, electrochemical deposition, plasma chemical vapor deposition, plasma enhanced chemical vapor deposition) are used. Among the methods/technologies based on the physical phenomena and that use the transport of the particles of the material to be deposited by pulverizing, electrostatic deposition [23-25] can be considered. This last deposition technology supposes the existence of an intense electric field in which the electrically charged particles of covering powder move to the workpiece surfaces following the electric field lines. Usually, after the proper coating with powder in the electrostatic field, a mass polymerization in an oven is necessary to melt the powder and to increase its adherence to the workpiece surface.

In the case of the disks necessary in the investigation of the behavior of the plastic layers that include solid lubricants particles to the friction processes, equipment for electrostatic deposition was used. As final operations, before applying the electrostatic deposition, the steel disks were ground and subjected to a thermo-chemical phosphating treatment. As a result of applying the grinding process, the value of the surface roughness parameter $R a$ was of about $0.8 \mu \mathrm{m}$.

Powders with distinct concentrations of solid lubricants particles (powders of molybdenum disulfide or graphite) were sent to the spray nozzle of the electrostatic deposition equipment. A PP 101/9010/A qualicoat P0369, GSB 140o, 18728-387 polyester was used as the main coating material that could include particles of molybdenum disulfide (with an average size of $40 \mu \mathrm{m}$ ) or graphite (with an average size of $80 \mu \mathrm{m})$.

Polymerization was developed in an oven where the temperature was of about 180 to $200{ }^{\circ} \mathrm{C}$ and the duration of this process was of about 15 to $17 \mathrm{~min}$.

As a result of applying the electrostatic painting process, a polyester layer with a thickness of $90 \mu \mathrm{m}$ was achieved on the surfaces of the disks.

\section{Experimental Research}

To develop an investigation concerning the behavior of the deposited layers of polyester that includes the particles of molybdenum disulfide and graphite in friction conditions using the Amsler type testing machine, the diameters of the disks were calculated by means of the Equation (1), to obtain a specific sliding $\varepsilon$ of $0 \%, 25 \%$ and $50 \%$.

As a work/testing principle, it was agreed to use a friction couple that includes a disk covered with the polyester that includes solid lubricant particles and a disk without such a deposited layer. The diameters of the coated disks were of $48 \mathrm{~mm}$. As above mentioned, the thickness of the coating layer was of about $90 \mu \mathrm{m}$.

In comparison with other testing equipment and schemes, the Amsler type testing machine and the adopted testing scheme were preferred since they ensure a relatively simple change of the testing conditions (testing normal force, testing speed, replacing of the samples, etc.). Even the testing scheme is simple; it takes into consideration the general operating conditions specific to many industrial machines. Due to the simplicity of the testing scheme, the characteristics of the friction processes can also be clearly highlighted.

The experimental research was developed in accordance with the work conditions shown in Columns 3,4, and 5 from Table 1. Practically, an L9 Taguchi triangular arrow (three independent factors and three experimental levels) was taken into consideration for each of the tested coating materials.

As a deposited layer lifetime $T$, the interval from starting the test up to the complete removal of the polyester layer on the disk cylindrical peripheral surface was considered.

In the Columns 3,4, and 5, the values of the process input factors are written as fractions, considering the codified values ( 1 for the minimum value, 2 for the intermediate value, and 3 for the maximum value) as numerators and the proper values of the process input factors as denominators. In Table 1 , the values of the process input factors and of the experimental results are written both for the polyester layer that includes particles of molybdenum disulfide and for the polyester layer that contains graphite particles. 


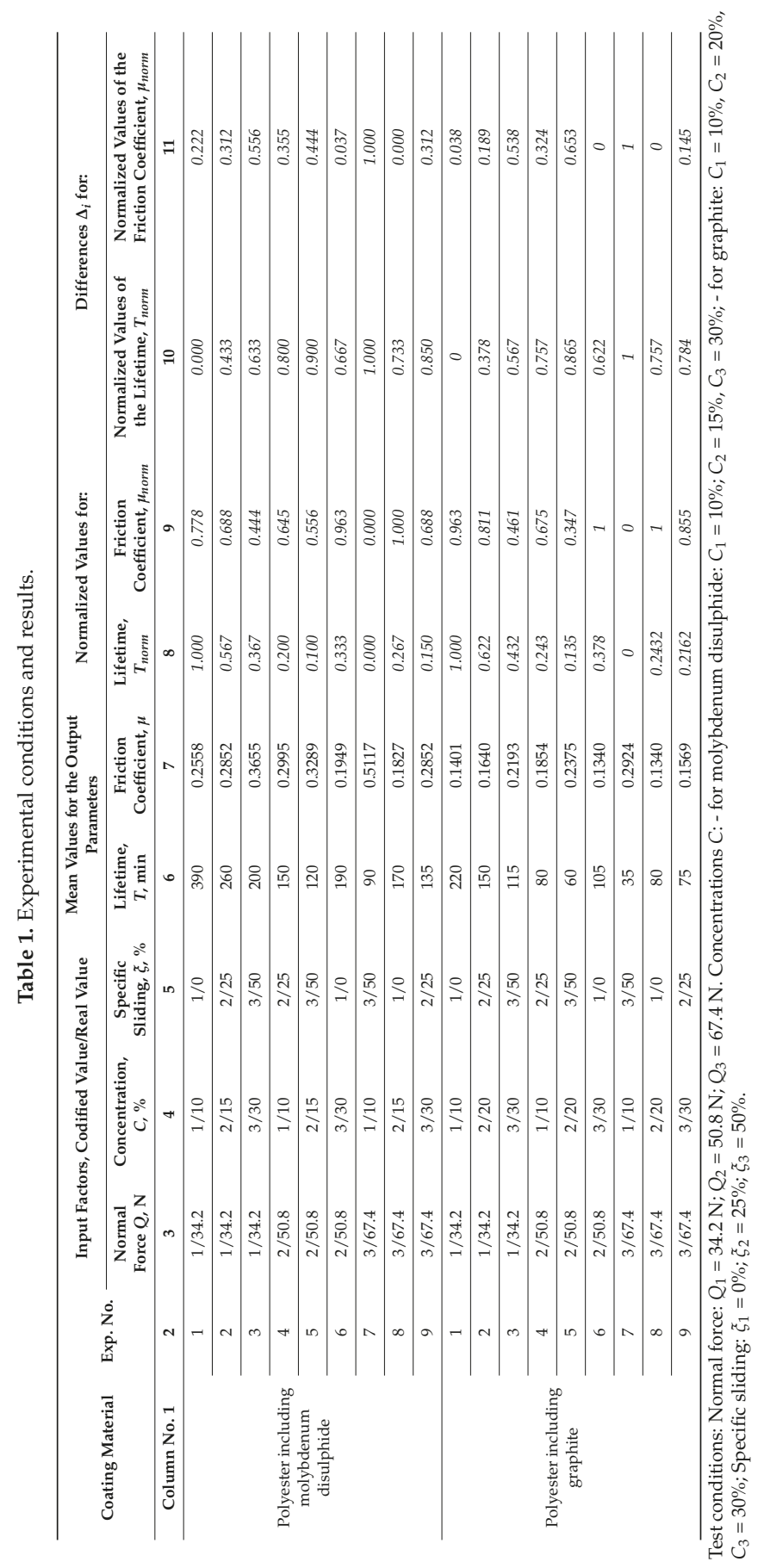


The information included in the Columns 8,9,10, and 12 is the result of a partial processing of the experimental results.

The friction moment $M_{t}$ was determined by means of the pendulum mechanism of the Amsler type testing machine. The normal radial force $Q$ was generated using the screw-spring mechanism of the testing machine.

The values of the layers' lifetimes, $T$, were included in the Column 6 of Table 1 , while the values of the friction coefficient, $\mu$, were calculated using the Equation (1) and mentioned in the Column 7.

\section{Use of the Grey Relational Analysis}

To establish the set of the values of the friction process input factors that could ensure convenient values for the process output parameters, the grey relational analysis was considered. The theory of grey systems was proposed by the Chinese professor Julong Deng in the 1980s to characterize situations where there is limited or inadequate information.

Essentially, the grey relational analysis evaluates the quantitative relation between the elements included in two series. One appreciates that one of these series incorporates entities of the best quality. The comparison takes into consideration the grey relational coefficient, whose values depend on the similitude level and variability level, respectively.

To apply the grey relational analysis in the case of the achieved experimental research, a preprocessing of the experimental results (normalization of the experimental results) can be applied using the following Equations [26-28].

- For the situation when the higher is the better:

$$
X_{i j}=\frac{Y_{i j}-\min _{i} Y_{i j}}{\max Y_{i j}-\min Y_{i j}}
$$

- For the situation when the lower is the better:

$$
X_{i j}=\frac{\max Y_{i j}-Y_{Y i j}}{\max Y_{i j}-\min Y_{i j}}
$$

where $Y_{i j}$ is the value with the order number $i$ of the characteristics in the experiment with the order number $j ; \max Y_{i j}$ and $\min Y_{i j}$ are the minimum and the maximum values of the characteristics in the experiment no. $i$ for the alternative $j$.

In accordance with the above-mentioned equations, the normalized values for $T$ and $\mu$ are mentioned in the Columns 8 and 9 of Table 1.

In the case of the presented experimental results, we use Equation (3) in the case of the polyester layer lifetime $T$ (when a higher value of the lifetime is more convenient) and the Equation (4) in the case of the friction coefficient $\mu$ (since diminished value of this coefficient is considered more convenient).

After the results normalization, the grey relational coefficient $\xi_{i j}$ was determined by means of the relation

$$
\xi_{i j}=\frac{\min _{i} \min _{j}\left|X_{j}^{0}-X_{i j}\right|+\xi \max _{i}\left|X_{j}^{0}-X_{i j}\right|}{\left|X_{j}^{0}-X_{i j}\right|+\xi \max _{i}\left|X_{j}^{0}-X_{i j}\right|}
$$

where $X^{0}{ }_{j}$ is the ideal normalized result for the performance characteristics of order $j$ (this ideal normalized value corresponds to the maximum value of the normalized ratio $S / N$, since a high value of the ratio $S / N$ is preferred, $S$ being the signal, and $N$, the noise) and $\xi$ is the distinguished coefficient, to which distinct values could be attributed.

A shorter expression of the relation that corresponds to the grey relational coefficient $\xi$ is given by the equation:

$$
\xi_{i j}=\frac{\Delta_{\min }-\xi \Delta_{\max }}{\Delta_{0 i}+\xi \Delta_{\max }}
$$


where $\xi$ is the distinguished coefficient and $\Delta_{0 i}$ is the difference between the absolute value $X^{0}{ }_{j}$ of the normalized result for the performance characteristics (the output parameter) $j$ and $X_{i j}, \Delta_{0 i}=\left|X^{0}{ }_{j}-X_{i j}\right|$, $\Delta_{\min }$ is the lowest value of $\Delta_{0 i}$, and $\Delta_{\max }$ is the highest value of $\Delta_{0 i}$.

The grey relational grade $\gamma_{i}$ is calculated as an average value of the grey relational coefficients $\xi_{i j}$ that correspond to each experiment $i$, and it is defined by the equation

$$
\gamma_{i}=\frac{1}{n} \sum_{j=1}^{n} W_{k} \xi_{i j}
$$

where $W_{k}$ is the normalized weight of the factor, and that could be considered as equal to 1 , and $n$ is the number of the considered performance characteristics. In this case, the lifetime $T$ and the friction coefficient $\mu$ are the two considered performance characteristics, and this means $n=2$.

To calculate the values corresponding to the use of the grey relational analysis and to identify the most convenient sets of the values of the friction process input factors faster, specialized software in MATLAB environment was elaborated. The algorithm underlying this software is presented in Figure 1.

START

Input of the no. of factors (type of solid lubricant, normal force $Q$ [N], concentration C [\%], specific sliding $\xi$ [\%]) Choosing the type of the used Taguchi table $(L 9)$

Input of the no. of output factors (Lifetime T[min], Friction coefficient $\mu$ [-])

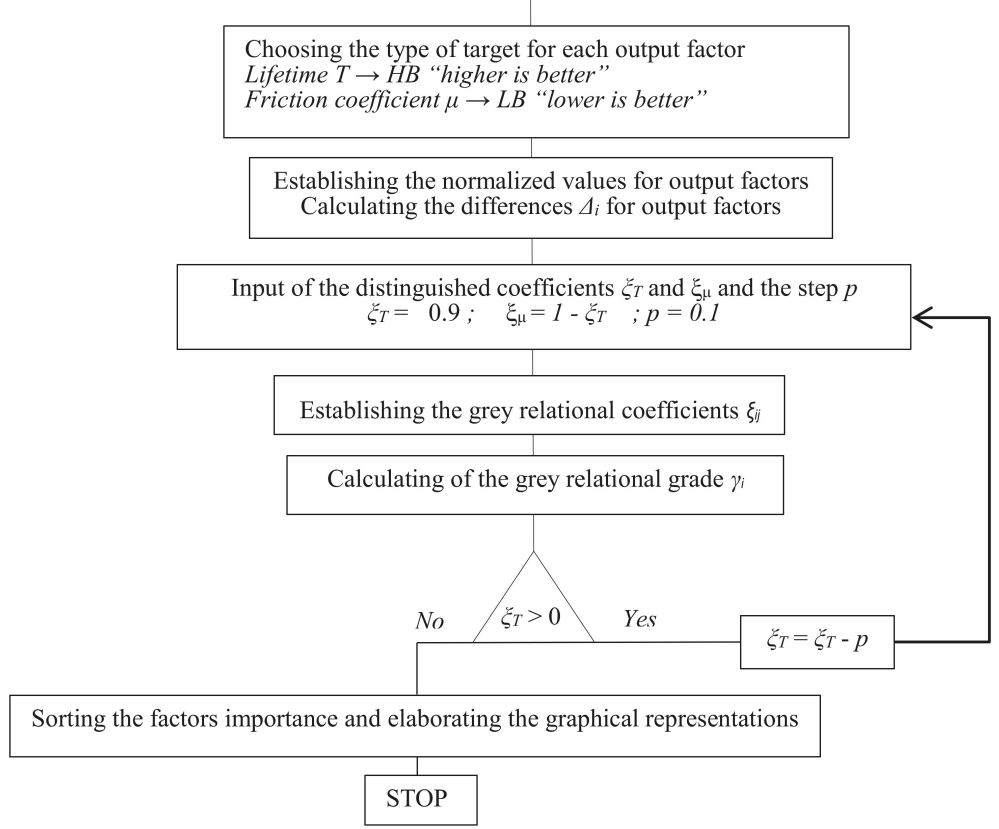

Figure 1. Algorithm used to calculate the values of the sizes specific to the grey relational analysis.

Three distinct situations were initially taken into consideration for distinct values of the distinguished coefficient $\xi$, namely a situation when $\xi_{T}=\xi_{\mu}=0.5$ both for the lifetime $T$ and the friction coefficient $\mu$; another situation when $\xi_{T}=0.9$ for the lifetime $T$ and $\xi_{\mu}=0.1$ for the friction coefficient $\mu$, and the third situation, when $\xi_{T}=0.7$ for the lifetime $T$ and $\xi_{\mu}=0.3$ for the friction coefficient $\mu$. The results of the calculus for the first situation in the case of both solid lubricant types are included in Table 2. 
Machines 2019, 7, 16

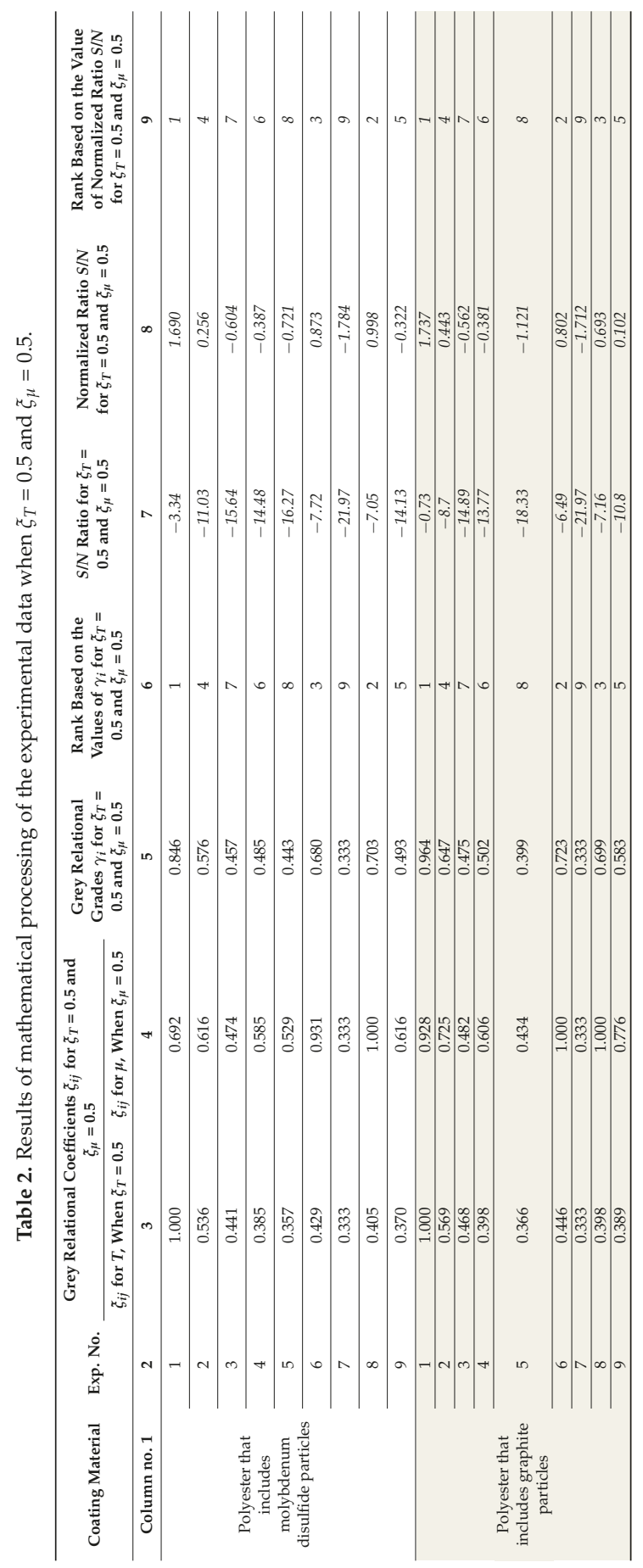


The values of the normalized values of the grey relational grades $\gamma_{i}$ can be seen in the Column 5 of Table 2.

In the case when $\xi=0.5$ for both process output factors (Table 2), the highest value of the grey relational grades $\gamma_{i}$ corresponds to Experiment 1 for the both types of solid lubricants particles $\left(\gamma_{i}=0.846\right.$ for the polyester that includes molybdenum disulfide particles and $\gamma_{i}=0.964$ for the polyester that includes graphite particles) and this means that the values of the process input factors that correspond to Experiment 1 both in the case of using molybdenum disulfide and graphite ( $Q=34.2 \mathrm{~N}, \mathrm{C}=10 \%, \xi=0$ both in the case of molybdenum disulfide and graphite) can be considered as the closest value to those values able to ensure a maximum lifetime $T$ and a minimum value for the friction coefficient $\mu$.

We can also consider that the two process output factors are not of equal importance. For example, we can appreciate that the factor lifetime $T$ has higher importance, evaluated by a distinguished coefficient $\xi_{T}=0.9$, while the friction coefficient importance $\mu$ is evaluated by a distinguished coefficient $\xi=0.1$. In such a situation, a new order of the experiments can be identified, and the most convenient combination of the process input factors can have values that correspond to the Experiment 8 for the molybdenum disulfide particles $(Q=67.4 \mathrm{~N}, \mathrm{C}=15 \%, \xi=0)$ and to the Experiment 1 for the graphite particles $(Q=34.2 \mathrm{~N}, C=10 \%, \xi=0)$.

Another interpretation of the experimental results can be based on considering, for example, a distinguish coefficient $\xi_{T}=0.7$, for the lifetime $T$ and $\xi_{\mu}=0.3$, for the friction coefficient $\mu$. For the considered experimental results, this situation shows that the most convenient combination of the process input factors values is the same with that valid in the case when $\xi_{T}=0.5$, and $\xi_{\mu}=0.5$.

The analysis could be continued by considering some principles specific to the Taguchi method, by using the ratio signal/noise $S / N$.

Thus, the value of the quality loss function has to be calculated. If an evaluation type "higher the better" is taken into consideration, this function is given by

$$
L_{i j}=\frac{1}{n} \sum_{k=1}^{n} \frac{1}{Y_{i j k}^{2}}
$$

where $n$ is the number of experiments for the same values of the input factors, $k$ - the number of tests and $Y_{i j k}$ - the value of the output parameter obtained for the test $i$, the experiment $j$ and test $k$.

If a "lower the better" type evaluation is considered, the function $L_{i j}$ is given by the equation

$$
L_{i j}=\frac{1}{n} \sum_{k=1}^{n} Y_{i j k}^{2}
$$

The value of the ratio $S / N$ can be determined for both above-mentioned situations, using the equation

$$
\eta_{i j}=-10 \log \left(L_{i j}\right)
$$

The ratio $S / N$ can be used in the case of the mono-answer problems (mono-criterial optimization), while in the case of the multicriterial optimization, there is the recommendation to use the normalized values NSN of the ratio's $S / N$ [26]. Distinct ways can be used to determine the normalized values NSN [26,29]. In this case, the following relation (adapted from [29]) was preferred to determine the normalized value $N S N$ of the ratio's $S / N$ :

$$
N S N=\frac{\eta_{i j}-u_{S / N}}{\sigma}
$$

where $\mu_{S / N}$ is the average value of the ratio $S / N$ and $\sigma$ is the standard deviation of the ratio $S / N$.

The calculated values for the normalized value NSN are mentioned in the Column 8 of Table 2, while in the Column 13 the ranks based on the normalized values NSN of the ratio S/N are included. 
As expected, we can observe that the ranks determined in this case are the same as those resulted by considering the grey relational grades $\gamma_{i}$.

We notice that the experiments with the longest lifetime were found in the first position of ranking both for polyester that includes molybdenum disulfide particles and for the polyester that includes graphite particles. This fact can be explained by the developing of the experiments in similar initial conditions (process input factors), and the effects both solid lubricants have on the same action direction.

As above-mentioned, conventionally we took into consideration as the lifetime of the polyester layer that includes particles of solid lubricant, only the interval of time up to the total removal of the polyester layer on the disks surfaces as could be observed by visual examination, but particles of solid lubricant could yet remain (by adhesion) on the surfaces of the disks, thus, improving the disks' behavior in respect to the friction processes. This aspect could be considered in future research, as comparisons with other types of anti-friction coating can be studied.

An example of the use of layers including solid lubricant particles to improve friction behavior, may be gear transmissions that do not work in oil with the inclusion of solid lubricant particles and when gears can be changed under mild conditions. We considered that in such a case the life of the gears could be higher than the one in which the solid lubricant particles incorporated in a polyester layer are not used. We also considered that the cost of using such a method of coating with a polyester layer including particles of solid lubricants could be lower than that valid in the cases of other coating methods, for example in the cases of arc sprayed coating [11-13], laser cladding [13-16], plasma spray welding $[17,18]$, electrochemical deposition $[19,20]$, thermochemical treatment [21], etc.

As additional information concerning the influence exerted by the value of the distinguished coefficient $\xi$ on the size of the ratio $S / N$ is offered by the graphical representations in Figures 2 and 3 , where the values of the grey relational grade $\gamma_{i}$ are highlighted as functions of the distinct values for the ratio between the distinguished coefficients $\xi_{T} / \xi_{\mu}$, by considering all the nine experimental tests. For ratios, $\xi_{T} / \xi_{\mu}$ equals with $0.9 / 0.1,0.5 / 0.5$, and $0.1 / 0.9$, the values indicated in Figures 2 and 3 corresponds to the rank based on the values of grey relational grade $\gamma_{i}$. As a general remark, we can notice that the decrease of the ratio $\xi_{T} / \xi_{\mu}$ has, as a result, an increase of the values grey relational grade $\gamma_{i}$ for the Experiment 1 and a decrease of the value of the same grey relational grade $\gamma_{i}$ that corresponds to the Experiment 8.

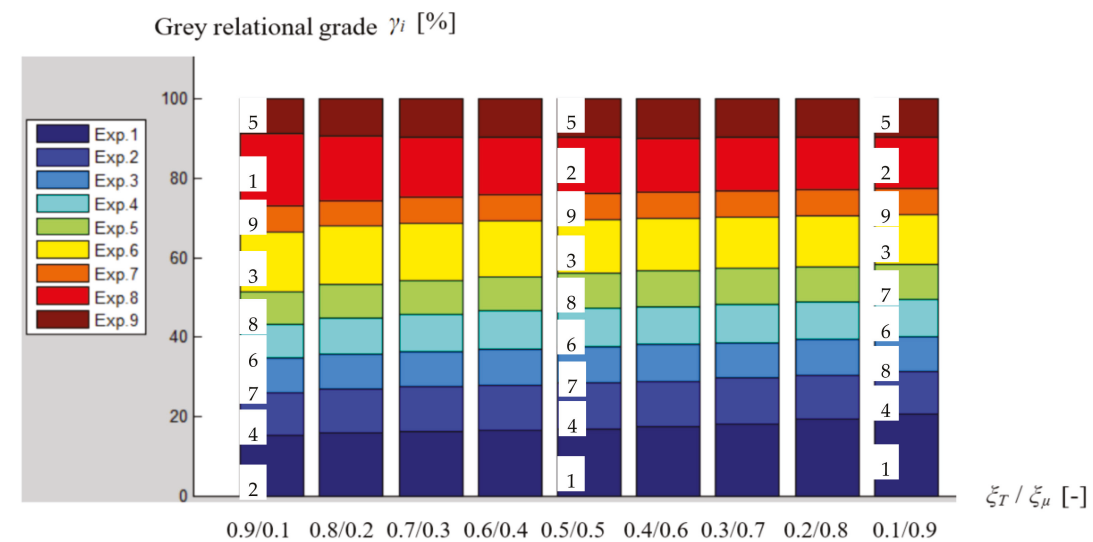

Figure 2. Influence exerted by the decrease of the ratio $\xi T / \xi \mu$ on the size of the grey relational grade $\gamma i$, for all nine experimental tests, in the case of using polyester that includes particles of molybdenum disulfide. 
Grey relational grade $\gamma_{i}[\%]$

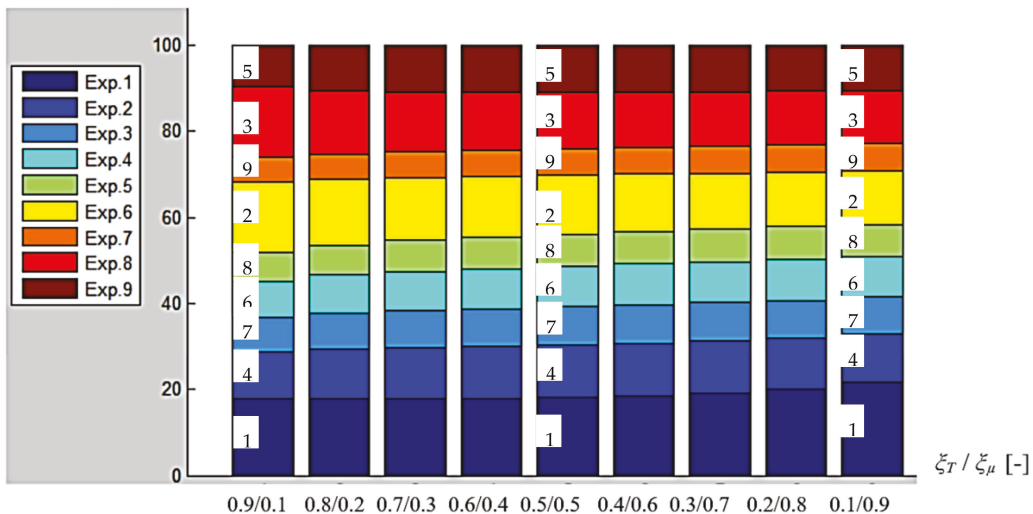

Figure 3. Influence exerted by the decrease of the ratio $\xi T / \xi \mu$ on the size of the grey relational grade $\gamma$, for all nine experimental tests, in the case of using polyester that includes particles of graphite.

As it is actually formulated, the grey relational analysis only allows the identification of the most convenient set of process input factors among many such experimental sets. To refine the results, another set of experiments could be designed for values of the process input factors found immediately around of the values that correspond to the best results obtained in the first set of experiments; in this way a better prediction of the experimental setting could be made, to obtain a more adequate compromise of the values that correspond to the two output parameters.

If the problem of the cost of applying the electrostatic deposition of polyester layers including particles of solid lubricants is approached, we can notice that the final cost is higher than the cost of simply introducing the particles of solid lubricants in the industrial oil used to diminish the negative effects of the friction processes, but when only dry operation is allowed to the parts involved in friction processes, the coating alternative investigated in this paper could be considered. If the cost of the solid lubricant particles and of applying the electrostatic deposition are analyzed, the final costs are about 1 euros $/ \mathrm{dm}^{2}$ when using particles of molybdenum disulfide and of about 1.2 euros $/ \mathrm{dm}^{2}$ when using particles of graphite. In this way, even if the deposited layer lifetime is lower than that corresponding to the deposition of hard material layers, the electrostatic deposition of the polyester layer including particles of solid lubricants represents a solution to be considered when the diminishing of the friction processes' negative effects is investigated, especially if we examine the costs many times higher in the cases of hard material depositions.

\section{Conclusions}

The investigation into the ways of increasing the lifetime and of decreasing the friction coefficient value in the case of machine elements affected by friction processes showed that covering of the surfaces involved in the friction process with a polyester layer that incorporates particles of molybdenum disulfide or graphite could lead to better results from the points of view of energy losses and machine elements lifetime. In comparison with other more complex coating methods, it can be appreciated that the use of polyester layers including particles of solid lubricant could have a lower cost. Experimental research in accordance with the requirements specific to a Taguchi $L 9$ array was designed and materialized to identify the set of the process input factors able to improve the parts' behavior in friction processes. As process input factors, the normal force $Q$, the concentration $C$ of the solid lubricant particles, and the specific sliding $\xi$ were taken into consideration, while the lifetime $T$ and the friction coefficient $\mu$ were considered as process output parameters. The experiments achieved by the disk-on-disk Amsler testing machine and the processing of the experimental results by means of the grey relational analysis and the ratio signal/noise specific to the Taguchi method 
developed inclusively in the MATLAB environment showed that a certain set of the process input factors can ensure convenient values for the considered process output parameters and can highlight the influence exerted by the change of the ratio $\xi_{T} / \xi_{\mu}$ on the size of the grey relational grade $\gamma$ appreciated as evaluation criterion. Some combinations of the process input factors able to ensure optimal values for the process output parameters were determined for distinct weightings allocated to the process output parameters. Specialized software developed in MATLAB environment was used to process the experimental results faster and determine the optimal combination for the normal force, and the concentration of the solid lubricant particles in the polyester layer. Distinct values of the distinguished coefficient necessary to calculate the grey relational grades were allocated to each process output parameter.

Author Contributions: O.D. designed and performed the experiments and the numerical calculations with support from G.N. A.H. was involved in drafted the manuscript and designed the figures. L.S. proposed the general structure of the paper and had the idea of using grey relational analysis for identifying the optimal input factors. All authors discussed the results and commented on the manuscript.

Acknowledgments: This research was partially supported by Gheorghe Asachi Technical University of Iaşi, România.

Conflicts of Interest: The authors declare no conflict of interest.

\section{References}

1. Mamalis, A.G.; Kundrák, J.; Markopoulos, A. Numerical Simulation for the Determination of the Temperature Fields and the Heat Affected Zones in Grinding. Prod. Syst. Inf. Eng. Misk. 2003, 1, 3-16.

2. Olaru, D.; Benchea, M.; Balan, M.R.; Bodi, G.; Stamate, C.V.; Laboratory Work No. 2. The Study of the Friction Phenomenon in Couples of Second and Third Class (in Romanian). 2016. Available online: http: //www.mec.tuiasi.ro/ro/index.php/studenti/download-descarca2 (accessed on 25 December 2018).

3. Perez-Diaz, J.L.; Diez-Jimenez, E.; Valiente-Blanco, I.; Cristache, C.; Alvarez-Valenzuela, M.-A.; Sanchez-Garcia-Casarrubios, J. Contactless Mechanical Components: Gears, Torque Limiters and Bearings. Machines 2014, 2, 2-4. [CrossRef]

4. Wolf, B. Handbook of Ion Sources; CRC Press: Boca Raton, FL, USA, 1995; ISBN 0-8493-2502-1.

5. Martins, R.C.; Moura, P.S.; Seabra, J.O. $\mathrm{MoS}_{2}$ /Ti low-friction coating for gears. Tribol. Int. 2006, 39, 1686-1697. [CrossRef]

6. Abdullah, M.A.; Saleman, S.A.; Tamaldin, N.; Suhaimi, M.S. Reducing wear and friction by means of lubricants mixtures. Procedia Eng. 2013, 68, 338-344. [CrossRef]

7. Bhaumik, S.; Pathak, S.D. Effect of nano and micro friction modifier based lubricants on wear behavior between steel-steel contacts. Tribol. Int. 2017, 39, 136-143. [CrossRef]

8. Ghaednia, H.; Jackson, R.L. The role of nanoparticles in lubricants; performing lubricated and dry friction tests. Tribol. Lubric. Technol. 2015, 71, 20-24.

9. Lee, C.-G.; Hwang, Y.-J.; Choi, Y.-M.; Lee, J.-K.; Choi, C.; Oh, J.-M. A study on the tribological characteristics of graphite nano lubricants. Int. J. Precis. Eng. Manuf. 2009, 10, 85-90. [CrossRef]

10. Hwang, Y.; Lee, C.; Choi, Y.; Cheong, S.; Kim, D.; Lee, K.; Lee, J.; Kim, S.H. Effect of the size and morphology of particles dispersed in nano-oil on friction performance between rotating discs. J. Mech. Sci. Technol. 2011, 25, 2853-2857. [CrossRef]

11. Dallaire, S. Hard arc-sprayed coating with enhanced erosion and abrasion wear resistance. J. Therm. Spray Technol. 2001, 10, 511-519. [CrossRef]

12. Pokhmurska, H.; Dovhunyk, V.; Student, M.; Bielanska, E.; Beltowska, E. Tribological properties of arc sprayed coatings obtained from FeCrB and FeCr-based powder wires. Surf. Coat. Technol. 2002, 151-152, 490-494. [CrossRef]

13. Slătineanu, L.; Nagîţ, G.; Dodun, O.; Coteaţă, M.; Chinesta, F.; Gonçalves-Coelho, A.; Pamies Teixeira, J.; San Juan, M.; Santo, L.; Santos, F. Non-Traditional Manufacturing Processes; Publishing House Tehnica Info: Chișinău, Republic of Moldova, 2004; ISBN 9975-63-164-9. 
14. Zhang, J.; Hu, Y.; Tan, X.-J.; Guo, L.; Zhang, Q. Microstructure and high temperature tribological behavior of laser cladding Ni60A alloys coatings on 45 steel substrate. Trans. Nonferrous Met. Soc. China 2015, 25, 1525-1532. [CrossRef]

15. Cheng, H.; Yi, J.; Fang, Z.; Dai, S.; Zhao, X. Tribology property of laser cladding crack free Ni/WC composite coating. Mater. Trans. 2013, 54, 50-55. [CrossRef]

16. Wu, Q.; Li, W.; Zhong, N.; Gang, W.; Haishan, W. Microstructure and wear behavior of laser cladding VC-Cr7C3 ceramic coating on steel substrate. Mater. Design 2013, 49, 10-18. [CrossRef]

17. Wang, V.; Li, W.; Xu, H. Microstructures and properties of plasma sprayed Ni based coatings reinforced by TiN/C1-xNxTi generated from in-situ solid-gas reaction. Materials 2017, 10, 785. [CrossRef] [PubMed]

18. Huang, S.; Sunn, D.; Wang, W.; Xu, H. Microstructures and properties of in-situ TiC particles reinforced Ni-based composite coatings prepared by plasma spray welding. Ceram. Int. 2015, 41, 12202-12210. [CrossRef]

19. Gurrappa, I.; Binder, L. Electrodeposition of nanostructured coatings and their characterization-A review. Sci. Technol. Adv. Mat. 2008, 9, 043001. [CrossRef] [PubMed]

20. Srivastava, M.; William Grips, V.K.; Rajam, K.S. Electrochemical deposition and tribological behaviour of Ni and Ni-Co metal matrix composites with SiC nano-particles. Appl. Surf. Sci. 2007, 253, 3814-3824. [CrossRef]

21. Habig, K.H. Wear behaviour of surface coatings on steels. Tribol. Int. 1989, 22, 65-73. [CrossRef]

22. Dodun, O.; Slătineanu, L.; Coteaţă, M.; Nagîț, G. Tribological behaviour of solid lubricants-polyester composites coatings. In Proceedings of the 11th International Conference THE " $\mathrm{A}$ " Coatings in Manufacturing Engineering, Thessaloniki, Greece, 1-3 October 2014; pp. 351-360.

23. Barletta, M.; Gisario, A.; Tagliaferri, V. Electrostatic spray deposition (ESD) of polymeric powders on thermoplastic (PA66) substrate. Surf. Coat. Technol. 2006, 201, 296-308. [CrossRef]

24. Barletta, M. Dry sliding wear response of some industrial powder coatings. Tribol. Int. 2011, 44, 1236-1250. [CrossRef]

25. Zouari, M.; Kharrat, M.; Dammak, M.; Barletta, M. A comparative investigation of the tribological behavior and scratch response of polyester powder coatings filled with different solid lubricants. Prog. Org. Coat. 2014, 77, 1408-1417. [CrossRef]

26. Balasubramanian, S. Grey relational analysis to determine optimum process parameters for wire electro discharge machining (WEDM). IJEST 2011, 3, 95-101.

27. Naresh Babu, M.; Muthukrishnan, N.; Chandrasekaran, M. Estimation of Optimal Process Parameters in Abrasive Waterjet Machining of AISI 202 Using Grey Relational Analysis and Simulated Annealing. Wulfenia J. 2012, 19, 408-425.

28. Tosun, N. Determination of Optimum Parameters for Multi-Performance Characteristics in Drilling by Using Grey Relational Analysis. Int. J. Adv. Manuf. Technol. 2006, 28, 450-455. [CrossRef]

29. Devore, J.L. Probability \& Statistics for Engineering and Sciences, 8th ed.; Cengage Learning: Boston, MA, USA, 2012; ISBN 978-0-538-73352-6. p. 157.

(C) 2019 by the authors. Licensee MDPI, Basel, Switzerland. This article is an open access article distributed under the terms and conditions of the Creative Commons Attribution (CC BY) license (http:/ / creativecommons.org/licenses/by/4.0/). 


\title{
Article \\ A Comparative Study of Open-Source and Licensed CAD Software to Support Garment Development Learning
}

\author{
Evridiki Papachristou ${ }^{1, *}$, Panagiotis Kyratsis ${ }^{2}$ and Nikolaos Bilalis ${ }^{1}$ \\ 1 School of Production Engineering and Management, Technical University of Crete, 73100 Kounoupidiana, \\ Crete, Greece; nbilalis@isc.tuc.gr \\ 2 Department of Mechanical Engineering \& Industrial Design, Western Macedonia University of Applied \\ Sciences, 50100 Grevená, Greece; pkyratsis@teiwm.gr \\ * Correspondence: epapachristou@isc.tuc.gr
}

Received: 1 April 2019; Accepted: 26 April 2019; Published: 1 May 2019

\begin{abstract}
Most universities have included computer-aided design (CAD) pattern making systems education and training in their clothing technology courses in recent years, so as to respond to the actual needs of the fashion world for high-skilled fashion designers and clothing engineers. With the rapid rise in the use of open source software (OSS) in all types of applications, it is important to know if the existing OSS CAD software for garment prototyping development can successfully support the learning process. The present study compares two commercial licensed CAD systems for pattern design (Polypattern and Create) to an open source software, Seamly2D, and to Wild Ginger's Caveo V6 programme, which runs within an OSS. In total, two licensed and two OSS systems have been evaluated in their weights in accomplishing the garment development of ten different pattern designs. The results obtained for the evaluation of a set of OS and licensed CAD systems are presented and critically discussed.
\end{abstract}

Keywords: open-source CAD software; pattern design; licensed CAD; CAD teaching; teaching/learning strategies

\section{Introduction}

The skilled labour-dependent nature of apparel design, the globalisation of the market, the proliferation of information, the typical iterative "optimisation" trial-and-error process of apparel product development, the reduced time to market and continuous pressures of cost are just some of the factors that add to the fashion industry's already complex activities. Digital prototypes in the textile and clothing industry are part of the technology adoption in the product development process, a process that involves various operators in different stages and places, with various skills and competencies and different necessities of formalising and defining in a deterministic way the result of their activities [1]. Taking into account the recent trends in the industry, the product development cycle and the use of new digital technologies cannot be restricted in the "typical cycle", but additional tools and skills require integration for these developments to be taken into account [2].

Since the fashion industry is the most skilled labour-dependent industry, and any cost saving through new computer-aided design (CAD) technologies has become a requirement in gaining a competitive advantage, most universities have included CAD pattern making systems education and training as part of their clothing technology courses in recent years, so as to respond to the actual needs of the fashion world for high-skilled fashion designers and clothing engineers. CAD/CAM (Computer Aided Manufacture) systems allow a design to be generated rapidly and adjusted equally quickly without diminishing creativity, and provide better communication and integration between 
product development systems [3]. They have been instrumental in reducing lead times, improving accuracy, and putting apparel products in retail stores much closer to the time they are needed by the consumer [4].

With the rapid rise in the use of open source software (OSS) in all types of applications, it is important to know if the existing OSS CAD software for garment prototype development can successfully support the learning process. Summers and Shah [5] noted that an objective assessment of CAD model complexity can be useful in assessing case studies, evaluating the results of experiments, or evaluating student projects. Several other authors have highlighted the likely effects of CAD model complexity [6-8]. Johnson, Valverde and Thomison [9] noted that modelling procedure includes the amount of time spent engaging in particular modelling activities. The amount of time required to create a CAD model has been reported and used as a metric for CAD modelling [10-12] and alteration $[13,14]$ quality. The number of operations is a proxy for the number of features or operations required to create a specific piece of CAD geometry. The present study compares commercial licensed CAD systems for pattern design to an open source software, Seamly2D [15], and to MacroGen's Cameo v6 [16] programme which runs within an OSS. This assessment could be taken into account when assessing development timelines in academic projects, especially in institutions where sources for licensed CAD software are limited, or for students who want to practise and/or use a CAD apparel prototype system outside institutions' premises. In total, two licensed and two OSS systems have been evaluated in their weights in accomplishing the garment development of ten different pattern designs. The results obtained for the evaluation (based on the metric of time) of a set of OS and licensed CAD systems are presented and critically discussed.

\section{CAD-Based Design Skills for Fashion Education}

Textile engineering (TE) and fashion technology (FT) educational programmes are always undergoing continuous formal assessment under different accreditation bodies. ABET (Accreditation Board for Engineering and Technology) [17], recommend seven student outcomes, concerning the content of a course (or a series of courses). Traditional computer aided design (CAD) and drawing courses introduce mainly geometric modelling using wireframe, surface, and solid modelling. Ullah and Harib [18] suggested that the content of a course regarding CAD/CAM should help students attain at least the following four outcomes: (1) an ability to apply the knowledge of mathematics, science, and engineering; (2) an ability to design a system, component, or process to meet the desired needs; (3) an ability to identify, formulate, and solve engineering problems; and (4) an ability to use the techniques, skills, and modern engineering tools necessary for engineering practice. The same authors [18], proposed a customised, software-free methodology for teaching design and manufacturing in the field of engineering, but their research addresses the issue of integrating advanced machine tools (e.g., hexapod-based machine tools) with solid modelling. Garment prototyping and digital pattern development has taken place in commercial CAD tools with surface modelling.

Open-source CAD software has emerged in many fields as a promising alternative to commercial and licensed off-the-shelf systems, but college and universities' courses in fashion design and textile engineering still depend the effectiveness of such courses on teaching the effective design approach based on licensed pattern design CAD software-licenses with a usual high cost even as educational forms.

Almost every bachelor's and master's degree course in the industrial and mechanical engineering areas include at least one computer-design class, wherein students can learn CAD-based design principles. Many universities adopt even three-dimensional (3D) CAD licensed software primarily to keep close contact with the industry environment, the place where CAD skill and expertise are actually requested [19]. Two-dimensional (2D) CAD software, such as Autodesk AutoCAD, is fundamental, and to many countries like Spain, according to [20], all the major 3D CAD licensed software is used at all the industrial schools. In fashion and textile engineering, however, $3 \mathrm{D}$ software is not so popular yet, but 2D CAD software tools, such as Lectra's Modaris [21], Gerber's Accumark [22], Crea's Create [23], Polytropon's Polypattern [24], and Optitex's PDS [25], provide fashion students with knowledge on: 
- development principles and functions;

- the principles of garment pattern design;

- the rules of pattern design by size;

- the definition of a style and its versions;

- marker making;

- creating markers on fabrics with definition and changing parameters;

- preproduction garment specifications;

- preparation of pattern blocks for 3D simulation in 3D virtual prototype tools.

The teaching of commercial CAD systems for garment development in combination with draping and fitting evaluation has already been tested successfully. Those fashion students could design and develop their virtual 3D-model ideas from the CAD software directly into physical 3D physical garment prototypes. Thus, the students could improve their understanding of design rules suitable for draping and proper fitting. However, all CAD-licensed software has a limited useful life, since they are bound to become obsolete in time given the constant update of operating systems and the unstoppable growth of hardware and software and the improvement of their performance in a very demanding and competitive race [19]. CAD vendors for garment development release new versions in order to offer new features and guarantee a state-of-the-art performance. As a consequence, however, more often than not, universities are compelled to hold back updates because of the costs in which hardware and software entail.

\section{Methodology}

As a first step, comprehensive internet research was conducted along with the literature research as an inquiry into freeware and OSS tools. It came as a surprise that although a relatively large number of software tools exist for other disciplines like mechanical, electronic, or industrial engineering, similar tools for apparel pattern development were hard to find. Moreover, reviews on open source and freeware CAD systems for disciplines other than fashion and clothing have already been done, for example, Junk \& Kuen [26] have researched OSS for 3D Printing. Subsequently, a search for classification of open source CAD systems available online for pattern drafting have verified that the only CAD open-source, parametric, variational, feature-based, and procedural software available (15 December 2017) is Seamly2D. Another CAD software tool which was chosen for evaluation and comparison was Wild Ginger's Cameo v6, as it is not such a costly educational version when compared with the other licensed CAD software tools.

The licensed tools that were used to complete the comparison and evaluation were Crea's Create for 2D CAD pattern development and Polytropon's Polypattern. Students were shown a demonstration of all the software solutions, and after the completion of their learning process the students that were most efficient in the use of the tools and understanding of garment pattern developing were selected to participate in the research.

Seamly2D (formerly Valentina) is a patternmaking cross-platform programme that allows the development of garment patterns by professional designers or individual users. The software allows the user to insert his/her individual set of measurements or to use standard sizing tables as another option. The programme runs on Windows, Mac OSX, and Ubuntu, and is downloadable. Seamly2D can provide any sewer or clothing manufacturer the opportunity to create and develop digital patterns of any garment style; it can be easily downloaded from the internet and offers support in the context of using the interface and its tools. According to its forum [27], Seamy2D's open data formats and collaborative culture enables independent designers to become ethically profitable, and can empower designers focused on eco fashion and slow fashion. Another advantage of downloading Seamly2D and creating digital patterns with it instead of choosing a licensed and costly software is that independent small designers and manufacturers can create small-batch and custom-sized clothing collections which 
are essential to create a sustainable future. This way, local garment districts can be rebuilt, can reduce or eliminate low-wage labour and unethical working conditions, and even scale up to bigger productions.

Wild Ginger's Cameo v6 Pattern Design is an apparel pattern development software for professional pattern makers. Cameo's apparel production tools allow users to draft and edit patterns, customise size or grade patterns, lay markers, and create technical drawings and specifications. The software solution allows pattern creation and modification by anyone having appropriate skills. It contains all the tools that a pattern maker needs, such as the creation and transfer of darts, slash/spread, adding seam allowance, and pattern marking. Cameo is not an open source tool; it is sold in modules and libraries. Cameo runs only in Windows and, for the purpose of the research, the authors worked in the downloadable demo version of the software.

From observing Cameo v6's webpage, it is clear that the specific software is mainly focused on new CAD pattern making users and/or students as it suggested in the Digital Flat Pattern: The Apparel Designer's Handbook. This instruction book, which is not free, provides instructions for creating patterns for a wide range of styles-including bodices, dresses, jackets, skirts, pants, sleeves, collars, and pockets. Although, as mentioned above, the CAD software is not an OSS, its price is more affordable compared with other commercial programmes, and it includes free tutorial CAD software and example files for completing all styles illustrated in the book.

\subsection{Aim of the Research}

The aim of this research was to evaluate the usability of the existing OSS CAD software for garment prototype development and see if it can successfully support the learning process compared with two licensed forms of software. The metric used was the amount of time required to create a specific garment in all four CAD systems (Table 1). In order to do so, fourth year students with the knowledge of all four systems were asked to create 10 different digital patterns at the end of their learning process of CAD modelling in garment pattern making.

Table 1. Developing time for each style and each CAD system.

\begin{tabular}{ccccc}
\hline \multicolumn{5}{c}{ Time in Minutes for Each Pattern Cutting Programme } \\
\hline Type of Garment & Seamly2D & Cameo V6 & Polypattern & Crea \\
\hline Straight skirt & $30^{\prime}$ & $8^{\prime}$ & $5^{\prime}$ & $13^{\prime}$ \\
\hline Culottes & $45^{\prime}$ & $20^{\prime}$ & $9^{\prime}$ & $46^{\prime}$ \\
\hline Basic trousers & $3 \mathrm{~h}$ & $32^{\prime}$ & $20^{\prime}$ & $45^{\prime}$ \\
\hline Tracksuit trousers & $13^{\prime}$ & $12^{\prime}$ & $5^{\prime}$ & $13^{\prime}$ \\
\hline $\begin{array}{c}\text { Close fitting } \\
\text { bodice block }\end{array}$ & $40^{\prime}$ & $20^{\prime}$ & $20^{\prime}$ & $9^{\prime}$ \\
\hline Tracksuit top & $15^{\prime}$ & $19^{\prime}$ & $8^{\prime}$ & $19^{\prime}$ \\
\hline Basic shirt & $55^{\prime}$ & $1 \mathrm{~h} 7^{\prime}$ & $1 \mathrm{~h} 10^{\prime}$ & $58^{\prime}$ \\
\hline Vest & $1 \mathrm{~h}$ & $40^{\prime}$ & $35^{\prime}$ & $26^{\prime}$ \\
\hline Tailored jacket & $45^{\prime}$ & $33^{\prime}$ & $45^{\prime}$ & $45^{\prime}$ \\
\hline Two-piece sleeve & $30^{\prime}$ & $20^{\prime}$ & $35^{\prime}$ & $23^{\prime}$ \\
\hline
\end{tabular}

\subsection{Literature Research}

In other sectors (i.e., mechanical engineering) companies commonly organise tailored courses and training sessions in collaboration with leading global vendors in order to achieve a deeper knowledge on specific CAD-based software for specific fields of application according to the professional profile and the level of expertise of their users [28]. Such an approach, however, is not completely satisfactory, since it produces very well-trained CAD users but, often, does not take care of either the design thinking [29] or the linguistic basics [30] needed to fully exploit CAD performance. On the contrary, 
in the fashion industry, garment development learning and pattern design skills can be obtained through higher education fashion courses. Digital pattern development can be taught individually by CAD-software companies and their training teams, by attending a pattern design course (full-time, part-time, seminar) in a college, or attending an online course. Most of the higher educational institutes that provide fashion courses or clothing technology courses have access to educational licenses of CAD software for pattern development. However, according to [31], online education is increasingly becoming a dominant part of our education system.

\subsection{Problem Statement}

Leaving aside the question of the economic and ethical implications of adopting open-source software instead of licensed software, the issue addressed in the present paper is connected to the following question: Can any open-source CAD system for developing clothing patterns effectively support university courses when the teaching focus needs to be on the method rather than on the instrument itself?

In order to evaluate the performance of a 2D CAD system, the authors established a comparison between the already taught commercial CAD systems, an open-sourced software, and a fairly accessible -in terms of price-software available to fashion students. In a design-oriented approach, CAD students need to complete the assigned tasks by using the various tools available within the CAD environment. Hence, a CAD system is considered compliant with design education and training if it offers all the tools requested for modelling and drawing clothing products. The related CAD workbenches are thus considered:

- New pattern creation-the workbench to draw a new pattern piece from scratch with specific measurements;

- Insert new points and notches-the workbench to put grading and curve points on any place of the pattern;

- Measuring - the workbench to evaluate if a specific distance is correct;

- Curves- the workbench to model curves;

- Editing - the workbench to edit any part of the pattern by move, cut, unite, rotate, mirror, etc.;

- Darts, folds and gathers-the workbench to create, edit, and delete darts, and to fold and gather to any point of the garment.

The method workflow consists of three steps:

1. Selection of the basic pattern blocks in a standard size (12) that the students have the skills to develop digitally.

2. Development of prototype patterns in all four CAD systems through monitoring the passage of time for every task and every different CAD system.

3. Analysis of the results with respect to the time, efficiency, and number of steps.

\section{Results}

\subsection{Selection of Basic Pattern Blocks in a Standard Size 12}

Basic block patterns in a standard size 12 [32], were used to develop designs for the prototypes based on the instruction of metric pattern cutting of Winifred Aldrich [33]. More specifically, 10 styles were decided to be developed in all four programmes:

1. Straight skirt, 2. culottes 3 . basic trousers, 4. tracksuit trousers, 5. close fitting bodice block, 6. tracksuit top, 7. basic shirt, 8. vest, 9. the tailored jacket block, and 10. two-piece sleeve block.

Seam allowance was only put where it was permitted by the software. Grading was omitted, since it was not supported by the four and was not part of the current research. Size 12 was indicated 
as appropriate, therefore the basic block for each individual garment was based on the body measures of a size 12 (UK).

4.2. Development of Prototype Patterns in All Four CAD Systems with Monitoring the Passage of Time for Every Task and Every Different CAD System

Figures 1 and 2 show the digital patterns of the previous selection in the Polypattern CAD system:

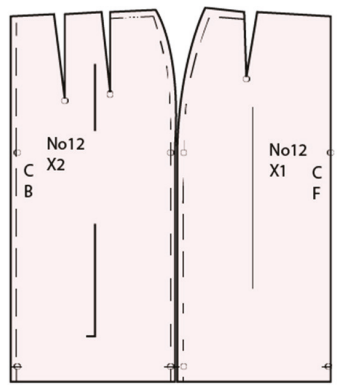

(a)

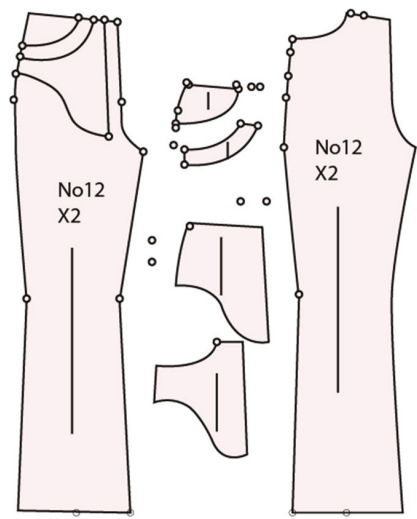

(b)

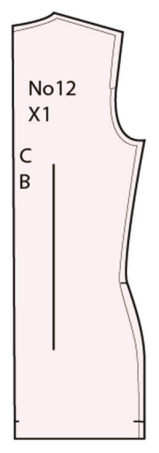

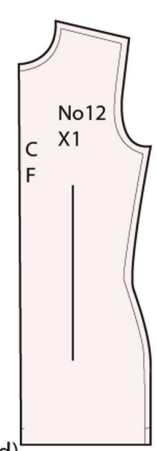

(d)

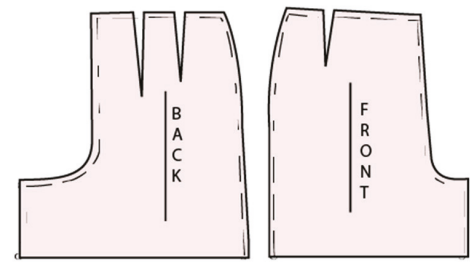

(c)
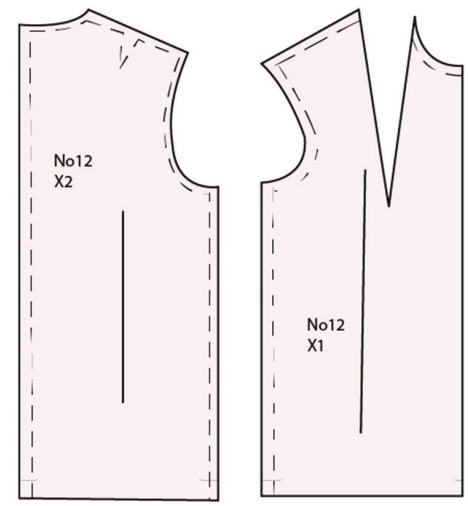

(f)

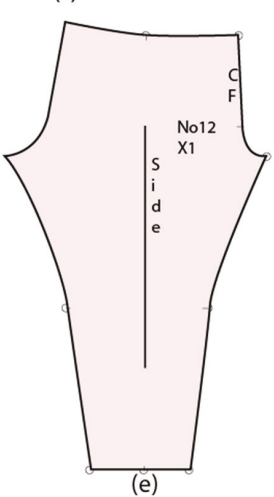

Figure 1. Polypattern computer-aided design (CAD): basic skirt (a), basic trousers (b), culottes (c), track-suit top (d), tracksuit trousers (e), close-fit bodice block (f). 

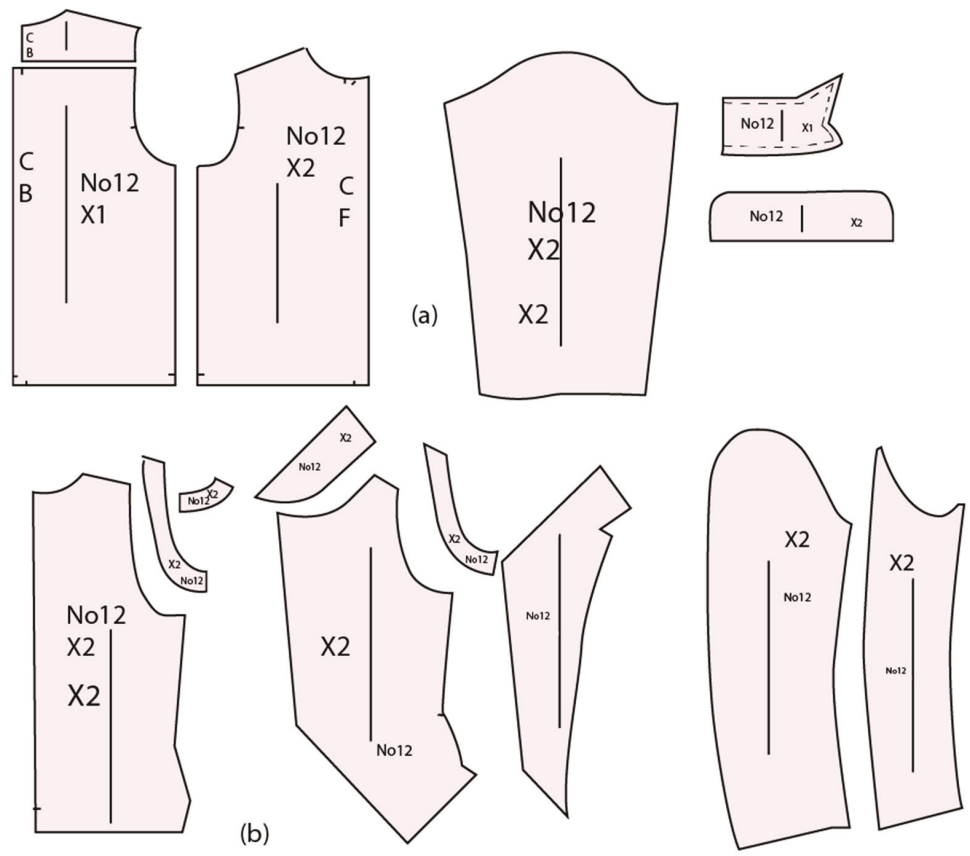

(c)
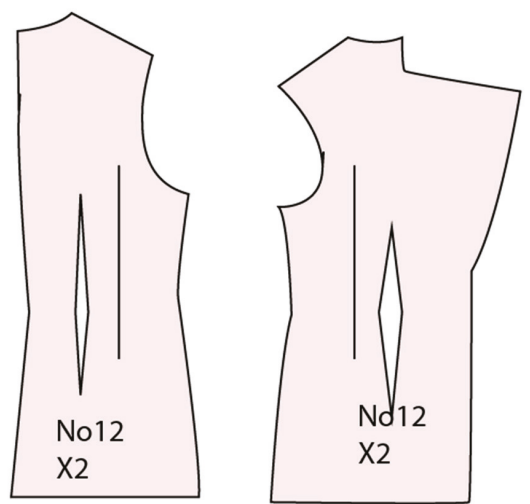

(d)

Figure 2. Polypattern CAD: basic shirt (a), vest (b), two-piece sleeve (c), basic jacket block (d).

\subsection{Analysis of the Results with Respect to the Time, Efficiency, and Number of Steps}

From the results obtained when analysing and comparing Seamly2D and Wild Ginger's Cameo v6 with the licensed Polypattern and Create, it has been concluded that currently this open-source CAD has not reached a sufficient level to replace commercial licensed parametric, variational, feature-based, and procedural CAD systems in academic courses. This is mainly because it lacks the implementation of some strategic tools:

- Creation of a new pattern piece: The development method in the non-licensed software (Seamly2D and (ameo) has many similarities to the traditional pattern development by hand. Above all, it is time consuming. 
- New point and notch inputs: All four software tools have different ways to put a new point or a notch on a pattern. However, moving a point takes longer in Seamly2D and Cameo.

- Measure tape: The ruler and measure tape for distances and curves is one of the basic tools of a programme. However Seamly2D does not support such a feature.

- Create curves: All four programmes can easily create curves

- Section move: Too complicated for Seamly2D, feasible in Cameo, easier in Polypattern and Crea

- Darts, folds and gatherings: The easier way to create them is in Crea and Polypattern. Open source Seamly2D needs to create a new pattern from the beginning and the exact distances for every new point are required by the user. Cameo requires multiple moves; the functions are not automatic.

- Cut and unite of pattern pieces: Seamly2D cannot unite cut pieces. Comparing all four, Polypattern provides the easiest and more efficient method.

- Rotation of pattern pieces: Seamly2D cannot rotate; the other three can do this easily.

- Seams: An older version of Seamly2D had a tool for seam allowance. The newer version has none. Cameo also lacks this function. If the user wants to add seams, they need to create parallel lines with the desired distance. Polypattern and Crea provide the seam allowance with three clicks.

- Sizing: Seamly2D and Cameo cannot cover this very important need for a pattern developer. Crea and Polypattern are both focused in satisfying the demands of creating complex styles in a rapid changing manufacturing environment like the one of apparel.

\section{Conclusions}

OSS for garment pattern development is still at an experimental stage. While such software can manipulate standard demands in digital garment prototyping—such as the creation of a new pattern piece from the beginning and drawing lines-dealing with commands such as cutting, rotating, adding seam allowance, and especially grading in other sizes, is still problematic. Procedures in OSS are complicated and follow the mentality of doing the pattern by hand. Within the experimental work, certain processes could only be done in licensed CAD systems and not in OSS. For example, section distance measuring could be done only in Polypattern, Crea, and Cameo, but not in OSS Seamly2S. The study found that the creation of darts, folds, and fabric gathering in OSS was by trial and error. Although prescribed procedures were followed, the control of adding seam allowance or moving a section was problematic, as the tutorial for Seamly2D referred to an older version that probably provided the function, but was no longer found in the newer version. Two-dimensional pattern design software based on flat patternmaking techniques has been successfully explored for patternmaking, grading, and creating pattern libraries within software for future retrieval [34]. More importantly, grading in different sizes, which is an irreplaceable tool and command for pattern developers in the fashion industry, is simplified as a process only in professional licensed CAD systems. Wild Ginger lacks this function, catering well to the needs of only small garment units, boutiques, and custom apparel makers. Measurements need to be put into the system to obtain the pattern block. OSS, like Seamly 2D, cannot successfully support the learning process. Unless the complexity decreases, and the OSS project employs a modular approach to software production, the project becomes less attractive to new users, resulting in a technical success decrease. Academic institutions, in order to prepare fashion students for situations they will face once they have entered the job market, need to provide the industry-based experiential-learning opportunities required for translating innovative designs into marketable garments. OSS tools for garment prototyping need further development in order to achieve this goal.

Author Contributions: Data curation, E.P.; Formal analysis, E.P.; Investigation, E.P.; Methodology, E.P.; Resources, P.K.; Supervision, N.B.; Writing — review \& editing, E.P.

Funding: This research received no external funding.

Conflicts of Interest: The authors declare no conflict of interest. 


\section{References}

1. Papachristou, E.; Bilalis, N. 3D virtual prototyping traces new avenues for fashion design \& product development-A qualitative study. J. Text. Sci. Eng. 2017, 6, 297. [CrossRef]

2. Papachristou, E.; Bilalis, N. Can 3D prototype conquer the apparel industry? J. Fash. Technol. Text. Eng. 2016, 4, 2. [CrossRef]

3. Istook, C. Rapid prototyping in the textile \& apparel industry: A pilot project. J. Text. Appar. Technol. Manag. 2000, 1,1 .

4. Bae, J.; May-Plumplee, T. Customer focused textile \& apparel manufacturing systems: Toward an Effective e-commerce model. J. Text. Appar. Technol. Manag. 2005, 4, 1-19.

5. Summers, J.D.; Shah, J.J. Mechanical Engineering Design Complexity Metrics: Size, Coupling, and Solvability. J. Mech. Des. 2010, 132, 021004. [CrossRef]

6. Amadori, K.; Tarkian, M.; Ölvander, J.; Krus, P. Flexible and robust CAD models for design automation. Adv. Eng. Inform. 2012, 26, 180-195. [CrossRef]

7. Bodein, Y.; Rose, B.; Caillaud, E. A roadmap for parametric CAD efficiency in the automotive industry. Comput. Aided Des. 2013, 45, 1198-1214. [CrossRef]

8. Bodein, Y.; Rose, B.; Caillaud, E. Explicit reference modeling methodology in parametric CAD system. Comput. Ind. 2014, 65, 136-147. [CrossRef]

9. Johnson, M.D.; Valverde, M.L.; Thomison, D.W. An investigation and evaluation of computer-aided design model complexity metrics. Comput.-Aided Des. Appl. 2018, 15, 61-75. [CrossRef]

10. Diwakaran, R.P.; Johnson, M.D. Analyzing the effect of alternative goals and model attributes on CAD model creation and alteration. Comput.-Aided Des. 2012, 44, 343-353. [CrossRef]

11. Hamade, R.F.; Ammouri, A.H.; Artail, H. Toward pre-dicting the performance of novice CAD users based on their profiled technical attributes. Eng. Appl. Artif. Intell. 2012, 25, 628-639. [CrossRef]

12. Hamade, R.F.; Artail, H.A.; Jaber, M.Y. A study of the impact of the willingness-to-learn of CAD novice users on their competence development. Comput. Ind. Eng. 2011, 61, 709-720. [CrossRef]

13. Camba, J.D.; Contero, M.; Company, P. Parametric CAD modelling: An analysis of strategies for design reusability. Comput.-Aided Des. 2016, 74, 18-31. [CrossRef]

14. Johnson, M.D.; Diwakaran, R.P. An educational exercise examining the role of model attributes on the creation and alteration of CAD models. Comput. Educ. 2011, 57, 1749-1761. [CrossRef]

15. Seamly2D. Available online: http://valentina-project.org/ (accessed on 10 October 2017).

16. Cameo v.6 (Wild Ginger). Available online: https://www.wildginger.com/downloads/cameo6download.htm (accessed on 10 October 2017).

17. ABET. Available online: https://www.abet.org/accreditation/accreditation-criteria/criteria-for-accreditingengineering-programs-2019-2020/\#GC3 (accessed on 20 January 2019).

18. Ullah, S.; Harib, K. Tutorials for Integrating CAD/CAM in Engineering Curricula. Educ. Sci. 2018, 8, 151. [CrossRef]

19. Di Angelo, L.; Di Stefano, P.; Leali, F. Can Open-Source 3D Mechanical CAD Systems Effectively Support University Courses? Int. J. Eng. Educ. 2016, 32, 1313-1324.

20. Garcia, R.R.; Santos, R.G.; Quiros, J.S.; Penin, P.I.A. Present state of CAD teaching in Spanish Universities. Comput. Educ. 2005, 44, 201-215. [CrossRef]

21. Modaris, Lectra. Available online: https://www.lectra.com/en/modaris (accessed on 2 October 2017).

22. Accumark Gerber Technologies. Available online: http://www.gerbertechnology.com/fashion-apparel/plan/ accumark/ (accessed on 3 May 2018).

23. Crea Solution. Available online: http://www.creasolution.it/en/products/design/2d-cad-fashion/?lang=en (accessed on 25 March 2018).

24. Polypattern Polytropon. Available online: http://www.polytropon.com/en/PolyPattern/cad-pattern-designsoftware.html (accessed on 25 March 2018).

25. Optitex. Available online: https://optitex.com/solutions/odev/pattern/ (accessed on 25 March 2018).

26. Junk, S.; Kuen, C. Review of Open Source and Freeware CAD Systems for Use with 3D-Printing. Procedia CIRP 2016, 50, 430-435. [CrossRef]

27. Seamly. Available online: https://seamly2d.wordpress.com/about/ (accessed on 20 January 2019). 
28. Field, D.A. Education and training for CAD in the auto industry. Comput.-Aided Des. 2004, 36, 1431-1437. [CrossRef]

29. Katz, R. Integrated thinking in mechanical engineering education. Int. J. Eng. Educ. 2015, 31, 1613-1621.

30. Cheng, N. Teaching CAD with language learning methods. Acadia 1997, 97, 173-188.

31. Singh, V.; Holt, L. Learning and best practices for learning in open-source software Communities. Comput. Educ. 2013, 63, 98-108. [CrossRef]

32. Beazley, A. Size and fit: The development of size charts for clothing_Part 3. J. Fash. Mark. Manag. 1999, 3, 66-84. [CrossRef]

33. Aldrich, W. Metric Pattern Cutting for Women's Wear, 6th ed.; Wiley: Hoboken, NJ, USA, 2015.

34. Jhanji, Y. Computer-aided design-Garment designing and patternmaking. In Automation in Garment Manufacturing; Nayak, R., Padhye, R., Eds.; A Volume in the Textiles Institute Book Series; Technological Institute of Textile and Sciences: Bhiwani, India, 2018; pp. 253-290.

(C) 2019 by the authors. Licensee MDPI, Basel, Switzerland. This article is an open access article distributed under the terms and conditions of the Creative Commons Attribution (CC BY) license (http://creativecommons.org/licenses/by/4.0/). 
Article

\title{
Optimization of the Manufacturing Strategy, Machining Conditions, and Finishing of a Radial Impeller
}

\author{
Fotios I. Stratogiannis, Nikolaos I. Galanis, Nikolaos E. Karkalos and Angelos P. Markopoulos * \\ Laboratory of Manufacturing Technology, School of Mechanical Engineering, National Technical University of \\ Athens, Heroon Polytechniou 9, 15780 Athens, Greece; fstratog@gmail.com (F.I.S.); \\ ngalanis@central.ntua.gr (N.I.G.); nkark@mail.ntua.gr (N.E.K.) \\ * Correspondence: amark@mail.ntua.gr; Tel.: +30-210-772-4299
}

Received: 21 November 2019; Accepted: 24 December 2019; Published: 27 December 2019

\begin{abstract}
Impellers are the most crucial components of pumps, as they directly determine the velocity profile of the fluid flowing through the pump and its efficiency. Given that the impellers have a complex geometry, they pose an important challenge to the manufacturer in order to construct them with the best possible dimensional accuracy and surface quality, and also achieve short machining times. In the present paper, the machining operations for the manufacture of a radial impeller were designed and implemented for the case of a single-entry semi-closed radial flow impeller. At first, the best milling strategies, optimum cutting conditions, and appropriate cutting tools were selected for each of the three machining phases, namely, roughing, semi-finishing, and finishing. Then, an experimental investigation was conducted, especially for the optimum process conditions during finishing of impeller blades, using Taguchi L16 orthogonal array. After the analysis of surface roughness was conducted for the 16 experiments, it was found that the most important parameters were spindle speed and feed. Furthermore, the optimum settings were determined as the maximum spindle speed and the lowest feed per tooth value and a regression model correlating process parameters with surface roughness was established with a high degree of accuracy.
\end{abstract}

Keywords: milling; radial impeller; computer-aided manufacturing (CAM); CNC machining; Taguchi method; analysis of variance (ANOVA)

\section{Introduction}

An impeller is the main rotating component of a centrifugal pump. Usually, it is composed of blades and a hub, with its main function being the transfer of energy from the motor to the working fluid. Impeller blades are composed of a suction surface, a leading edge, and a pressure surface. In the relevant literature, it can be observed that there are more than 120 varieties of impellers [1,2]. The design and manufacturing stages of a pump impeller should comply with three separate, but equally important requirements. At first, the impeller should provide an appropriate relative velocity distribution on both the pressure and suction surfaces of the blade in order to minimize the possibility of flow separation and efficiency reduction. Moreover, the blade shape must be selected in a way that it can be manufactured with adequate precision and with relatively low cost on a computer numerical control (CNC) machine tool. Finally, the blade should be safe regarding its mechanical strength, thus reducing the possibility of excessive deformation or even fracture during its operation $[3,4]$.

Machining of complex 3D geometries has been a topic of interest for several decades as it constitutes a demanding process. Such geometries are usually encountered in the aircraft industry, surgical prostheses, components with optical characteristics, and automotive and electronics industries, among others. In the manufacturing process of complex parts, one of the most important subjects 
is the tool path patterns, as they determine how the cutting tool processes the surfaces, whether the paths are well-planned, and if efficiency and surface quality can be increased. In the case of impellers, several works have been conducted during the past few decades. Young and Chuang [5] were among the first to investigate the feasibility of machining of impellers on five-axis machine tools in order to overcome common problems arising when machining complex parts on three-axis machine tools, such as possibility of collision and overcut, and at the same time maintain a reasonable machining time. Thus, they designed a detailed algorithm for tool-path generation dividing the machining area into two regions, namely the blades and the hub; they successfully verified the results in simulation software and conducted a detailed analysis of machining error based on comparison with the original geometry as well. Kaino [6] presented various methods for machining of large impellers on five-axis machining centers. He underlined the main difficulties of machining impeller blades such as the constant change of cutting depth and cutting resistance, low machine tool stiffness for rotary axes, and chattering, and proposed using a special technique for the improvement of machining efficiency, adopting contour machining, and employing a tool with variable pitch and lead angle.

The majority of scientific work on impeller manufacturing was concentrated on efficient tool-path generation strategies or optimization of the milling strategies in respect to various indicators. Wu et al. [7] studied the effect of integral impeller stiffness on the machining process in order to determine the optimum machining path. An open impeller was machined in a five-axis vertical machining center and, for the measurements, a single blade was selected. Afterwards, the stiffness matrix of the blade in respect to other parts of the system was created and its performance relevant to the cutter movements was evaluated and validated with experiments in order to determine the optimum feed direction, reduce vibrations, and improve dimensional accuracy. Fan and $\mathrm{Xi}$ [8] proposed an adaptive method for the optimization of tool-path during three-axis machining of impeller blades. Their method included the division of the blade surface into four sub-surfaces after their geometry is mathematically defined, and then the tool-paths were generated using an optimization algorithm, also taking in consideration the fluid flow requirements for the impeller. They stated that, using the proposed approach, machining costs can be reduced, tool-path generation is simplified, and geometrical characteristics are in accordance with computational fluid dynamics (CFD) analysis requirements.

Fan et al. [9] developed a novel tool-path generation method for the case of centrifugal impellers with arbitrary surface blades using the flank milling technique. They noted that, although the point machining technique was usually used for arbitrary surfaces, it could be beneficial to combine this technique with features of flank machining in order to increase the accuracy of geometrical characteristics of the blades. Thus, they modeled the arbitrary blade as an approximate ruled blade and applied the flank machining method for rough and semi-finish machining. Finally, they concluded that this approach led to the reduction of machining time by reduction of the path-line length. Li et al. [10] developed a method for smooth machining of ruled-surface blades represented by third-order non-uniform rational basis spline (NURBS) curves. After creating the computer-aided design (CAD) model of the blades, the machining process was programmed and verified in a CNC machine tool. Their findings indicate that the CAD model using NURBS required fewer points than other types of surfaces; the adopted interpolation method led to smoother and more precise trajectories with lower machining error. Fan and Xi [11] presented also a new tool-path generation method for special cases of machining centrifugal impellers. At first, they noticed that the commonly employed isoparametric method for tool-path generation was not sufficient, as it led to an increase in machining time. The proposed method was based on the generation of a new type of machining layers of the final geometry and was able to produce sparser tool-paths with a shorter length, something that simplified the calculation process of the tool path curves and increased the efficiency of the machining process.

Tang et al. [2] presented an interesting study about the tool-path generation during the clean-up stage of the impeller machining process. In order to be able to remove the unwanted material remaining after the finishing process in some regions, they developed a method related to point-searching for determining the appropriate tool paths and implemented it on computer-aided manufacturing 
(CAM) software to test its feasibility. Their findings showed that the method is efficient in planning the appropriate tool-paths for the clean-up process in a simple way and led to rapid and accurate determination of the clean-up regions. Fan et al. [12] created a novel strategy of five-axis machining of centrifugal impellers based on regional milling for both roughing and finishing stages. Specifically, this approach can combine favorable features of both flank and sub-surface machining methods. For the roughing stage, the objective was to choose a cutter with relatively large diameter and achieve the shortest path length, whereas for the finishing stage, owing to the fluid flow requirements, interlinking of tool path curves in some regions as well as reduction of tool interference should be achieved. Finally, machining efficiency during roughing by reducing the required time and better distribution of machining errors along with increased aerodynamic efficiency during finishing was achieved.

Wang et al. [13] presented a multi-parameter optimization study regarding the manufacturing of an axial impeller in a five-axis machining center. They introduced a cost-effective method for machining parameters optimization based on absolute average error and standard deviation of online measured points using grey relational theory to define a single objective optimization problem with three variables, namely, the length to diameter ratio, depth of cut, and feed rate. Arriaza et al. [14] conducted a study regarding the compromise between machining time and energy consumption during rough machining of impellers. In their work, they conducted an optimization using the response surface methodology with four input variables, namely, spindle speed, feed rate, depth and width of cut, and two responses (consumed energy and machining time). Their findings indicated that the selection of an appropriate feed rate value can lead to reduction of the necessary spindle speed as well as the depth and width of cut; spindle speed was found to be the most important factor for controlling energy consumption and width of cut was the most important factor regarding machining time.

Chaves-Jacob et al. [15] presented a numerical method for the optimization of the finishing process for the five-axis machining of impeller blades. In their work, they focused both on geometric and cost indicators and compared point milling and flank milling strategies using these indicators for the case of an industrial impeller. They proposed that this method can be employed to determine the optimum strategy in other cases of complex workpieces. Peng et al. [16] compared different methods for fabrication of impellers such as conventional manufacturing, additive manufacturing, and remanufacturing, regarding their environmental impact. More specifically, they employed plunge milling, laser cladding forming, and additive remanufacturing techniques, and then a life cycle analysis was conducted for them. It was shown that remanufacturing was the better choice, followed by additive manufacturing and conventional manufacturing. However, the pure additive manufacturing processes can sometimes be less environmentally friendly than the conventional ones, owing to increased power and material consumption.

Young et al. [17] further investigated the roughing strategies for five-axis impeller machining in order to develop a methodology especially suited for the efficient roughing of centrifugal impellers by taking into consideration the appropriate depths of cut required, the residual material thickness and surface conditions on the tool path, and the control of step-over. Tang et al. [18] investigated the effect of the use of a varying feed rate during machining of blades in a four-axis machining center. They noted that the use of constant feed rate on four-axis machining centers results in overcutting near the leading and trailing edges of the blade, and thus they determined the appropriate lead angle and speed of each axis to overcome this problem. By controlling the lead angle, they achieved the avoidance of collisions and, by imposing limitations on the feed speed and acceleration, overcut was also avoided and precision was improved for the produced blade. Heo et al. [19] proposed an efficient method for roughing of impellers in the case of five-axis CNC machine tools. At first, they noticed that, owing to more complex control requirements for five-axis machines, the required time for roughing was increased compared with that for three-axis machines. Thus, they developed a novel method for machining the impeller by dividing it into various unit machining regions, where machining would be performed in a similar way as in three-axis machines using a repetitive procedure. This can be achieved by fixing the rotating and tilting axes of the machine bed and then, by maintaining the cutting 
tool at a suitable inclination angle in respect to the blade surface, it was ensured that no collision would happen as well. Kim et al. [20] also proposed a method for the machining of impellers by integrating techniques applied to three-axis and five-axis machines in order to reducing roughing time. They noted that five-axis machines require long machining times for producing a single product, although they can avoid collisions more easily than three-axis machines. Their approach involved two distinct steps: a first step of three-axis machining and a final step of full five-axis machining for the completion of the roughing process. The method was applied to both a splitter and non-splitter type impeller and it was shown that, in both cases, the tool-path was shorter and total machining time was reduced by $17 \%$ and $11 \%$, respectively.

From the aforementioned studies in the relevant literature, it can be concluded that the majority of works regarding impeller manufacturing have focused on the generation of optimum tool-paths and optimization of process parameters for different machining phases. However, works on manufacturing of radial impellers were somewhat limited, as well as the studies on optimum finishing conditions using high spindle speed values. Thus, in the present work, it is intended to present a detailed study on the manufacturing of a radial pump impeller, beginning with the design of required machining operations, their actual implementation, and the evaluation of surface quality of the radial impeller after conducting an investigation regarding the optimum finishing conditions.

\section{Methodology}

After the initial design of the appropriate geometry of the radial impeller, illustrated in Figure 1, as well as its evaluation regarding its aerodynamic characteristics, which were investigated in a previous study [21], the manufacturing of the actual impeller was able to be conducted. The design of the machining process of the radial impeller, which includes complex geometries, is essential to be conducted using specialized CAM software, such as NX CAM, which can be accessed through Siemens NX software. Some of the main challenges regarding the machining of complex geometries of the impeller blades or vanes and hub are the achievement of the required dimensional accuracy and surface quality, as well as the reduction of machining time. Apart from the use of cutting tools with a special geometry, the machining strategy needs to be carefully planned in order to achieve the desired geometrical features and suitable process parameters are required to be determined as well. Thus, all of these tasks need to be appropriately addressed by the use of CAM software in order to successfully perform the machining process of the impeller.

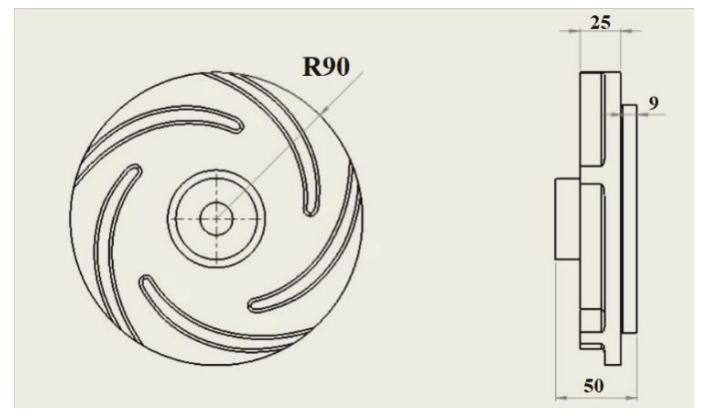

Figure 1. Geometry of the radial impeller with basic dimensions.

In the present work, the various stages of manufacturing of a radial pump impeller are presented in detail. At first, the machining processes required for the fabrication of the impeller are planned using dedicated CAM software. The manufacturing of the impeller is divided into three phases, namely, the roughing, semi-finishing, and finishing phase, and for each phase, the appropriate milling strategies, process parameters, cutting tools, and fixtures are determined, either using recommended 
values from manufacturers or the CAM software or by initial machining tests. After all phases are simulated in the environment of the CAM software, the appropriate G-code is produced and then the actual machining stage takes place in a three-axis vertical machining center. Finally, the manufactured impeller is evaluated according to its surface quality. Regarding the surface quality evaluation, a series of experiments is conducted under various spindle speed, axial depth of cut, and feed per tooth values in order to determine the optimum conditions for the finishing of the blades' inner and outer surfaces. The stages of the manufacturing of the radial pump impeller are presented in a schematic in Figure 2.

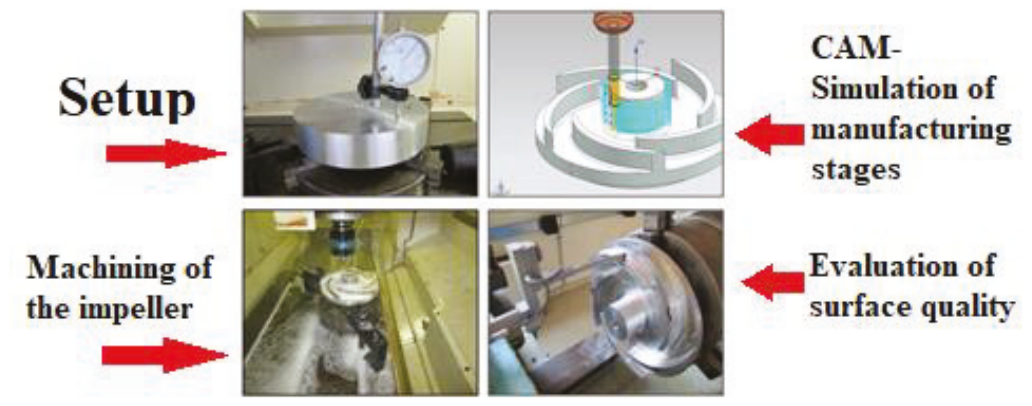

Figure 2. Schematic of the steps required for the design and manufacture of the radial impeller. CAM, computer-aided manufacturing.

The manufacturing process of the radial pump impeller is carried out on a vertical CNC machining center; the CNC machining center, presented also in Figure 3, is OKUMA MX-45 VAE with an OSP7000M control unit with three-axis, maximum power $7.5 \mathrm{~kW}$, and $10 \mu \mathrm{m}$ accuracy. For high speed machining, during some of the manufacturing phases of the impeller, a GERARDI GSS-10 spindle speeder was employed, with capabilities of achieving a six-fold increase of spindle speed using planetary gear mechanism. In order to fix the cutting tools on the tool holder when spindle speeder is used, ER16 type collets were employed.

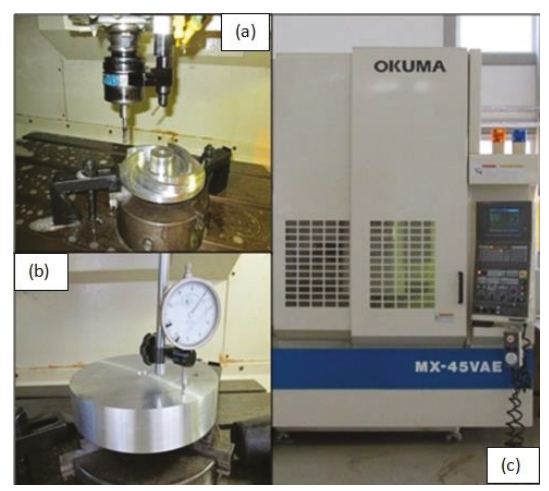

Figure 3. (a) Spindle speeder, (b) workpiece, and (c) computer numerical control (CNC) milling machine used for impeller manufacturing.

As it will be explained in detail in Section 3, four different cutting tools are employed in various phases of the machining process. The cutting tools are presented in Figure 4 and their characteristics are summarized in Table 1. 


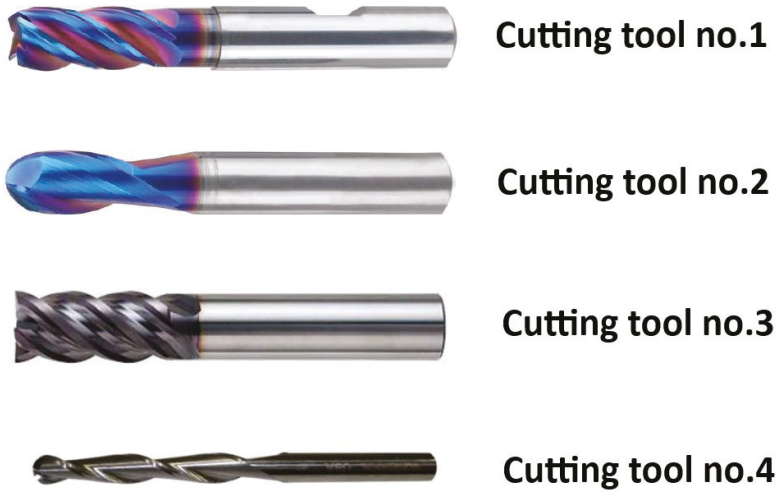

Figure 4. Cutting tools employed in the present work.

Table 1. Characteristics of the cutting tools employed in the present work.

\begin{tabular}{cccc}
\hline No of Cutting Tool & Type & Diameter $(\mathbf{m m})$ & Material \\
\hline 1 & End mill & 10 & Cemented Carbide H10 \\
2 & Ball nose & 10 & Cemented Carbide H10 \\
3 & End mill & 10 & Cemented Carbide H10 \\
4 & Ball nose & 4 & Cemented Carbide H10 \\
\hline
\end{tabular}

Cutting is performed under wet conditions by using P3 Multan S cutting fluid; this cutting fluid is semi-synthetic coolant mixed with water in a 1:3 ratio. Finally, the workpiece material for the radial impeller is Aluminum alloy 7075 (also denoted with the ISO name AlZn5.5MgCu). This aluminum alloy has zinc as the main alloying element and is of high strength and toughness, which is very frequently used in applications in the aviation industry [22,23]. It has low corrosion resistance with mechanical stress leading to brittle fracture-something that can be further treated with special heat treatments [23]. It can also be hardened with precipitation after heat treatment of solubilization, quenching, and aging [24]. The typical chemical composition of Al 7075 alloy is presented in Table 2.

Table 2. Typical chemical composition of aluminum alloy 7075 [22].

\begin{tabular}{cccccccccc}
\hline Zn (\%) & Mg (\%) & Cu (\%) & Si (\%) & Fe (\%) & Mn (\%) & Cr (\%) & Ti (\%) & Other & Al (\%) \\
\hline 5.67 & 2.21 & 1.35 & 0.40 & 0.30 & 0.08 & 0.08 & 0.06 & 0.06 & Balance \\
\hline
\end{tabular}

\section{Machining Processes for the Manufacturing of the Impeller}

\subsection{First Phase of Machining}

Roughing is usually the first phase of the machining processes. This phase constitutes the main material removal phase, where the initial bulk material is removed up to a specific thickness until the second phase of semi-finishing will take place and, eventually, the final surface will be created after the finishing phase. Consequently, during this first phase, there are no strict requirements regarding surface roughness, as the main objective is the removal of a large quantity of material in as little machining time as possible. In the present work, a total of two different impellers were machined by different roughing conditions in order to evaluate two different strategies, namely the trochoidal and follow periphery strategy, and finally select the most appropriate among the two for the case of the manufacturing of the radial impeller.

For the case of the trochoidal milling strategy, depicted in Figure 5, roughing is performed with an axial depth of cut (denoted as $\mathrm{a}_{\mathrm{p}}$ ) of $15 \mathrm{~mm}$, step-over of $20 \%$, and an end mill with $10 \mathrm{~mm}$ diameter 
as cutting tool. More specifically, these values were selected according to the recommendations of the CAM software for this milling strategy; the depth of cut value should be defined as less than two times the tool diameter, the step-over value should be defined less than $20 \%$ of the end mill diameter, feed per tooth (denoted as $\mathrm{f}_{\mathrm{z}}$ ) can have high values, and cutting speed (denoted as $\mathrm{v}_{\mathrm{c}}$ ) can also be defined 10 times higher than the other conventional strategies. This milling strategy can exploit the end mill cutting edge to a great extent, leading to uniform tool wear along the cutting edge, but also to increased machining time. In total, the roughing stage for the first impeller was performed in three steps. During the first step, the hub was created by peripheral milling, with an axial depth of cut of 15 $\mathrm{mm}$ and a step-over value of $1 \mathrm{~mm}$. During the second step, the trochoidal method was employed with the aforementioned conditions. The third step was carried on to remove material in the space between adjacent blades, which could not be previously removed owing to the limited gap between them. When the trochoidal method was employed, spindle speed (denoted as N) was set to $5000 \mathrm{rpm}$ and feed speed (denoted as $\mathrm{v}_{\mathrm{f}}$ ) at $1000 \mathrm{~mm} / \mathrm{min}$. The total time required for this phase was calculated to be $32 \mathrm{~min}$ and $15 \mathrm{~s}$.

\section{Roughing of the hub}

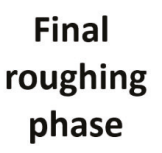

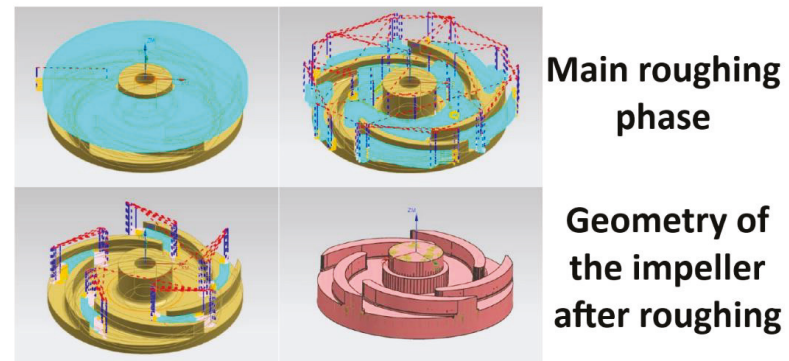

Figure 5. Snapshots of the roughing phase of the radial impeller using the trochoidal milling strategy.

For the second impeller the follow periphery milling strategy, available in the NX CAM software, was employed for roughing, as can be seen in Figure 6 With this method, the same spindle speed and feed speed values were selected as with the trochoidal method, namely $5000 \mathrm{rpm}$ and $1000 \mathrm{~mm} / \mathrm{min}$, respectively, whereas depth of cut was $2 \mathrm{~mm}$ and step-over value was $2 \mathrm{~mm}$. In this case, a carbide end mill with a diameter of $10 \mathrm{~mm}$ was employed. When the follow periphery strategy is employed, higher tool wear is observed closer to the lower part of the cutting edge, up to $2 \mathrm{~mm}$, which is very different compared with the tool wear when the trochoidal milling strategy is employed. However, it is observed that the machining time is much lower using the follow periphery strategy. More specifically, the total time required for this phase was calculated to be $19 \mathrm{~min}$ and $45 \mathrm{~s}$, almost half the time required for the trochoidal milling strategy. After the roughing process was completed, a material layer of 0.3 $\mathrm{mm}$ thickness remained at the floor surface of the impeller, as well as a layer of $2 \mathrm{~mm}$ at the blades surfaces and a layer of $5 \mathrm{~mm}$ at the hub.

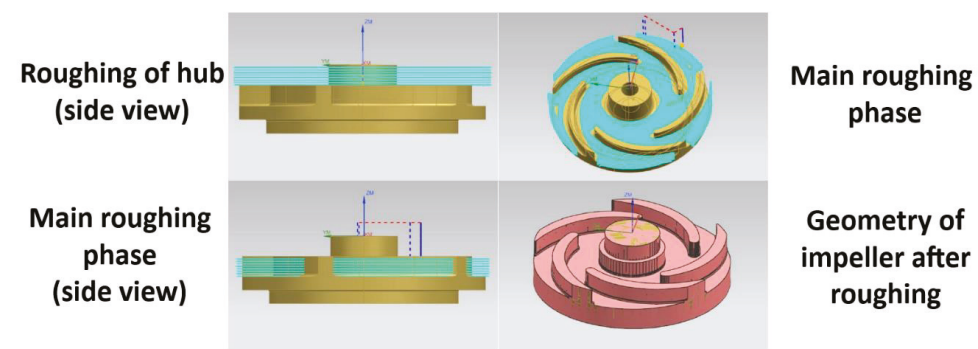

Figure 6. Snapshots of the roughing phase of the radial impeller using the follow periphery strategy. 


\subsection{Second Phase of Machining}

The second phase of the machining process of the radial impeller was the semi-finishing phase, presented in Figure 7 During this phase, the same milling strategy and cutting conditions were selected for each of the two impellers that were previously processed with two different roughing strategies. For this phase of machining, three cutting tools were selected, both end mills and ball nose cutters. With the ball nose tool of $10 \mathrm{~mm}$ diameter, $7000 \mathrm{rpm}$ spindle speed and feed speed of $500 \mathrm{~mm} / \mathrm{min}$ was selected and then, with the ball nose cutter of $4 \mathrm{~mm}$ diameter, $6000 \mathrm{rpm}$ spindle speed and feed speed of $200 \mathrm{~mm} / \mathrm{min}$ was selected. The duration of the semi-finishing stage was $4 \mathrm{~min}$ and $10 \mathrm{~s}$.

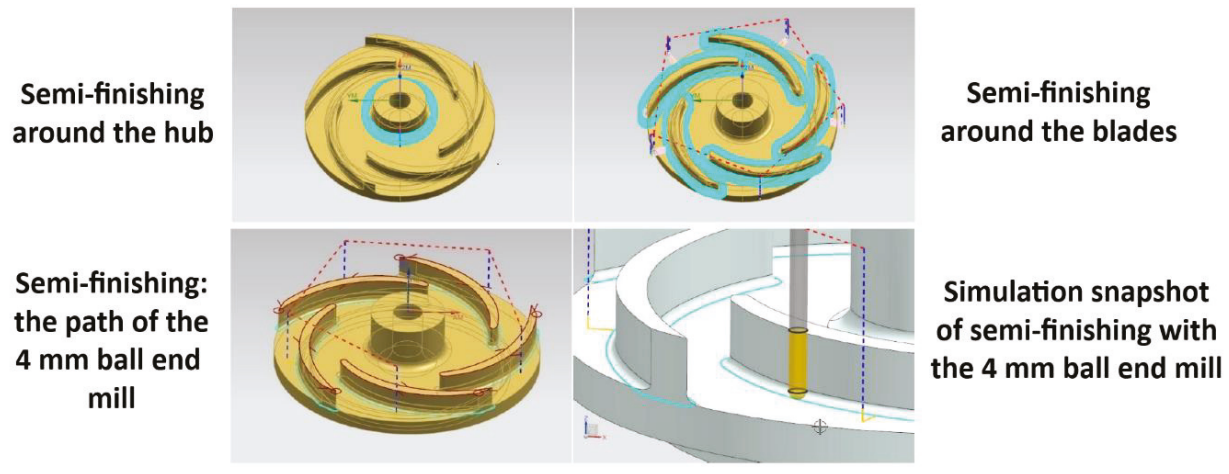

Figure 7. Snapshots of the semi-finishing phase of the radial impeller.

\subsection{Third Phase of Machining}

Finally, the finishing stage of machining process took place on the impellers, as depicted in Figure 8 Different cutting conditions were appropriately selected for various parts of the impeller in order to provide the maximum possible surface quality. For the upper part of the blades, $7000 \mathrm{rpm}$ spindle speed and feed speed of $420 \mathrm{~mm} / \mathrm{min}$ was selected with a ball nose cutting tool. Moreover, the bottom surface of the impeller was finished with the follow periphery method with a spindle speed of $7000 \mathrm{rpm}$ and feed speed of $420 \mathrm{~mm} / \mathrm{min}$. Furthermore, the hub of the impeller was machined at two sub-stages, with a $10 \mathrm{~mm}$ diameter end mill with radial depth of cut $2 \mathrm{~mm}$, spindle speed $7000 \mathrm{rpm}$, and feed speed values of 400 and $420 \mathrm{~mm} / \mathrm{min}$.

Especially, the cutting conditions for profile milling strategy on blades surfaces are calculated by the Taguchi method from the environment of Minitab 17 statistical software. Using the Taguchi method, orthogonal arrays are employed to investigate how different factors of a process can affect the mean and average of a response. Using the Taguchi method, it is possible to avoid using the full factorial approach, which involves all the possible combinations between the levels of factors and conduct experiments using a minimum number of these combinations. In the present work, three parameters, namely, spindle speed, axial depth of cut, and feed per tooth, are desired to be varied at four levels each, thus from Minitab Software, it is deduced that the Taguchi L16 orthogonal array should be employed. The selected range of parameters' values is in accordance with the cutting tool manufacturer's specifications for machining aluminum, and all different combinations are summarized in Table 3. It is to be noted that, in order to be able to use 16 different conditions, different conditions were applied on the external and internal surfaces of blades of two different impellers. 


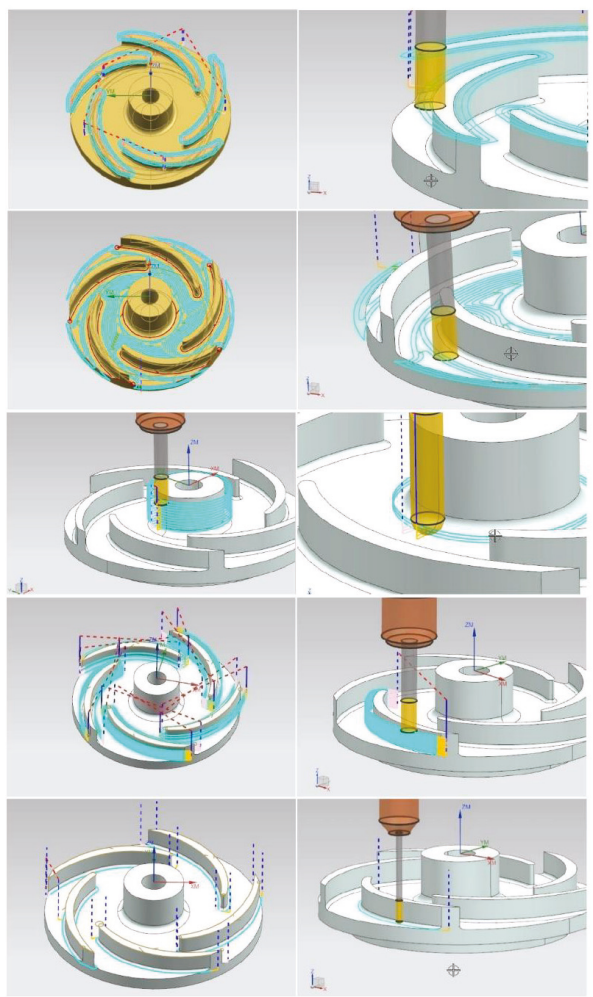

Finishing of the upper surface of the blades

Finishing of the "floor" surface of the impeller

Finishing of the hub

Finishing of the blades' surfaces with $10 \mathrm{~mm}$ ball end mill

Finishing of the blades' surfaces with $4 \mathrm{~mm}$ ball end mill

Figure 8. Snapshots of the finishing phase of radial impeller.

Table 3. Process conditions for the finishing of impeller blades.

\begin{tabular}{cccc}
\hline No of Experimental Test & Spindle Speed $(\mathbf{r p m})$ & $\mathbf{a}_{\mathbf{p}}(\mathbf{m m})$ & $\mathbf{f}_{\mathbf{z}}$ (mm/tooth) \\
\hline 1 & 10,000 & 1 & 0.0042 \\
2 & 10,000 & 2 & 0.0064 \\
3 & 10,000 & 3 & 0.0086 \\
4 & 10,000 & 4 & 0.0108 \\
5 & 12,600 & 1 & 0.0064 \\
6 & 12,600 & 2 & 0.0042 \\
7 & 12,600 & 3 & 0.0108 \\
8 & 12,600 & 4 & 0.0086 \\
9 & 15,300 & 1 & 0.0086 \\
10 & 15,300 & 2 & 0.0108 \\
11 & 15,300 & 3 & 0.0042 \\
12 & 15,300 & 4 & 0.0064 \\
13 & 18,000 & 1 & 0.0108 \\
14 & 18,000 & 2 & 0.0086 \\
15 & 18,000 & 3 & 0.0064 \\
16 & 18,000 & 4 & 0.0042 \\
\hline
\end{tabular}




\section{Impeller Manufacturing and Evaluation}

\subsection{Manufacturing Processes of the Impeller}

After the various phases of the machining process were determined in the CAM software, the setup of the three-axis CNC machining center is performed. As the initial bulk is a cylindrical workpiece, it was fixed on the machine tool with a chuck. After the cutting tools were selected and the relevant G-code was loaded onto the CNC machine, the first phase of the machining process took place, according to the predefined plan.

It is noteworthy to mention that, during the semi-finishing phase, when the outer surface of the five blades was machined with the $4 \mathrm{~mm}$ diameter ball nose cutter, the chattering phenomenon occurred with direct consequences on the condition of the cutting tool and the surface quality of the blades, as can be seen in Figure 9 In this case, several alterations to the initially chosen process conditions were conducted, mainly reducing the spindle speed and feed speed to values as low as $20 \%$ of the initial ones, namely spindle speed of $1200 \mathrm{rpm}$ and feed of $40 \mathrm{~mm} / \mathrm{min}$. The impact of the chatter to the surface quality of the blades was quantified through surface roughness measurement and is presented in Section 4.2. After the semi-finishing phase was completed, the finishing process took place with the predefined process conditions for each area of the impeller.

Finishing with $4 \mathrm{~mm}$ ball end mill

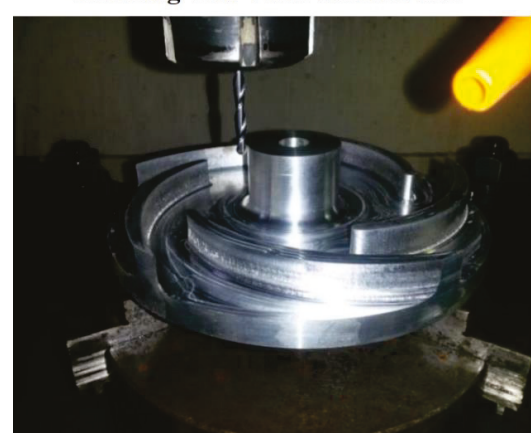

region with chatter marks

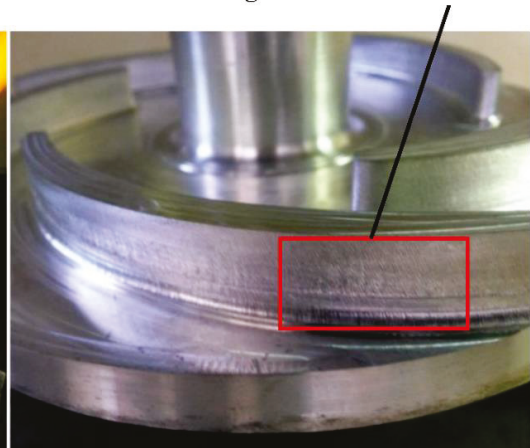

Figure 9. Characteristic marks on the outer surface of the impeller blades owing to chatter during the semi-finishing phase.

After the finishing phase was completed, the surface quality of the radial impeller was evaluated, and then the produced radial impellers were ground in order to render an excellent surface finish, as can be seen in Figure 10 It is to be noted that the grinding stage does not constitute a part of the investigation regarding the optimum conditions for improving surface quality during the finishing stage, but it was necessary to be performed before using the produced part in a real pumping facility.

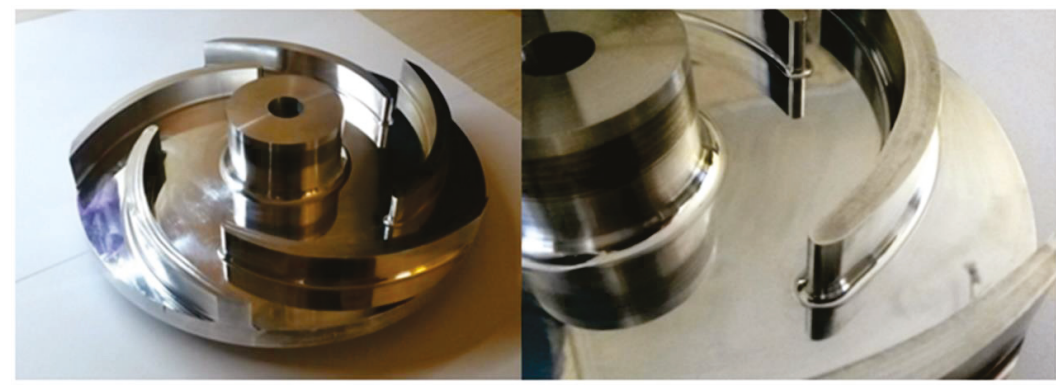

Figure 10. Surface quality of the radial impeller after grinding. 


\subsection{Evaluation of Surface Quality of the Impeller}

After the machining process of the impeller is completed, it is considered important to evaluate the quality of the produced surfaces during the finishing phase. Surface roughness is measured using a Taylor Hobson Surtronic 3+ portable profilometer. In order to facilitate the measurement process, the impeller was fixed on a lathe chuck and the profilometer was positioned on the moving part of the lathe, as can be seen in Figure 11.
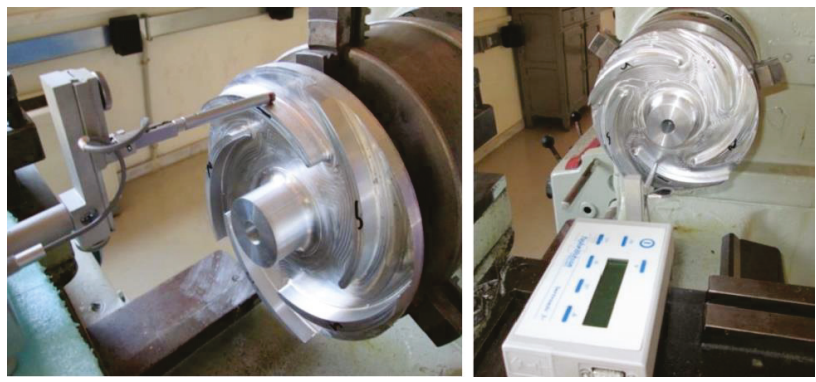

Figure 11. Roughness measurement: on the external surface of blades (left), on the internal surface of blades (right).

On each blade surface, surface measurements were repeated four times in different positions of the blades, as can be seen in Figure 12 The results are summarized in Table 4 and also presented in Figure 13.
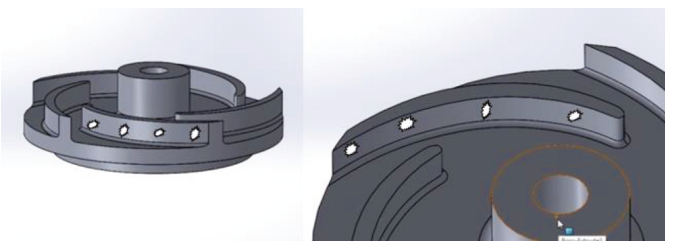

Figure 12. Roughness measurement points on the external and internal surface of the blades.

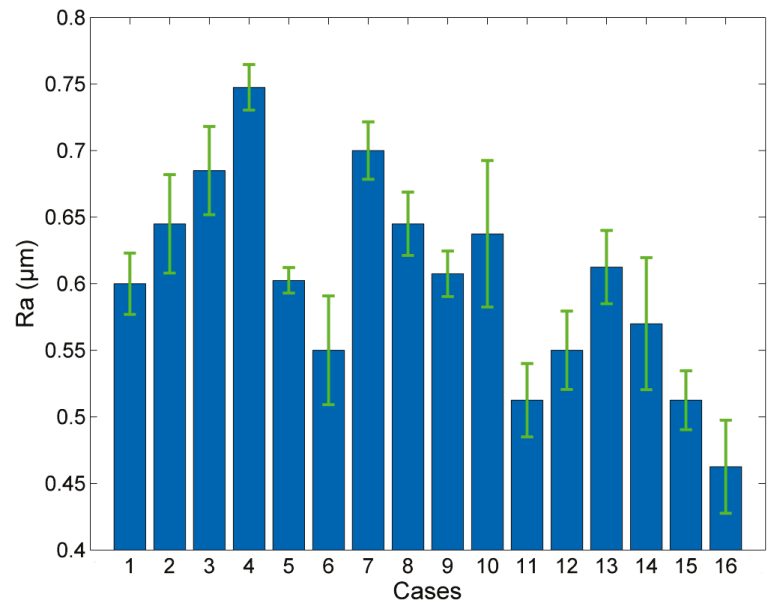

Figure 13. Average Ra values for all experimental cases. 
Table 4. Surface roughness measurement on impeller blade surfaces.

\begin{tabular}{|c|c|c|c|c|c|c|c|c|c|}
\hline \multirow[b]{2}{*}{$\begin{array}{c}\text { No of } \\
\text { Measurement }\end{array}$} & \multicolumn{3}{|c|}{ Process Conditions } & \multicolumn{4}{|c|}{$\begin{array}{c}\text { Roughness on Measurement } \\
\text { Points }(\mu \mathrm{m})\end{array}$} & \multirow[b]{2}{*}{$\begin{array}{l}\text { Average } \\
\operatorname{Ra}(\mu \mathrm{m})\end{array}$} & \multirow[b]{2}{*}{$\begin{array}{c}\text { Standard } \\
\text { Deviation of } \\
\text { Ra }(\mu \mathrm{m})\end{array}$} \\
\hline & $\begin{array}{l}\text { Spindle } \\
\text { Speed } \\
(\mathrm{rpm})\end{array}$ & $\begin{array}{c}a_{p} \\
(\mathrm{~mm})\end{array}$ & $\begin{array}{c}\mathbf{f}_{\mathrm{z}} \\
(\mathrm{mm} / \text { tooth})\end{array}$ & 1 & 2 & 3 & 4 & & \\
\hline 1 & 10,000 & 1 & 0.0042 & 0.62 & 0.58 & 0.58 & 0.62 & 0.60 & 0.02 \\
\hline 2 & 10,000 & 2 & 0.0064 & 0.66 & 0.62 & 0.61 & 0.69 & 0.65 & 0.04 \\
\hline 3 & 10,000 & 3 & 0.0086 & 0.69 & 0.66 & 0.66 & 0.73 & 0.69 & 0.03 \\
\hline 4 & 10,000 & 4 & 0.0108 & 0.75 & 0.73 & 0.74 & 0.77 & 0.75 & 0.02 \\
\hline 5 & 12,600 & 1 & 0.0064 & 0.61 & 0.59 & 0.60 & 0.61 & 0.60 & 0.01 \\
\hline 6 & 12,600 & 2 & 0.0042 & 0.58 & 0.51 & 0.52 & 0.59 & 0.55 & 0.04 \\
\hline 7 & 12,600 & 3 & 0.0108 & 0.70 & 0.69 & 0.68 & 0.73 & 0.70 & 0.02 \\
\hline 8 & 12,600 & 4 & 0.0086 & 0.66 & 0.63 & 0.62 & 0.67 & 0.65 & 0.02 \\
\hline 9 & 15,300 & 1 & 0.0086 & 0.61 & 0.59 & 0.60 & 0.63 & 0.61 & 0.02 \\
\hline 10 & 15,300 & 2 & 0.0108 & 0.65 & 0.60 & 0.59 & 0.71 & 0.64 & 0.06 \\
\hline 11 & 15,300 & 3 & 0.0042 & 0.53 & 0.48 & 0.50 & 0.54 & 0.51 & 0.03 \\
\hline 12 & 15,300 & 4 & 0.0064 & 0.57 & 0.52 & 0.53 & 0.58 & 0.55 & 0.03 \\
\hline 13 & 18,000 & 1 & 0.0108 & 0.63 & 0.60 & 0.58 & 0.64 & 0.61 & 0.03 \\
\hline 14 & 18,000 & 2 & 0.0086 & 0.60 & 0.50 & 0.57 & 0.61 & 0.57 & 0.05 \\
\hline 15 & 18,000 & 3 & 0.0064 & 0.52 & 0.49 & 0.50 & 0.54 & 0.51 & 0.02 \\
\hline 16 & 18,000 & 4 & 0.0042 & 0.48 & 0.45 & 0.42 & 0.50 & 0.46 & 0.04 \\
\hline
\end{tabular}

Apart from the blades surfaces, the surface roughness on the upper surface of the blades and the lower surface of the impeller was measured at $0.2 \mu \mathrm{m}$. Furthermore, the surface roughness was also measured on the blade that exhibited chatter. The results are presented in Table 5 It is to be noted that, in order to avoid chattering, feed per tooth values were decreased to $20 \%$ of the initial value in the experiments presented in Table 4. The considerably increased value of surface roughness when chattering occurs in comparison with the significantly lower values achieved with more favorable conditions are consistent with the observations conducted in the stereoscope, presented in Figures 14 and 15.

Table 5. Surface roughness measurement of a blade where chatter occurred.

\begin{tabular}{cccccccccc}
\hline \multicolumn{1}{c}{ Process Conditions } & \multicolumn{3}{c}{$\begin{array}{c}\text { Roughness on Measurement } \\
\text { Points }(\mu \mathrm{m})\end{array}$} \\
\hline $\begin{array}{c}\text { No of } \\
\text { Measurement }\end{array}$ & $\begin{array}{c}\text { Spindle } \\
\text { Speed } \\
(\mathrm{rpm})\end{array}$ & $\begin{array}{c}\mathbf{a}_{\mathrm{p}} \\
(\mathrm{mm})\end{array}$ & $\begin{array}{c}\mathbf{f}_{\mathrm{z}} \\
(\mathrm{mm} / \text { tooth) }\end{array}$ & $\mathbf{1}$ & 2 & 3 & 4 & $\begin{array}{c}\text { Average } \\
\text { Ra }(\mu \mathrm{m})\end{array}$ & $\begin{array}{c}\text { Standard } \\
\text { Deviation of } \\
\mathrm{Ra}(\mu \mathrm{m})\end{array}$ \\
\hline 1 & 10,000 & 1 & 0.021 & 4.16 & 7.14 & 4.54 & 1.99 & 4.46 & 2.11 \\
\hline
\end{tabular}

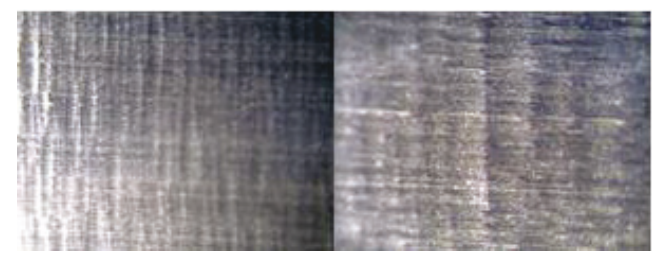

Figure 14. External blade surface after finishing test no. 16 . 


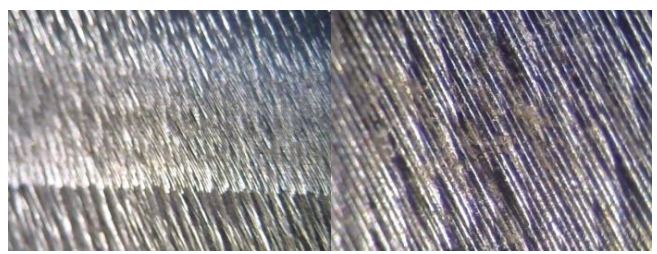

Figure 15. External blade surface when the chattering phenomenon occurs.

After the surface roughness results were obtained for all experimental conditions, statistical analysis was conducted and a regression model was derived in order to determine the correlation between process parameters and surface roughness, as well as determine the optimum process parameters. The results of the analysis of variance (ANOVA) are summarized in Table 6.

Table 6. Analysis of variance (ANOVA) table for the surface roughness measurements.

\begin{tabular}{cccccc}
\hline Source & DF & Adj SS & Adj MS & F-Value & $p$-Value \\
\hline Regression & 9 & 0.088711 & 0.009857 & 253.79 & 0.000 \\
$\mathrm{~N}$ & 1 & 0.000331 & 0.000331 & 8.53 & 0.027 \\
$\mathrm{a}_{\mathrm{p}}$ & 1 & 0.000000 & 0.000000 & 0.01 & 0.928 \\
$\mathrm{f}_{\mathrm{z}}$ & 1 & 0.000379 & 0.000379 & 9.76 & 0.020 \\
$\mathrm{~N}^{*} \mathrm{a}_{\mathrm{p}}$ & 1 & 0.000073 & 0.000073 & 1.89 & 0.218 \\
$\mathrm{~N}{ }^{*} \mathrm{f}_{\mathrm{z}}$ & 1 & 0.000015 & 0.000015 & 0.39 & 0.554 \\
$\mathrm{a}_{\mathrm{p}}{ }^{*} \mathrm{f}_{\mathrm{z}}$ & 1 & 0.000056 & 0.000056 & 1.44 & 0.275 \\
$\mathrm{~N}^{2}$ & 1 & 0.000083 & 0.000083 & 2.14 & 0.194 \\
$\mathrm{a}_{\mathrm{p}}{ }^{2}$ & 1 & 0.000006 & 0.000006 & 0.16 & 0.702 \\
$\mathrm{f}_{\mathrm{z}}{ }_{\text {Error }}$ & 1 & 0.000006 & 0.000006 & 0.16 & 0.702 \\
Total & 6 & 0.000233 & 0.000039 & 0.16 & \\
\hline
\end{tabular}

As can be seen from Table 6 that the most important parameters, which are statistically significant, are spindle speed and feed per tooth, as their $p$-value is below 0.05 and sum of squares is larger than that of the other factors.

Afterwards, a regression model was able to be developed as follows:

$$
\begin{gathered}
R a=0.6925-0.000021 N+0.0015 a_{p}+23.18 f_{z}-0.000001\left(N a_{p}\right)-0.000225\left(N f_{z}\right) \\
+1.149\left(a_{p} f_{z}\right)+0.00063 a_{p}^{2}-129 f_{z}^{2}
\end{gathered}
$$

For the evaluation of the regression model, the coefficient of determination $\left(\mathrm{R}^{2}\right)$, as well as $\mathrm{R}^{2}$-adjusted and $\mathrm{R}^{2}$-predicted, should be calculated. The $\mathrm{R}^{2}$-adjusted factor is particularly useful in cases where the regression model contains multiple inputs as its value does not increase when new variables are introduced, unless they can really contribute to the explanation of the variance of the model. The $\mathrm{R}^{2}$-predicted value can indicate the capability of the regression model to predict new data as it is calculated by removing successive observations and re-calculating the model equation. The developed model exhibited a high level of accuracy as the value of $R^{2}$ was $99.74 \%$, $R^{2}$-adjusted value was $99.35 \%$, and $\mathrm{R}^{2}$-predicted value was $98.62 \%$.

From the main effects plot, the effect of process parameters on surface roughness during the finishing process of the blades can be determined. From Figure 16, it can be seen that, as anticipated, an increase of spindle speed results in a decrease of surface roughness, as well as the reduction of feed per tooth value. However, the axial depth of cut does not affect the surface roughness considerably. At the same time, ANOVA results indicate that the feed per tooth is a slightly more important parameter than the spindle speed, but both are significantly more important than the axial depth of cut, indicating that considerable improvement in surface roughness can be obtained by regulating these two parameters. 
Finally, the optimum process parameter levels are as follows: 18,000 rpm spindle speed, 4 mm axial depth of cut, and $0.0042 \mathrm{~mm} /$ tooth feed per tooth. These findings indicate that the use of spindle speeder for the finishing process of the radial impeller is necessary, as it enabled a considerable decrease of the surface roughness values. After the optimum parameters for the finishing stage of the blades are selected, the recommended process conditions for every phase of the manufacturing process are determined.

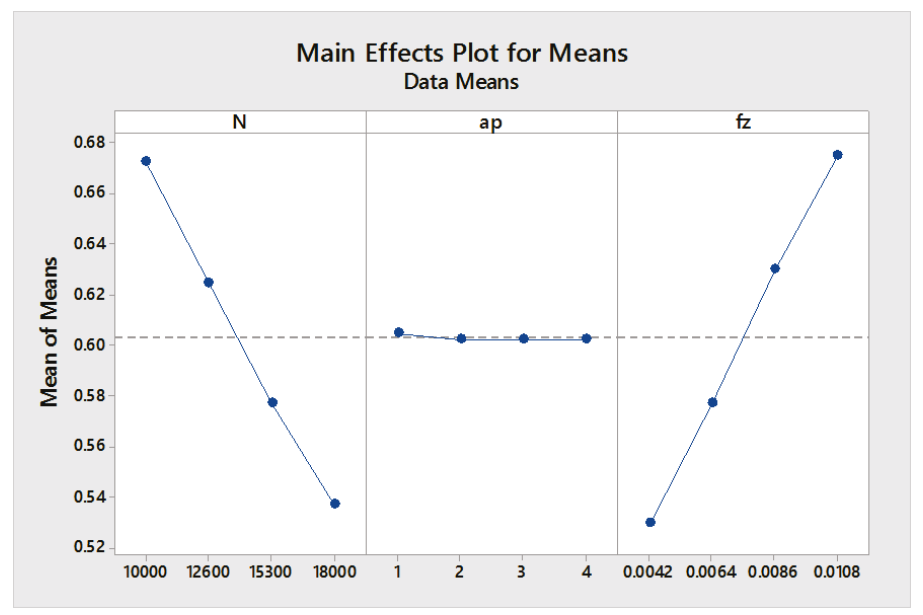

Figure 16. Main effects plot for means for surface roughness Ra.

\section{Conclusions}

In the present work, the manufacturing process of a radial pump impeller is discussed and described, including the design of the manufacturing process, their implementation, and the evaluation of the machined product quality.

At first, the machining operations for the manufacture of the radial impeller are designed in NX CAM software. During the three main phases, namely, roughing, semi-finishing, and finishing, the milling strategies, cutting tools, and process conditions required are determined before the actual machining process is implemented in the vertical CNC machining center.

It was found that the follow periphery strategy, with a $10 \mathrm{~mm}$ diameter end mill with a spindle speed of $7000 \mathrm{rpm}$, feed rate of $2000 \mathrm{~mm} / \mathrm{min}$, and depth of cut of $2 \mathrm{~mm}$, is the most favorable strategy during roughing, as it leads to lower machining time and minimal wear of the cutting edge. During the semi-finishing phase, the process conditions were altered in order to avoid chatter. Although when the $10 \mathrm{~mm}$ diameter end mill was used, the milling conditions were the same as in the design stage, namely spindle speed of $7000 \mathrm{rpm}$ and feed rate of $500 \mathrm{~mm} / \mathrm{min}$, the milling conditions for the case of $4 \mathrm{~mm}$ diameter ball end cutting tool, the final values of spindle speed and feed rate were reduced considerably at $1200 \mathrm{rpm}$ and $40 \mathrm{~mm} / \mathrm{min}$, respectively. Finally, the investigation regarding the optimum process conditions during finishing of the impeller blades, which was designed by L16 Taguchi orthogonal array, indicated that the spindle speed and feed per tooth are the most important parameters for the control of surface roughness, as anticipated, whereas the effect of axial depth of cut was insignificant. Spindle speed and feed per tooth were identified as the most important parameters. The recommended values for spindle speed, axial depth of cut, and feed per tooth determined from the investigation were $18,000 \mathrm{rpm}, 4 \mathrm{~mm}$, and $0.0042 \mathrm{~mm} /$ tooth, respectively, and it was shown that, in this case, the obtained surface roughness was as low as $0.46 \mu \mathrm{m}$. These results indicate the importance of the use of the spindle speeder, as it enabled a considerable decrease of surface roughness during the finishing process of the radial impeller. 
Author Contributions: Conceptualization, N.I.G. and A.P.M.; Data curation, F.I.S. and N.E.K.; Formal analysis, F.I.S. and N.E.K.; Funding acquisition, A.P.M.; Investigation, F.I.S. and N.I.G.; Methodology, N.I.G., N.E.K. and A.P.M.; Resources, N.I.G. and A.P.M.; Software, F.I.S. and N.E.K.; Supervision, A.P.M.; Validation, N.E.K.; Visualization, F.I.S.; Writing—original draft, F.I.S.; Writing—review editing, N.I.G. and A.P.M. All authors have read and agreed to the published version of the manuscript.

Funding: This research received no external funding.

Conflicts of Interest: The authors declare no conflict of interest.

\section{References}

1. Kumar, S.V.; Mani, V.G.S.; Devraj, N. Production Planning and Process Improvement in an Impeller Manufacturing using Scheduling and OEE Techniques. Procedia Mater. Sci. 2014, 5, 1710-1715. [CrossRef]

2. Tang, M.; Zhang, D.; Luo, M.; Wu, B. Tool Path Generation for Clean-up Machining of Impeller by Point-searching Based Method. Chin. J. Aeronaut. 2012, 25, 131-136. [CrossRef]

3. Bohez, E.L.J.; Senadhera, S.D.R.; Pole, K.; Duflou, J.R.; Tar, T. A Geometric Modeling and Five-Axis Machining Algorithm for Centrifugal Impellers. J. Manuf. Syst. 1997, 16, 422-436. [CrossRef]

4. Lee, J.H.; Kang, S.H.; Yang, D.Y. Novel forging technology of a magnesium alloy impeller with twisted blades of micro-thickness. CIRP Ann. 2008, 57, 261-264. [CrossRef]

5. Young, H.T.; Chuang, L.C. An integrated machining approach for a centrifugal impeller. Int. J. Adv. Manuf. Technol. 2003, 21, 556-563. [CrossRef]

6. Kaino, T. Machining technology for large impellers of centrifugal compressors. Kobelco Technol. Rev. 2015, 33, $56-60$.

7. Wu, S.; Yang, L.; Liu, X.; Zheng, M.; Li, R. Study on performance of integral impeller stiffness based on five-axis machining system. Procedia CIRP 2016, 56, 485-490. [CrossRef]

8. Fan, H.Z.; Xi, G. Optimizing tool-path generation for three-axis machining of a sculptured impeller blade surface. Proc. Inst. Mech. Eng. Part B J. Eng. Manuf. 2012, 226, 43-51. [CrossRef]

9. Fan, H.Z.; Wang, S.J.; Xi, G.; Cao, Y.L. A novel tool-path generation method for five-axis flank machining of centrifugal impeller with arbitrary surface blades. Proc. Inst. Mech. Eng. Part B J. Eng. Manuf. 2017, 231, 155-166. [CrossRef]

10. Li, M.; Liu, X.; Jia, D.; Liang, Q. Interpolation using non-uniform rational B-spline for the smooth milling of ruled-surface impeller blades. Proc. Inst. Mech. Eng. Part B J. Eng. Manuf. 2015, 229, 1118-1130. [CrossRef]

11. Fan, H.F.; Xi, G. Efficient tool path generation for five axis machining of a difficult machined centrifugal impeller. Adv. Mech. Eng. 2017, 9, 1-10. [CrossRef]

12. Fan, H.Z.; Xi, G.; Wang, W.; Cao, Y.L. An efficient five-axis machining method of centrifugal impeller based on regional milling. Int. J. Adv. Manuf. Technol. 2016, 87, 789-799. [CrossRef]

13. Wang, G.; Li, W.L.; Rao, F.; He, Z.R.; Yin, Z.P. Multi-parameter optimization of machining impeller surface based on the on-machine measuring technique. Chin. J. Aeronaut. 2019, 32, 2000-2008. [CrossRef]

14. Arriaza, O.V.; Kim, D.-W.; Lee, D.Y.; Suhaimi, A. Trade-off analysis between machining time and energy consumption in impeller NC machining. Robot Comput.-Integr. Manuf. 2017, 43, 164-170. [CrossRef]

15. Chaves-Jacob, J.; Poulachon, G.; Duc, E. Optimal strategy for finishing impeller blades using 5-axis machining. Int. J. Adv. Manuf. Technol. 2012, 58, 573-583. [CrossRef]

16. Peng, S.; Li, T.; Wang, X.; Dong, M.; Liu, Z.; Shi, J.; Zhang, H. Toward a sustainable impeller production: Environmental impact comparison of different impeller manufacturing methods. J. Ind. Ecol. 2017, 21, S216-S229. [CrossRef]

17. Young, H.T.; Chuang, L.C.; Gerschwiler, K.; Kamps, S. A five-axis rough machining approach for a centrifugal impeller. Int. J. Adv. Manuf. Technol. 2004, 23, 233-239. [CrossRef]

18. Tang, Q.C.; Yin, S.H.; Geng, J.X.; Luo, H.; Chen, Y.P. The study of variational feed rate in 4-axis machining of blades. Int. J. Precis. Eng. Manuf. 2018, 19, 1419-1428. [CrossRef]

19. Heo, E.Y.; Kim, D.W.; Kim, B.H.; Jang, D.K.; Chen, F.F. Efficient rough-cut plan for machining an impeller with a 5-axis NC machine. Int. J. Comput. Integr. Manuf. 2008, 21, 971-983. [CrossRef] 
20. Kim, D.W.; Suhaimi, M.A.; Kim, B.M.; Cho, M.H.; Chen, F.F. Rough cut machining for impellers with 3-axis and 5-axis NC machines. In Advances in Sustainable and Competitive Manufacturing Systems, Lecture Notes in Mechanical Engineering, 1st ed.; Azevedo, A., Ed.; Springer Science \& Business Media: Chan, Switzerland, 2013; pp. 609-616.

21. Mentzos, M.D.; Markopoulos, A.P.; Galanis, N.I.; Margaris, D.P.; Manolakos, D.E. Design, Numerical Analysis and Manufacture of Radial Pump Impellers with Various Blade Geometries. Int. Rev. Mech. Eng. 2015, 9, 104-111. [CrossRef]

22. Kumar, R.; Dhiman, S. A study of sliding wear behaviors of Al-7075 alloy and Al-7075 hybrid composite by response surface methodology analysis. Mater. Des. 2013, 50, 351-359. [CrossRef]

23. Li, J.F.; Peng, Z.W.; Li, C.X.; Jia, Z.Q.; Chen, W.J.; Zheng, Z.Q. Mechanical properties, corrosion behaviors and microstructures of 7075 aluminum alloy with various aging treatments. Trans. Nonferrous Met. Soc. China 2008, 18, 755-762. [CrossRef]

24. Rajan, K.; Wallace, W.; Beddoes, J.C. Microstructural study of a high-strength stress-corrosion resistant 7075 aluminium alloy. J. Mater. Sci. 1982, 17, 2817-2824. [CrossRef]

(C) 2019 by the authors. Licensee MDPI, Basel, Switzerland. This article is an open access article distributed under the terms and conditions of the Creative Commons Attribution (CC BY) license (http://creativecommons.org/licenses/by/4.0/). 
MDPI

St. Alban-Anlage 66

4052 Basel

Switzerland

Tel. +41 616837734

Fax +41 613028918

www.mdpi.com

Machines Editorial Office

E-mail: machines@mdpi.com

www.mdpi.com/journal/machines

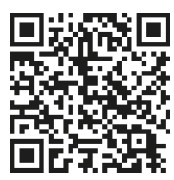



MDPI

St. Alban-Anlage 66

4052 Basel

Switzerland

Tel: +41 616837734

Fax: +41 613028918

www.mdpi.com 